\title{
5 Allergic Diseases (and Differential Diagnoses)
}

\subsection{Diseases with Possible IgE Involve- ment ("Immediate-Type Allergies")}

There are many allergic diseases manifesting in different organs and on the basis of different pathomechanisms (see Sect. 1.3). The most common allergies develop via IgE antibodies and manifest within minutes to hours after allergen contact ("immediate-type reactions"). Not infrequently, there are biphasic (dual) reaction patterns when after a strong immediate reaction in the course of $6-12 \mathrm{~h}$ a renewed hypersensitivity reaction (late-phase reaction, LPR) occurs which is triggered by IgE, but amplified by recruitment of additional cells and mediators. These LPRs have to be distinguished from classic delayed-type hypersensitivity (DTH) reactions (type IV reactions) (see Sect. 5.5).

What may be confusing for the inexperienced physician is familiar to the allergist: The same symptoms of immediate-type reactions are observed without immune phenomena (skin tests or IgE antibodies) being detectable. These reactions are called "pseudo-allergic reactions" (PARs), the term "pseudo" only reflecting the not detectable participation of the immune system and not implying "psychological" phenomena. People can die from pseudoallergic reactions! The term is negatively defined; with better techniques allowing the detection of antibodies or sensitized cells, PAR may turn into true allergy. IgE-mediated drug allergies will be covered together with other adverse drug reactions (see Sect. 5.7).

In atopic eczema, IgE antibodies play a role in many patients in the eliciting phase, albeit in close connection with $\mathrm{T}$-cell-mediated reac- tions (combination of type I and type IV b reactions). Atopic eczema will be discussed in a separate section (see Sect. 5.5.3).

The maximal manifestation of IgE-mediated immediate-type allergic reaction is anaphylaxis. In the development of clinical symptoms, different organs may be involved and symptoms of well-known allergic diseases of skin and mucous membranes [also called "shock fragments" (Karl Hansen)] may occur according to the severity (see Sect. 5.1.4).

\subsubsection{Allergic Rhinitis}

\subsubsection{Introduction}

Apart from being an aesthetic organ, the nose has several very interesting functions (Table 5.1). It is true that people can live without breathing through the nose, but disturbance of this function can lead to disease. Here we are interested mostly in defense functions against particles and irritants (physical or chemical) with clinical symptoms occurring physiologically under certain conditions (e.g., secretion, sneezing, obstruction) and which can take on the characteristics of disease in intense or chronic expression [10, 12]. For these complaints, the term "rhinitis" has been accepted internationally, although the demonstration of

Table 5.1. Functions of the nose

\begin{tabular}{ll}
\hline - Airway & Warming of air \\
Olfactory sensory & - Air-conditioner \\
organ & Body of voice resonance \\
- Filter organ & Killing of microbes \\
- Humidifier &
\end{tabular}


inflammation cannot be done in each case. Therefore, "rhinopathy" would be a more logical term, although it is not often used $[3,4,10]$. Normal findings and disease conditions overlap in rhinitis much more often than in asthma. Often the conjunctiva is also affected ("rhinoconjunctivitis") (see Sect. 5.1.7 on "Allergy and Eye").

The most common form of allergic rhinitis and the most frequent atopic disease is pollinosis (pollen rhinitis, pollen conjunctivitis, pollen asthma, hay fever, hay asthma, hay rhinitis) [19].

The disease was known in Arabic medicine and in the late middle ages it was known as rose fever. The first scientific description dates back to 1819 when John Bostock described his own symptoms. He saw the high summer temperature as being the cause although many people called the disease "hay fever." It was not until 1873 that Charles Blackley, using a skin and provocation test, proved the disease was caused by pollen. Wolff-Eisner classified the disease in 1906 as being hypersensitivity against pollen protein (the term "allergy" had only just been introduced) (for literature see Chap. 1).

\subsubsection{Symptoms and Pathophysiology}

In industrialized countries, $10-20 \%$ of the population suffer from pollinosis [21]. As first symptoms of allergic rhinitis, sneezing (1-2 min after allergen contact) and early secretion ( $5 \mathrm{~min}$ ) develop triggered by a reflex mechanism. In parallel, edema (obstruction) of the mucosa occurs, reaching a maximum after 30 min with itch, a "nasal voice," disturbance of olfactory and gustatory sensation, sinus complaints, and formation of polyps in the chronic course as products of hyperplastic rhinosinusitis $[4,7,10,12]$.

Aqueous rhinorrhea is due to a cholinergic reflex (possibly via tachykinins) while the symptom of a "blocked nose" is due to vascular dilatation and edema formation.

Among the numerous mediators of allergic reactions, histamine plays the most important role in nasal symptoms, but also other mediators have been found in nasal secretions after allergen provocation such as kinins, eicosanoids, and proteases [1].
The following mechanisms contribute to the development of nasal hyperreactivity:

- Increase in permeability

- Increase in sensitivity of irritant receptors

- Increase in number of receptors per cell surface

- Change of nerval impulses in the CNS

- Increase in number of inflammatory cells

- Increase in function of effector cells (increased releasability)

- Hormonal influences (estrogens?)

Increased mast cells and basophil leukocytes (especially during late phase reactions) have been found in the nasal smear in allergic rhinitis [9].

Clinical stigmata of patients with allergic rhinitis comprise:

- "Adenoid face"

- Permanent mouth breathing

- Periorbital halo ("allergic shiners")

- Lower lid edema

- "Allergic greeting" (frequent wiping of the nose tip) (Fig. 5.1)

- Lateral fold in the lower nasal part

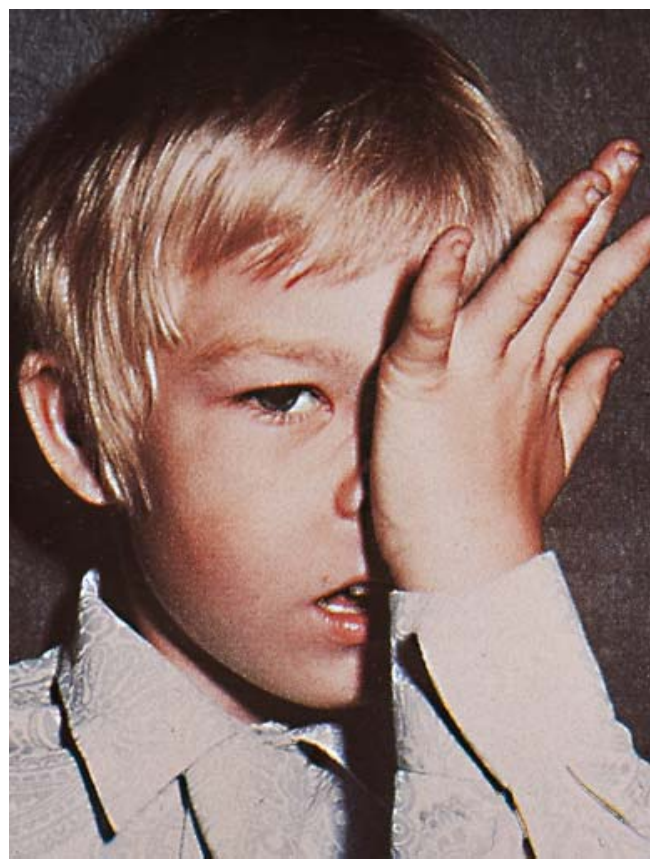

Fig. 5.1. "Allergic salutation" seen typically in children with allergic rhinitis (H. Behrendt) 


\subsubsection{Classification of Different Forms of Rhinitis}

In patients with symptoms of rhinitis (itch, sneezing, secretion, obstruction), other causes of impaired nasal ventilation have to be excluded such as mechanical obstruction, structural abnormalities, septum deviation, tumors, foreign bodies, atresia, as well as other severe organ diseases (cystic fibrosis, Wegener's granulomatosis, lepra, or infectious diseases) $[6,19]$ (Table 5.2).

For the diagnosis of "infectious rhinitis," usually no detection of an infectious agent is

Table 5.2. Classification of rhinitis (according to WHO)

\section{Infectious \\ - Viral \\ - Bacterial \\ - Others}

\section{Allergic \\ - Intermittent \\ - Persistent}

Occupational (allergic, non-allergic)

- Intermittent

- Persistent

Drug-induced

- Acetylsalicylic acid

- Others

Hormonal

Others

- NARES (non-allergic rhinitis eosinophilia syndrome)

- Irritants

- Gustatorial rhinitis

- Emotional factors

- Atrophic rhinitis

- Gastrointestinal reflux

- Idiopathic required. Normally, the diagnosis is done according to the type of secretion (putrid, milky) and the rhinoscopic finding. With unilateral symptoms, hemorrhagic secretion and painfulness, rhinoscopy is obligatory. If the secretion is clear or aqueous, further classification into "allergic" and "non-allergic" (also called "vasomotor") rhinitis is done (Fig. 5.2).

While previously allergic rhinitis was classified into seasonal (hay fever) in the spring and summer months and perennial (all year), the new WHO classification in the document Allergic Rhinitis and Its Impact on Asthma (ARIA) recommends a new classification into "intermittent" (duration of symptoms of less than 4 weeks) and "persistent" (symptoms longer than 4 weeks). This new classification, however, does not replace the practically important distinction between seasonal and perennial.

Furthermore, the classification of the severity of allergic rhinitis into "mild," "moderate," and "severe" is important. Symptoms like "sleep disturbance," "impairment of daily activities," "impairment in school or working place," as well as other impairments in the quality of life are important.

Regarding therapy of allergic rhinitis, it is important to know that some symptoms such as itching, secretion, and sneezing respond quite well to antihistamines, while nasal obstruction is best treated with corticosteroids. This is reflected in the guidelines for therapy of allergic rhinitis [6].

While seasonal allergic rhinitis can mostly be diagnosed with classical allergy diagnosis, in perennial rhinitis sometimes overlaps between allergic (housedust mite allergy) and

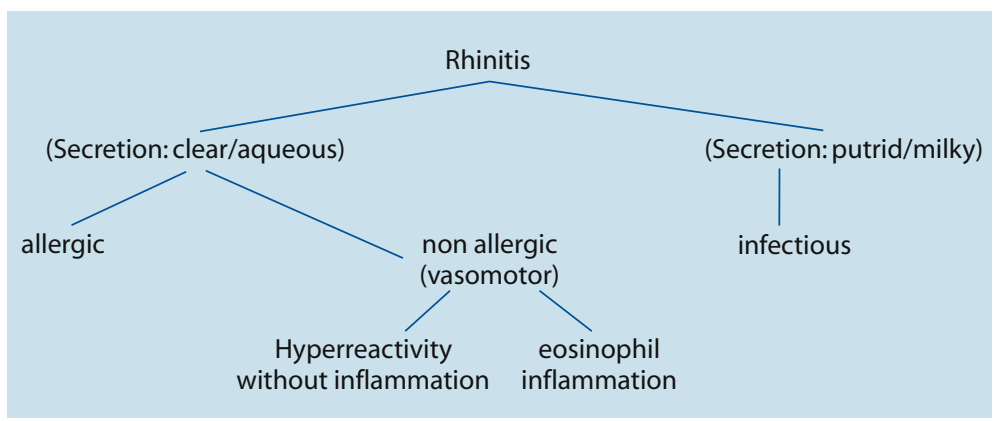

Fig. 5.2. Breakdown of rhinitis into its various forms 
non-allergic mechanisms are observed. All forms of rhinitis have in common a hyperreactivity of the nasal mucosa similar to bronchial hyperreactivity in asthma.

In the group of non-allergic vasomotor rhinitis, two forms may be distinguished according to nasal cytology: an inflammatory form with increased eosinophil granulocytes and the non-inflammatory form. The form of vasomotor rhinitis with increased eosinophils is often characterized by strong swelling, formation of polyps and concomitant acetylsalicylic acid [10]. It responds better to antihistamines and glucocorticosteroids than the non-inflammatory form, which is very resistant to therapy and may respond to anticholinergics (ipratropium bromide).

Patients with vasomotor rhinitis show an increased reactivity to unspecific irritants (Table 5.3) with a pathophysiologic correlate of "autonomic nervous system dysregulation" corresponding possibly to an extreme variant of physiologic reactivity [2,10,14]. Dryness (draughts of air, cold air, dust) is a common triggering factor.

The relationship between allergic rhinitis and otitis media has been discussed. It seems that with atopics there is an increased risk of serous otitis media, although the latter cannot be regarded as allergic disease.

The simple hypothesis that particle size determines deposit and organ manifestation (pollen grains with diameters of around $25 \mu \mathrm{m}$ cause rhinitis in the nose, mold spores $5 \mu \mathrm{m}$ in diameter in the bronchi cause asthma and small actinomycete particles below $2 \mu \mathrm{m}$ in diameter in the alveoli lead to alveolitis) is surely

Table 5.3. Irritative factors as elicitors of rhinitis

Dust, smoke (particles)

Chemical irritants (solvents, alcohol, washing powder)

- Kitchen vapors, odors, halogens, formaldehyde, ether, etc.

- Change of temperature (especially cold)

Air draught

- Change of position

Dryness

- Hormonal influence (e.g., rhinitis in the third pregnancy trimenon) too mechanistic, although of didactic value [10]. We know that pollen fragments may also reach the bronchi.

\subsubsection{Therapy}

The general therapy of allergic rhinitis is covered in the sections on "Immunotherapy" (Sect. 6.3.1) and "Pharmacotherapy" (Sects. $6.2,6.3$ ) [6]. A characteristic of rhinitis therapy is the use of $\alpha$-adrenergics as vasoconstrictors (orally as pseudoephedrine or norephedrine or topically as naphthazoline, xylometazoline, or oxymetazoline). The possible adverse reaction of rhinitis medicamentosa after long-term use of topical vasoconstrictors with mucosal damage should be mentioned!

When selecting pharmacotherapy, the clinical symptoms should be considered. If obstruction is prominent, a combination of antihistamines, vasoconstrictors, and steroids is recommended while patients with predominant rhinorrhea usually respond well to antihistamines and anticholinergics. Mucosal dryness with increased irritability can be treated in perennial rhinitis with ointments and inhalations or lavages.

In very severe cases of allergic rhinitis, sinusitis can occur. Recently "fungal allergic sinusitis," a disease corresponding to allergic bronchopulmonary mycosis, has seen renewed interest (see Sect. 5.4 on "Hypersensitivity Pneumonitis"). Interactions between allergic rhinitis and diseases of the ear (vestibular or tube ventilatory disturbances) have been reported without clear pathophysiological evidence. There is no good evidence for an allergic mechanism in morbus Menière, tinnitus, or chronic labyrinthitis, although anecdotal cases have been reported.

To summarize: Allergic rhinitis is not a neglectable bagatelle condition! It occurs with systemic symptoms and often represents the beginning of severe asthma ("united airway disease") $[3,4,6,7,10,12,13,16,19]$. 


\section{References}

1. Bachert C, Hauser U, Prem B, Rudack C, Ganzer U (1995) Proinflammatory cytokines in allergic rhinitis. Eur Arch Otorhinolaryngol 1 [Suppl]: 44-49

2. Bachmann W, Bachert C (1984) Quantitative evaluation of rhinomanometric curves. A new simple method. Laryngol Rhinol Otol 63:58-61

3. Bousquet J, Vignola AM, Campbell AM, Michel FB (1996) Pathophysiology of allergic rhinitis. Int Arch Allergy Immunol 110:207-218

4. Busse WW, Holgate ST (eds) (1995) Asthma and rhinitis. Blackwell, Oxford

5. Canonica GW, Ciprandi G, Pesce GP, Buscaglia S, Paolieri F, Bagnasco M (1995) ICAM-1 on epithelial cells in allergic subjects: a hallmark of allergic inflammation. Int Arch Allergy Immunol 107: 99- 102

6. Durham SR (1998) Mechanisms of mucosal inflammation in the nose and lungs. Clin Exp Allergy 28 [Suppl 2]:15 - 16

7. Ellegard E, Karlsson G (1999) Nasal congestion during pregnancy. Clin Otolaryngol 24:307-311

8. Heppt W (1998) Zytologie der Nasenschleimhaut. Springer, Berlin Heidelberg New York

9. Malm L, van-Wijk RG, Bachert C (1999) Guidelines for nasal provocations with aspects on nasal patency, airflow, and airflow resistance. Rhinology $37: 133-135$

10. Mygind N, Dahl R, Pedersen S, Thestrup-Pedersen K (1996) Essential Allergy. Blackwell Science, Oxford

11. Mygind N, Laussen LC, Dahl M (2000) Systemic corticosteroid treatment for seasonal allergic rhi-

\subsubsection{Bronchial Asthma}

\subsubsection{Definition}

"Asthma is characterized by increased reactivity of the airway to various stimuli with decreased forced expiration changing in intensity either spontaneously or under therapy" (definition of the American College of Chest Physicians 1975). Newer definitions stress the bronchial hyperreactivity, defining asthma as airway disease with bronchial hyperreactivity [ 1 , 17, 23, 35, 37]. "Reversible obstructive disturbance of ventilation" is the obligatory and central symptom of bronchial asthma, whereby two characteristic aspects are crucial:

- Attacks of dyspnea

- Hyperreactivity of airways against various stimuli nitis: a common but poorly documented therapy. Allergy 55:11 - 15

12. Naclerio RM (1997) Pathophysiology of perennial allergic rhinitis. Allergy 52:41-44

13. Nolte D, Renovanz HD, Schumann K (1982) Nase und Respirationstrakt. Obere und untere Luftwege als funktionelle Einheit. Dustri, Munich

14. Passalacqua G, Bachert C, Davies RJ, Durham SR, et al. (2000) Inhaled and nasal corticosteroids: safety aspects. Position paper. Allergy 55:16-33

15. Simons FE (1996) Learning impairment and allergic rhinitis. Allergy Asthma Proc 17:185-189

16. Simons FE (1999) Allergic rhinobronchitis: The asthma-allergic rhinitis link. J Allergy Clin Immunol 104:534-540

17. van Cauwenberge P, Bachert C, Passalacqua G, Bousquet J, Canonica GW, Durham SR, Fokkens WJ, Howarth PH, Lund V, Malling HJ, Mygind N, Passali D, Scadding GK, Wang DY (2000) Consensus statement on the treatment of allergic rhinitis. European Academy of Allergology and Clinical Immunology. Allergy 55:116-134

18. Tas E, Bircher AJ (2001) Therapie der Rhinitis allergica. Ther Umsch 58:309-314

19. van Wijk RG, de Graaf-in 't Veld C, Garrelds IM (1999) Nasal hyperreactivity. Rhinology 37:50-55

20. World Health Organization (2004) Allergic rhinitis and its impact on asthma (ARIA). In: Bousquet J, et al. (eds) Executive summary. WHO (in press)

21. Wüthrich B, Schindler C, Leuenberger P, Ackermann-Liebrich U (1995) Prevalence of atopy and pollinosis in the adult population of Switzerland (SAPALDIA study). Swiss Study on Air Pollution and Lung Diseases in Adults. Int Arch Allergy Immunol 106:149-156

A new international definition of an expert group of the NIH [1] is:

"Asthma is a chronic inflammatory airway disease with participation of numerous inflammatory cells like mast cells, eosinophils, T lymphocytes, neutrophils, and epithelial cells. In sensitive individuals, inflammation leads to attacks of wheezing, dyspnea, tightness, and cough, especially during nights and early morning hours. These episodes go commonly with generalized but variable increased airway resistance which is reversible either spontaneously or following therapy. The airway inflammation causes increased airway sensitivity against a variety of different stimuli." Using this definition, bronchial asthma can be distinguished in the differential diagnosis from other conditions with dyspnea (Table 5.4). 
Table 5.4. Differential diagnosis of bronchial asthma

- Mechanical ventilation disturbance (tumors, struma, mediastinal tumors, thymus hyperplasia, foreign body aspiration)

- Disturbance of ventilatory regulation (hyperventilation)

- Infection (bronchopneumonia, pertussis, acute epiglottitis ["pseudo-Krupp"], parasitoses)

- Gastroesophageal reflux

- Cardiac disease (left ventricular insufficiency with pulmonary edema, vitium cordis, coronary disease)

- Toxic or drug-induced bronchoconstriction

- Lung vessel disease (pulmonary embolism, pulmonary hypertension, vasculitis)

- Diseases of larynx and trachea (tracheal stenosis, tracheomalacia, acute laryngitis, functional laryngospasm)

- Other lung diseases (emphysema, fibrosis, sarcoidosis, interstitial lung disease, alveolitis)

- Sleep-apnea syndrome

- Chronic obstructive pulmonary disease (COPD)

The Deutsche Atemwegsliga (German Airway League) gives the following definition: "Asth$\mathrm{ma}$ is an inflammatory airway disease with bronchial hyperreactivity and variable airway obstruction. Typical symptoms are cough and attacks of dyspnea, especially during the night and early morning, wheezing and clear viscous sputum" [46].

Bronchial asthma is the most common allergic lung disease, but can occur without detection of immune reactions ("intrinsic asthma"). In children, approximately $80 \%$ of asthma is allergic in origin, in adults approximately $60 \%$.

\subsubsection{Symptomatology}

The major clinical symptom of an asthma attack is the sudden dyspnea (also tachypnea or orthopnea) with noisy breathing, characteristic dry noises (wheezing and humming), attacks of coughing and expectoration of a clear but viscous sputum. The attack often starts with tightness of the chest and a dry cough. Patients have difficulty speaking longer sentences.

Through the increasing difficulty in ventilation, respiratory auxiliary muscles are more intensely used. The suprathoracic veins are often filled, and cyanosis may occur. With an increased pulse rate, pulsus paradoxus often occurs. If an asthma attack persists in spite of therapy with beta-adrenergics and xanthine derivatives for more than $24 \mathrm{~h}$, the term "status asthmaticus" ("acute severe asthma") is used. The breathing noises become less pronounced ("silent lung").

Sometimes an asthma attack occurs along with other symptoms of the upper respiratory airways (nasal blockage, sneezing, or itching eyes) as well as gastrointestinal complaints, increased diuresis, or fatigue $[35,36,45,46]$. In the chest X-ray, few changes are seen, but in severe cases increased air with a pronounced inspiratory position of the thorax is seen. In contrast to lung emphysema, the lung vessels are not constricted in bronchial asthma. The characteristic finding in lung function is obstructive ventilatory disturbance with increased airway resistance and decreased forced expiratory volume $\left(\mathrm{FEV}_{1}\right)$.

The German Airway League has graded asthma according to severity (Table 5.5) [37, 46].

\subsubsection{Different Forms of Bronchial Asthma}

Bronchial asthma can be classified according to eliciting stimuli, sensitivity of the patient, test results or other underlying diseases $[5,11,17$, $18,19,23,34,35,36,37]$. The best classification
Table 5.5. Classification of severity in bronchial asthma (German Airway League)

\begin{tabular}{lllll} 
Grade & Term & $\begin{array}{l}\text { Symptoms } \\
\text { Day }\end{array}$ & Night & $\begin{array}{l}\text { FEV1 or PEF } \\
\text { (\% normal) }\end{array}$ \\
\hline I & Intermittent & $\leq 2$ times/week & $\begin{array}{l}\leq 2 \text { times/ } \\
\text { month }\end{array}$ & $>80 \%$ \\
II & Persistent, mild & $<$ Once/day & $\begin{array}{l}>2 \text { times/week } \\
\geq 1 \text { times/week }\end{array}$ & $\begin{array}{l}\geq 80 \% \\
>60 \%\end{array}$ \\
III & Persistent, moderate & $\begin{array}{l}\text { Daily } \\
\text { Continuous }\end{array}$ & Frequent & $<60 \%$ \\
IV & Persistent, severe & Conch & \\
\hline
\end{tabular}


Table 5.6. Forms of bronchial asthma

- Allergic (IgE-mediated, extrinsic)

- Physical-irritative, chemotoxic

- Intrinsic (cryptogenic, unknown etiology)

- Special forms ${ }^{\mathrm{a}}$ :

Infection-associated

Psychogenic

Analgesic (additive) idiosyncrasy (Samter's triad)

Pharmacologic (beta-blockers, histamine

liberators)

Exercise-induced

Mixed forms

a These stimuli can trigger both allergic and intrinsic asthma

follows pathophysiologic criteria (Table 5.6). The frequent distinction between "extrinsic" (= allergic) and "intrinsic" (no antibodies detected) is not satisfactory since the term "intrinsic" is ill defined and would be better replaced by "cryptogenic." Mostly, the so-called infect-allergic or pathophysiologically unclear conditions are included. In intrinsic asthma, the typical signs and symptoms of atopy, such as increased serum IgE, detection of specific sensitizations in skin tests or RAST, are miss- ing. However, eosinophilia in blood and sputum is often demonstrable.

Furthermore, asthma can be classified according to prognosis and therapeutic response. Intrinsic asthma responds to a lesser degree to beta-adrenergics, cromoglycate or theophylline. Sometimes, anticholinergics or ketotifen are effective; most patients, however, are glucocorticosteroid dependent [17, 20,35].

The most important allergens in elicitation of extrinsic asthma are so-called inhalation or aeroallergens (pollen, animal epithelia, mold spores, housedust mites, etc.; see Sect. 3.4). The most important occupational triggers of allergic asthma are listed in Table $5.7[6,15,16,47]$. In the differential diagnosis, allergic alveolitis (hypersensitivity pneumonitis), mostly caused by organic dusts, should be considered (see Sect. 5.4).

Exogenous toxic irritative factors able to trigger and maintain bronchial asthma comprise chemicals [ozone, chlorides, sulfur oxides, nitric oxides, isocyanates (partly also allergic)] and physical stimuli (cold, mechanical dust effects, cigarette smoke, etc.), which act

\begin{tabular}{ll} 
Allergen & Occupation (examples) \\
Pollen & Agriculture, gardening, floristry \\
Storage mites & Agriculture \\
Animal epithelia & Zoology, laboratory research, bed clothing industry \\
Molds & Cheese-making \\
Enzymes & Washing powder, bakery \\
Castor oil & Agriculture \\
Cotton dust & Cotton harvesting \\
Silk & Textile industry \\
Coffee (raw) & Coffee harvesting \\
Flour and grain dust & Bakery, milling, pastry making, agriculture \\
Insect allergens & Zoology, food industry, cosmetics \\
Gum arabic & Printing \\
Lycopodium & Pharmacy \\
Rubber & Medical care, health workers \\
Metal salts (e.g., platinum) & Metal refinement, catalyzer production \\
Drugs & Health workers, pharmacy \\
Colophony & Paper production, printing \\
Wood dust & Forestry, woodcutting \\
Latex & Rubber industry, health personnel \\
Blooming plants & Gardening, kitchen \\
Small chemicals & Plastics, varnishes, furnishings, etc. \\
Irritative toxic substances & \\
Aliphatic amines & Chemical industry \\
Persulfates & Chemical industry, hairdressers, photo laboratory \\
Epichlorhydrine & Resins, softeners, hardeners \\
Acrylates & Plastic industry, dentistry \\
\hline
\end{tabular}

Table 5.7. Occupational IgE-mediated and irritative toxic asthma 
via cholinergic irritant receptors leading to bronchial constriction $[4,14,17,23,27]$. It is possible that the well-known exercise-induced asthma is caused by cold air or hyperosmolarity through water loss and can be improved by mouth protection. So-called psychogenic asthma (see Chap. 7) and infect-allergic asthma also belong here. Asthma in patients with analgesic or additive idiosyncrasy occurs together with polyposis nasi and sinusitis (Samter's triad) (see Sect. 5.7.2). All these stimuli can trigger both allergic and intrinsic asthma.

\subsubsection{Pathophysiology}

The reversible obstructive ventilation disturbance in bronchial asthma develops on the basis of bronchial hyperreactivity. This is due to inflammatory reactions caused either by allergen exposure or by other epithelial damage (infection, toxic agents, etc.) $[4,8,14,19,21,22$, 23, 30, 35, 43, 45] (Figs. 5.3, 5.4).

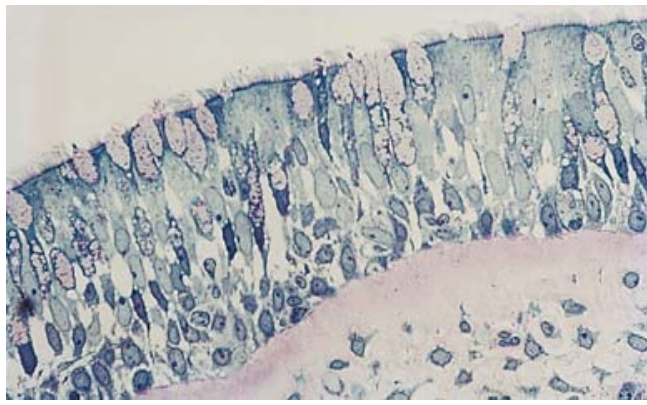

Fig. 5.3. Semi-thin-layer preparation of bronchial epithelia taken from a patient with bronchial asthma viewed under the light microscope (H. Behrendt)

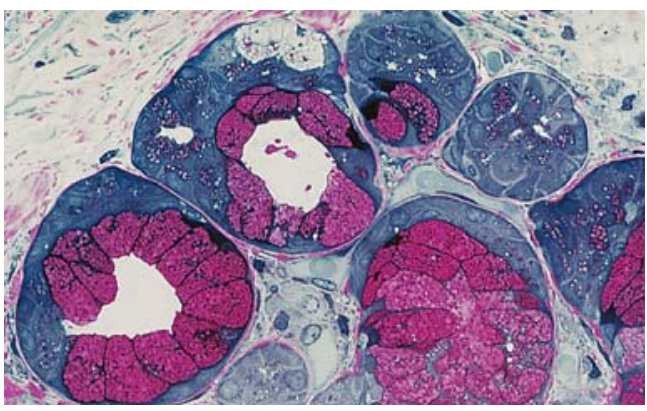

Fig. 5.4. Semi-thin-layer preparation of muciparous glands taken from a patient with bronchial asthma viewed under the light microscope (H. Behrendt)
In the development and maintenance of bronchial hyperreactivity, neurogenic factors play an increasing role (Table 5.8) [14, 19, 27, 31]. The nerve growth factor (NGF) induces neurotransmitters (Table 5.8) influencing neuronal plasticity of the airway nervous system. On the other hand, lymphocytes carry receptors for neurotransmitters or secrete neurotrophins as shown for $\mathrm{TH} 2$ cells secreting brainderived neurotrophic factor (BDNF) [24]. These mechanisms might help to understand the well-known psychosomatic interactions in bronchial asthma (see Chap. 7).

The so-called Herxheimer's triad (mucous dyscrinia, mucosal edema, and bronchoconstriction) determines the intensity of clinical symptoms. In the sputum, Curschmann's spirales and Charcot-Leyden's crystals (crystalline forms of lysophospholipase from eosinophils) are found. The constriction affects both small and large bronchi.

Ventilation and perfusion rate are irregularly distributed with a decrease in $\mathrm{CO}_{2}$ pressure (hypocapnia).

The airway resistance is increased, the flow rate decreased, and the ventilatory work increases, leading to premature closing of airways and lung emphysema. The intrathoracic gas volume and the functional residual capacity are increased.

Characteristic cardial symptoms in bronchial asthma comprise sinus tachycardia, signs of pulmonal hypertension (ECG changes) as well as pulsus paradoxus.

While previously in asthma the reversibility of acute bronchoconstriction was stressed, we know today that in chronic asthma, remodeling of the peribronchial tissue occurs with epithelial damage, and activation of myofibroblasts and fibroblasts (growth factors EGF, IGF, or TGF- $\beta$ ). This leads to a thickening of the basal membrane together with an increased fibrotic manteling and chronicity of the bronchial obstruction with persistent symptoms and deposits of collagens type I, III, and V [8, 23, 33, 39] (Fig. 5.5). 
Table 5.8. Neurotransmitters (NT) and receptors in the airways

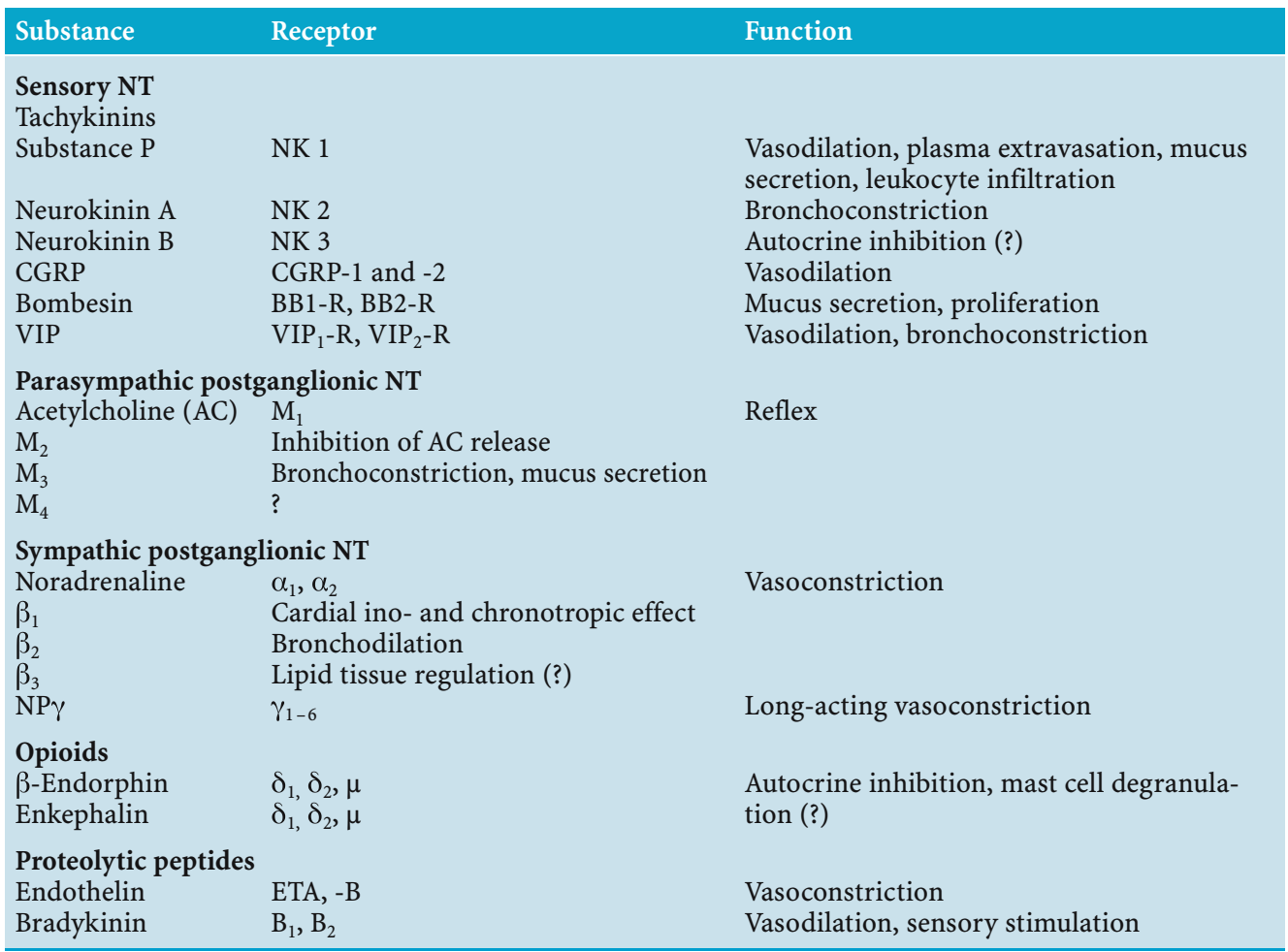

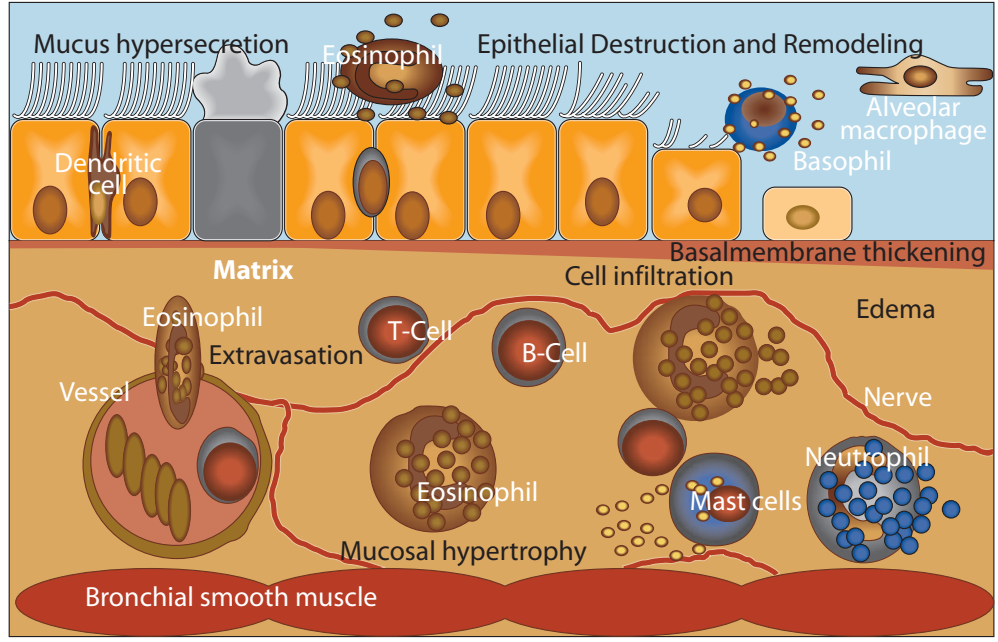

Fig. 5.5. Components of asthmatic inflammation (according to SchultzeWerninghaus)

\subsubsection{Diagnosis}

The diagnostic procedure in asthma is shown in Table 5.9. For allergy diagnosis in general, see Chap. 4. In bronchial provocation tests, unspecific stimuli like acetyl (or methyl) choline, histamine, dust, cold air, exercise or hyperventilation are used $[1,2,13,18,34,37,41]$. The following test concentrations are used: acetylcholine $(1.0-100 \mathrm{mg} / \mathrm{ml})$; methylcholine (0.05$50 \mathrm{mg} / \mathrm{ml})$; carbamylcholine $(0.05-50 \mathrm{mg} / \mathrm{ml})$; 
Table 5.9. Diagnostic procedure in allergic bronchial asthma

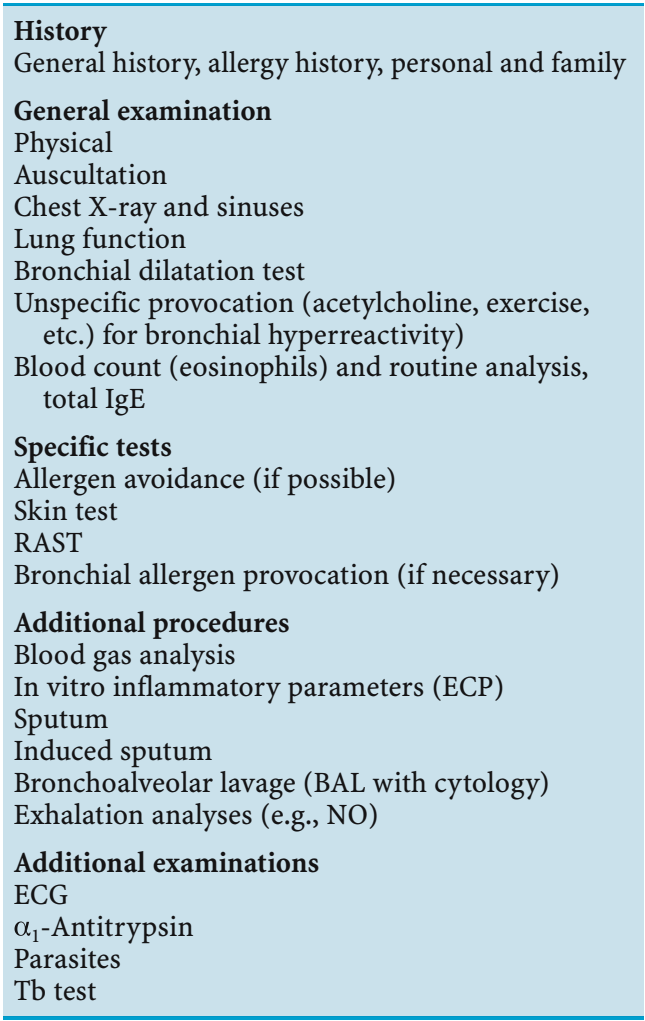

histamine $(0.05-50 \mathrm{mg} / \mathrm{ml})$ [17]. Cholinergic hyperreactivity is a cardinal symptom of asthma [40].

Bronchial provocation tests with allergens need to follow strict indications (see Sect. 4.4).

\subsubsection{Differential Diagnosis}

The most important differential diagnosis of bronchial asthma in adults is chronic obstructive bronchitis, which as persistent obstructive ventilation disturbance leads to chronic obstructive pulmonary disease (COPD) $[4,10,15$, $21,26,30,33]$. In some cases, the differential diagnosis from severe chronic asthma may be difficult (Table 5.10). The main risk factor for COPD is tobacco smoke, but also other indoor air pollutants or occupational toxic exposures play a role. In contrast to bronchial asthma, COPD responds only weakly to pharmacotherapy [30]. Steroids and thiotropin are used with moderate effect.

Differential diagnosis also comprises allergic bronchopulmonal aspergillosis as well as interstitial lung diseases such as hypersensitivity pneumonitis (see Sect. 5.3). Functional laryngospasm, also called "vocal cord dysfunction," may be triggered by physical and chemical stimuli and induce wheezing. Among the many forms of sleep apnea syndromes, there are obstructive variants similar to nightly asthma attacks.

\subsubsection{Therapy}

Avoidance Measures. The only causal therapy is avoidance of eliciting stimuli including all noxious influences. This implies careful allergy diagnosis. Apart from avoidance of occupational allergens, avoidance measures in daily life are of major importance (see Sect. 3.4 on "Aeroallergens"). Items to be avoided include:
Table 5.10. Differential diagnosis of bronchial asthma and "chronic obstructive pulmonary disease" (COPD)

\begin{tabular}{lll} 
Finding & Bronchial asthma & COPD \\
\hline Age & Childhood, adults & Mostly over 50 \\
Allergy & Frequent & Rarely \\
Smoking & Rare & Almost always \\
Nightly dyspnea & Yes & A little \\
Symptom-free intervals & Yes & No \\
Obstruction & Central and peripheral & Mostly peripheral \\
Eosinophilia (blood and sputum) & Frequent & Rare \\
Inflation & Sometimes reversible & Always irreversible \\
Blood gases & Normal & Abnormal \\
Variability of obstruction & Yes & No \\
Response to $\beta$-adrenergics & Good & Little \\
Response to steroids & Good & Little \\
\hline
\end{tabular}


Table 5.11. "Unspecific irritation syndrome" (according to H. Düngemann)

Physical
Temperature change, dust, fog
Chemical
E.g., exhaust, smog, odors, chemical irritants
Pharmacodynamic
E.g., histamine liberators, $\beta$-blockers, certain
spices, drinks, and drugs
Infectious diseases
Infections of the upper airways
Psychological
Stress, emotional disturbance

feathers in bed clothing, animal or plant mattresses (horse hair, seaweed), pets (including furs!), carpets, old upholstery, humidity, moist walls, plants (mold), as well as all dust-collecting furniture, sprays, and certain humidifiers.

In all forms of asthma, the avoidance of nonspecific stimuli is important, which can lead to deterioration of any kind of asthma ("unspecific irritation syndrome" according to Düngemann [12]) (Table 5.11).

Finally, therapy of underlying infectious disease should be mentioned, for instance putrid sinusitis, polypectomy with impaired nose breathing, and short-term antibiotic treatment after microbiological examination (e.g., Haemophilus influenzae).

Allergen-Specific Immunotherapy (Hyposensitization). In uncomplicated allergic asthma, allergen-specific immunotherapy is effective when started early and with the right indications [38] (see Sect. 6.3).

Physical Therapy. Adequate breathing technique and correction of malposition of the thorax are important. Training of respiratory abdominal and back musculature; connective tissue massage and local heat application; and secretion drainage (deliverance of sputum in the downward position, etc.) are important $[1,3$, $11,20,25,38]$.

Psychosomatic Consultation. Psychosomatic consultation may help also with regard to avoidance of trigger situations and can im- ply behavioral therapy, group therapy, autogenic training, etc. (see also asthma schools below).

Climate Therapy. For rehabilitation of chronic asthma, climate therapy at sea level (North Sea) or at high altitude (e.g., Davos, Switzerland) has been shown to improve asthma by decreasing allergen exposure and unspecific climatic effects [7].

Mast Cell Blockers. Mast cell stabilizers (e.g., disodium cromoglycate) act prophylactically on the mucous membranes in preventing asthma attacks. Disodium cromoglycate is given either as a powder or as a $1 \%$ solution $(4 \times$ daily every $6 \mathrm{~h}$ ). Ketotifen acts both as a mast cell stabilizer and as an antihistamine, has no direct bronchodilating effect but is prophylactically effective. Nedocromil sodium has mast cell stabilizer and anti-inflammatory properties.

Antihistamines. Histamine $\mathrm{H}_{1}$ antagonists do not play a major role in the treatment of asthma (see Sect. 6.2 on "Pharmacotherapy").

Leukotriene Antagonists and Inhibitors. Inhibitors of lipoxygenase as well as antagonists of sulfidoleukotrienes have a place in asthma therapy, especially in reducing glucocorticosteroids in severe asthma [44].

Xanthine Derivatives. Xanthine derivatives have been used for decades for bronchospasmolysis [23, 27]. New galenic formulas have decreased the problem of the small therapeutic range of theophylline. If side effects are suspected, the plasma level should be measured and kept between 10 and $20 \mu \mathrm{g} / \mathrm{ml}$. Average daily dose for adults ranges between 10 and $15 \mathrm{mg} /$ $\mathrm{kg} /$ day, with higher doses for smokers [46].

$\boldsymbol{\beta}_{2}$ Adrenergics. While classical beta-adrenergics (e.g., isoproterenol) often lead to cardial side effects due to $\beta_{1}$-stimulation (tachycardia), selective $\beta_{2}$-adrenergics have predominant bronchodilatory effects. Furthermore, they have mast cell stabilizing properties and can be used orally or as an aerosol (one to two breaths every $4 \mathrm{~h}$ ), and also in long-term therapy. 
Long-acting $\beta_{2}$-adrenergics have greatly improved asthma therapy.

Anticholinergics. The atropine derivates ipratropium bromide and oxitropium bromide can be used as aerosols and act - more weakly than $\beta$-adrenergics - as bronchodilators, also prophylactically. They can be combined with $\beta_{2}$ agonists.

Secretolysis. Adequate volume replacement (2-3 1/day) and humidification of the inhaled air are important. Furthermore, detergents and mucolytics are used for secretolysis (acetylcysteine, bromhexine, or ambroxol as well as etheric oils).

Glucocorticosteroids. Glucocorticosteroids act at different levels in the asthmatic reaction: when given over longer periods they have a bronchodilatory and preventive effect on immediate reactions, decrease bronchial hyperreactivity, inhibit mucous secretion and increase the effect of $\beta_{2}$-adrenergics. Through the anti-inflammatory effect, mucosal edema and sputum viscosity will decrease. Systemic glucocorticosteroids are used in severe asthma, the dose depending upon the severity of the condition.

In status asthmaticus (acute asthma attack), doses of $250 \mathrm{mg}$ up to $2 \mathrm{~g}$ prednisolone are indicated combined with $\beta_{2}$-adrenergics (with nebulizer) and theophylline (with perfusor). Persistent wheezing over more than $4 \mathrm{~h}$, pulsus paradoxus, persistent tachycardia over 100/min, $\mathrm{FEV}_{1}$ under $1 \mathrm{l} / \mathrm{s}$, and abnormal blood gases are signs of an acute asthma attack. Immediate hospital admission is indicated. Therapy follows the above-mentioned rules; in addition, infusions, oxygen, sometimes anesthesia with mechanical ventilation and bronchoscopic removal of secretion are implied [26].

In cortisone-dependent chronic asthma, usually 40-80 mg prednisolone are given with a slow dose reduction (not more than $5 \mathrm{mg}$ / week) until a minimal dose is "titrated."

Great progress for glucocorticosteroid therapy was achieved through the development of topical steroids (beclomethasone, budesonide, mometasone, triamcinolone). These are also prophylactically active and allow a reduction of systemic steroids in steroid-dependent asthma. Side effects comprise the possible occurrence of candida infection as well as changes in voice quality [28]; in children, a significant but small and reversible growth impairment has been observed. Topical Glucocorticosteroids can be combined with long-activity $\beta$-agonists.

Antibiotics. In intrinsic asthma and signs of infection, short-term antibiotic therapy may be helpful.

Surgical Treatment. Previously surgical measures such as vago- or sympathicotomy, cutting of the nervus laryngicus cranialis or resection of the glomus caroticum have been recommended, which today do not play a major role. The side effects of these operations are considerable; bronchial hyperreactivity can persist in spite of "denervation" of the lung [17].

New Immunotherapeutic Approaches. New approaches can be seen in the development of monoclonal humanized antibodies against IgE (omalizumab) [32]. Antagonists of interleukin4 (soluble interleukin-4 receptor), adhesion molecules, tachykinins, as well as antibodies to other cytokines (anti-interleukin-5 = mepolizumab) are being tested in clinical trials (see Sect. 6.3).

Procedures Without Proven Efficacy. Often in asthma, so-called unconventional therapies are used such as acupuncture, use of certain bacterial "vaccines," homeopathy, standard gammaglobulins, and others (see Sect. 6.4).

Asthma Schools. The general concept of asthma management requires the cooperation of the informed patient. Schooling programs for children and adults have been proven helpful and are also paid for by insurance in some countries [40] (see also Sect. 6.5 on "Prevention"). Asthmatics may also do sports when treated properly [47]. 


\section{References}

1. National Institutes of Health (1997) Expert Panel Report 2: Guidelines for the diagnosis and management of asthma. Publication 97-4051, NIH, Bethesda

2. American Thoracic Society (2000) Guidelines for methacholine challenge and exercise challenge testing. Am J Respir Crit Care Med (2000) 161: 309-329

3. Bachert C (1997) Asthma and rhinitis: management implications. Eur Respir J 7:294-295

4. Barnes PJ, Chung F, Page CP (1998) Inflammatory mediators of asthma. An update. Pharmacol Rev 50:515-596

5. Baur X (1986) Asthma, alveolitis, aspergillose. Charakterisierung ursächlicher Allergene. Springer, Berlin Heidelberg New York

6. Bernstein DJ (1997) Allergic reactions to workplace allergens. JAMA 278:1907-1913

7. Borelli S, Düngemann H (eds) (1981) Fortschritte der Allergologie und Dermatologie. IMP-Verlag, Basel

8. Busse WW, Elias J, Sheppard D, et al. (1999) Airway remodeling and repair. Am J Respir Crit Care Med 160:1035-1042

9. Crapo RO (1994) Pulmonary function testing. N Engl J Med 331:25-30

10. Debelic M (ed) (1986) Bronchitis im Kindes- und Jugendlichenalter. Dustri, Munich

11. Doerschug KC, Peterson MW, Dayton CS, et al. (1999) Asthma guidelines. An assessment of physician understanding and practice. Am J Respir Crit Care Med 159:1735 - 1741

12. Düngemann H (1978) Karenz-Expositionsprophylaxe. Atemwegs Lungenkrankh 4

13. Dykewicz MS, Fineman S (eds) (1998) Diagnosis and management of rhinitis: Complete Guidelines of the Joint Task Force on Practice Parameters in Allergy, Asthma, and Immunology. Ann Allergy Asthma Immunol 81:478-518

14. Fischer A, McGregor GP, Saria A, Philipp B, Kummer W (1996) Induction of tachykinin gene and peptide expression in guinea pig nodose primary afferent neurons by allergic airway inflammation. J Clin Invest 98:2284-2291

15. Fruhmann G (1994) Sonstige Berufskrankheiten: Obstruktive Atemwegserkrankungen. In: Ferlinz R (ed) Pneumologie. Thieme, Stuttgart, p $622 \mathrm{ff}$

16. Fuchs E (1982) Gewerbliche Allergene als Ursache obstruktiver Lungenerkrankungen. Früherkennung und Abklärung. Schweiz Med Wochenschr 112:185

17. Fuchs E, Schultze-Werninghaus G (1986) Asthma bronchiale. Themen der Medizin 7. Wander, Nürnberg

18. Gonsior E, Henzgen M, Jörres RF, Kroidl RF, Merget R, Riffelmann FW, Wallenstein GW (2001) Leitlinie für die Durchführung bronchialer Provokationstests mit Allergenen. Deutsche Ges für
Allergologie und klinische Immunologie. Allergo J 10:193 - 199, 257-264

19. Hansen K (1957) Bronchialasthma (Bronchiolenasthma) und verwandte Störungen. In: Hansen K (ed) Allergie. Thieme, Stuttgart

20. Hansel TT, Bauer PJ (eds) (2001) New drugs for asthma, allergy and COPD. Progress in respiration research, vol 31. Karger, Basel

21. Henderson WR, Shelhamer JH, Reingold DB, Smith LJ, Evans R, Kaliner M (1979) Alpha-adrenergic hyper-responsiveness in asthma. $\mathrm{N} \mathrm{Engl}$ J Med 300:642-647

22. Holgate ST, Davies DE, Lackie PM, Wilson SY, Puddicombe SL, Lordan JL (2000) Epitheliolmesenchymal interactions in the pathogenesis of asthma. J Allergy Clin Immunol 105:193-204

23. Kay AB, Austen KF, Lichtenstein LM (eds) (1984) Asthma. Physiology, immunopharmacology and treatment. Academic Press, London

24. Kerschensteiner M, Gallmeier E, Behrens L, Vargas Leal V, Misgeld T, Klinkert WEF, Kohlbeck R, Hoppe E, Oropeza-Wekerle RL, Bartke I, Stadelmann C, Lassmann H, Wekerle H, Hohlfeld R (1999) Activated human T cells, B cells, and monocytes produce brain-derived neutrophic factor in vitro and in inflammatory brain lesions: A neutroprotective role of inflammation? J Exp Med 189:865-870

25. Kjellmann N-IM (1976) Immunoglobulin E and atopic allergy in childhood. Linköping University Medicine Dissertation No. 36

26. König P (1985) Therapie des Status asthmaticus. Internist 26:208

27. Kunkel G (2001) Neurogene Aspekte der allergischen Entzündungsreaktion. In: Ring J, Darsow V (eds) Allergie 2000: Probleme, Strategien und praktische Konsequenzen. Dustri, Munich, pp $179-181$

28. Kroegel C (ed) (1997) Moderne Therapie des Asthma bronchiale. Thieme, Stuttgart

29. Lebowitz MD, Barbee R, Burrows B (1984) Family concordance of IgE, atopy, and disease. J Allergy Clin Immunol 73:259-264

30. Magnussen H (1990) Überempfindlichkeit der Atemwege. Dtsch med Wochenschr 115:1604-1610

31. Middleton E Jr et al. (eds) (1998) Allergy: principles and practice, 5 th edn. Mosby, St. Louis, pp 544-558

32. Milgrom H, Fick RB, Su JQ, et al. (1999) Treatment of allergic asthma with monoclonal antiIgE antibody. N Engl J Med 341:1966-1973

33. Nadel JA (ed) (1980) Physiology and pharmacology of the airways. Marcel Dekker, New York

34. Niggemann B, Illi S, Madloch C (2001) Histamine challenges discriminate between symptomatic and asymptomatic children. MAS study group. Eur Resp J 17:246-253

35. Nolte D (1996) Asthma: Das Krankheitsbild, der Asthmapatient, die Therapie, 6th edn. Urban \& Schwarzenberg, Munich 
36. Reinhardt D (ed) (1996) Asthma bronchiale im Kindesalter. Springer, Berlin Heidelberg New York

37. Schultze-Werninghaus G (ed) (1999) Deutsche Atemwegsliga: Empfehlungen zur Allergiediagnostik bei Atemwegserkrankungen in der Praxis. Pneumologie 48:300-304

38. Schultze-Werninghaus G (1997) Die Immuntherapie (allergenspezifische Hyposensibilisierung) bei Asthma bronchiale. Atemw Lungenkrh 23: $701-707$

39. Slavin RG, Reisman RE (eds) Expert guide to allergy and immunology. American College of Physicians, Philadelphia, pp 23-40

40. Szepanski R, Lecheler J (1995) Standard- und Qualitätssicherung der Asthmaschulung im Kindes- und Jugendalter. Präv Rehab 7:1-41

41. Tiffeneau R, Beauvallet M (1945) Production exclusive d'effets pulmonaires locaux par inhalation d'aerosol d'acetylcholine. Son utilisation comme test d'insufficance respiratoire. Sem Hop (Paris) 21:154-166

42. Townsley RG (1976) IgE levels and methacholine inhalation responses in monozygous and dizygous twins. J Allergy Clin Immunol 57:227

\subsubsection{Urticaria and Angioedema}

\subsubsection{Definition}

Urticaria is a disease with occurrence of selfvanishing erythematous elevated skin lesions which disappear and blanch under pressure (wheals) (Figs. 5.6, 5.7). Identical skin lesions are observed after injection of histamine into the skin (Lewis' triad: mild redness = local vasodilation, edema $=$ increase in capillary permeability, flare $=$ axon reflex). When the reaction occurs in the subcutaneous tissue, the disease is called angioneurotic or angioedema (also "Quincke's edema”) (Fig. 5.8). Urticaria comprises several clinical manifestations and may be caused by immunological and non-immune pathomechanisms.

\subsubsection{Classification}

Clinically, urticaria can be classified according to:

1. The course: acute urticaria ( $<6$ weeks) and chronic urticaria ( $>6$ weeks). In between are acute intermittent urticaria (several acute episodes) and chronic relapsing urti-
43. Virchow JC, Kroegel C, Walker C, Matthyss H (1994) Cellular and immunological markers of allergic and intrinsic bronchial asthma. Lung 172:313-334

44. Virchow JC, Prasse A, Naya I, Summertin A, Harris A (2000) Zafirlukast improves asthma control in patients receiving high-dose inhaled corticosteroids. Am J Respir Crit Care Med 62:578 - 585

45. Wahn U, Seger S, Wahn V (eds) (1999) Pädiatrische Allergologie und Immunologie, 3rd edn. Urban und Fischer, Munich

46. Wettengel R, Berdel D, Cegla U, et al. (1994) Empfehlungen der Deutschen Atemwegsliga zum Asthmamanagement bei Erwachsenen und Kindern. Med Klin 89:57-67

47. Worth H, Meyer A, Folgering H, Kirsten D, Lecheler J, Magnussen H, Pleyer K, Schmidt S, Schmitz M, Taube K, Wettengel R (2000) Empfehlungen der Deutschen Atemwegsliga zum Sport und körperlichen Training bei Patienten mit obstruktiven Atemwegserkrankungen. Pneumologie 54: 61-67

48. Wüthrich B (1976) Zum Allergenkatalog beruflicher Inhalationsallergien. Berufsdermatosen 24: 123

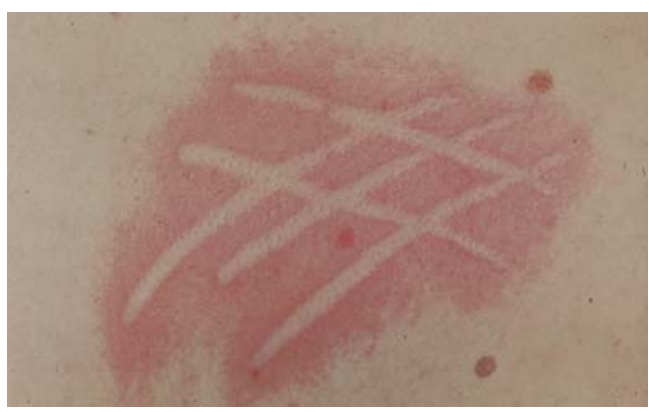

Fig. 5.6. Urticaria factitia caused by tangential application of force

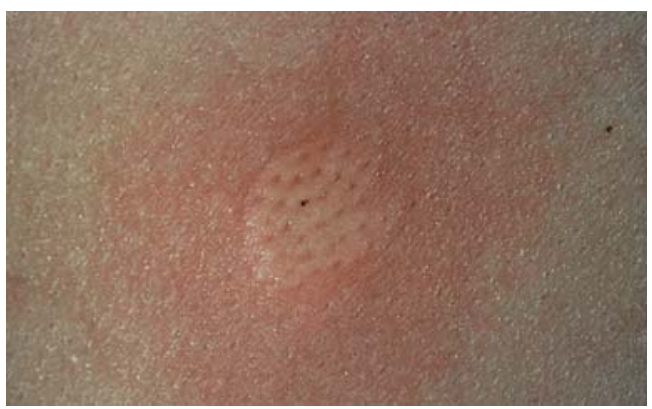

Fig. 5.7. Hive following a histamine injection

caria (continuous relapses with short remissions of several days). 


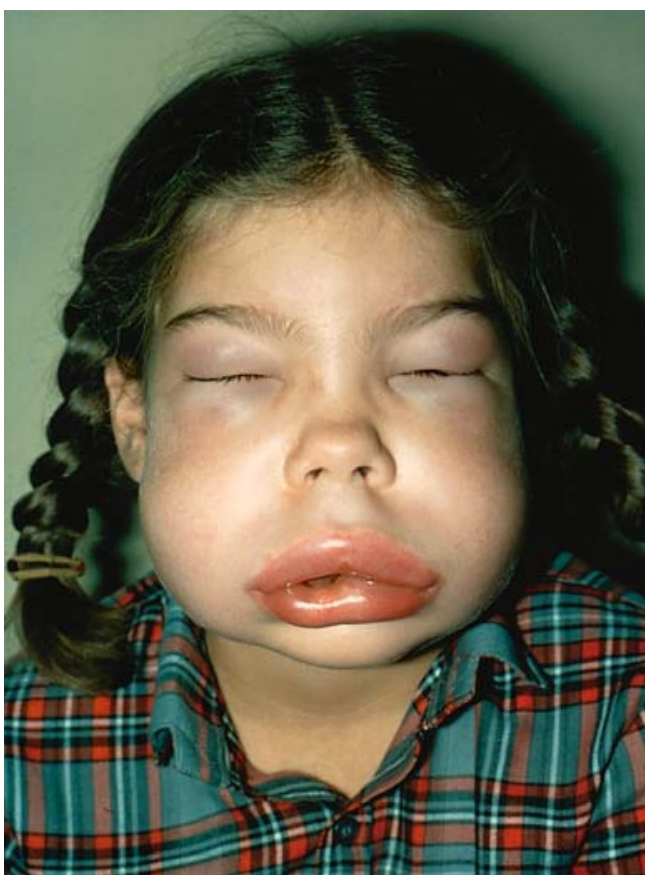

Fig. 5.8. Quincke’s edema

2. Pathophysiological aspects (Table 5.12): There are few epidemiological studies regarding the prevalence of urticaria. It seems that the incidence of urticaria has been constant during recent years [10]. Prevalence of chronic urticaria is estimated at $1-3 \%[4,5$, 9, 40]; in 1991, after German reunification, urticaria was more common in West German children compared to the East, following the pattern of hay fever and asthma prevalence (see Sect. 3.3.2).

Acute urticaria is the most common type of urticaria; it is estimated that $20-30 \%$ of the population suffer once in their life from an episode of acute urticaria. Mostly, acute urticaria heals spontaneously, and sometimes medical help is necessary. The etiopathogenesis often remains unclear: Apart from acute infections, allergic reactions need to be discussed. Histamine is one of the most important mediator substances $[5,11]$. Often acute urticaria occurs after drug medication during acute infection. In these cases the suspected drugs are often tolerated at a later point in time. In up to $50 \%$ no cause for acute urticaria can be elucidated. There is an
Table 5.12. Classification of urticaria according to etiopathophysiology

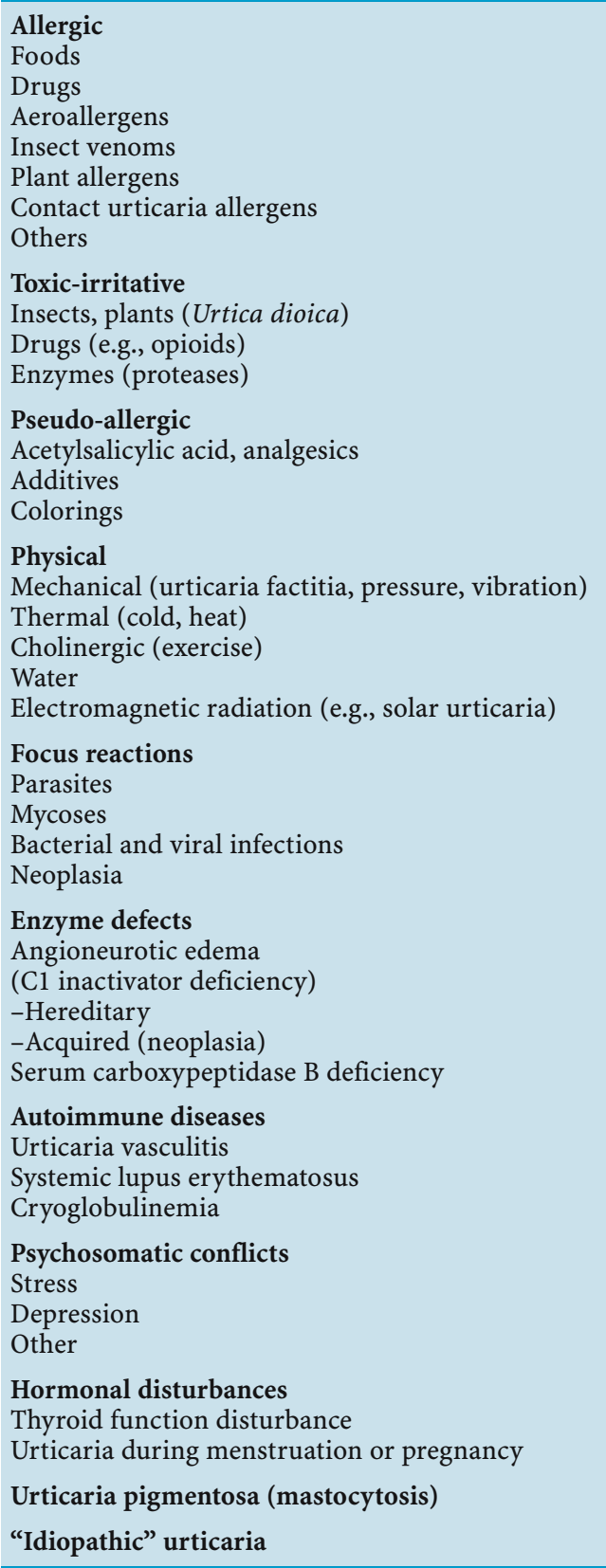

indication of more intense diagnosis in either very severe clinical manifestations (first degree of anaphylaxis), relapses, or when changing into chronic urticaria. 
When chronic urticaria is subdivided according to pathophysiology (Table 5.12), approximately $5-10 \%$ is allergic in nature, $15-20 \%$ is pseudo-allergic, and $15-20 \%$ is triggered by physical stimuli. A large percentage (approximately 50\%) remain etiopathophysiologically unclear (except for the rare cases of hereditary angioedema). Psychosomatic influences as well as so-called "focus reactions" are discussed when, e.g., gastrointestinal disturbance, chronic infectious disease, autoimmune disease, neoplasms, or parasitic infestation give rise to chronic urticaria. In recent years, a new concept of autoimmune pathogenesis has been postulated: Autoantibodies against the high-affinity IgE receptor may play a role which can be found in up to $50 \%$ of patients with severe chronic urticaria $[9,12,28]$.

Chronic urticaria in adults is more frequent in females ( $\mathrm{f}: \mathrm{m}=2: 1)$.

\subsubsection{Physical Urticaria}

A common subgroup of urticaria is represented by the different forms of physical urticaria (Table 5.13) when specific physical stimuli induce wheals either:

- On the site of contact (e.g., contact cold urticaria) or

- Generalized in a reflex phenomenon (e.g., cholinergic urticaria, cold reflex urticaria)
The most common form of physical urticaria is urticaria factitia (also called "dermographic urticaria"), when tangentially acting forces in the upper dermis induce histamine release. This form is often associated with psychosomatic stress, but is also found in combination with IgE-mediated allergy. The occurrence of urticaria factitia is variable and sometimes directly stress dependent (a female colleague of mine only had urticaria factitia on Thursdays when Prof. Braun-Falco was doing his grand rounds). I sometimes try to console my patients: "Be glad that you are living today; some centuries ago, you would have been burnt as a witch!"

Cholinergic urticaria is characterized by the occurrence of small follicular wheals triggered by exercise, sweating, or strong psychologic stress.

The differential diagnosis of chronic urticaria comprises localized heat urticaria, where at the site of heat application $\left(45-50^{\circ} \mathrm{C}\right)$ wheals can be triggered [31]. In vitro warming of a basophil suspension can induce histamine release [32].

Rather common is exercise-induced urticar$i a$, which is often connected with food allergy and sometimes the first stage of anaphylaxis (see Sect. 5.1.4).

A frequent form ( $15 \%$ of physical urticaria) is cold urticaria (Fig. 5.9), which can rarely

Table 5.13. Classification of physical urticaria ( $f$, frequent; $r$, rare; $v r$, very rare; $A H$, antihistamine; TAD, tricyclic antidepressant; $M S$, mast cell stabilizer; $G C$, glucocorticosteroid)

\begin{tabular}{|c|c|c|c|}
\hline Elicitor & & Pathophysiology & Therapy \\
\hline $\begin{array}{l}\text { Dermographism (urti- } \\
\text { caria factitia) }\end{array}$ & $\mathrm{f}$ & Psychosomatic influence, summation with $\operatorname{IgE}$ & $\begin{array}{l}\mathrm{AH}_{1}+\mathrm{AH}_{2}, \mathrm{TAD}, \text { Coun- } \\
\text { seling }\end{array}$ \\
\hline Cholinergic (sweating) & $\mathrm{f}$ & Small follicular wheals, frequently psychosomatic & $\mathrm{AH}+$ anticholinergics \\
\hline Localized heat & vr & $?$ & $\mathrm{AH}$ \\
\hline Exercise & $\mathrm{f}$ & Summation with food allergy, anaphylaxis & $\mathrm{AH}, \mathrm{MS}$ \\
\hline Cold & $\mathrm{f}$ & $\begin{array}{l}\text { Rarely familiar, cryoglobulinemia, neutrophil in- } \\
\text { filtrate }\end{array}$ & $\mathrm{AH}$, penicillin, dapsone \\
\hline Pressure & $\mathrm{f}$ & $4-6 \mathrm{~h}$, neutrophils, ESR elevation & AH?, GC, dapsone \\
\hline Vibration & vr & Angioedema & $\mathrm{AH}, \mathrm{GC}$ \\
\hline $\begin{array}{l}\text { Electromagnetic radia- } \\
\text { tion (solar urticaria) }\end{array}$ & $\mathrm{r}$ & $\begin{array}{l}\text { Histamine not involved, specific eliciting wave } \\
\text { lengths }\end{array}$ & $\begin{array}{l}\text { AH?, photoprotection, } \\
\text { chloroquine, hardening }\end{array}$ \\
\hline Water & vr & Autoantigens in S. corneum? & Skin care, $\mathrm{AH}$ \\
\hline
\end{tabular}




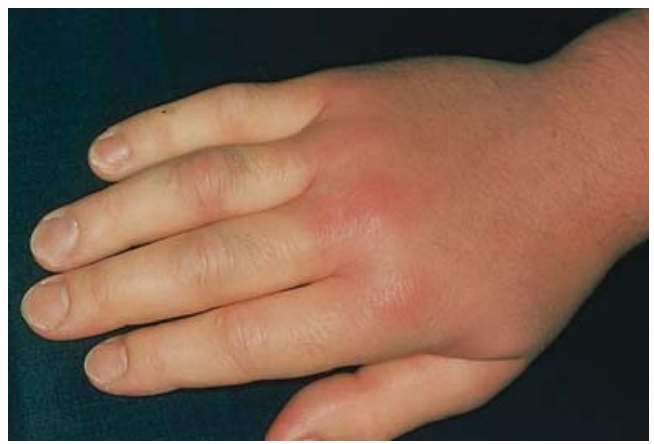

Fig. 5.9. Urticaria induced by cold

occur as a familial form, or be found along with cold-sensitive antibodies (e.g., cryoglobulinemia, cold hemagglutinins). In dermatohistopathology, neutrophil infiltrates are found; sometimes ESR is increased. Cold urticaria can be a sequel of chronic infection (e.g., borreliosis). Antihistamines have little effect. High-dose intravenous penicillin has led to improvement without the mechanisms being known [13].

Pressure urticaria occurs mostly in young men (22-50 years) doing heavy physical work. There is an immediate type where wheals develop acutely within minutes up to $1 \mathrm{~h}$ and a delayed type which only $4-6 \mathrm{~h}$ after pressure application (5-10 kg over 10-20 min) elicits massive whealing. Antihistamines have little effect; dapsone has been tried successfully.

Light urticaria summarizes all forms of urticaria where the effect of electromagnetic radiation (from X-rays to visible light) induces whealing. The most common form is solar urticaria, where radiation mostly in the UV-A range elicits whealing. Histamine and mast cell reactions do not seem to play a major role; possibly direct nerval stimulation takes place (E. Hölzle, $\mathrm{H}$. Behrendt, personal communication).

For therapy, UVA rush-hardening can be used in solar urticaria [2].

Aquagenic urticaria is rare (not to be confused with the much more common aquagenic pruritus); it has been speculated that a watersoluble autoantigen is released from the stratum corneum and induces histamine release [11]. Prophylactic skin care prior to water contact may help.
In the treatment of all forms of physical urticaria, one should warn patients not to do "heroic self-experiments" (for hardening), since anaphylactic reactions may occur (my first patient with solar urticaria suffered anaphylactic shock in a solarium).

\subsubsection{Special Forms of Urticaria and Angioedema}

Contact Urticaria. In these patients, epidermal contact of the unlesional skin with eliciting agents (either irritative like nettle, Urtica dio$i c a$, or allergenic like latex proteins) leads to wheal formation, sometimes deteriorating into anaphylaxis ("contact anaphylaxis") [19].

Urticaria Pigmentosa (Mastocytosis). This type differs from the other urticarias since there are irreversible long-lasting skin lesions corresponding to local accumulations of mast cells in the skin. In childhood, isolated mastocytomas are common, which after physical stress (hot baths or thumb sucking) can trigger generalized urticaria, sometimes local bulla formation. The prognosis is good.

In adulthood, urticaria pigmentosa with characteristic brownish red disseminated skin lesions is common, which show after rubbing urticarial dermographism (Darier's sign). The brownish color is not postinflammatory hyperpigmentation but corresponds to activation of epidermal melanocytes through stem cell factor (SCF).

Mastocytosis may be limited to the skin or be found along with systemic involvement (bone marrow, gastrointestinal tract). Very rare are mast cell leukemias or precursors such as "aggressive mastocytosis" with lymphadenopathy.

Recently cases of "occult mastocy tosis" have been reported where without visible skin lesions patients were suffering from relapsing urticaria or anaphylactoid reactions; diagnosis can be made from the strongly elevated mast cell tryptase level in the serum (see also Sect. 3.1.4).

A rare form of mastocytosis is teleangiectasia eruptiva macularis perstans. 
Urticaria Vasculitis. Here the single wheals do not vanish within hours but persist over $12-48 \mathrm{~h}$, being found along with painful large erythematous swellings. Histologically, leukocytoclastic vasculitis as well as immune complex deposits with direct immunofluorescence is found $[16,21]$. Urticaria vasculitis sometimes is a precursor of autoimmune disease such as lupus erythematosus and can be concomitant with petechial bleeding (see Sect. 5.3).

\section{Hereditary Angioneurotic Edema (HANE).}

This genetically determined disease is characterized by acute attacks of circumscribed giant edema formation especially in the face (eyelids, lips), but also in the genitals without concomitant urticaria. Sometimes attacks are triggered by local trauma (e.g., at the dentist). There is a chemical or functional defect of $\mathrm{C} 1$-inactivator (C1-esterase inhibitor) in the complement system leading to a decrease of $\mathrm{C} 4$ and $\mathrm{C} 2$ with activation of the complement and the kallikrein kinin system. HANE is a severe and life-threatening disease (note: laryngeal edema), sometimes manifesting only as acute colic-like abdominal pain (angioedema of the GI tract). In rare cases the disease is acquired in the context of neoplasia [3]. There is a third form of HANE without detectable $\mathrm{C} 1$ inactivator deficiency and a still unknown pathophysiology [3].

Severe attacks of angioedema have also been observed in patients under angiotensin-converting enzyme inhibitors (ACE inhibitors) where a pathophysiological role of kallikrein kinin activation has been speculated $[15,16]$.

Idiopathic Urticaria. The diagnosis "idiopathic urticaria" only should be made when all other (Table 5.12) possible causes have been excluded. Diagnosis of chronic urticaria is often tedious for the physician and patient $[4,5,9,10$, $11,23,27,34,36]$.

\subsubsection{Diagnosis}

In the diagnosis of chronic urticaria, a threestep program has proven helpful and practical, increasing the intensity of diagnostic work-up according to the intensity of the disease [27] (Fig. 5.10). Between the single diagnostic steps,

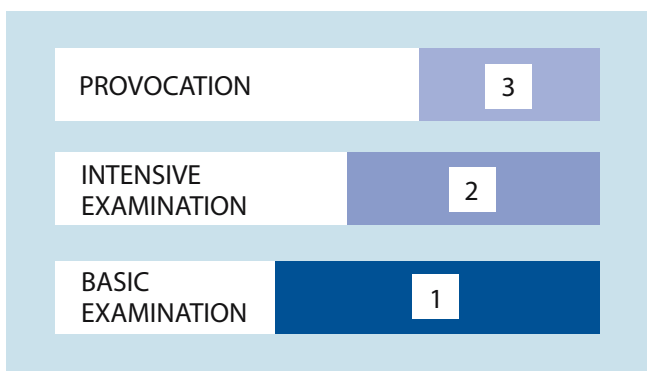

Fig. 5.10. Three-step plan for urticaria diagnostics (according to Ring and Przybilla)

apart from possible causal therapy of the pathological findings detected, symptomatic treatment with $\mathrm{H}_{1}$ antihistamines over 1 month is employed. If - after stopping pharmacotherapy - new lesions occur, the next step is started. Each step of the three-step program comprises history, clinical examination, laboratory examination and special test procedures.

\section{Urticaria Diagnosis: Step 1 (Basic Examination).} Step 1 comprises basic examinations performed in all patients with chronic urticaria (Table 5.14).

Table 5.14. Urticaria diagnosis: step 1 (basic examination)

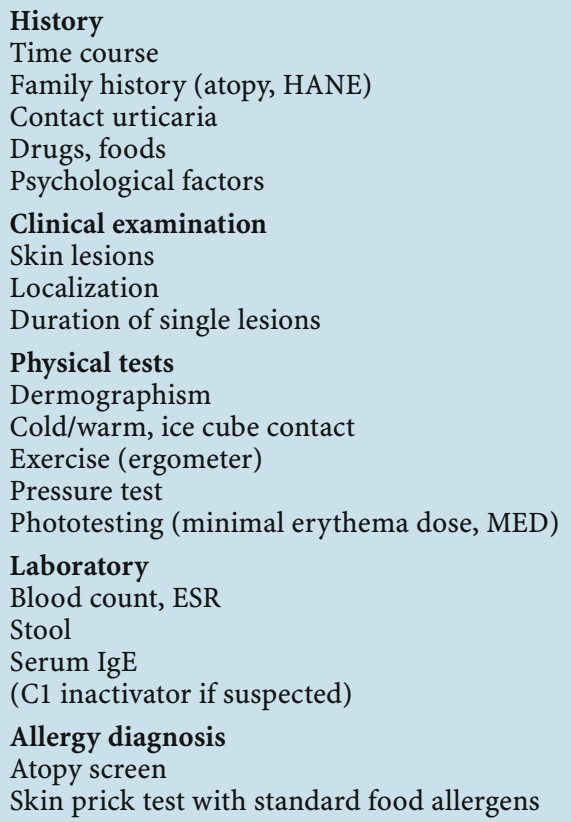


A careful history taken by experienced allergists/dermatologists is crucial. Psychosocial factors should be considered. HANE can be excluded by a careful family history and clinical observation (almost never wheals!). In the differential diagnosis of lid edema, sinusitis or emphysema of the orbita should also be excluded.

Physical provocation tests are an essential part of urticaria diagnosis and comprise provocation with cold, warmth, pressure, exercise, as well as dermographism. Phototests with UV light are only done when there is a history of light urticaria. History should also cover contact urticaria [9]. HANE is characterized by a deficiency in $\mathrm{C} 1$ inactivator, which can be detected immunochemically, although in $15 \%$ only functionally $[3,15,24]$.

Urticaria Diagnosis: Step 2 (Intensive Examination). In step 2 the history is repeated. In addition, the patient is advised to keep a diary of diet and symptom course. A clinical examination search for "foci" (Table 5.15) is performed in cooperation with the relevant other disciplines. Especially gastrointestinal disturbances (e.g., Helicobacter pylori) may play a role. Urticaria vasculitis as the precursor of autoimmune disease should be excluded. In the serum, autoantibodies against the high-affinity IgE receptor (FceRI) of classes IgG 1 and IgG 3 can be detected by immunoblot or functionally with the

Table 5.15. Urticaria diagnosis: step 2 (intensive examination)

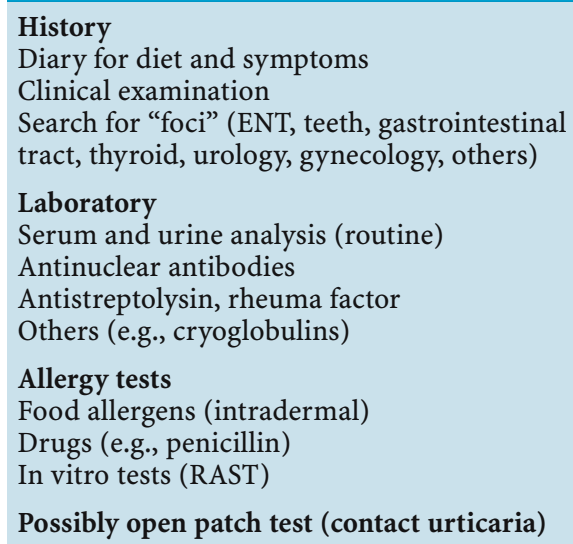

autologous serum test (“Greaves test”) $[8,9,12$, 23]. These patients may represent a subgroup where only systemic steroids or immunosuppression is effective. For the autologous serum test, we recommend a serum dilution of 1:100 in the intradermal test in order to avoid falsepositive results [23]).

Examination of thyroid function is also recommended (4-6\% show disturbed thyroid function or autoantibodies) [11, 17]. Amplification of in vitro histamine release through thyroid hormones has been described [22].

Urticaria Diagnosis: Step 3 (Provocation Tests). Step 3 comprises provocation testing using different dietary approaches sometimes employed under inpatient conditions in order to standardize other environmental conditions and guarantee possible emergency therapy for anaphylaxis (Table 5.16). Provocation tests include suspected foods as well as food additives ("oral provocation test for idiosyncrasy," OPTI) (see Sect. 5.1.5 on "Food allergy"). The marker substance in the provocation of chronic urticaria is acetylsalicylic acid; a high percentage $(20-30 \%)$ of patients have significant and partly dramatic exacerbation of skin lesions, sometimes together with anaphylactoid reactions $[5,6]$.

Table 5.16. Urticaria diagnosis: Step 3 (provocation tests)

History

Elimination and provocation diets

Clinical examination

Skin biopsy with direct immunofluorescence

Laboratory

Complement levels

Thyroid hormones and antibodies Others

Allergy tests
Avoidance diet
Provocation tests (food challenge)
Oral provocation test for idiosyncrasy (OPTI) with
additives and ASA
Autoimmune diagnostics (“Greaves test," anti-
bodies against FceRI)




\subsubsection{Therapy}

Treatment of acute urticaria is done using $\mathrm{H}_{1}$ antihistamines [25], in severe cases preferably intravenously (dimetinden maleate or clemastine fumarate); if the patient does not respond glucocorticosteroids (e.g., $100 \mathrm{mg}$ prednisolone) are given. For severe cases see treatment of anaphylaxis (Sect. 5.1.4).

In therapy of chronic urticaria, $\mathrm{H}_{1}$ antagonists are the first choice [30]. Often they are not dosed adequately $[13,30]$. Obviously, the dose to suppress urticaria has to be higher than doses applied for hay fever. During the day, non-sedating antihistamines should be used (fexofenadine, loratadine, desloratadine, mizolastin, cetirizine, levocetirizine); if people suffer from nightly attacks the use of classical sedating antihistamines in the evening is an option (see also Sect. 6.2 on "Pharmacotherapy"). Antihistamines with a mast cell stabilizing effect (ketotifen) are sometimes helpful.

Some patients respond better to a combined use of $\mathrm{H}_{1}$ plus $\mathrm{H}_{2}$ antagonists. Doxepin as a tricyclic antidepressant has both $\mathrm{H}_{1}$ and $\mathrm{H}_{2}$ antagonizing effects. Antihistamines also showing antiserotonin effects may be helpful in some cases of physical urticaria (cold urticaria) (e.g., cyproheptadiene, hydroxyzine), and some cases of cold urticaria can be improved by parenteral penicillin therapy.

$\beta_{2}$-Adrenergics (e.g., terbutaline) have been found helpful in some cases of chronic urticaria, as has dapsone [14].

Leukotriene antagonists (Montelukast) have been used with controversial effects [15]; a subgroup of patients has been reported to experience possible improvement [7]. Some studies have also recommended using calcium antagonists especially when flush attacks are predominant [15].

Due to the strong psychosomatic interaction in chronic urticaria, tricyclic antidepressants with antihistamine effects (e.g., opipramol) as well as psychosomatic counseling can be helpful.

Systemic glucocorticosteroids should only be used in severe cases together with antihistamines.

In very severe cases (sometimes with a positive autologous serum test and autoanti- bodies), immunosuppressive treatment (cyclosporin) or high-dose intravenous immunoglobulin $\mathrm{G}$ infusions have been effective $[9,23]$.

In some patients, alterations of the gastrointestinal flora may induce improvement. BraunFalco recommended the "Munich scheme" with a combination of antibiotic (tetracycline), antimycotic (amphotericin B, nystatin), anthelmintic, and antihistamine followed by restoration of the GI flora with lactobacilli and other agents $[1,4]$. When there is evidence of Helicobacter pylori involvement, eradication may be helpful.

There is no specific urticaria diet; however, if food allergy has been proven, a specific avoidance diet is indicated (see Sect. 5.1.5 on "Food Allergy).

In rare cases of HANE, androgens like danazol $[3,24]$ or stanazolol induce an increase in the decreased $\mathrm{C} 1$ inhibitor concentration in serum. In acute attacks, purified $\mathrm{C} 1$ inactivator can be given as a life-saving infusion. Patients

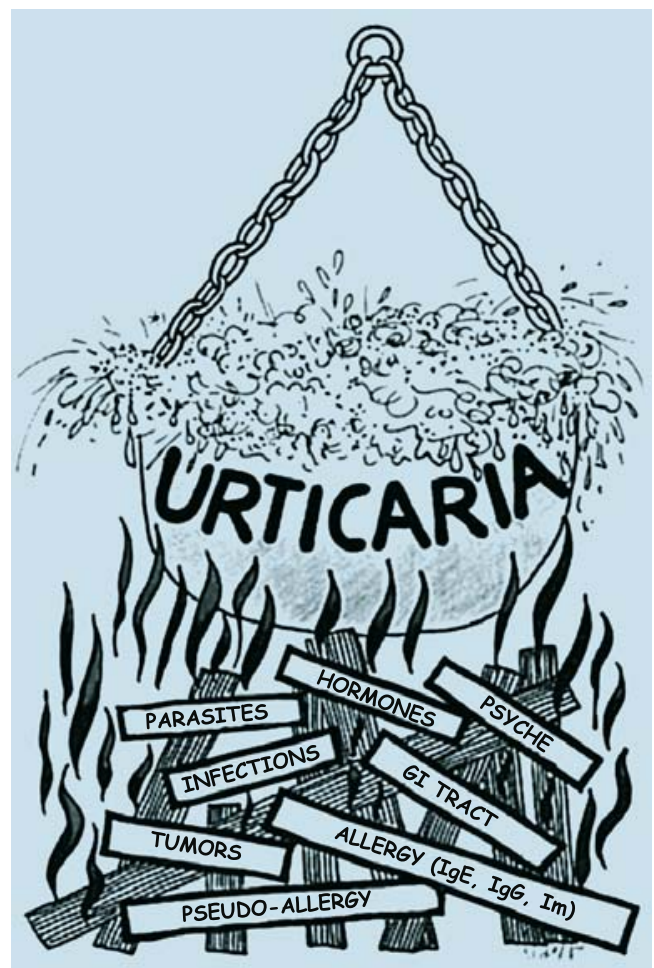

Fig. 5.11. The "witches"” cauldron of urticaria 
and physicians need to know where they can get this preparation!

In solar urticaria and mastocytosis, UV hardening (UV-A or PUVA) can be used.

The general principle of any kind of urticaria management is the elimination of triggering or maintaining factors, which keep the process "boiling" (Fig. 5.11)!

\section{References}

1. Abeck D, Thomsen S, Plötz S, Ring J (1999) Die Biologische Urtikaria-Therapie. Acta Biol $38: 3-23$

2. Beissert S, Stauder H, Schwarz T (2000) UVA rush hardening for the treatment of solar urticaria. J Am Acad Dermatol 42:1030 - 1032

3. Bork K, Witzke G (1989) Long-term prophylaxis with $\mathrm{C}_{1}$-inhibitor $\left(\mathrm{C}_{1} \mathrm{INH}\right)$ concentrate in patients with recurrent angioedema caused by hereditary and acquired $\mathrm{C}_{1}$-inhibitor deficiency. J Allergy Clin Immunol 83:677

4. Braun-Falco O (1976) Entwicklungen in der Dermatologie. In: Braun-Falco O, Marghescu S (eds) Fortschritte der praktischen Dermatologie und Venerologie, vol 8. Springer, Berlin Heidelberg New York, p 417

5. Champion RH (1988) Urticaria then and now. Br J Dermatol 119:427-436

6. Doeglas HMG (1975) Reactions to aspirin and food additives in patients with chronic urticaria, including the physical urticarias. Br J Dermatol 93:135

7. Ellis MH (1998) Successful treatment of chronic urticaria with leukotriene antagonists. J Allergy Clin Immunol 102:876-877

8. Fiebiger E, Hammerschmid F, Stingl G, Maurer D (1998) Anti-FceRI $\alpha$ autoantibodies in autoimmunemediated disorders. J Clin Invest 101:243-251

9. Greaves M (2000) Chronic urticaria. J Allergy Clin Immunol 105:664-671

10. Haas N, et al. (1995) Vergleichende Studie zur Häufigkeit, Diagnostik und Therapie der Urtikaria in einer Hautpoliklinik. Allergologie 18:110113

11. Henz BM (1996) Das Spektrum der Urtikaria. In: Henz BM, Zuberbier T, Grabbe J (eds) Urtikaria. Klinik, Diagnostik, Therapie. Springer, Berlin Heidelberg New York, pp 1-17

12. Hide M, Francis DM, Grattan CE, Hakimi J, Kochan JP, Greaves MW (1993) Autoantibodies against the high-affinity IgE receptor as a cause of histamine release in chronic urticaria. N Engl J Med 328:1599-1604

13. Illig L, Paul E (1978) Die Stellung der Antihistaminika in der Urtikaria-Therapie. Hautarzt 29:407
14. Juhlin L (1981) Modem approaches to treatment of chronic urticaria. In: Ring J, Burg G (eds) New trends in allergy. Springer, Berlin Heidelberg New York, p 279

15. Kaplan AP (1981) The pathogenic basic of urticaria and angioedema: Recent advances. Am J Med 70:755-757

16. Kumar SA, Martin BL (1999) Urticaria and angioedema: diagnostic and treatment considerations. J Am Osteopath Assoc 99 [Suppl]:1 -4

17. Leznoff A, Sussmann GL (1989) Syndrome of idiopathic chronic urticaria and angioedema with thyroid autoimmunity: A study of 90 patients. J Allergy Clin Immunol 84:66

18. Leznoff A (1998) Chronic urticaria. Can Fam Physician 44:2170-2176

19. Maibach HI, Johnson HL (1975) Contact urticaria syndrome. Contact urticaria to diethyltoluamide. Arch Dermatol 111:720 - 730

20. Merk H (1992) Urticaria und Rhinitis allergica: In: Hornbostel H, Kaufmann W, Siegenthaler W (eds) Innere Medizin in Praxis und Klinik, 4th edn. Thieme, Stuttgart, pp 3281-3293

21. Meurer M (1981) Urticaria vasculitis. In: Ring J, Burg G (eds) New trends in allergy. Springer, Berlin Heidelberg New York, pp 148-151

22. Müller J, Vieluf D, Ring J (1993) Schilddrüsenhormone als Amplifikatoren der Histamin-Freisetzung unter Insektengift-Hyposensibilisierung. Allergo J 2 [Suppl 2]:77-80

23. Ollert M, Ring J (2000) Urtikaria und Angioödem. In: Przybilla B, Bergmann K, Ring J (eds) Praktische allergologische Diagnostik. Steinkopff, Darmstadt, pp 328-334

24. Opferkuch W, Kövary PM, Jaeger U, EchternachtHapple K, Gronemeyer W, Hammar C, Niemczyk H, Rieger C (1981) Clinical aspects and therapy of hereditary angioneurotic edema. In: Ring J, Burg G (eds) New trends in Allergy. Springer, Berlin Heidelberg New York, p 272

25. Paul E, Bödeker R-H (1987) Behandlung der chronischen Urticaria mit Terfenadin und Ranitidin. Allergologie 10:113

26. Ring J, Brockow K, Ollert M, Engst R (1999) Antihistamines in urticaria. Clin Exp Allergy 29 [Suppl 1]:31 - 37

27. Ring J, Przybilla B (1987) Diagnostik der chronischen Urtikaria. Med Welt 38:256-259

28. Sabroe RA, Grattan CE, Francis DM, Barr RM, Kobza Black A, Greaves MW (1999) The autologous serum skin test: A screening test for autoantibodies in chronic idiopathic urticaria. Br J Dermatol 140:446-452

29. Schäfer T, Ring J (1996) Epidemiology adverse food reactions due to allergy and other forms of hypersensitivity. In: Eisenbrand $\mathrm{G}$ et al. (eds) Food allergies and intolerances. DFG, VCH Weinheim, pp $40-54$

30. Schmutzler W (1997) Histamin als Mediator allergischer Reaktionen. Allergologie 20:536 - 542 
31. Skrebova N, Takiwaki H, Miyaoka Y, Arase S (2001) Localized heat urticaria: a clinical study using laser Doppler flowmetry. J Dermatol Sci 26:112-118

32. Schrallhammer-Baenkler S, Ring J, Landthaler M (1985) Localized heat urticaria. Arch Dermatol Res 277:406

33. Toubi E, Blant A, Kessel A, Golan TD (1997) Low dose cyclosporin $\mathrm{A}$ in the treatment of severe chronic idiopathic urticaria. Allergy 52:312-316

34. Warin RP, Champion RH (1974) Urticaria. Saunders, London

\subsubsection{Anaphylaxis}

\subsubsection{Definition}

Anaphylaxis is the maximal variant of allergic immediate-type reaction involving the whole organism. Usually the allergen is transmitted through the blood (by injection or oral ingestion). However, anaphylaxis can also be induced after intense contact with the skin or mucous membrane surfaces (contact urticaria, contact anaphylaxis, also by aeroallergens).

When Richet and Portier (1902) first observed the condition while doing animal experiments on the yacht of the Prince of Monaco and later on in Paris, they wanted to name it "condition without protection" [28]; this was, however, both linguistically and pathophysiologically wrong ("without protection" should have been "aphylaxis"). Today anaphylaxis is best translated as "excessively deviated defense reaction" " $\alpha v \alpha$ " = up, over; " $\varphi \nu \lambda \alpha \xi$ " = guardian, protection).

Some authors restrict the term anaphylaxis to IgE-mediated reactions. However, there are other mechanisms such as immune complex anaphylaxis by circulating IgG or IgM antibodies (e.g., against IgA or dextran); furthermore, there are non-immunological reactions leading to identical clinical symptoms (see Sect. 5.7.2 on "Pseudo-allergy"). Therefore the term "anaphylactoid reaction" is also used as a clinical entity before pathophysiological investigations can be done [31].

Recently, the term anaphylaxis has been defined as also comprising non-immune reactions as a "maximal variant of an acute generalized hypersensitivity reaction" [15]. With this definition, the term "anaphylactoid" becomes superfluous.
35. Wüthrich B (1989) Therapie der akuten und chronischen Urtikaria und des Quincke-Ödems. Schweiz Rundschau Med 78:576-581

36. Zuberbier T, Henz BM (1996) Diagnostik der Urtikaria. In: Henz BM, Zuberbier T, Grabbe J (eds) Urtikaria. Klinik, Diagnostik, Therapie. Springer, Berlin Heidelberg New York, pp 137-156

37. Zuberbier T, Aberer W, Grabbe J, Hartmann K, Merk H, Ollert M, Rueff F, Wedi B, Wenning J (2004) Diagnostik und Therapie der Urtikaria. Leitlinie der DDG und DGAI. Allergo J (in press)

\subsubsection{Clinical Symptomatology and Elicitors}

Clinically, anaphylaxis represents a syndrome of different symptoms involving different organs which may develop either alone or simultaneously or subsequently. The acute occurrence is characteristic, and the rapid progression within a few minutes is according to route of contact and resorption characteristics.

Case Report. Patient M.H., female, 53 years old, received an infusion of $5 \%$ human serum albumin on the 3rd day after colectomy. After a few minutes, the patient complained of nausea, and on the face and the trunk patchy wheals developed. At the same time, tachycardia and hypotension were present. The doctor starting the infusion was still present and stopped the infusion after $30 \mathrm{ml}$ and replaced it with physiological saline. The patient became unconscious, blood pressure was no longer measurable, peripheral pulses were not palpable, and there was no carotid pulse. Cardiac noises were no longer audible. Immediate resuscitation including cardiac massage, artificial respiration, oxygen and volume replacement together with $500 \mathrm{mg}$ prednisolone i.v. led to a restoration of the cardiac and respiratory function. The patient survived this severe anaphylactic reaction (grade IV) without sequelae [31].

For this example, human serum albumin as elicitor was selected on purpose to show that practically there is no "a priori" innocent drug in allergy! Of course some drugs have a higher and some a lower risk of anaphylaxis. In the United States 100-500 fatalities annually are attributed to penicillin (see Sect. 6.7 on "Drug Allergy"). Apart from drugs, foods (e.g., nuts, celery, poppy seeds, rarely also ethanol [25], 
fish, etc.) can elicit anaphylaxis. Insect venom anaphylaxis will be considered in a separate section (Sect. 5.1.6).

Aeroallergens or vapors (e.g., fish odor) may elicit anaphylaxis in highly sensitized individuals as well as contact urticariogens (contact anaphylaxis against rubber gloves, ointments, or in the open patch test) [33]. Similarly, all the elicitors of physical urticaria (see Sect. 5.1.3) may in severe cases lead to anaphylaxis (anaphylactic shock in the solarium in solar urticaria). Finally, so-called "idiopathic anaphylaxis" exists where people suffer repeatedly from anaphylactic episodes without clear-cut reasons, sometimes following exercise [32,36].

Not infrequently, the combination of different simultaneously acting stimuli (e.g., exercise or psychological stress together with certain otherwise tolerated foods) elicit a reaction which we call "summation anaphylaxis" [21, 32]. Beta-blockers may enhance anaphylaxis [13].

Symptoms of anaphylaxis comprise mainly:

- The skin (itch, flush, urticaria, angioedema) and the neighboring mucous membranes; itchy palms, paresthesia in the pharynx, or genital mucosa are often the first symptoms

- The respiratory tract (sneezing, rhinorrhea, hoarseness, dysphonia, laryngeal edema, cough, bronchospasm, respiratory arrest)

- Abdominal symptoms (nausea, cramps, vomitus, defecation, also miction and uterus cramps occur)

- The cardiovascular system (tachycardia, blood pressure changes - not necessarily hypotension, but also transient hypertension has been observed as first symptoms arrhythmia, shock, cardiac arrest). Primary cardiac manifestation in anaphylaxis has been observed in ECG changes (T-flattening, supraventricular arrhythmia, AV block) [20, 24, 43, 44]. Marked changes of central-venous pressure are common [39]. During anaphylaxis, myocardial infarction may occur [1, 6, 24, 31, 34, 43].

Prodromi of anaphylaxis comprise paresthesia on palms and soles, metallic "fishy" taste, anxiety, sweating, headache, or disorientation.

According to the intensity of anaphylactic symptoms, a severity grading from I to IV has proven helpful (Table 5.17) [30].

\begin{tabular}{|c|c|c|c|c|}
\hline Grade & Skin & Abdomen & Airways & $\begin{array}{l}\text { Cardiovascular } \\
\text { system }\end{array}$ \\
\hline I & $\begin{array}{l}\text { Itch } \\
\text { Flush } \\
\text { Urticaria } \\
\text { Angioedema }\end{array}$ & - & - & - \\
\hline \multirow[t]{3}{*}{ II } & Itch & Nausea & Rhinorrhea & $\begin{array}{l}\text { Tachycardia } \\
(>20 / \text { min })\end{array}$ \\
\hline & Flush & Cramps & Hoarseness & $\begin{array}{l}\text { Hypotension } \\
\text { (>20 mm Hg syst.) }\end{array}$ \\
\hline & $\begin{array}{l}\text { Urticaria } \\
\text { Angioedema } \\
\text { (not obligatory) }\end{array}$ & & Dyspnea & Arrhythmia \\
\hline III & $\begin{array}{l}\text { Itch } \\
\text { Flush } \\
\text { Urticaria } \\
\text { Angioedema } \\
\text { (not obligatory) }\end{array}$ & $\begin{array}{l}\text { Vomitus } \\
\text { Defecation }\end{array}$ & $\begin{array}{l}\text { Laryngeal edema } \\
\text { Bronchospasm } \\
\text { Cyanosis }\end{array}$ & Shock \\
\hline IV & $\begin{array}{l}\text { Itch } \\
\text { Flush } \\
\text { Urticaria } \\
\text { Angioedema } \\
\text { (not obligatory) }\end{array}$ & $\begin{array}{l}\text { Vomitus } \\
\text { Defecation }\end{array}$ & $\begin{array}{l}\text { Respiratory } \\
\text { arrest }\end{array}$ & Cardiac arrest \\
\hline
\end{tabular}

Table 5.17. Severity grading of anaphylactic reactions (according to [30]) 
Autopsy of fatal cases has shown few specific findings; sometimes there is inflation of the lung, and pulmonary edema with peribronchial eosinophilic infiltrates. Sometimes hemorrhages in the gastric mucosa as well as hepatosplenomegaly are reported [1]. In immune complex anaphylaxis, fibrinoid deposits in the lung have been observed [38].

Some authors define anaphylaxis exclusively by the occurrence of cardiovascular symptoms. For these cases, of course, grade I and II will be missed, which, however, often turn into more severe anaphylaxis at the next contact. Rohrer and Pichler examined 118 patients with cardiovascular involvement and found skin symptoms in $88 \%$, respiratory reactions in $72 \%$, and gastrointestinal symptoms in $44 \%$ [35].

\subsubsection{Pathophysiology}

Classical anaphylaxis is mediated by $\operatorname{IgE}$ antibodies on the surface of mast cells and basophil leukocytes, which after bridging with an at least bivalent allergen trigger the secretion reaction of preformed and newly synthesized mediators (see Chap. 2). In spite of our knowledge of mast cell activation and IgE antibodies, the exact mechanisms of amplification are not yet understood, which make it possible that a healthy individual may be killed by a few micrograms of an allergen within minutes.

The extent of mediator release reaction differs between individuals but also in one and the same individual at different times. The term "releasability" describes this phenomenon. Factors influencing releasability comprise cyclic nucleotides, cytokines, psychoneurogenic (autonomic nervous transmitters, neuropeptides) and hormonal influences (e.g., thyroid). Among the cytokines, interleukin-3 has special importance in priming mast cells and basophils and enhancing releasability. These phenomena are not only of scientific interest, but gain practical relevance in helping to explain the often confusing variability of symptomatology underlying the term "summation" or "augmentation anaphylaxis" (see below).

Apart from IgE, other antibody classes may elicit anaphylactic reactions: There is immune complex anaphylaxis with high concentrations of circulating IgG or IgM antibodies with complement activation and formation of anaphylatoxins. Clinical examples are anaphylactic reactions after blood products, e.g., in IgA-deficient persons after plasma replacement, anaphylaxis in serum sickness, or after xenogenic proteins (antilymphocyte serum) as well as dextran anaphylaxis [17, 29, 31, 38].

Besides immunological there are non-immune mechanisms, which will be considered in Sect. 5.7.2 on "Pseudo-allergic Reactions."

Neuropsychogenic reflex mechanisms should be considered especially when we know that psychic stress alone can lead to increased plasma histamine (see Chap. 7 on "Psyche and Allergy").

In the end phase of an anaphylactic reaction, similar mechanisms lead to clinical symptoms: postcapillary plasma exudation and microcirculatory disturbance leads to decreased capillary pressure and perfusion $[9,22]$.

Mast cell dependent anaphylactic reactions occur with an increase of mast cell tryptase in the serum (see Chap. 4), which can be detected even hours (sometimes also postmortem) after a reaction [3].

The mediator release reaction from mast cells and basophils is not a cytolytic process but energy, calcium, and temperature dependent and can be inhibited by specific antagonists (e.g., via cAMP-elevating agents) (see Chap. 2). The concomitant use of beta-blockers and possibly also angiotensin-converting enzyme inhibitors (ACE inhibitors) may lead to an enhancement of anaphylactic symptoms [13]. In patients with insect venom anaphylaxis, we found a significant inverse correlation between the plasma angiotensin II level and the severity of anaphylactic symptoms in history [14]. Under allergen-specific immunotherapy, the previously lowered angiotensin II levels normalized [14].

\subsubsection{Allergens and Elicitors}

The most common elicitors of anaphylaxis are drugs, proteins, foods, aeroallergens, additives, body fluids, latex, microbial antigens, but also physical factors (Table 5.18). 
Table 5.18. Elicitors of anaphylactic reactions

Drugs (all forms!)
Additives
Foods
Occupational agents (e.g., latex)
Insect venoms
Aeroallergens
Contact urticariogens
Seminal fluid
Echinococcal cysts
Cold, heat, UV radiation
Exercise
Summation (infection, stress, exercise, other
$\quad$ allergen concomitant exposure, medication
$\quad$ as $\beta$-blockers, NSAIDs, ACE inhibitors, etc.)
Idiopathic (?)
Underlying diseases:
C1 inactivator deficiency
Systemic mastocytosis

Rare cases of passive transfer of IgE antibodies via blood transfusion as well as suicide attempts (penicillin-allergic nurse) have been reported. Murder has been attempted by eliciting anaphylaxis in the detective literature. Also anaphylaxis factitia ("Münchhausen's syndrome") exists [I remember the case of a 17year-old girl with repeated severe anaphylactic (grade III and IV) episodes on the basis of serious somatoform disturbance]. Epidemiology of anaphylaxis mostly focuses on the elicitors. The rate of drug-induced anaphylaxis ranges from $0.001 \%$ up to $10 \%$ per dose applied [2, 31]. Rarer reactions have been observed after poppy seeds, beer (hops and barley), but also due to ethanol [25].

The elicitor of anaphylaxis may be transmitted to the organism via the air (fish allergens in vapors around fish stores, latex allergens in rooms decorated with air balloons). The application of an ointment on unlesional skin may elicit contact anaphylaxis in sensitized individuals [33]. In recent years, increasing reports describe patients who only suffer anaphylaxis after combined action of different stimuli, for instance, physical exercise, mental or emotional stress, acute infection, or concomitant exposure against other relevant allergens. We call this phenomenon "summation" or "augmentation anaphylaxis" and think that it may be much more common than generally suspected. Possibly, this type of reaction is the rule and
Table 5.19. Differential diagnosis of anaphylaxis

Pharmacologic-toxic effects
Cramps
Syncope (cardial, cerebral)
Pulmonary embolism
Bolus aspiration
Hypoglycemia
Hyperventilation
Vasovagal reflexes
Vocal cord dysfunction
Hysterical fit
"Anaphylaxis factitia" (Münchhausen's syndrome)

that explains why fortunately many sensitized individuals tolerate allergen contact without clinical incompatibility symptoms! We believe that many cases of so-called idiopathic anaphylaxis may thus be explaianed $[32,45]$.

\subsubsection{Diagnosis and Differential Diagnosis}

The clinical symptomatology of anaphylaxis is so characteristic that diagnosis usually is not difficult. Nevertheless several differential diagnoses need to be considered (Table 5.19).

Patients having survived an anaphylaxis have to undergo allergy diagnosis! This diagnostic procedure has three aims:

1. Determination of the eliciting agent

2. Description of the relevant pathomechanism (e.g., IgE)

3. Offering of a compatible alternative (see Sect. 5.7 on "Drug Allergy").

\subsubsection{Prophylaxis and Therapy}

For prophylaxis (Table 5.20), abstaining from polypragmatic pharmacotherapy is as important as the endeavors of the pharmaceutical industry to produce better and less allergenic drugs.

Knowledge of possible complications is the best basis for successful therapy. Being prepared for such complications enables one to react more quickly. This also implies knowledge of additives (stabilizers, preservatives, colorings, etc.) in drugs against which people can react.

The question regarding adverse drug reactions in the history allows the risk groups to be pinpointed. The importance of atopic diathesis 
Table 5.20. Prophylaxis of anaphylactic reactions

Exact diagnosis
Avoidance strategies
Information from the patient (“allergy passport")
Strict indication for pharmacotherapy
Avoidance of $\beta$-blockers
If possible oral administration
Observance of the patient after injection
"Prophetic" testing in selected cases
Hyposensitization (or "adaptive deactivation")
Tolerance induction
Hapten inhibition
Premedication (e.g., with histamine $\mathrm{H}_{1}$ and $\mathrm{H}_{2}$
antagonists or antihistamines plus steroids)
Emergency set (for self-medication)

as a risk factor is controversial and is probably limited to IgE-mediated reactions.

Only in a few cases is specific prophylaxis possible such as induction of tolerance against xenogenic immunoglobulin in heterologous protein therapy [31] or by hapten inhibition in dextran anaphylaxis [17, 29, 31].

The combined administration of $\mathrm{H}_{1}$ and $\mathrm{H}_{2}$ antagonists or antihistamines together with glucocorticosteroids is recommended for the prophylaxis of anaphylactoid reactions after volume substitutes or radiographic contrast media [19] (see Sect. 5.7.2 on "Pseudo-allergic Reactions").

Observation of the patient in the first minutes after parenteral drug administration is the basis of prophylaxis. General rule: The more severe the anaphylactic symptoms to be expected, the sooner they will become manifest! Of course, there are exceptions from the rule in the form of "tricky" late anaphylactic reactions after several hours [31, 41]; often, however, mild symptoms occur within the first $20 \mathrm{~min}$ which tend to be overlooked.

\subsubsection{Therapy}

The treatment of anaphylaxis follows the severity of symptoms (Fig. 5.12). If the reaction only involves the skin (urticaria) with a stable cardiovascular system, antihistamines may be sufficient. In any case, an intravenous catheter should be placed and an infusion prepared.

If the reaction proceeds (and the differential diagnosis is easy!) glucocorticoids and epinephrine $(0.3 \mathrm{mg}$ i.m., in children $0.1 \mathrm{mg} / \mathrm{kg}$ body wt.) should be given, in dyspnea together with theophylline $(0.24-0.48 \mathrm{mg})$ plus $\beta_{2}$-adrenergics.

In fully developed anaphylactic shock, the general principles of shock therapy are applied $[8,10,11,22,26,27,37,42]$. Epinephrine can be given intravenously (dilute the commercial ampule $1 \mathrm{ml}$ in $10 \mathrm{ml}$ saline for slow infusion of 1-3 ml under pulse control; if needed, up to $10 \mathrm{ml}$ and more) or more practically subcutaneously. In patients on $\beta$-blockers, i.v. glucagon
Fig. 5.12. Immediate action to be taken in the event of anaphylactic reactions of varying severity

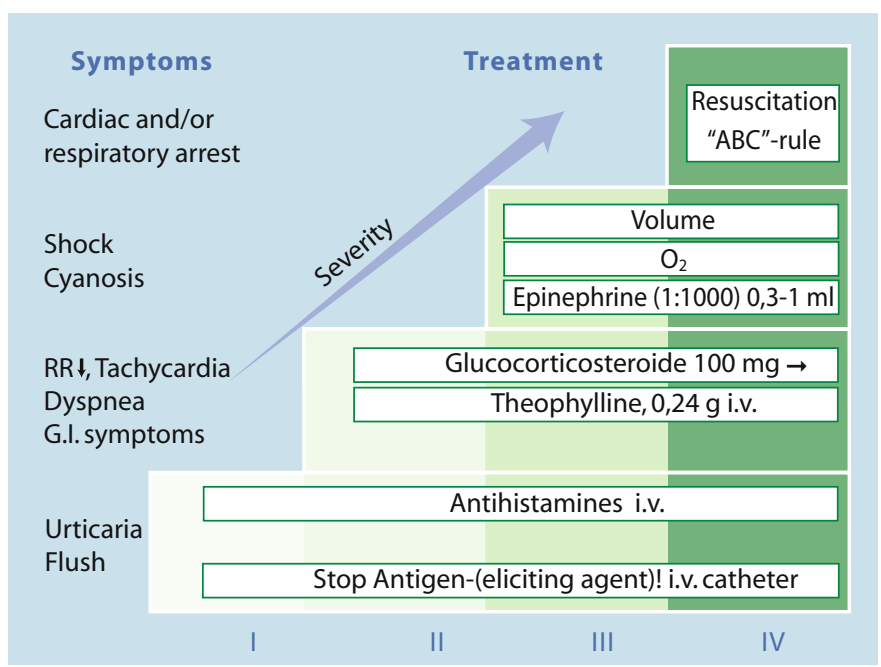


(1-2 mg) is beneficial [46] in restoring $\beta$-receptor responsiveness. For self-medication, epinephrine as autoinjector ("Epi-pen" or "Fastject") is recommended. The undoubted effect of epinephrine, however, does not guarantee a successful outcome: in spite of early epinephrine, fatal anaphylactic reactions have been observed [18]. Furthermore, epinephrine may induce severe cardiac arrhythmia until ventricular fibrillation occurs especially in elderly patients $[4,23,39,40,44]$.

In severe hypotension, intensive volume replacement (e.g., crystalloids or hydroxyethyl starch up to $1,000 \mathrm{ml}$ as rapid infusion) is vital. Levarterenol [12], metaraminol, or dopamine may also be applied. In grade IV reactions (cardiac or respiratory arrest), only immediate and adequate resuscitation measures are life-saving [8] (Table 5.21).

In addition to the classical rule of resuscitation ( $\mathrm{ABC}$ rule), the treatment of severe anaphylaxis requires the AAC rule (Fig. 5.13) [31].

The use of glucocorticosteroids in anaphylaxis is controversial (see references cited in $[31,34])$. Steroids need some time until they act (approximately $15 \mathrm{~min}$ ). They are not as useful for monotherapy as antihistamines in the treat-

Table 5.21. Basic rules of resuscitation

Diagnosis (evaluation of severity, carotid pulses)
Airways (clearing and respiration)
Oxygen
Call help (get someone to call)
Cardiac massage/respiration
Venous catheter plus volume therapy (pressure in-
fusion)
Intubation
ECG (?)
Defibrillation (?)
Pharmacotherapy (epinephrine, sodium bicarbon-
ate, dopamine, lidocaine, possibly atropine, etc.)

\begin{tabular}{|c|c|c|}
\hline Airway & & Antigen off \\
\hline Breathing & + & Adrenaline \\
\hline Circulation & & Cortisone $^{2}$ \\
\hline
\end{tabular}

1 1:1000: $0.5 \mathrm{ml}$ i.m. or slowly i.v.

${ }^{2}$ e.g. prednisolone: $1-2 \mathrm{~g}$

Fig. 5.13. The "AAC Rule" ment of grade I and II reactions. Possibly, $\mathrm{H}_{2}$ antagonists have an additional beneficial effect in anaphylaxis [7]. We recommend in severe anaphylaxis the additional administration of high-dose glucocorticosteroids (e.g., 1 g prednisolone i.v.), if only to avoid late complications [31].

The necessary emergency equipment for treatment of anaphylaxis is listed in Table 5.22.

Patients who have suffered an anaphylactic reaction of grade III and IV should be kept un-

Table 5.22. Emergency equipment for the allergist's office

Tourniquet, disinfectant

Syringes, cannulas, infusion sets, connecting pieces

Blood pressure, stethoscope

Laryngoscope

Guedel and intratracheal tubes (size 0-5 Guedel, 28-32 Wendel, 3-8 $\mathrm{mm}$ intratracheal)

Oxygen

Breathing masks (for children and adults)

Ventilation device (Ambu)

Suction pump

ECG (possibly with defibrillator)

Infusion solutions $(\mathrm{NaCl}$, human serum albumin, hydroxyethyl starch, sodium bicarbonate)

Antihistamines (e.g., clemastine, dimetinden, ranitidine ampules)

Glucocorticosteroids (e.g., prednisolone hemisuccinate $250 \mathrm{mg}$, triamcinolone $1 \mathrm{~g}$ )

Atropine (0.5-mg ampules)

Theophylline (0.24-g ampules)

Epinephrine (e.g., Suprarenin ampules = epinephrine $1: 1,000$ )

Beta-adrenergics (e.g., fenoterol, salbutamol)

Glucagon (ampules)

Spasmolytics (e.g., diazepam)

Antiemetics (e.g., metoclopramide)

Analgesics (tramadol)

Antihypertensives ( $\alpha$-blockers)

Antiarrhythmics (lidocaine $2 \%$ ampules, digoxin ampules)

Calcium ampules, glucose ampules, saline, aqua dest. ampules 
der supervision in hospital at least overnight; occasional cases of "late shock," e.g., second anaphylactic episode after $6-12 \mathrm{~h}$, are dangerous complications $[31,40]$. These patients also represent a risk group for skin testing, which should only be done under emergency conditions.

\section{References}

1. Barnard JH (1973) Studies of 400 Hymenoptera sting deaths in the United States. J Allergy Clin Immunol 52:259-264

2. Bochner BS, Lichtenstein LM (1991) Anaphylaxis. N Engl J Med 324:81 - 88

3. Brockow K, Kiehn M, Riehtmüller C, Vieluf D, Berger J, Ring J (1997) Efficacy of antihistamine pretreatment in the prevention of adverse reactions to Hymenoptera venom immunotherapy: a prospective randomized placebo-controlled trial. J Allergy Clin Immunol 100:458-463

4. Brown MJ, Brown DC, Murphy MB (1983) Hypokalemia from beta-2-receptor stimulation by circulating epinephrine. N Engl J Med 309: 1414- 1419

5. Capurro N, Levi R (1975) The heart as target organ in systemic allergic reactions. Circ Res 36:520 - 528

6. Delage C, Irey HC (1972) Anaphylactic deaths: a clinicopathologic study of 43 cases. J Forens Sci 17:525

7. De Soto H, Turk P (1989) Cimetidine in anaphylactic shock refractory to standard therapy. Anesth Analg 69:264-265

8. Eisenberg MS, Mengest TJ (2001) Cardiac resuscitation. N Engl J Med 344:1304-1313

9. Endrich B, Ring J, Intaglietta M (1979) Effects of radiopaque contrast media on the microcirculation of the rabbit omentum. Radiology 132: $331-339$

10. Fisher MMD (1986) Clinical observations on the pathophysiology and treatment of anaphylactic cardiovascular collapse. Anesth Intensive Care $17: 17-21$

11. Fuchs E, Ferlinz R (1986) Allergische Krankheiten. In: Wolff HR v, Weihrauch TR (eds) Internistische Therapie, 6 th edn. Urban und Schwarzenberg, Munich, pp 275-288

12. Gronemeyer W (1980) Noradrenalin statt Adrenalin beim anaphylaktischen Schock. Dtsch Med Wochenschr 102:101

13. Hannaway PJ, Hoppler GDK (1983) Severe anaphylaxis and drug induced beta-blockage. N Engl J Med 308:1536

14. Hermann K, Ring J (1997) The renin-angiotensin system in patients with repeated anaphylactic reactions during Hymenoptera venom hyposensiti- zation and sting challenge. Int Arch Allergy Immunol 11:251 - 156

15. Johansson SGO, Hourihane JOB, Bousquet J, Bruijnzeel-Koomen, Dreborg S, Haahtela T, Kowalski ML, Mygind N, Ring J, van Cauwenberge P, van Hage-Hamsten M, Wüthrich B (2001) A revised nomenclature for allergy. An EAACI position statement from the EAACI nomenclature task force. Allergy 56:813-824

16. Kleinhans D (1987) Anstrengungs-induzierte Urtikaria und Anaphylaxie. Med Klein 82:103-104

17. Laubenthal H (1986) Dextrananaphylaxie, Pathomechanismus und Prophylaxe. Ergebnisse einer multizentrischen Studie. Springer, Berlin Heidelberg New York

18. Lockey RF, Benedict LM, Turkeltaub TB, Bukantz SC (1987) Fatalities from immunotherapy (IT) and skin testing (ST). J Allergy Clin Immunol 79:666-677

19. Lorenz W, Doenicke A, Dittmann I, Hug P, Schwarz B (1977) Anaphylaktoide Reaktionen nach Applikation von Blutersatzmitteln beim Menschen. Verhinderung dieser Nebenwirkung von Haemaccel durch Praemedikation mit $\mathrm{H}_{1}$ und $\mathrm{H}_{2}$-Antagonisten. Anaesthesist 26:644

20. Marone G, Patelle V, Crescanzo A de, Genovese M (1995) Human heart mast cells in anaphylaxis and cardiovascular disease. Int Arch Allergy Immunol 107:72-75

21. Maulitz RM, Pratt DS, Schocket AL (1979) Exercise-induced anaphylactic reaction to shellfish. J Allergy Clin Immunol 63:433

22. Meßmer K (1983) Plasma substitutes and indications for their use. In: Tinker J, Rapin M (eds) Care of the critically ill patient. Springer, Berlin Heidelberg New York, pp 569-575

23. Müller U (2001) Spätkomplikationen bei Anaphylaxie. In: Ring J, Darsow U (eds) "Allergie 2000: Probleme, Strategien und praktische Konsequenzen”. Dustri, Munich, pp 249-252

24. Pavek K, Wegmann A, Nordström L, Schwander D (1982) Cardiovascular and respiratory mechanisms in anaphylactic and anaphylactoid shock reactions. Klin Wochenschr 60:941 - 947

25. Przybilla B, Ring J (1983) Anaphylaxis to ethanol and sensitization to acetic acid. Lancet 1:483

26. Pumphrey RS (2000) Lessons for management of anaphylaxis from a study of fatal reactions. Clin Exp Allergy 30:1144-1150

27. Reimers A, Müller U (2000) Behandlung des anaphylaktischen Schocks. Ther Umschau 58:325328

28. Richet C (1904) De l'anaphylaxie ou sensibilite croissante des organismes a des doses successives de poison. Arch Fisiol 1:129

29. Richter W, Hedin H, Ring J, Kraft D, Messmer K (1980) Anaphylaktoide Reaktionen nach Dextran I. Immunologische Grundlagen und klinische Befunde. Allergologie 3:9

30. Ring J, Messmer K (1977) Incidence and severity 
of anaphylactoid reactions to colloid volume substitutes. Lancet 1:466-468

31. Ring J (1978) Anaphylaktoide Reaktionen nach Infusion naturlicher und künstlicher Kolloide. Springer, Berlin Heidelberg New York

32. Ring J, Darsow U (2002) Idiopathic anaphylaxis. Curr Allergy Asthma Rep 2:40-45

33. Ring J, Galosi A, Przybilla B (1986) Contact anaphylaxis from emulgade F. Contact Dermatitis 15:49-40

34. Ring J, Behrendt H (1999) Anaphylaxis and anaphylactoid reactions. Classification and pathophysiology. Clin Rev Allergy Immunol 17:387399

35. Rohrer CL, Pichler WJ, Helbling A, et al. (1998) Anaphylaxie: Klinik, Ätiologie und Verlauf bei 118 Patienten. Schweiz Med Wochenschr 128: $53-63$

36. Sheffer AL, Austen KF (1980) Exercise-induced anaphylaxis. J Allergy Clin Immunol 66:106

37. Simons FE, Gu X, Johnston LM, Simons KJ (2000) Can epinephrine inhalations be substituted for epinephrine injection in children at risk for systemic anaphylaxis? Pediatrics 106:1040 - 1044

38. Smedegard G, Revenäs B, Arfors KE (1979) Anaphylaxis in the monkey: hemodynamics and blood flow distribution. Acta Physiol Scand 106:191

39. Smith PL, Kagey-Sobotka A, Blecker ER, Traystman R, Kaplan AP, Gralink H, Valentine MD, Permut S, Lichtenstein LM (1980) Physiologic mani-

\subsubsection{Food Allergy and Other Adverse Food Reactions}

\subsubsection{Classification and Symptomatology}

Adverse food reactions represent an increasing problem in allergy practice. The clinical symptoms range from nausea, vomiting, abdominal pain, gastroenteritis, diarrhea, urticaria, asthmoid complaints, allergic rhinitis to full anaphylaxis or serum sickness type reactions with arthralgia and vasculitis $[9,26,42,67-70]$ (Table 5.23).

As in all fields of allergology, clinically similar but pathophysiologically different non-immunologically elicited conditions (pseudo-allergic reactions) need to be distinguished $\mathrm{Ta}$ ble 5.24); in this chapter, particularly enzyme deficiency (e.g., lactase) as well as toxic effects of contaminants (bacterial toxins) should be considered. Diseases due to malnutrition will not be covered here $[11,12,48,51]$. festations of human anaphylaxis. J Clin Invest 60:1072

40. Sullivan TJ (1982) Cardiac disorders in penicillininduced anaphylaxis: association with intravenous epinephrine therapy. J Am Med Assoc 248:2161

41. Stark BJ, Sullivan TJ (1986) Biphasic and protracted anaphylaxis. J Allergy Clin Immunol 78:76-83

42. Tryba M, Ahnefeld FW, Barth J, Dick W, Doenicke A, Fuchs T, Gervais $H$, Laubenthal $H$, Löllgen $H$, Lorenz W, Mehrkens HH, Meuret GH, Möllmann H, Piepenbrock S, Przybilla B, Ring J, Schmutzler W, Schultze-Werninghaus G, Schüttler J, Schuster JP, Sefrin P, Zander J, Zenz M (1994) Akuttherapie anaphylaktoider Reaktionen. Ergebnisse einer interdisziplinären Konsensuskonferenz. Allergo J 3:211-222

43. Waldhausen E, Keser G, Marquardt B (1987) Der anaphylaktische Schock. Anästhesist 36:150 - 158

44. Wegmann A, Reuker H, Pavek K, Schwander D (1983) Katecholamintherapie und Herzrhythmusstörungen im anaphylaktischen und anaphylaktoiden Schock. Anaesthesist 32 [Suppl]:320

45. Wiggins CA, Dykowicz MS, Patterson R (1988) Idiopathic anaphylaxis. Classification, evaluation and treatment of 123 patients. J Allergy Clin Immunol 82:849-855

46. Zaloga GP, Delacey W, Holmboe E, Chernow B (1986) Glucagon reversal of hypotension in a case of anaphylactoid shock. Ann Intern Med 105: 65-66

Table 5.23. Clinical manifestation of adverse food reactions

\begin{tabular}{|c|c|}
\hline Skin & Panniculitis? \\
\hline Itching & Melkersson-Rosenthal \\
\hline Flushing & Syndrome? \\
\hline Urticaria & Eve and airways \\
\hline Angioedema & \\
\hline Atopic eczema & $\begin{array}{l}\text { Rhinoconjunctivitis } \\
\text { Laryngeal edema }\end{array}$ \\
\hline $\begin{array}{l}\text { Lip swelling and swelling } \\
\text { of oral mucosa }\end{array}$ & $\begin{array}{l}\text { Laryngeal edema } \\
\text { Bronchial asthma }\end{array}$ \\
\hline $\begin{array}{l}\text { Stomatitis, glossitis } \\
\text { (papillitis linguae) }\end{array}$ & $\begin{array}{l}\text { Gastrointestinal tract } \\
\text { Nausea }\end{array}$ \\
\hline Relapsing aphthae & Vomiting \\
\hline $\begin{array}{l}\text { Immune complex vascu- } \\
\text { litis }\end{array}$ & $\begin{array}{l}\text { Meteorism } \\
\text { Acute gastroenteritis }\end{array}$ \\
\hline $\begin{array}{l}\text { Purpura pigmentosa } \\
\text { progressiva }\end{array}$ & $\begin{array}{l}\text { Diarrhea } \\
\text { Colitis? }\end{array}$ \\
\hline $\begin{array}{l}\text { Hematogenous (system- } \\
\text { ic) contact dermatitis }\end{array}$ & Cardiovascular system \\
\hline Protein contact dermatitis & \\
\hline $\begin{array}{l}\text { Phototoxic and photo- } \\
\text { allergic reactions }\end{array}$ & \\
\hline Exanthematous eruptions & \\
\hline $\begin{array}{l}\text { Dermatitis herpetifor- } \\
\text { mis Duhring (gluten) }\end{array}$ & \\
\hline
\end{tabular}


Table 5.24. Classification of adverse food reactions

\begin{tabular}{|c|c|c|c|c|c|c|c|}
\hline Mechanism & $\begin{array}{l}\text { Allergy } \\
\text { IgE }\end{array}$ & $\operatorname{IgG} / \mathrm{M}$ & IgA (?) & $\begin{array}{l}\text { Lympho- } \\
\text { cytes }\end{array}$ & $\begin{array}{l}\text { Mediator } \\
\text { release }\end{array}$ & $\begin{array}{l}\text { Enzyme } \\
\text { defects }\end{array}$ & $\begin{array}{l}\text { Pseudo- } \\
\text { allergy/ } \\
\text { intolerance }\end{array}$ \\
\hline Examples & $\begin{array}{l}\text { Immediate } \\
\text { reaction }\end{array}$ & $\begin{array}{l}\text { Serum } \\
\text { sickness }\end{array}$ & $\begin{array}{l}\text { Gluten- } \\
\text { sensitive } \\
\text { entero- } \\
\text { pathy }\end{array}$ & $\begin{array}{l}\text { Cellular } \\
\text { allergy }\end{array}$ & $\begin{array}{l}\text { Colorings, } \\
\text { preserva- } \\
\text { tives, } \\
\text { salicylates }\end{array}$ & $\begin{array}{l}\text { Lactase } \\
\text { - Inherited } \\
\text { - Secondary } \\
\text { Galactokinase } \\
\text { Gal-1-PO } \\
\text { Uridyltrans- } \\
\text { ferase }\end{array}$ & $\begin{array}{l}\text { Poisons, } \\
\text { histamine } \\
\text { Serotonin, ca- } \\
\text { techolamines, } \\
\text { psychoactive } \\
\text { substances }\end{array}$ \\
\hline $\begin{array}{l}\text { Clinical } \\
\text { symptoms: } \\
\text { (selection) }\end{array}$ & $\begin{array}{l}\text { Urticaria, } \\
\text { anaphylax- } \\
\text { is, diarrhea } \\
\text { Colics } \\
\text { Anaphy- } \\
\text { laxis } \\
\text { (atopic ec- } \\
\text { zema) }\end{array}$ & $\begin{array}{l}\text { Vasculitis, } \\
\text { arthralgia }\end{array}$ & $\begin{array}{l}\text { Diarrhea, } \\
\text { malab- } \\
\text { sorption }\end{array}$ & $\begin{array}{l}\text { Systemic } \\
\text { contact } \\
\text { Contact } \\
\text { dermatitis } \\
\text { Exanthem- } \\
\text { atous } \\
\text { eruption } \\
\text { Colitis (?) } \\
\text { Diarrhea }\end{array}$ & $\begin{array}{l}\text { Urticaria, } \\
\text { angio- } \\
\text { edema } \\
\text { Anaphy- } \\
\text { laxis }\end{array}$ & $\begin{array}{l}\text { Diarrhea, } \\
\text { malabsorp- } \\
\text { tion } \\
\text { Blood pres- } \\
\text { sure changes }\end{array}$ & $\begin{array}{l}\text { Anaphylaxis/ } \\
\text { anaphylac- } \\
\text { toid reaction } \\
\text { Mental con- } \\
\text { fusion (?) }\end{array}$ \\
\hline
\end{tabular}

Food allergies manifest frequently on the skin $(60 \%)$, the GI tract $(20 \%)$, the airways $(20 \%)$ and the cardiovascular system (10-15\%) [29]. Food-induced contact urticaria or contact dermatitis represent special forms.

Adverse food reactions are a frequent problem (Sect. 3.1.2).

Few fields of allergology have comparable difficulties with parascientific practices such as food allergy, especially when patients only suffer from subjective complaints elicited through foods (tension, fatigue, behavioral changes, etc.). The movement of "clinical ecology" has focused interest on so-called allergic reactions against pollutant chemicals especially in foods manifesting as psychiatric diseases $[14,19]$ (see Sect. 5.10 on "Eco-syndrome").

\subsubsection{Food Allergens}

The most common food allergens in Central Europe are cow's milk, hen's eggs, nuts, spices, vegetables, cereals, fish, meat, and fruits. Regional, ethnic-cultural aspects play an important role as well as age and underlying diseases.

Of practical importance are cross-reactions between different fruits (e.g., apple, peach, cherry) and tree pollen (e.g., hazel, birch, al- der) as well as between mugwort pollen and spices (anis, curry, etc.) and celery (see Sect. 3.3.4 on "Allergens") $[1,57,67]$.

Food allergens may be altered by preparatory procedures (e.g., boiling) [20]. Many allergens, however, are relatively resistant to $\mathrm{pH}$ changes, heat, and proteases.

IgE-inducing food allergens are glycoproteins. Small chemicals may elicit systemic contact dermatitis (e.g., nickel, fragrances) [32]. Elicitors of pseudo-allergic reactions comprise additives and biogenic amines [29, 31, 39].

Gene Technology and Food Allergy. Gene technology can lead to food changes of allergological relevance. This can be either as increased risk as in the introduction of the major allergen of Brazil nuts into soy [38] or as chance (production of hypoallergenic rice). The recommendations of the German Society for Allergology and Clinical Immunology (DGAI) regarding gene technology and foods are listed in Table 5.31.

In the following, the most important food allergens are briefly discussed:

Cow's Milk. Milk is the secretion product of the mammary glands of mammals. The species 
Table 5.25. Dietary recommendations employed in food allergy and other adverse food reactions

\section{Diagnostic diets}

Allergy diet no. 1 (“allergen-free"): short-term, up to 10 days, prior to provocation or after acute reaction

Allergy diet no. 2 (“allergen-poor”): up to 3 weeks, basis for provocation tests

Allergy diet no. 3 ("additive-free"): can be given over months, basis for provocation with additives

2. Stepwise diets (diagnostic and therapeutic) Stepwise elimination (interval days or weeks)

Stepwise provocation (interval days or weeks)

3. Therapeutic diets

Specific allergen avoidance

Additive-free diet (hypersensitivity to additives)

Nickel- or fragrance-free diet (in patients with positive oral provocation test and systemic contact dermatitis)

Gluten-free diet (in sprue, dermatitis herpetiformis)

4. Prophylactic diets (general antiallergic diet)

Breastfeeding in infants

Hydrolyzed cow's milk formula

Hypoallergenic (oligoantigenic) diet of the mother during lactation is important. Plant extracts should not be falsely called "milk" (e.g., "soy milk"). Cow's milk contains up to $30-35$ g protein $/ \mathrm{ml}, 80 \%$ of which is casein and $20 \%$ whey protein (beta-lactoglobulin, alpha-lactalbumin, bovine serum albumin, as well as immunoglobulins). The most common allergens are whey proteins (beta-lactoglobulins) but also casein, which is not species-specific and shows cross reactions between cattle, goat, sheep, etc. During milk preparation, whey proteins remain in solution while casein coagulates; in spite of this, whey proteins may be present in cheese or butter as well as casein in whey. Casein is heat-stable, whereas whey proteins are partly denatured.

Allergenic proteins may be denatured to different degrees by hydrolysis, leading to socalled hypoallergenic infant formulas. The term "hypoallergenic" is not well defined. One distinguishes between prophylactically hypoallergenic preparations (a low degree of hydrolysis) and strongly hydrolyzed products, which can be used for therapy of cow's milk allergic individuals. This needs to be evaluated using a prick test [3].

Cross reactions between cow's milk and beef or veal are possible but rare (most likely due to BSA). Allergies against horse mare's milk (also after topical application) can occur.

The common dietary recommendation of pork avoidance in allergic individuals or atopics is rarely based on manifest allergy, but is rather of historic, cultural origin.

Hen's Eggs. Specific IgE antibodies against hen's eggs are the best marker of atopy risk in the newborn (even if the child has been exclusively breast-fed); obviously, small amounts of allergens reach the infant through the maternal nutrition and breast milk. The major allergen is ovomucoid (Gal d 1) from the clear part besides ovalbumin ( Gal d 2) and ovotransferrin (Gal d 3 ) and lysozyme (Gal d 4). In the yellow part of the egg, livetin, apovitillin, and vosviten can be found, which may play a role in adult hen's egg allergics. Cross-sensitizations between hen's eggs and poultry meat (chicken, turkey, duck, goose) have been described.

Cereals. Here we have to distinguish between the food and the respiratory allergy (in bakers). It is interesting that most asthmatic flour-allergic bakers may be able to eat cereals without problems. Cross-reactions between different flours are less frequent than between pollen allergens of the same species. The most frequent cereal allergy is wheat allergy; patients are not required to avoid other cereals. In one-fourth of patients cross-reactions exist to grass pollen and other cereal flours without symptoms of food allergy. Cereals may elicit exacerbation of atopic eczema which may be diagnosed using the atopy patch test (see Sect. 5.5.3).

Vegetables/Fruit. Many patients with pollen allergy are also allergic against fruit and vegetables on the basis of the known cross-reactions (see Sect. 3.4). The relevant plant proteins exert different functions (hydrolases, carrier proteins, enzyme inhibitors, stress proteins).

One of the most common pathogenesis-related proteins is the major allergen from birch pol- 
len (Bet v 1), which is not only present in pollen of different trees (hazel, alder, oak, beech, etc.) but also in foods (apple, prunes, carrots, nuts, celery). It is heat-sensitive. Many apple-allergic individuals tolerate apple mousse. Bet v $2=$ profillin as a structural protein is heat-stable [13].

Celery represents a major problem for many food-allergic individuals; minute amounts may elicit severe reactions (anaphylaxis) (e.g., celery salt in salad).

Patients with latex allergy often show crosssensitization to certain foods such as kiwifruit, avocado, buckwheat, chestnut, and lychee.

Among the legumes, the most common allergens are soy and peanut (peanuts are not nuts!). Severe reactions to minute amounts of peanut allergen in other foods prepared in the same machines where peanut butter has been prepared have been reported.

Soy not only is a relevant allergen for children (supplement for cow's milk) but also for adults. Often, allergic individuals do not recognize soy in the food ("hidden allergens") (allergic reactions to peas and lentils are rather rare).

Fish and Seafood. Fish allergy is especially common in populations on the coast. The first chemically defined food allergen was the major allergen of codfish ( $\mathrm{Gad} \mathrm{c} 1)$ [1]. There are multiple cross-reactivities to other fish but rarely to crustaceans and mollusks. The fish allergen is very heat-stable and also volatile (patients with severe asthmatic reaction and anaphylaxis over $50 \mathrm{~m}$ distance from a fish food store).

While seafood represents a delicacy in some countries, it is a basic food for large populations of the world. The major allergen of shrimps (Met e 1) corresponds chemically to a tropomyosin and shows cross-reactivity to some arthropods (housedust mites).

\subsubsection{Pathomechanisms}

Little is known about the mechanism of sensitization in food allergy $[2,24,25,56]$. Apart from the genetic predisposition, acute inflammatory diseases of the gut may play a role in the devel- opment of food allergy perhaps through enhanced resorption as well as absorption-enhancing substances (alcohol, spices) or hectic and excessive monoalimentation (e.g., case of hen's egg allergy after the intake of 24 raw eggs during a bet) [66].

Immune reactions play a role in normal gastrointestinal physiology; this has been shown in experiments when sensitized dogs digested orally applied proteins much better, probably due to gastrin release, stimulated via antigenpresenting cells and $\mathrm{T}$ cells in the gastric mucosa and release of cytokines [41]. Gastrin itself acts on mast cells as a histamine liberator. It is not yet clear whether allergens need to be absorbed totally in order to elicit food-allergic reactions. Normally proteins and high molecular weight food constituents are enzymatically digested in the gut. Only the gut of the infant and small child shows a higher permeability. Experimental investigations, however, show that also in adult organisms, a small percentage of high molecular weight proteins passes the gut undigested and with immunologic activity [53].

Food allergies may develop via different mechanisms (Table 5.24). The most important clinical conditions are due to IgE-mediated allergic or corresponding pseudo-allergic immediate-type reactions [29, 31, 47, 62].

Rare forms of IgG- or IgM-mediated reactions manifesting a serum sickness, arthralgia, or vasculitis and fever can occur [17]. Cellular hypersensitivity against microbial or mucosal antigens has been discussed in the pathogenesis of ulcerative colitis or m. Crohn $[9,30]$.

The obvious relationship between the gastrointestinal tract and skin in food allergy has not been explained pathophysiologically. Pichler [40] distinguishes three types of food allergy:

Type A: The sensitization occurs orally and in early life; major allergens are cow's milk, hen's eggs, fish, peanut, etc. Each foreign protein in foods is specifically recognized, but induces tolerance in normal individuals. In early life, there is a risk of IgE formation in the special conditions of "immune deviation." While cow's milk and 
hen's egg allergy are mostly reversible during childhood, fish and peanut allergies are often lifelong conditions.

Type B: Here the sensitization occurs in adulthood against aeroallergens with cross-reacting food allergens (see Sect. 3.4) (celery-mugwort-carrotspice syndrome). A high percentage of pollinosis patients are also sensitized against foods.

Type C: The sensitization is acquired orally in adulthood (isolated cow's milk allergy of the adult with anaphylaxis).

\subsubsection{Diagnosis}

The diagnostic recommendations for food allergy are:

1. Reproducible elicitation of symptoms by the suspected food
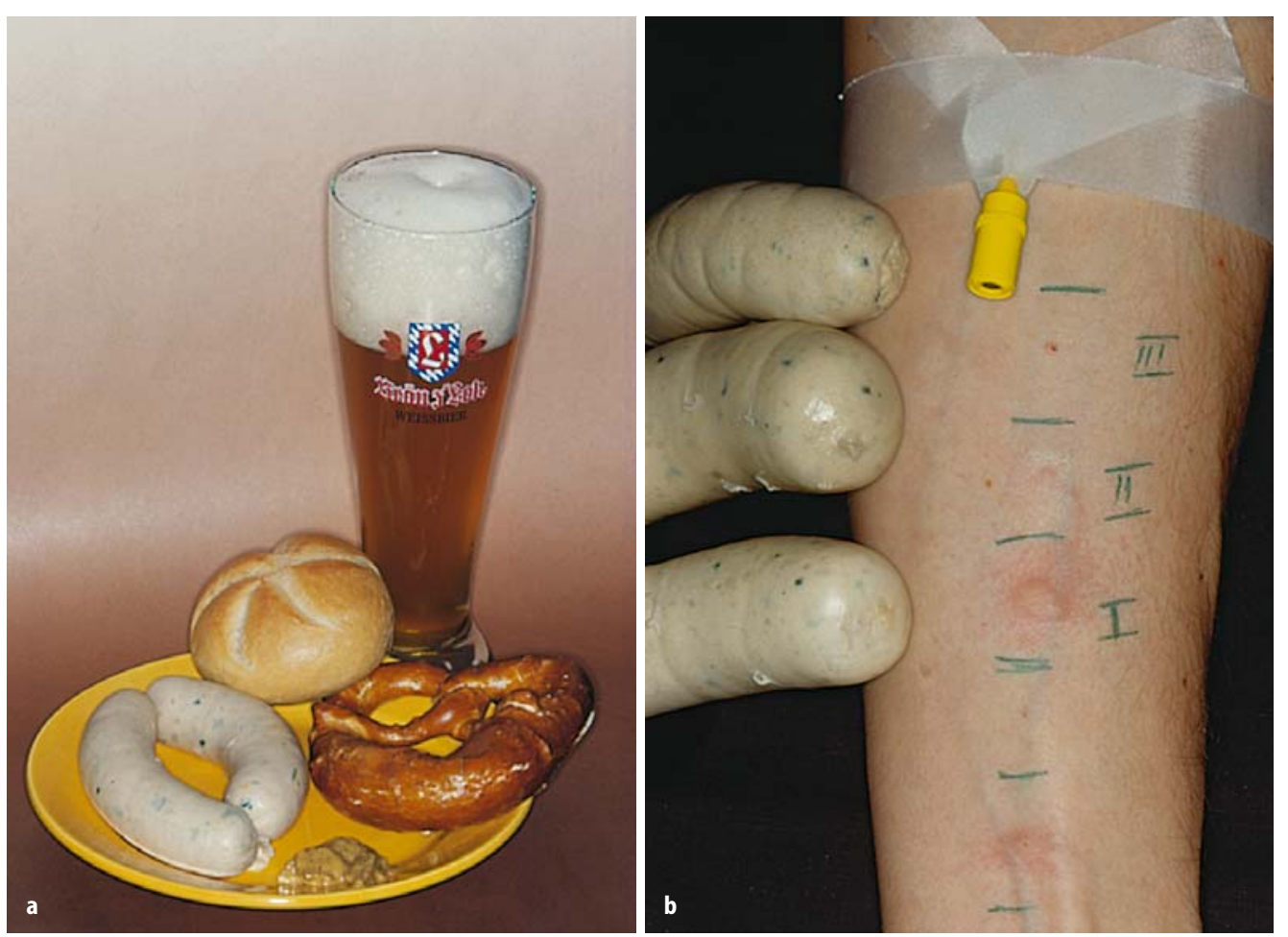

Fig. 5.14a,b. The cause of a severe anaphylactic reaction occurring after a breakfast of Munich white sausage in a patient who regularly ate white sausage from the same butcher's shop was elucidated with the RAST inhibition test [54]: Chicken allergens (due to the non-declared addition of turkey meat to the sausage meat) proved to be the culprit!

2. Exclusion of other possibilities of incompatibility

3. Demonstration of immunological sensitization

Taking the history for food allergy may be difficult (e.g., to obtain the recipe for certain dishes). We were able to solve a case of severe anaphylaxis after the patient had partaken of "Prinzregententorte" (a Bavarian delicacy without nuts) as being due to nut allergy only after obtaining the recipe from the pastry maker, who had used a coconut-derived lipid for the glazing [60].

The diagnostic workup in a patient with severe anaphylaxis after a breakfast including the Munich delicacy "white sausage" (obtainable from only one special butcher) was successful only by demonstrating chicken meat in the sausage (I) in RAST inhibition [54] (Fig. 5.14a,b). 
Table 5.26. Stepwise diet for adults (according to Ring and Braun-Falco [47])

\begin{tabular}{ll}
\hline Step 1 & Cow's milk and cow's milk products \\
Step 2 & Carbohydrates and vegetables \\
Step 3 & Meat \\
Step 4 & Poultry and hen's eggs \\
Step 5 & Fish and seafood \\
Step 6 & Mixed food containing additives \\
\hline
\end{tabular}

Table 5.27. Stepwise diet in small children

\begin{aligned} & Step Foods to be added \\ & \hline 1 Tea (fennel) with glucose plus mineral water \\ & 2 Carrots \\ & 3 Oats \\ & 4 Potatoes \\ & 5 Bread (wheat) \\ & 6 Noodles \\ & 7 Pears \\ & 8 Rice \\ & 9 Soy \\ & 10 Cow's milk \\ & 11 Veal \\ & 12 Beef \\ & 13 Pork \\ & 14 Chicken \\ & 15 Hen's eggs \\ & 16 Leguminosae \\ & 17 Citrus fruits \\ & 18 Chocolate, lemonade, sweets \\ & \hline\end{aligned}

In cases with an unclear history, patients should keep a diet diary and try to certain avoidance diets [47] (Table 5.25). In parallel, allergy diagnosis in vivo and in vitro should be done. After avoidance diets (most suspected substances), provocation diets with a slow reintroduction of different foods (Tables 5.26, 5.27) are tried out, which need to be individually tailored $[6,21,47]$.

If necessary, oral provocation tests with foods and food additives should be performed such as the oral provocation test for idiosyncrasy (OPTI) (Table 5.28). Preservatives such as benzoates and sulfites sometimes are not declared properly and can elicit pseudo-allergic reactions (see Sect. 5.1.3 on "Urticaria"). Sulfites are contained especially in dried fruit, fruit juice, wine, but also deep-frozen vegetables (e.g., potatoes) and at the salad bar [54].

Provocation tests should be done blinded, at least single-blind, in order to reduce the psychosomatic influence $[6,10,15,37]$. Placebo
Table 5.28. Oral provocation test for idiosyncrasy (OPT1) (according to Ring and Przybilla)

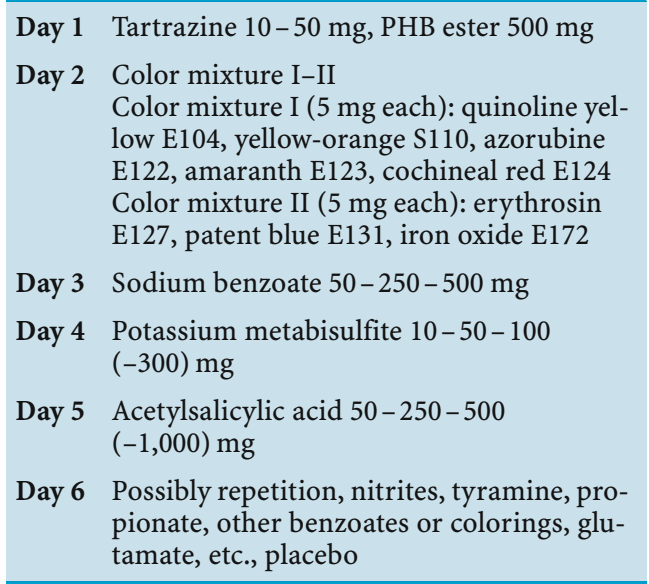

capsules contain coal, mannose or silicate. Foods can be blinded with carob and colored juices (blackcurrant). In severe reactions or multiple allergies, food challenges should be performed under inpatient conditions in order to guarantee optimal standardization and avoidance of additional allergens.

Provocation parameters include subjective and objective complaints (pulse, blood pressure, inspection of the skin, platelet and leukocyte count, sometimes measurement of vasoactive mediators for, e.g., histamine, ECP, tryptase).

After oral provocation, alterations of the mucosal surface have been observed on X-ray [66]. Using intragastral provocation under endoscopic control (IPEC), local mucosal reactions can be visualized [43]. Similarly, intramucosal allergen injection into the colon (colonic allergen application $=$ COLAP) has been performed [7]. These investigations cannot be recommended for routine diagnosis and should be used for rare cases with unclear test results. From our experience with IPEC, however, we know that double-blind placebo-controlled food challenge can have false-negative results: In spite of massive erythema and petechial bleeding of the gastric mucosa, there were no subjective complaints felt by the patient! 


\subsubsection{Therapy}

Avoidance is the most important principle in the management of food allergy. This may be difficult when basic foods are involved. In patients with additive hypersensitivity, knowledge of the E-numbers is important (Table 5.29). In occasional cases, oral (or even subcutaneous) immunotherapy with allergen extracts after careful allergy diagnosis has been attempted $[22,30,34$,
35] with success, but side-effects can occur and may lead to changes in doses. Of course, during hyposensitization strict avoidance should be kept. After reaching a maintenance dose, natural foods can be tried. In cow's milk allergy, for instance, a daily dose of $200 \mathrm{ml}$ cow's milk needs to be drunk. After longer intervals (5-7 days), the effect may be lost.

Therapy and prophylaxis of cow's milk allergy plays a major role in infants (Table 5.30). A

Table 5.29. Food additives and European (E) numbers

\begin{tabular}{|c|c|c|c|}
\hline Colorings & E No. & Preservatives & E No. \\
\hline Lactoflavin (riboflavin) & E101 & Sorbic acid & E200 \\
\hline Beta-carotene & E160a & Sodium sorbate & E201 \\
\hline Caramel & E150 & Potassium sorbate & E202 \\
\hline Silver & E174 & Calcium sorbate & E203 \\
\hline Gold & E175 & Benzoic acid & E210 \\
\hline Curcumin & E100 & Sodium benzoate & E211 \\
\hline Tartrazine & E102 & Potassium benzoate & E212 \\
\hline Quinoline yellow & E104 & Calcium benzoate & E213 \\
\hline Riboflavin-5-phosphate & E106 & Ethyl $p$-hydroxybenzoate & E214 \\
\hline Orange yellow $\mathrm{S}$ & E110 & Sodium ethyl $p$-hydroxybenzoate & E215 \\
\hline Carmine (carminic acid, cochineal) & E120 & Propyl $p$-hydroxybenzoate & E216 \\
\hline Azorubine & E122 & Sodium propyl $p$-hydroxybenzoate & E217 \\
\hline Amaranth & E123 & Methyl $p$-hydroxybenzoate & E218 \\
\hline Cochineal red A (Ponceau 4R) & E124 & Sodium methyl $p$-hydroxybenzoate & E219 \\
\hline Erythrosine & E127 & Sulfur dioxide & E220 \\
\hline Patent blue V & E131 & Sodium sulfite & E221 \\
\hline Indigotin I (indigo carmine) & E132 & Sodium hydrogen sulfite & E222 \\
\hline Chlorophyll & E140 & Sodium metabisulfite & E223 \\
\hline Copper-containing chlorophyll complexes & E141 & Potassium metabisulfite & E224 \\
\hline Brilliant acid green BS (lisamine green) & E142 & Calcium sulfite & E226 \\
\hline Brillant black BN & E151 & Calcium hydrogen sulfite & E227 \\
\hline Vegetable carbon & E153 & Formic acid & E236 \\
\hline Alpha-carotene & E160a & Sodium formiate & E237 \\
\hline Gamma-carotene & & Calcium formiate & E238 \\
\hline Bixin, norbixin (Annatto, Orlean) & $\mathrm{E} 160 \mathrm{~b}$ & Propionic acid & E280 \\
\hline Capsanthian, Capsorubin & E160c & Sodium propionate & E281 \\
\hline Lycopene & E160d & Calcium propionate & $\mathrm{E} 282$ \\
\hline Beta-apo-8'-carotenal & E160e & Potassium propionate & E283 \\
\hline Beta-apo-8'-carotenoic acid ester & E160f & Biphenyl & E230 \\
\hline Xanthophyll & E161 & Orthophenyl phenol & $\mathrm{E} 231$ \\
\hline Flavoxanthin & E161a & Sodium orthophenyl phenol & E232 \\
\hline Lutein & E161b & Thiabendazol & E233 \\
\hline Cryptoaxanthin & E161c & Potassium ascorbate & E303 \\
\hline Rubixanthin & E161d & Tocopherols & E306 \\
\hline Violaxanthin & E161e & Alpha-tocopherol & E307 \\
\hline Rhodoxanthin & E161f & Delta-tocopherol & E309 \\
\hline Canthaxanthin & E161g & & \\
\hline Betanin & E162 & & \\
\hline Anthocyanin & E163 & & \\
\hline Aluminum & E173 & & \\
\hline Calcium carbonate & E170 & & \\
\hline Titanium dioxide & E171 & & \\
\hline Iron oxides and hydroxides & E172 & & \\
\hline
\end{tabular}


Table 5.29. (Cont.)

$\begin{array}{llll}\text { Antioxidants } & \text { E No. } & \text { Carriers } & \text { E No. } \\ \text { Propyl gallate } & \text { E310 } & \text { Ammonium alginate } & \text { E403 } \\ \text { Octyl gallate } & \text { E311 } & \text { Potassium alginate } & \text { E402 } \\ \text { Dodecyl gallate } & \text { E312 } & \text { Sodium alginate } & \text { E401 } \\ \text { Butylated hydroxyanisole (BHA) } & \text { E320 } & \text { Glycerol } & \text { E422 } \\ \text { Butylated hydroxytoluol (BHT) } & \text { E321 } & \text { Pectin } & \text { E440 } \\ \text { Ascorbic acid } & \text { E300 } & \text { Sorbitol } & \text { E420 } \\ \text { Sodium L-ascorbate } & \text { E301 } & \text { Carrageenan } & \text { E407 } \\ \text { Calcium ascorbate } & \text { E302 } & \text { Gum arabic } & \text { E414 } \\ \text { Citric acid } & \text { E330 } & & \\ \text { Sodium citrate } & \text { E331 } & & \\ \text { Potassium citrate } & \text { E332 } & & \\ \text { Calcium citrate } & \text { E333 } & & \\ \text { Lactic acid } & \text { E270 } & & \\ \text { Sodium lactate } & \text { E125 } & & \\ \text { Potassium lactate } & \text { E326 } & & \\ \text { Calcium lactate } & \text { E327 } & & \\ \text { Lecithin } & \text { E322 } & & \\ \text { Glycerides of fatty acids esterified with citric acid } & \text { E472c } & \\ \text { Sodium orthophosphate } & \text { E339 } & \\ \text { Potassium orthophosphate } & \text { E340 } & \\ \text { Orthophosphate } & \text { E341 } & \\ \text { 6-Palmitoyl-L-ascorbic acid } & \text { E304 } & \\ \text { Tartric acid } & \text { E334 } & \\ \text { Sodium tartrate } & \text { E335 } & \text { E336 } & \\ \text { Potassium tartrate } & \text { E337 } & \\ \text { Sodium potassium tartrate } & & \end{array}$

distinction should be made between prophylactic and therapeutic hypoallergenic formulas (Table 31 ). Strongly hydrolyzed products have been proven in a large epidemiological study (GINI) as being equivalent to breast feeding $[3,61]$.

It is open for discussion whether the addition of probiotic lactobacillae with immunomodulating effects in the gastrointestinal tract plays a role in atopy prevention [27].
For pharmacotherapeutic prevention, mast cell stabilizers have been used successfully (oral cromoglycate) $[28,54]$, possibly also antihistamines.

Food-allergic individuals do not have to spend the rest of their life with appalling restrictions and impairment of quality of life. If correctly diagnosed, there are recipes for each kind of food allergy in order to allow for an agreeable diet $[5,52]$.
Table 5.30. Hydrolyzed cow's milk formulas for infant food

\begin{tabular}{llll} 
Protein basis & Hydrolysis & Name & Producer \\
Whey & Partial & Beba HA & Nestlé \\
& Strong & Aletemil HA & Nestlé \\
& Partial & Humana HA & Nestlé \\
& Partial & Nutrition Pepti & Milupa \\
& Strong & Hipp HA & Hipp \\
& Partial & Aptamil HA & Mead-Johnson \\
Casein & Strong & Pregomin & Milupa \\
Soy & - & Sinlac, Neocate & Nestlé \\
\hline
\end{tabular}


Table 5.31. Statement published by the German Society for Allergology and Clinical Immunology (DGAI) regarding gene technology and food allergy

Many people are worried by the introduction of gene technologically altered foods. In this context, the question regarding the risk of food allergy through gene technological procedures is real. The German Society for Allergology and Clinical Immunology (DGAI), therefore, publishes the following statement:

1. Food allergies are a real and widely prevalent clinical problem, independent of gene technology. The prevalence of food allergy in the total population is not precisely known. Estimates range from $2 \%$ to $4 \%$ in adults and from $5 \%$ to $10 \%$ in childhood. The symptoms of allergic food reactions are multiple and cover mild reactions (itching, nausea, etc.) up to life-threatening shock conditions (anaphylaxis).

2. In the cultural development of mankind "artificial" procedures have been used for millennia by which the nature of possible allergens is changed through technological procedures (e.g., boiling of food). On the other hand, classical breeding techniques in botany have led to the creation of new species characterized by a multitude of altered proteins ( $500-1,000$ genes involved); this phenomenon has never led to anxiety in the general population.

Through the progress in gene technology, for the first time it is exactly known which genes are involved and how they are altered and expressed in foods. The major novel aspect of this technology is the tremendously improved state of knowledge.

3. Gene technological procedures may lead to changes in foods with possible relevance for allergy; this regards both the risk (e.g., Brazil nut allergen in soy beans) and chance (e.g., hypoallergenic rice).

4. Therefore, it is important prior to the introduction of a novel product to fulfill specific safety criteria regarding allergy:

- Sequence homology of the altered proteins has to be compared with well-known allergens

- Immune reactivity against positive sera or skin test reactions in sensitized individuals has to be tested

- Stability against enzymatic digestion has to be studied.

- Unless these safety data exist, gene technologically altered products should not be used for the prevention of allergic disease in infants.

- One actual problem has to be seen in the fact that the evaluation of immunoreactivity in humans can only be tested with known allergens in defined sensitized populations. New proteins cannot be tested in this manner. Here, animal experiments or in vitro models for predictive testing need to be developed.

5. The German Society for Allergology and Clinical Immunology has recommended for many years an improvement in the declaration not only of additives, but also of food contents, independently of technological procedures. It remains open whether the "gene technologically produced" procedure should be especially declared in identical proteins.

6. The German Society for Allergology and Clinical Immunology recommends the presence of persons with allergological expertise on the relevant committees involved with food production and control.

\section{References}

1. Aas K (1978) The diagnosis of hypersensitivity to ingested foods. Reliability of skin prick testing and the radioallergosorbent test with different materials. Clin Allergy 8:39-50

2. André C (1984) L'allergie digestive, concept ou realité? Presse Med 27:1667 - 1669

3. Bauer CP Grübl A (2002) Hypoallergene Babynahrung. In: Behr-Völtzer C, Hamm M, Vieluf D, Ring J (eds) Diät bei Nahrungsmittelallergien und -intoleranzen, 2nd edn. Urban \& Vogel, Munich, pp $105-111$

4. Ballmer-Weber BK, Wüthrich B (2001) Die Nahrungsmittelallergie und ihre diätetische Behandlung. Aktuell Ernähr Med 26:196-201

5. Behr-Völtzer C, Hamm M, Vieluf D, Ring J (eds) (2002) Diät bei Nahrungsmittelallergien und -intoleranzen, 2nd edn. Urban \& Vogel, Munich
6. Balmer-Weber B, Bengtsson U, et al. (2004) Standardization of food challenges in patients with immediate reactions to foods. Position paper EAACI. Allergy (in press)

7. Bischoff SC, Mayer J, Wedemeyer J, et al. (1997) Colonoscopic allergen provocation (CO-LAP): a new diagnostic approach for gastrointestinal food allergy. Gut 40:745-753

8. Bock SA, Sampson HA, Atkins FM, Zeiger RS, et al. (1988) Double-blind, placebo-controlled food challenge (DBPCFC) as an office procedure: a manual. J Allergy Clin Immunol 82:986-997

9. Brostoff J, Challacombe SJ (eds) (1987) Food allergy and intolerance. Bailliere Tindall, London

10. Bruijnzeel-Koomen C, Ortolani C, Aas K, et al. (1995) Adverse reactions to food. European Academy of Allergology and Clinical Immunology Subcommittee. Allergy 50:623-635 
11. Deutsche Gesellschaft für Ernährung (ed) (1995) Richtig essen. F+G Rollendruck, Berlin

12. Diätverband - Bundesverband der Hersteller von Lebensmitteln für besondere Ernährungszwecke (ed) (1998) Product \& Diät. Presto, Hemmingen

13. Ebner C, Hirschwehr R, Bauer L, et al. (1995) Identification of allergens in fruits and vegetables: IgE cross-reactivities with the important birch pollen allergens Bet $\mathrm{v} 1$ and Bet $\mathrm{v} 2$ (birch profilin). J Allergy Clin Immunol 95:962 - 969

14. Egger J, Carter CM, Wilson J, Turner MW, Soothill JF (1983) Is migraine food allergy? A double blind controlled trial of oligoantigenic diet treatment. Lancet 2:865-869

15. Ehlers I, Henz B, Zuberbier T (1996) Diagnose und Therapie pseudo-allergischer Reaktionen der Haut durch Nahrungsmittel. Allergologie 19: $270-276$

16. Eisenbrand G, Aulepp H, Dayan AD, et al. (1996) Food allergies and intolerances. VCH Verlagsgesellschaft, Weinheim

17. Eisenmann A, Ring J, Helm D von der, Meurer M, Braun-Falco O (1988) Vasculitis allergica durch Nahrungsmittelallergie. Hautarzt 39:318-321

18. Ewan PW, Clark AT (2001) Long-term prospective observational study of patients with peanut and nut allergy after participation in a management plan. Lancet 357:111-115

19. Feingold B (1975) Why your child is hyperactive. Random, New York

20. Franck P, Moneret Vautrin DA, Dousset B, et al. (2002) The allergenicity of soybean-based products is modified by food technologies. Int Arch Allergy Immunol 128:212 - 219

21. Häberle M (1987) Klinische und lebensmittelchemische Aspekte bei Unverträglichkeits-Reaktionen auf Salicylat- und Additiva-haltige Lebensmittel. Zbl Haut 153:75 - 95

22. Henzgen M, Schlenvoigt G, Diener C, Jäger L (1991) Nahrungsmittelallergie bei Frühblüherpollinose und deren Beeinflussung mittels Hyposensibilisierung. Allergologie 14:90-94

23. Hjorth N, Roed-Petersen J (1976) Occupational protein contact dermatitis in food handlers. Contact Dermatitis 2:28-42

24. Holt PG (1998) Mucosal immunity in relation to the development of tolerance/sensitization. Allergy 53:6-19

25. Host A (1991) Importance of the first meal on the development of cow's milk allergy and intolerance. Allergy Proc 12:27 - 32

26. Hourihane JO, Kilburn A, Dean P, Warner JO (1997) Clinical characteristics of peanut allergy. Clin Exp Allergy 27:634-639

27. Isolauri E (2001) Probiotics in the prevention and treatment of allergic disease. Pediatr Allergy Immunol 12 [Suppl 14]:56-59

28. Jäger L, Wüthrich B (1998) Nahrungsmittelallergien und -intoleranzen. Gustaf Fischer, Ulm

29. Jarisch R, Pirker C, Möslinger T, Götz M (1997)
The role of histamine in wine intolerance. J Allergy Clin Immunol 89:197

30. Jorde W (1980) Orale Desensibilisierung. In: Fillipp G (ed) Allergologie, vol 2. Banaschewski, Munich, pp 53

31. Kanny G, Hatahet R, Moneret-Vautrin A, Kohler C, Bellut A (1994) Allergy and intolerance to flavouring agents in atopic dermatitis in young children. Allerg Immunol 6:204-210

32. Klaschka F (1987) Hämatogenes Kontaktekzem durch Nahrungsmittel. Allergologie 10:93-96

33. Kurek M, Janowska E (2001) Allergische und pseudoallergische Reaktionen auf Aromastoffe in der Nahrung. Z Hautkrankheiten H+G 76:699703

34. Mempel M, Rakoski J, Ring J, Ollert M (2003) Severe anaphylaxis to kiwi fruit: Immunologic changes related to successful sublingual allergen immunotherapy. J Allergy Clin Immunol 111: $1406-1409$

35. Möller C (1989) Effect of pollen immunotherapy on food hypersensitivity in children with birch pollinosis. Ann Allergy 62:343-345

36. Montes RG, Perman JA (1991) Lactose intolerance: pinpointing the source of nonspecific gastrointestinal symptoms. Postgrad Med 89:175178

37. Niggemann B, Reibel S, Roehr CC, et al. (2001) Predictors of positive food challenge outcome in non-IgE-mediated reactions to food in children with atopic dermatitis. J Allergy Clin Immunol 106:1053-1058

38. Nordlee JA, Taylor SL, Townsend JA, Thomas LA, Bush RK (1996) Identification of a Brazilnut allergen in transgenic soybeans. N Engl J Med 334: 688-692

39. Ortolani C, Ballmer-Weber BK, Hansen KS, et al. (2000) Hazelnut allergy: a double-blind, placebocontrolled food challenge multicenter study. J Allergy Clin Immunol 105:577 - 581

40. Pichler WJ, Stich O (1993) Nahrungsmittelallergien bei Pollensensibilisierungen, part II: Kreuzreaktionen bei Beifußpollen-Sensibilisierungen. Allergologie 16:494-501

41. Pratschke E (1986) Mediatoren der immunologischen Stimulation gastraler Funktionen: Experimentelle Untersuchungen am Beispiel der Gastrinfreisetzung. Habilitationsschrift, München

42. Przybilla B, Ring J (1990) Food allergy and atopic eczema. Semin Dermatol 9:220-225

43. Reimann HJ, Ring J, Ultsch B, Wendt P (1985) Intragastral provocation under endoscopic control (IPEC) in food allergy. Clin Allergy 15:195-202

44. Ring J (1984) Nahrungsmittelallergie und andere Unverträglichkeitsreaktionen durch Nahrungsmittel. Klin Wochenschr 62:795-802

45. Ring J (1999) Nahrungsmittel-Allergie und Gentechnik. In: Steinhart H, Tanner W (eds) Bayerische Akademie der Wissenschaften. Rundgespräche der Kommission für Ökologie, vol 16. Lebens- 
mittel und Gentechnik. Dr. Friedrich Pfeil, $\mathrm{Mu}-$ nich, pp $61-72$

46. Ring J (1997) Gentechnologie und Lebensmittelallergie (DGAI-Stellungnahme). Allergo J 6:214

47. Ring J, Braun-Falco O (1987) Allergie-Diät Verfahren zur Diagnostik und Therapie von Nahrungsmittel-Allergien und -Pseudo-Allergien. Hautarzt 38:198-205

48. Roe DA (1986) Nutrition and the skin. Liss, New York

49. Sampson HA (2001) Utility of food-specific IgE concentrations in predicting symptomatic food allergy. J Allergy Clin Immunol 107:891 - 896

50. Schäfer T, Bohler E, Ruhdorfer S, et al. (2001) Epidemiology of food allergy/food intolerance in adults: associations with other manifestations of atopy. Allergy 56:1172-1179

51. Schauder P, Ollenschläger G (2002) Ernährungsmedizin. Prävention und Therapie, 2nd edn. Urban \& Fischer, Munich

52. Schindler H, Bräckle J, Karch B (1981) Kochbuch für Allergiker. Ehrenwirth, Munich

53. Seifert J, Ring J, Brendel W (1975) Prolongation of skin allografts after oral application of antilymphocyte serum in rats. Nature 249:776

54. Stefanini GF, Saggioro A, Alvisi V, et al. (1995) Oral cromolyn sodium in comparison with elimination diet in the irritable bowel syndrome, diarrheic type. Multicenter study of 428 patients. Scand J Gastroenterol 30:535-541

55. Stevenson DD, Simon RA (1981) Sensitivity to ingested metabisulphites in asthmatic subjects. J Allergy Clin Immunol 68:26-32

56. Strobel S, Hourihane JO (2001) Gastrointestinal allergy: clinical symptoms and immunological mechanisms. Pediatr Allergy Immunol 12 [Suppl 14]:43-46

57. Thiel CL, Fuchs E (1981) Über korrelative Beziehungen bei Kräuterpollen- und Gewürzallergenen, RAST 3. Berichtsband. Grosse, Berlin, pp 178-185

\subsubsection{Insect Venom Allergy}

Allergic reactions against insect venoms are not infrequent: $0.8-5 \%$ of the population react to the venoms of wasps, bees, and hornets with systemic allergic symptoms (19\% with hyperergic local reactions) [31, 33, 47, 49]. In Germany, 10-40 fatalities per year are estimated with a high "hidden number" of cases of unexplained cardiac death $[2,11,37,52]$. Most reactions arise on the basis of IgE-mediated sensitization against insect venoms. Rare cases of immune complex anaphylaxis as well as pseudoallergic reactions should be distinguished.
58. Turjanmaa K (2001) Atopy patch test, an additional new tool in the diagnosis of food allergy. Acta Dermatovenerol Croat 9:69-71

59. Vieths S, Meyer AH, Ehlers I, et al. (2001) Zur Deklaration "versteckter Allergene" in Lebensmitteln. Allergo J 10:130 - 136

60. Wagner G, Ring J (1981) Anaphylaktische Reaktionen bei Nuß- und Mohnallergie. Notfallmedizin 7:361

61. Wahn U, Seger R, Wahn V (1999) Pädiatrische Allergologie und Immunologie, 3rd edn. Urban \& Fischer, Munich

62. Warin RP, Smith RJ (1975) Challenge test battery in chronic urticaria. Br J Dermatol 94:401 - 406

63. De Weck AL, Griot-Wenk M, Schneider H, et al. (2002) Human allergogeneticists should listen to their dog's barking. In: Ring J, Behrendt $\mathrm{H}$ (eds) New trends in allergy V. Springer, Berlin Heidelberg New York, pp 27-36

64. Werfel T (2000) Allergenspezifische T-Zell-Antwort bei Ekzemkrankheiten. Dustri, MünchenDeisenhofen

65. Werfel T, Wedi B, Kleine-Tebbe J, et al. (1999) Vorgehen bei Verdacht auf eine pseudoallergische Reaktion auf Nahrungsmittelinhaltsstoffe. Allergo J 8:135-341

66. Werner M (1967) Krankheiten infolge peroraler Allergeninvasion. In: Hansen K, Werner M (eds) Lehrbuch der klinischen Allergie. Thieme, Stuttgart, p 179

67. Wüthrich B (1986) Nahrungsmittelallergien. Internist 27:362-371

68. Wüthrich B, Ballmer-Weber BK (2001) Food-induced anaphylaxis. Allergy 56 [Suppl 67]:102-104

69. Wüthrich B (2000) Lethal or life-threatening allergic reactions to food. J Invest Allergol Clin Immunol 10:59-65

70. Wüthrich B (2002) Nahrungsmittel und Allergie. Dustri, München-Deisenhofen

\subsubsection{Insect Venoms}

The most important insects honeybee (Apis mellifera) and certain wasps (Vespula germanica, V. vulgaris, Dolichovespula) belong to the order of Hymenoptera [12, 29, 34] (Figs. 5.15, 5.16). Rarer elicitors are bumblebees (Bombus), hornets (Vespa crabro), field wasps (Polistes), ants (Formicidae), and mosquitos (Diptera). Insect venoms contain toxic and allergenic substances.

A painful, itching, or burning sensation with a surrounding wheal and flare at the sting site is normal. Moreover, in certain localizations (upper airways) or after an excessive 


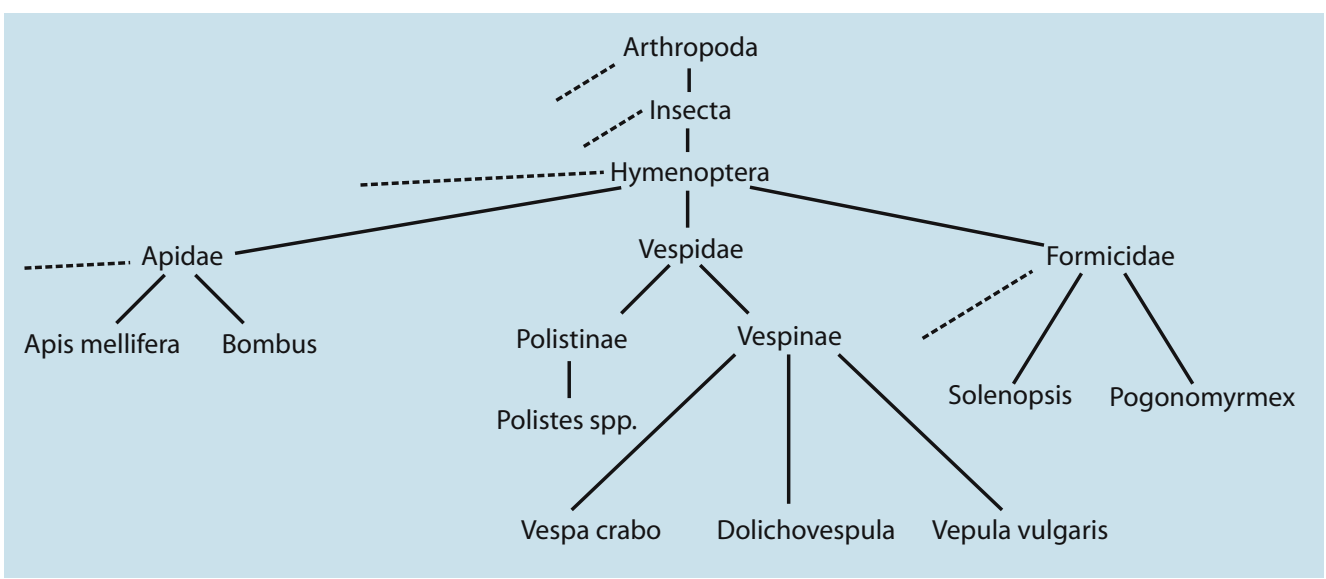

Fig. 5.15. Taxonomic classification of the most important Hymenoptera species responsible for insect venom allergies
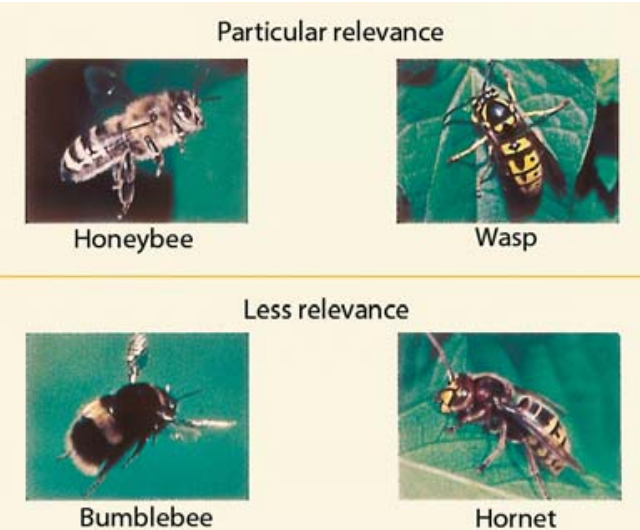

Fig. 5.16. The most important Hymenoptera species responsible for insect venom allergies (R. Jarisch)

amount of stings, individuals who are not sensitized may be in danger [44]. Table 5.32 shows the contents of bee and wasp venom $[5,12]$. In bee venom, the peptide melittin represents the major product, characterized by a strongly basic group on one end and a hydrophobic sidechain on the other end, of the molecule. This detergent effect leads to lysis of cells. Melittin is a weak allergen. Only $3 \%$ of bee-venom-allergic individuals are sensitized to melittin. The major allergen of bee venom is the enzyme phospholipase $A_{2}$. Apamin has neurotoxic effects. The phospholipase $A_{2}$ from wasp venom shows no cross-reaction to the corresponding enzyme in bee venom. Wasp venom also contains antigen 5 as well as hyaluronidase. There is a marked cross-reactivity between the venoms of different species of the order Vespidae $[19,34,35,50,51]$. Hornet venom also contains kinins and acetylcholine.

\subsubsection{Symptomatology}

Allergic reactions against insect stings have been known for a long time [26] and range from hyperergic local reactions to anaphylactic shock. Strong local reactions also are often IgE mediated [1], but do not represent an indication for allergen-specific immunotherapy. They are more frequent in hematologic disease (e.g., lymphatic leukemia) [54, 58]. Anaphylactic symptoms can be classified according to severity (see Sect. 5.1.4 on "Anaphylaxis"; Table 5.17). The severity scale proposed by H.L. Mueller et al. is more complicated in practice [30].

\subsubsection{Diagnosis}

History. Often the eliciting insect species cannot be remembered $[28,29]$. The severity of the reaction also needs to be determined through cooperation with the physician treating the reaction and the therapy given. The question regarding atopy is important for interpretation of skin test and RAST results [39]. There are standardized questionnaires [47]. 


\begin{tabular}{|c|c|c|c|c|}
\hline \multicolumn{2}{|l|}{ Contents } & $\begin{array}{l}\text { Molecular } \\
\text { weight }\end{array}$ & Percentage & $\begin{array}{l}\text { Table } 5.32 \text {. Contents of } \\
\text { honeybee and wasp } \\
\text { venom }\end{array}$ \\
\hline \multicolumn{5}{|l|}{ Bee venom } \\
\hline \multirow[t]{4}{*}{ Proteins } & Phospholipase $\mathrm{A}_{2}$ & 15,800 & $12 \%$ & \\
\hline & Hyaluronidase & 45,000 & $2 \%$ & \\
\hline & Acid phosphatase (allergen B) & 49,000 & $?$ & \\
\hline & Allergen $\mathrm{C}$ & 105,000 & $?$ & \\
\hline \multirow[t]{4}{*}{ Peptides } & Melittin & 2,840 & $50 \%$ & \\
\hline & $\begin{array}{l}\text { Mast cell degranulating peptide } \\
\text { (MCDP) }\end{array}$ & 2,593 & $2 \%$ & \\
\hline & Apamine & 2,038 & $2 \%$ & \\
\hline & Other peptides & $?$ & $15 \%$ & \\
\hline \multirow[t]{2}{*}{ Mediators } & Histamine & 111 & $1 \%$ & \\
\hline & Leukotriene $\mathrm{B}_{4}$ and $\mathrm{C}_{4}$ & 336 & $<0.001 \%$ & \\
\hline \multicolumn{5}{|c|}{ Vespid venom } \\
\hline \multirow[t]{4}{*}{ Proteins } & Antigen 5 & 25,000 & $15 \%$ & \\
\hline & Phospholipases & $\sim 35,000$ & $10 \%$ & \\
\hline & Hyaluronidase & 45,000 & $2 \%$ & \\
\hline & Proteases & ? & $?$ & \\
\hline Peptides & Kinins & $\sim 2,000$ & $?$ & \\
\hline \multirow[t]{5}{*}{ Mediators } & Histamine & 111 & $4 \%$ & \\
\hline & Serotonin & & $\sim 1 \%$ & \\
\hline & Leukotriene $\mathrm{B}_{4}$ and $\mathrm{C}_{4}$ & 336 & $\sim 0.001 \%$ & \\
\hline & Dopamine & & $\sim 5 \%$ & \\
\hline & Acetylcholine $^{\mathrm{a}}$ & & $5 \%$ & a Only for Vespa cabro \\
\hline
\end{tabular}

Skin Tests. Skin tests (4 weeks after the sting) are performed under emergency conditions using endpoint titration with venom extracts (skin prick test beginning with $1 \mu \mathrm{g} / \mathrm{ml}$ and increasing the concentration to $300 \mu \mathrm{g} / \mathrm{ml}$; if negative, intradermal tests are performed with $0.01-1 \mu \mathrm{g} / \mathrm{ml}$ ). A second reading after $24 \mathrm{~h}$ for documentation of non-IgE-mediated reactions is sensible.

In Vitro Allergy Tests. Apart from total serum IgE, specific IgE - possibly also IgG subclasses - against bee and wasp venom is determined [9]. Using cellular tests as in vitro histamine release or basophil activation (CD 63) or CAST ELISA, additional information can be obtained [47] (see Chap. 4 on "Allergy Diagnosis").

Indication for Allergen-Specific Immunotherapy. On the basis of history, skin test, and in vitro tests, the indication for immunotherapy is evaluated by considering possible ris factors (Table 5.33). Allergen-specific immunotherapy is indicated in patients with an objective generalized systemic reaction and demonstration of IgE-mediated sensitization. For general contra-
Table 5.33. Risk factors for insect venom allergy (according to [46])

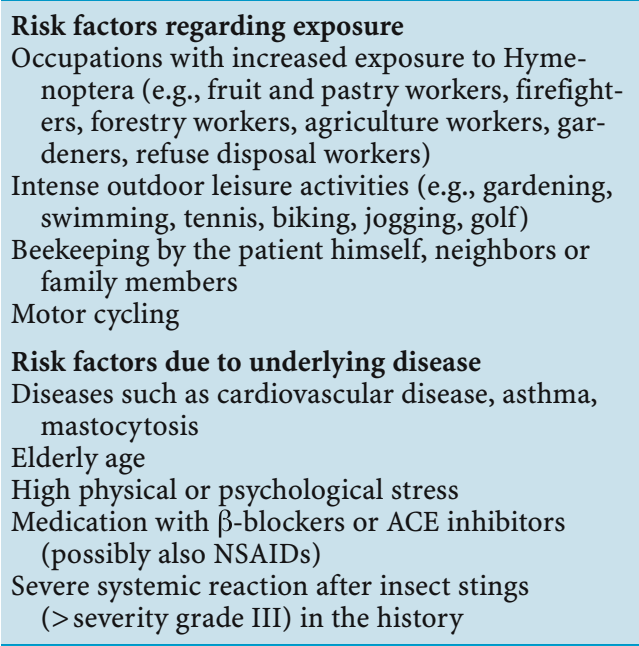

indications, see Sect. 6.3 ("Immunotherapy"). Age alone does not represent a contraindication [18].

Sting Provocation. Sting challenge with honeybees or wasps should not be used as a diag- 
nostic instrument in patients prior to allergenspecific immunotherapy! It is an instrument of control of therapeutic efficacy. Severe complications have been observed [3].

\subsubsection{Allergen-Specific Immunotherapy (Hyposensitization)}

In 1930, Benson and Semenov reported the case of a beekeeper suffering from asthma and anaphylaxis while working with bees [4]. After immunotherapy with a whole-body extract of homogenized honeybee, the asthma improved. Based on this report, a worldwide practice of immunotherapy of insect venom allergy with whole-body extracts started with reports of therapeutic effects in up to $75 \%$ of cases [30]. Early evidence of possible hyposensitization with purified bee venom $[17,26]$ was probably not followed because of anaphylactic complications $[10,27]$. Only after it was shown that bee venom and whole-body extracts contain very different allergens [23] and that the relevant allergens are in the venom [22] was hyposensitization with venom extracts proposed $[9,14,22$, $40,43,56]$. Lichtenstein et al. pioneered the work with a double-blind study: From three groups of 20 patients each, $58 \%$ of the placebotreated, $64 \%$ of the whole-body extract treated, but only $5 \%$ of the bee venom extract treated patients reacted to sting challenge. This study was only possible through the production of purified venom extracts in larger amounts. Bee venom is produced by electrical stimulation of bees [5]; wasps have to be killed, operated on, and the venom sac removed. For $500 \mathrm{~g}$ wasp venom, 250 collectors have to work for 1 year and need 74 million insects $(=6,000 \mathrm{~kg})$.

The future will show the place of recombinant allergens (recombinant phospholipase $\mathrm{A}_{2}$ from bee venom) in practical allergy [32].

There are various methods of allergen-specific immunotherapy (Table 5.34) by which the standard maintenance dose of $100 \mu \mathrm{g}$ every 4 weeks is reached. According to a schedule of rush hyposensitization with up to four injections a day the maintenance dose can be reached in approximately 1 week.

We start with $0.1 \mathrm{ml}$ of a concentration corresponding to $1 / 100$ of the lowest prick test
Table 5.34. Dose schedule (in micrograms) for rush hyposensitization. The schedule holds true for patients with optimal dose increases

\begin{tabular}{|c|c|c|c|}
\hline Day & $\begin{array}{l}\text { Conven- } \\
\text { tional }\end{array}$ & $\begin{array}{l}\text { Hamburg } \\
\text { schedule }\end{array}$ & "Ultrarush" \\
\hline 1 & $\begin{array}{l}0.02 \\
0.04 \\
0.08 \\
0.2\end{array}$ & $\begin{array}{l}0.001 \\
0.01\end{array}$ & $\begin{array}{c}0.01 \\
0.1 \\
1.0 \\
10.0 \\
20.0 \\
40.0 \\
80.0\end{array}$ \\
\hline 2 & $\begin{array}{l}0.4 \\
0.8 \\
1.0 \\
4.0\end{array}$ & $\begin{array}{l}0.1 \\
0.4 \\
0.7\end{array}$ & $\begin{array}{l}100.0 \\
100.0\end{array}$ \\
\hline 3 & $\begin{array}{r}8.0 \\
10.0 \\
20.0 \\
30.0\end{array}$ & $\begin{array}{l}1.0 \\
4.0 \\
7.0\end{array}$ & \\
\hline 4 & $\begin{array}{l}10.0 \\
20.0 \\
60.0 \\
70.0\end{array}$ & $\begin{array}{l}10.0 \\
40.0 \\
70.0\end{array}$ & \\
\hline 5 & $\begin{array}{l}40.0 \\
50.0 \\
60.0 \\
70.0\end{array}$ & 100.0 & \\
\hline 6 & $\begin{array}{r}80.0 \\
90.0 \\
100.0\end{array}$ & & \\
\hline 8 & & & 100.0 \\
\hline $\begin{array}{l}15 \\
22\end{array}$ & $\begin{array}{l}100.0 \\
100.0\end{array}$ & $\begin{array}{l}100.0 \\
100.0\end{array}$ & \\
\hline 36 & 100.0 & 100.0 & 100.0 \\
\hline $\begin{array}{l}50 \\
71\end{array}$ & $\begin{array}{l}100.0 \\
100.0\end{array}$ & $\begin{array}{l}100.0 \\
100.0\end{array}$ & (Day 43) 100.0 \\
\hline $\begin{array}{r}92 \\
120\end{array}$ & $\begin{array}{l}100.0 \\
100.0\end{array}$ & $\begin{array}{l}100.0 \\
100.0\end{array}$ & $\begin{array}{l}\text { Day 71) } 100.0 \\
\text { (Day 99) } 100.0\end{array}$ \\
\hline (to $\mathrm{b}$ & ntinued $\epsilon$ & ry 4 weeks) & \\
\hline
\end{tabular}

positive allergen solution and increase the dose by $0.2,0.4$, and $0.8 \mathrm{ml}$ to the next higher concentration. "Ultrarush" schedules have been published $[6,42,57]$, increasing the dosis over 1 or 2 days. Conventional immunotherapy protocols with weekly injections should only be performed preseasonally [15]. After reaching the maintenance dose, intervals are slowly increased from 1, 2, 3 to finally 4 weeks.

Therapeutic Efficacy. As demonstrated by sting challenge under emergency conditions, allergen-specific immunotherapy with Hymenoptera venoms is effective in $80-100 \%$ of pa- 


\begin{tabular}{|c|c|c|c|c|c|}
\hline \multirow{2}{*}{$\begin{array}{l}\text { Systemic anaphylac- } \\
\text { tic reactions after } \\
\text { sting provocation } \\
\text { (severity grade) }\end{array}$} & \multicolumn{5}{|c|}{ Systemic reactions in history (severity grade) } \\
\hline & $\begin{array}{l}\text { I } \\
n(\%)\end{array}$ & $\begin{array}{l}\text { II } \\
n(\%)\end{array}$ & $\begin{array}{l}\text { III } \\
n(\%)\end{array}$ & $\begin{array}{l}\text { IV } \\
n(\%)\end{array}$ & Total \\
\hline None & $19(90.5)$ & $61(78.2)$ & $40(75.5)$ & $4(80.0)$ & $125(79.6)$ \\
\hline I & $2(9.5)$ & $13(16.7)$ & $6(11.3)$ & $0(0)$ & $20(12.7)$ \\
\hline II & $0(0)$ & $4(5.1)$ & $4(7.5)$ & $1(20.0)$ & $9(5.8)$ \\
\hline III & $0(0)$ & $0(0)$ & $3(5.7)$ & $0(0)$ & $3(1.9)$ \\
\hline Total & $21(100)$ & $78(100)$ & $53(100)$ & $5(100)$ & $157(100)$ \\
\hline
\end{tabular}

Table 5.35. Results of sting provocation and severity grades (highest individually stated severity grades) of anaphylaxis in history (from [30]) tients. In our own experience, only $5 \%$ showed reactions equally as strong as before immunotherapy. When increasing the dose from 100 to $200 \mu \mathrm{g}$, most of these patients tolerated the subsequent sting challenge [40] (Table 5.35).

Side Effects: Local Reactions. Local reactions occur as swelling with wheal and redness and are observed in most patients, sometimes lasting $6-12 \mathrm{~h}$. The reactions occur mostly during the course of the dose increase at higher concentrations $(10-100 \mu \mathrm{g})$ and sometimes slow the further increase of dose. Local treatment with moist wraps and topical corticosteroids leads to improvement. Subsequent injections are usually well tolerated.

Side Effects: Systemic Reactions. In 3-35\% of patients, systemic reactions are observed [39, 46], which occur more frequently in bee than wasp venom allergic individuals [48]. After treatment, immunotherapy is continued with reduced dose (see Sect. 6.2). In patients with repeated systemic reactions, prophylaxis with $\mathrm{H}_{1}$ antihistamines can be considered [7, 15]. Rarely, serum sickness or immune complex reactions occur [8]; then therapy has to be discontinued.

\subsubsection{Therapy Control}

Under allergen-specific immunotherapy, most patients show an increase of specific IgE together with specific IgG antibodies (Fig. 5.17). However, in the individual case IgG concentrations do not give reliable prognostic information [3]. Possibly, the ratio sIgG4/sIgE in the immunoblot may be relevant regarding the protective effect of immunotherapy [36].

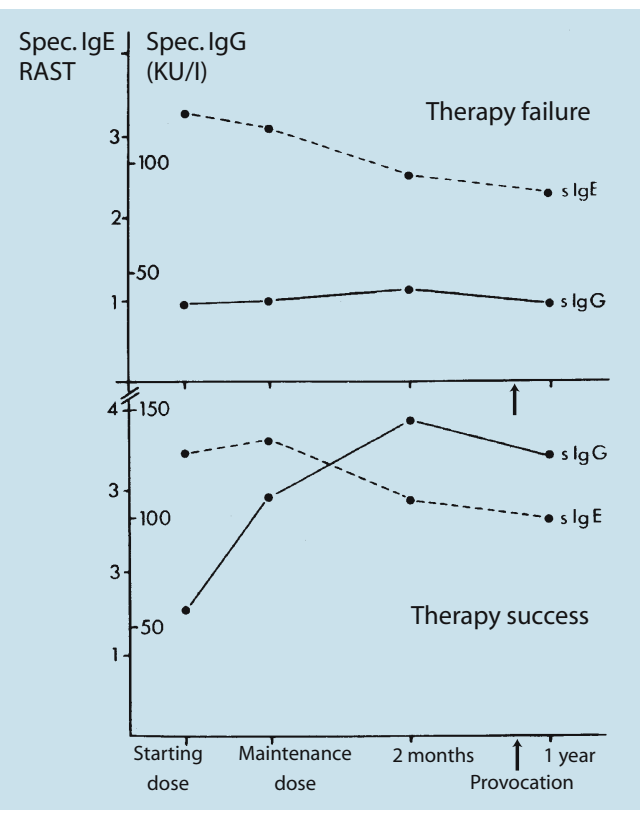

Fig. 5.17. Bee-venom-specific antibodies of the IgE and IgG class demonstrated in two patients undergoing hyposensitization treatment with bee venom extract

Sting Challenge. After reaching the maintenance dose and maintaining it over at least 3 months, sting challenge can be performed with a living insect in emergency conditions (Fig. 5.18). Sting challenge represents the only objective method for evaluation of therapeutic efficacy [40]. In patients still reacting to sting challenge, we increase the dose up to $200 \mu \mathrm{g}$ every 4 weeks or shorten the interval ( 3 weeks).

Duration of Treatment. Since there is no reliable prognostic marker which gives solid information on the duration of protection, some authors recommend lifelong immunotherapy. International recommendations vary between 3 and 5 years 
at least. In patients with risk factors (systemic reaction after sting challenge, mastocytosis, repeated anaphylactic reactions to immunotherapy injection), an increase in dose and a longer treatment duration is necessary [32, 47].

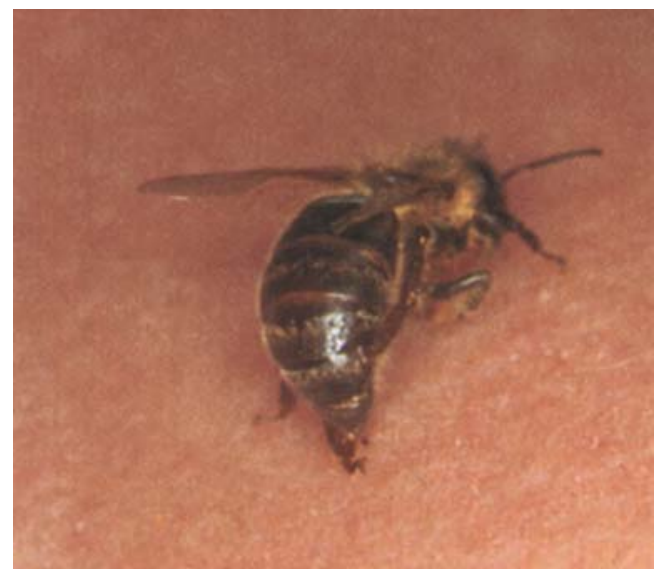

\section{Double Sensitizations to Bee/Wasp Venom}

Some patients are positive in skin test and/or RAST against both bee and wasp venom and the history remains doubtful. If cellular tests do not give additional information and only one anaphylactic episode was seen in the history, we usually use the species with stronger skin or RAST reactivity for immunotherapy. In unclear cases, immunotherapy against both Hymenoptera species has to be performed. Watching the kinetics of IgE response immediately after the sting event (anaphylaxis) and 4 weeks later, additional information about the relevant insect species may be obtained.

Passive Immunotherapy. Intramuscular administration of hyperimmunoglobulin from beekeepers has been proven to be protective and may also enhance efficacy of active immunotherapy $[21,38]$.

Fig. 5.18. Sting provocation with a living insect

Table 5.36. Patient information in honeybee and wasp venom allergy (according to $[28,47]$ )

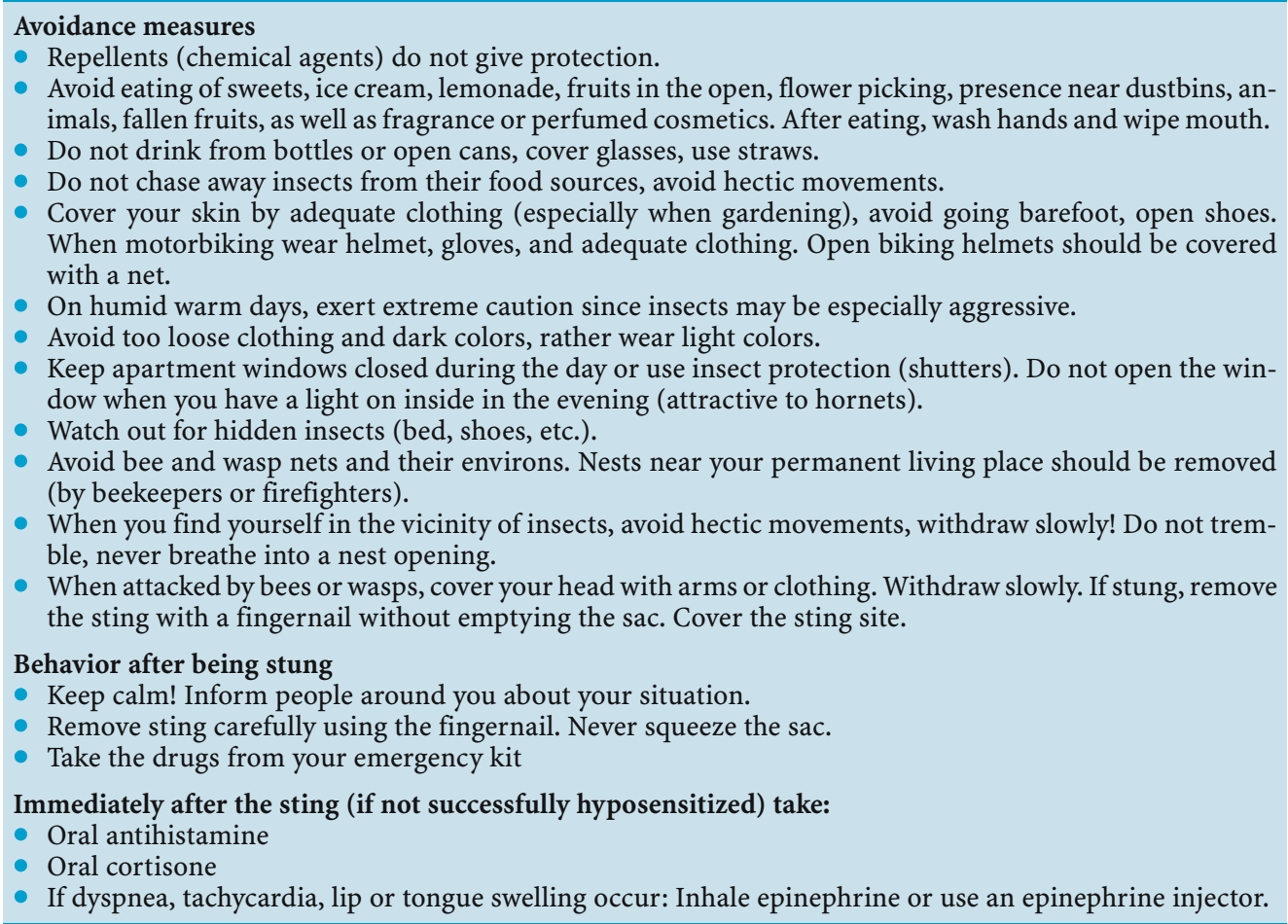


Problems. Rare allergic reactions against other insects such as mosquitos, ants, etc., represent an increasing problem due to the nonavailability of adequate amounts of purified extracts.

There are controversial opinions regarding indications for immunotherapy in patients with HIV infection and other immunodeficiencies or with malignancy. While this earlier was regarded as a contraindication - the problem was very rare in allergy praxis; however, due to the increasing allergy prevalence, more patients with this combination come and ask for a decision. We perform allergen-specific immunotherapy if criteria for indication are given and if known neoplasms have been surgically removed or HIV infection is under control with triple therapy. However, future studies are required to answer these questions.

\subsubsection{Patient Information}

Independently of immunotherapy, patients should be informed about sensible behavior after insect stings and also about prevention of stings (Table 5.36) [25, 28, 29, 43, 47], especially about the relevant risk factors [35]. All patients should carry with them an "emergency kit" (see Sect. 5.1.4 on "Anaphylaxis") with epinephrine for inhalation or self-injection (in severe cases).

\section{References}

1. Albrecht I, Eichler G, Müller U, Hoigné R (1980) On the significance of severe local reactions to hymenoptera stings. Clin Allergy 10:675

2. Barnard JH (1973) Studies of 400 hymenoptera sting deaths in the United States. J Allergy Clin Immunol 52:259

3. Bauer CP (1986) Stichprovokationen zur Diagnostik von Insektengift-Allergien? Allergologie 9:14

4. Benson R, Semenov H (1930) Allergy in its relation to bee sting. J Allergy 1:105

5. Benton AW, Morse RA, Stewart JD (1963) Venom collection from honey bees. Science 142:228

6. Brehler R (1999) Ultra-Rush-Hyposensibilisierung. Allergologie 22 [Suppl 2]:570-571

7. Brockow K, Kiehn M, Riethmüller C, et al. (1997) Efficacy of antihistamine treatment in the prevention of adverse reactions to Hymenoptera immunotherapy: A prospective, randomized, placebo-controlled trial. J Allergy Clin Immunol 100:458-463
8. De Bandt M, Atassi-Dumont M, Kahn MF, et al. (1997) Serum sickness after wasp venom immunotherapy: clinical and biological study. J Rheumatol 24:1195-1197

9. Forck G, Kästner H, Kalveram C (1981) Insect venom tolerance: IgG-"blocking" antibodies and sting provocation. In: Ring J, Burg G (eds) New trends in allergy. Springer, Berlin Heidelberg New York, p 269

10. Fuchs E (1959) Allergie. Münch Med Wochenschr 100:1711

11. Golden DBK, Valentine MD, Kagey-Sobotka A, Lichtenstein ML (1982) Prevalence of hymenoptera venom allergy. J Allergy Clin Immunol 69:124

12. Habermann E (1972) Bee and wasp venoms. Science $177: 314$

13. Hemmer W, Focke M, Jarisch R (1999) In-vitroDoppelpositivität gegen Bienen- und Wespengift. Allergologie 22 [Suppl 2]:63-64

14. Hunt KJ, Valentine MD, Sobotka AK, Benton AW, Amodio FJ, Lichtenstein LM (1978) A controlled trial of immunotherapy in insect hypersensitivity. N Engl J Med 299:157

15. Jarisch R (1980) Die Bienengiftallergie (Modell einer IgE-mediierten Soforttypallergie). Wien Klin Wochenschr 92 [Suppl 122]:3

16. Jeßberger B, Habig J, Karl S, et al. (1994) Hymenopterengiftallergie: Hyposensibilisierungstherapie trotz vorhandener Kontraindikationen. Allergologie 17:255-260

17. Kämmerer H (1941) Fragekasten. Münch Med Wochenschr 88:939

18. Kiehn M, Ring J (1993) Hyposensibilisierung mit Insektengiftextrakten bei Patienten mit Hymenopterengift-Allergie im höheren Lebensalter. Allergo J 2 [Suppl 2]:90 - 94

19. King TP, Lu G, Gonzalez M, Qian N, Soldatova L (1996) Yellow jacket venom allergens, hyaluronidase and phospholipase: Sequence similarity and antigenic cross-reactivity with their hornet and wasp homologues and possible implications for clinical allergy. J Allergy Clin Immunol 98:588-600

20. Lerch E, Müller UR (1998) Long-term protection after stopping venom immunotherapy: results of restings in 200 patients. J Allergy Clin Immunol 101:606-612

21. Lessof M, Sobotka AK, Lichtenstein LM (1976) Protection against anaphylaxis in hymenopterasensitive patients by passive immunization. J Allergy Clin Immunol 57:246

22. Lichtenstein LM, Valentine MD, Sobotka AK (1974) A case for venom treatment in anaphylactic sensitivity to hymenoptera sting. N Engl J Med 290:1223

23. Light WV, Reismann RE, Rosario NA, Arbesman CE (1976) Comparison of the allergenic properties of bee venom and whole bee body extract. Clin Allergy 6:293

24. Lockey RF (1975) Systemic reactions to stinging ants. J Allergy Clin Immunol 54:132 
25. Lonsdorf G, Ring J, Burg G (1981) Anaphylaktische Reaktionen nach Insektenstichen. Notfall Medizin 7:409

26. Lotter G (1939) Sensibilisierung für Bienengift durch Typhus-Antitoxin und Desensibilisierung mit Forapin. Münch Med Wochenschr 86:330331

27. Loveless MH, Fackler WR (1956) Wasp venom allergy and immunity. Ann Allergy 14:347

28. Mauss V (1999) Einfluß von Lebensweise, Populationsdynamik und Abwehrverhalten aculeater Hymenopteren auf das Stichrisiko für den Menschen. Allergologie 22 [Suppl]:542 - 545

29. Mauss V, Treiber R (1994) Betreuungsschlüssel für die Faltenwespen (Hymenoptera: Masarinae, Polistinae, Vespinae) der Bundesrepublik Deutschland. Deutscher Jugendbund für Naturbeobachtung, Hamburg

30. Mueller HL, Schmid WH, Rubinstein R (1975) Stinging-insect hypersensitivity. A 20-year old study of immunologic treatment. Pediatrics 55:530

31. Müller UR (1988) Insektenstichallergie. Klinik, Diagnostik und Therapie. G. Fischer, Stuttgart

32. Müller U (2001) New development in the diagnosis and treatment of hymenoptera venom allergy. Int Arch Allergy Immunol 124:447 - 499

33. Müller U, Mosbech H (1993) Position paper: Immunotherapy with hymenoptera venoms. Allergy 48 [Suppl 2]:37-46

34. Mumcuoglu Y, Rufli T (1980) Dermatologische Entomologie. 12. Apidael Bienen. 13. Vespidae Wespen. Schweiz Rundsch Med 69:1317, 1574

35. O'Connor R, Peck ML (1978) Venoms of Apidae. In: Handbook of experimental pharmacology, vol 48. Springer, Berlin Heidelberg New York, p 613

36. Ollert M, Ring J (1999) Prognostische Bedeutung von Immunoblot-Untersuchungen bei Hymenopterengift-Allergie. Allergologie 22 [Suppl 2]: 578-579

37. Parrish HM (1963) Analysis of 460 fatalities from venomous animals in the United States. Am J Med Sci 245:129

38. Przybilla B, Ring J, Galosi A, Geursen RG, Stickl HA (1986) Bee-venom immunoglobulin for prophylaxis of anaphylactic reactions during bee venom immunotherapy (rush hyposensitization). Immunol Allergy Practice 8:107-111

39. Przybilla B (1986) Pathophysiologische und klinische Aspekte der allergischen Reaktion vom Soforttyp und der Immunglobulin-E-Immunantwort: Untersuchungen unter besonderer Berücksichtigung der Bienen- und Wespengiftallergie. Habilitationsschrift, Munich

40. Przybilla B, Ring J, Grießhammer B, Braun-Falco O (1987) Schnellhyposensibilisierung mit Hymenopterengiften - Verträglichkeit und Therapieerfolg. Dtsch Med Wochenschr 112:416

41. Przybilla B, Ring J, Rieger B (1992) Die Indikation zur Hymenopterengift-Hyposensibilisierung kann nicht anhand eines diagnostischen Parameters bewertenden Punkteschemas gestellt werden. Allergologie 13:114-119

42. Rakoski J, Mayenburg J von (1986) Das UltraRush-Verfahren - eine neue Methode zur Überprüfung der Aktualität von Insektengiftallergien. Allergologie 9:73-74

43. Ring J, Lonsdorf G, Schury W, Burg G (1982) Bienen- und Wespengift-Allergie. Klinik Prophylaxe und Therapie. Münch Med Wochenschr 124:587

44. Ring J, Gottsmann M, Przybilla B, Eisenmenger W (1986) Tod nach 1000 Bienenstichen. Münch Med Wochenschr 128:339

45. Ring J, Przybilla B, Müller U (1997) Insektengiftallergie: Aktuelles für die Praxis. Allergo J 6 [Suppl 1]:571-572

46. Rueff F, Reißig J, Przybilla B (1997) Nebenwirkungen der Schnellhyposensibilisierung mit Hymenopterengift. Allergo J 6 [Suppl 1]:659-664

47. Rueff F, Przybilla B, Fuchs T, Gall H, Rakoski J, Stolz W, Vieluf D (2000) Diagnose und Therapie der Bienen- und Wespengiftallergie. Positionspapier der Deutschen Gesellschaft für Allergologie und klinische Immunologie (DGAI). Allergo J 9:458-472

48. Rzany B, Przybilla B, Jarisch R, et al (1991) Clinical characteristics of immunotherapy with Hymenoptera venoms. A retrospective study. Allergy 46:251 - 254

49. Schäfer T, Przybilla B (1996) IgE antibodies to hymenoptera venoms in the serum are common in the general population and are related to indications of atopy. Allergy 51:372-377

50. Schumacher MJ, Tveten MS, Egen NB (1994) Rate and quantity of delivery of venom from honeybee stings. J Allergy Clin Immunol 93:831 - 835

51. Schuberth KC, Golden DBK, Kagey-Sobotka A, Valentine M, Lichtenstein LM (1981) Evaluation and treatment of insect sting allergy. In: Ring J, Burg G (eds) New trends in allergy. Springer, Berlin Heidelberg New York, p 260

52. Settipane GA, Newstead GJ, Boyd GK (1972) Frequency of hymenoptera allergy in an atopic and normal population. J Allergy Clin Immunol 50:176

53. Stibich AS, Carbonaro PA, Schwartz RA (2001) Insect bite reactions: an update. Dermatology 202:193 - 197

54. Tokura Y (1994) Lymphocyte populations associated with exaggerated insect bite reactions. J Am Acad Dermatol 31:298

55. Tunget CL, Clark RF (1993) Invasion of the "killer" bees. Separating fact from fiction. Postgrad Med 94:92-102

56. Urbanek R (1979) Neue Konzepte der Behandlung von Insektengiftallergien. Derm Beruf Umwelt 27:44

57. Van der Zwan JC, Flintermann J, Jankowski IG, et al. (1983) Hyposensitisation to wasp venom in six hours. Br Med J 287:1329-1331

58. Weed RI (1965) Exaggerated delayed hypersensitivity to mosquito bite in chronic lymphocyte leukemia. Blood 26:257-268 


\subsubsection{Allergy and the Eye}

\subsubsection{Introduction}

Allergic eye diseases are sometimes only marginally covered in allergy textbooks, e.g., "rhinoconjunctivitis." Often, the most common elicitors of allergic conjunctivitis are called "inhalation allergens." Attempts to classify allergic eye diseases are difficult, partly due to different understandings of diseases as well as lack of knowledge of histopathophysiology of common conditions. The term "conjunctivitis" used by many allergists as a synonym for type I allergy - only has a descriptive character and is used for clinical conditions of quite different pathophysiology; it can be best compared with the term "dermatitis" in dermatology.

Transparency of the central part of the eye is the major basic condition for visual function. In cornea, anterior chamber, lens, and vitreous body, there are no lymph or blood vessels and no immunocompetent cells. The barrier between blood and chamber fluid as well as blood and retina is physiological. The anterior chamber of the eye is an immunologically privileged site $[2,5,6,11,14,21]$. Inflammatory reactions occur mostly in the neighboring tissue, especially conjunctiva, where $90 \%$ of the mast cells of the eye are situated $[2,20]$.

\subsubsection{Atopic Eye Diseases}

\subsection{Type I Allergic Conjunctivitis}

This acute form of allergic conjunctivitis is classically combined with hay fever, but also in perennial allergy against airborne allergens without nasal symptoms. Pathophysiology corresponds to IgE-mediated allergic rhinitis and allergic bronchial asthma (type I). The clinical symptoms comprise itching, burning, photophobia, immediate hyperemia, and chemosis of the conjunctiva (often aggravated by rubbing) and increased lacrimation. There is no papillary reaction and no corneal involvement. All the symptoms can be elicited by local histamine application. In animal experiments, this type of allergy is also called ocular anaphylaxis $[2,6,22]$. Prophylaxis and therapy comprise allergen avoidance, mast cell stabilizers, antihis-

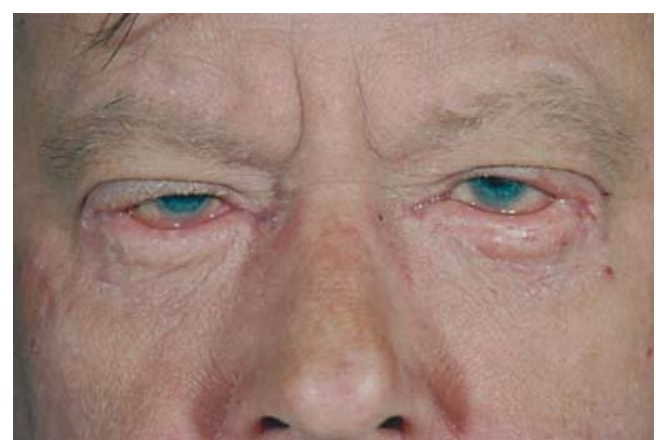

Fig. 5.19. Atopic keratoconjunctivitis

tamines, as well as vasoconstrictors [20]. Rarely, steroids are necessary. Occasionally, cyclooxygenase inhibitors such as ketorolac can help against itch [20].

\subsection{Atopic Keratoconjunctivitis}

Chronic atopic conjunctivitis (Fig. 5.19) often occurs with other manifestations of atopy and is predominantly observed in medium-aged males; the pathophysiology may be similar to that of atopic eczema with increased cellular infiltrates and high IgE in serum and tear fluid $[6,9]$. The conjunctiva is thickened, rather pale and chemotic. Not infrequently, the cornea can be affected, sometimes vascularized. Almost all patients also suffer from intense lid eczema with common superinfections. Mast cell stabilizers and glucocorticosteroids are recommended, generally topically (sometimes also systemically).

The so-called atopic cataract (prevalence of up to $25 \%$; in our opinion this has been overestimated in the past) is associated with atopic eczema $[2,21]$. This cataract involves the lens epithelium of the anterior lens capsule and can be clearly differentiated from steroid-induced posterior subcapsular cataract.

\subsection{Vernal Keratoconjunctivitis}

This chronically relapsing general conjunctivitis occurs predominantly in southern countries often seasonally in spring and summer and is characterized by papillary hyperplasia of the tarsal upper lid conjunctiva [8]. The disease be- 
gins often before the 10th year and subsides spontaneously after puberty. In $70-80 \%$ of cases, it occurs with other atopic diseases; boys are more often affected than girls (3:1). Two anatomic forms are differentiated: a palpebral form with typical "cobblestone conjunctivitis" of the upper lid and a limbal form (more common in colored people and American Indians).

Symptoms are characterized by intense itching. Patients feel like "scratching out their eyes." Furthermore, burning, redness, swelling, photophobia and in $50 \%$ also corneal involvement as superficial keratitis occur. Rarely, ulcus vernalis occurs by loosening of the cornea epithelium through eosinophil products [22].

A thick white mucous secretion can be seen containing numerous eosinophils. Histologically, mast cells are increased, and eosinophils and basophil leukocytes can be found in conjunctival epithelium [2]. In the tear fluid, histamine and complement products are elevated [1].

There is no clear-cut relation to aeroallergens in spite of sometimes positive prick test results. Therefore, specific immunotherapy mostly remains unsuccessful. As basic therapy, mast cell stabilizers are used, in acute exacerbation steroids, in severe cases even cyclosporin topically. Occasionally with massive mucous secretion, topical administration of mucolytics (acetylcysteine 10-20\%) has been tried. In corneal involvement, surgical removal of papillae with subsequent coagulation of the conjunctiva is helpful.

\subsection{Giant Papillary Conjunctivitis in Contact Lens Wearers}

This conjunctivitis is observed in people wearing predominantly soft - sometimes after some latency also hard - contact lenses as well as plastic eye prostheses and corresponds clinically and histologically to conjunctivitis vernalis in the early stage. There is no evidence for atopy. Allergic reactions against unknown allergens from contact lenses or cleaning fluid in the mucus are suspected $[6,17]$.

Avoidance of contact lenses is the first step, and renewal of contact lenses and changing to preservative-free lens fluids (especially enzymes!) are recommended.

\subsubsection{Contact-Allergic Conjunctivitis (Type IV)}

This common form of ocular allergy occurs with itching, redness and infiltration (sometimes "follicular") conjunctivitis; often simultaneous allergic contact dermatitis of the lid (blepharo-conjunctivitis) is seen. Pathophysiologically, type IV hypersensitivity corresponding to allergic contact dermatitis is present (see Sect. 5.5.2). The most common elicitors are therapeutics (antibiotics, local anesthetics, preservatives in eyedrops), but also chemicals, cosmetics, and phytoallergens $[10,11,21]$.

\subsubsection{Blepharitis and Lid Eczema}

The differential diagnosis of blepharitis and lid eczema comprises apart from allergic conditions (mostly type IV) and atopic eczema also irritative reactions such as cumulative toxic eczema (especially when eyedrops or wet wraps are applied too frequently), psoriasis, rosacea, seborrheic eczema, as well as infectious diseases with inflammatory reactions.

A common disease is microbial-allergic conjunctivitis: On the basis of an initiating staphylococcal infection, blepharoconjunctivitis occurs with hypersensitivity against bacterial exotoxins and the formation of conjunctival phlyctena or keratitis marginalis.

\subsubsection{Cicatricial Conjunctivitis in Erythema Exsudativum Multiforme or Lyell's Syndrome}

In rare cases, erythema exsudativum multiforme can occur with massive conjunctival swelling and cicatricial conjunctivitis ("syndroma muco-cutaneo-oculare Fuchs" or "StevensJohnson syndrome").

In the acute phase, bullous, partly pustular changes can be seen, leading to erosions with cicatricial healing. Conjunctiva is affected with hyperemia, chemosis, bulla formation, and ulceration. Sometimes scarring of the conjunctiva with entropium, trichiasis, and synechia occurs. Secondary disturbance of lacrimation and bacterial superinfection lead to severe corneal ulcers. The pathophysiology of this reaction is unclear. Apart from a postherpetic form 
("infect allergy"), drug-induced Stevens-Johnson syndrome has been described with subepithelial vesiculation, epithelial necrosis, and superficial inflammatory reaction [11].

A similar condition is observed in toxic epidermal necrolysis (TEN), also called druginduced Lyell's syndrome. The pathophysiology is unclear; type III and IV reactions as well as apoptotic processes are discussed (see Sect. 5.7.3 on "Drug Eruptions").

Early ophthalmologic counseling is the primary recommendation. Hourly nursing with steroids, topical artificial tears and regular prophylaxis of symblepharon is important; however, sometimes serious changes cannot be prevented. Early systemic corticosteroids are controversial. In cases with corneal involvement and opacification, prognosis quoad visum is poor. The cornea transplantation in these cases is often unsuccessful, synechiolysis shows a high relapse rate, mucous membrane transplantation is difficult, and sometimes amnion transplants succeed.

Ocular (Scarring) Mucous Membrane Pemphigoid. The processes in scarring pemphigoid are pathogenetically similar where autoantibodies against basement membrane have been formed.The disease manifests as chronic progredient scarring conjunctivitis with mostly severe corneal complications responding poorly to therapy (local therapy together with systemic immunosuppression with steroids, cyclophosphamide, dapsone, etc.).

\subsubsection{Eye Diseases of Questionable Allergic Origin}

Sympathetic Ophthalmia. Sympathetic ophthalmia is a diffuse granulomatous inflammation of the uvea of both eyes - also of the unlesional eye - as a consequence of a perforating trauma or intraocular surgery and represents a classic autoimmune disease [12]. The organism is sensitized against proteins with which the immune system because of the privileged anatomical site was previously not in contact. The time interval between primary trauma and occurrence of sympathetic ophthalmia is variable; $90 \%$ of cases occur within 1 year. The resulting uveitis may destroy the eye. Therapeutically, high-dose glucocorticosteroids with or without immunosuppressives, which are sometimes lifelong, are indicated $[11,18,19]$. Enucleation of the traumatized eye after the occurrence of sympathetic ophthalmia is rarely helpful.

Endogenous Autoimmune Uveitis. It has been discussed as to what degree certain forms of endogenous uveitis correspond pathophysiologically to an immune complex vasculitis [18].

Paraneoplastic Retinopathy. In patients with neoplasia or melanoma-associated retinopathy, autoimmune processes in the sense of a crossreaction between tumor antigens and retinal proteins have been found with the formation of antibodies against retinal constituents, leading to disturbance of retinal function. There is little therapy of these conditions, and in occasional cases plasmapheresis has been used.

Graft Versus Host Reactions. A rare complication of bone marrow transplantation in leukemia is severe keratoconjunctivitis with opacification and vascularization of the cornea.

\subsubsection{Therapy}

If possible, treatment should be topical - except for the severe autoimmune diseases. Table 5.37 lists some antiallergic eyedrops with different drugs. Long-term steroid treatment should be avoided. For lid eczema the new topical calcineurin inhibitors (tacrolimus and pimecrolimus) (see Sect. 5.5.3) are promising.

Table 5.37. Antiallergic eyedrops

\begin{tabular}{ll}
\hline Active substances & Flurbiprofen \\
DSCG (disodium & Diclofenac \\
cromoglycate) & Glucocorticosteroids \\
Lodoxamide & Betamethasone \\
Nedocromil & Dexamethasone \\
Azelastine & Fluorometholone \\
Emedastine & Prednisolone \\
Levocabastine & Rinaxolone \\
Non-steroidal anti-inflam- \\
matory drugs (NSAIDs) \\
Ketorolac
\end{tabular}




\section{References}

1. Abelson MB, Schaefer K (1993) Conjunctivitis of allergic origin: immunologic mechanisms and current approaches to therapy. Surv Ophthalmol 38:115-132

2. Allansmith MR (1982) The eye and immunology. Mosby, St. Louis

3. Allansmith MR, Ross RN (1986) Ocular allergy and mast cell stabilizers. Surv Ophthalmol 30:229-244

4. Anderson DF (1996) The conjunctival late-phase reaction and allergen provocation in the eye. Clin Exp Allergy 26:1105-1107

5. Bialasiewicz AA (1998) Augenheilkunde. In: Heppt W, Renz H, Röcken M (eds) Allergologie. Springer, Berlin Heidelberg New York, pp 262-271

6. Bielory L (2000) Allergic and immunologic disorders of the eye, part II: ocular allergy. J Allergy Clin Immunol 106:1019-1032

7. Bonini S, Bucci MG, et al. (1990) Allergen dose response and late symptoms in a human model of ocular allergy. J Allergy Clin Immunol 86/6: $869-876$

8. Bonini S, Bonini S, Lambiase A, et al. (2000) Vernal keratoconjunctivitis revisited: a case series of 195 patients with long-term followup. Ophthalmology 107:1157-1163

9. Foster CS, Rice BA, Dutt JE (1991) Immunopathology of atopic keratoconjuncitivitis. Ophthalmology 98:1190-1196

10. Friedlaender MH (1988) Contact allergy and toxicity in the eye. Int Ophthalmol Clin 28/4: 317-320

11. Friedlaender MH (1993) Allergy and immunology of the eye. Raven, New York

\subsection{Allergic Diseases by Cytotoxic Antibodies (Type II)}

\subsubsection{Mechanisms of Antibody-Mediated Cytotoxicity}

The cytotoxic reaction (type II) is mediated by antibodies with or without complement activation directed against markers on hematologic cells. The classical type II reaction is the transfusion reaction (hemolytic reaction caused by natural mostly IgM and complement-binding antibodies) against foreign blood group antigens [10]. The antigens of the AB0 system differ by the terminal sugar residue on a common glycolipid (paragloboside) with a terminal fucose $(=\mathrm{H}$-antigen in group 0$)$, to which either $\mathrm{N}$-acetyl-D-galactosamine (group A) or D-galactose (group B) are bound [29].
12. Fuchs E (1905) Über sympathisierende Entzündung. Albrecht v. Graefes Arch Ophthal 61:365

13. Hatinen A, Terasvirta M, Fakj JE (1985) Contact allergy to components in topical ophthalmologic preparations. Acta Ophthalmol 63:424-426

14. Jay JL (1981) Clinical factors and diagnosis of atopic keratoconjunctivitis and the effect of treatment with sodium cromoglycate. Br J Ophthal $60: 335-340$

15. McGill J (2000) Conjunctival cytokines in ocular allergy. Clin Exp Allergy 30:1355 - 1357

16. Montan PG, Biberfeld PJ, Scheynius A (1995) IgE, IgE receptors and other immunocytochemical markers in atopic and nonatopic patients with vernal keratoconjunctivitis. Ophthalmology 102: $725-732$

17. Neuhann T (1983) Papillomatös-hyperplastische Konjunktivitis durch Kontaktlinsen. Mbl Augenheilkunde 8:46-50

18. Ring I, Dechant W, Seifert J, Lund O-E, Grette J-H, Stefani FH, Brendel W (1978) Immunosuppression with antilymphocyte globulin (ALG) in the treatment of ophthalmic disorders. Ophthal Res 10:82-97

19. Silverstein AM, O'Connor GR (eds) (1979) Immunology and immunopathology of the eye. Masson, New York

20. Solomon A, Pe'er J, Levi-Schaffer F (2001) Advances in ocular allergy: basic mechanisms, clinical patterns and new therapies. Curr Opin Allergy Clin Immunol 1:477-482

21. Theodore FH, Schlossmann A (1958) Ocular allergy. Williams \& Wilkins, Baltimore

22. Trocme SD, Aldave AJ (1994) The eye and the eosinophil. Surv Ophthalmol 39:241-252

Another form of type II reaction is the hyperacute rejection after organ transplantation, mediated by specific antibodies [5].

Theoretically, some autoimmune diseases also have to be classified under this type of reaction when organ-specific antibodies play a role (certain forms of glomerulonephritis = Masugi nephritis, pemphigus vulgaris, bullous pemphigoid, Goodpasture's syndrome, autoimmune hemolytic anemia).

Cytotoxic antibodies may destroy cells via different mechanisms (Fig. 5.20).

- Complement-mediated cytotoxicity Binding of the antibody molecule to the cell surface leads to activation of complement via the classical pathway with subsequent cell lysis (activation of C6 to C9). 


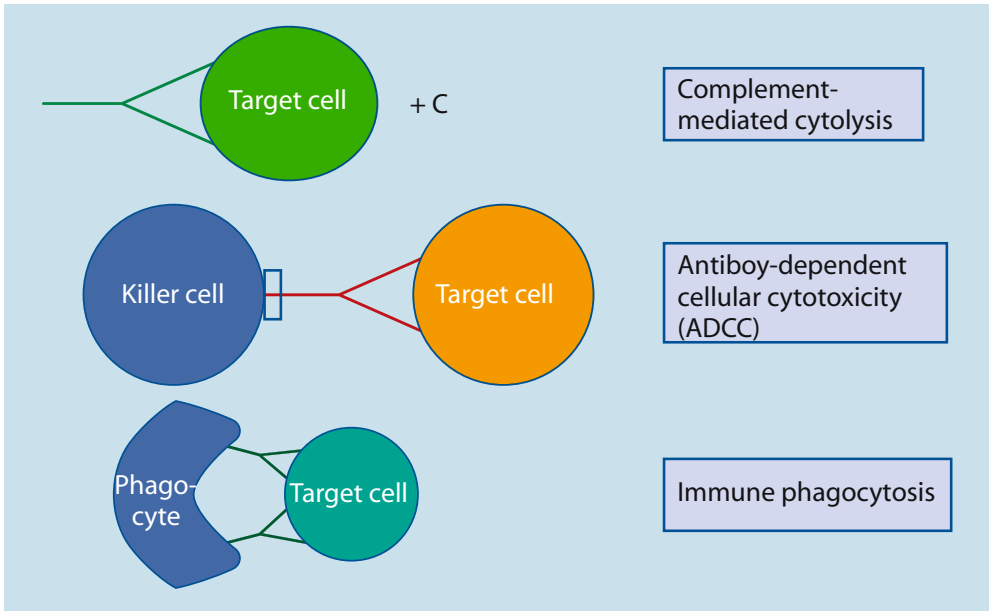

Fig. 5.20. Mechanisms of allergic cytotoxicity

\begin{tabular}{l|l} 
Ax. H.\$70 J. \\
\cline { 1 - 2 } Togal $\left.{ }^{\circledR} \cdot\right]$
\end{tabular}

Fig. 5.21. Course of a thrombocytopenia induced by quinine (in Togal). Remission followed termination of the drug (reprinted with the permission of Raif and Schubothe [20])

- Antibody-dependent cellular cytotoxicity (ADCC)

Here the antibody acts together with the so-called killer cell, to which it is bound. These cells represent a subgroup of lymphocytes with large granules showing neither typical T- nor B-cell characteristics. The cell destruction follows similar mechanisms such as T-cell-mediated cytotoxicity (perforin, etc.).

- Antibody-dependent phagocytosis (immune phagocytosis) Here cytotoxic antibodies are bound via Fc-receptors to the surface of macrophages. After binding of antigens on the target cell, the latter will be phagocytosed. 
These mechanisms are best investigated in peripheral blood cells; however, it is speculated that tissue destruction in parenchymatous organs occurs in a similar manner (e.g., hepatitis).

The most important allergic diseases of the blood (Figs. 5.20-5.22a) are triggered by drugs; similar conditions may also be elicited by infections (especially virus), lymphoproliferative diseases, other neoplasias or "idiopathically." The complex interaction between drug and target cell occurs in different ways (types of cytotoxic reaction) $[1,14,20]$ :

1. "Hapten" type. Here the drug is bound to the cell surface leading to a new antigen; with or without complement activation, specific antibodies lead to cell destruction (e.g., penicillin, cephalosporins). Hemolysis occurs extravascularly after high-dose administration; IgG can be detected on the surface of erythrocytes without complement products (e.g., C3d).

2. "Immune complex" type (not to be confused with immune complex reaction of type III!). Here a complex of antibody and antigen formed intravascularly with activation of complement leads to cell destruction [15] most likely via Fc receptors. Since the target cells only are lysed through secondary absorption of immune complexes, this reaction was also called "innocent bystander." This mechanism is the most common form of drug-induced allergic cytopenia. The reactions are acute after minute doses. C3d can be detected on the cell surface [22, 23].

3. "Autoimmune" type. The drug changes first the cell surface, leading to the develop-
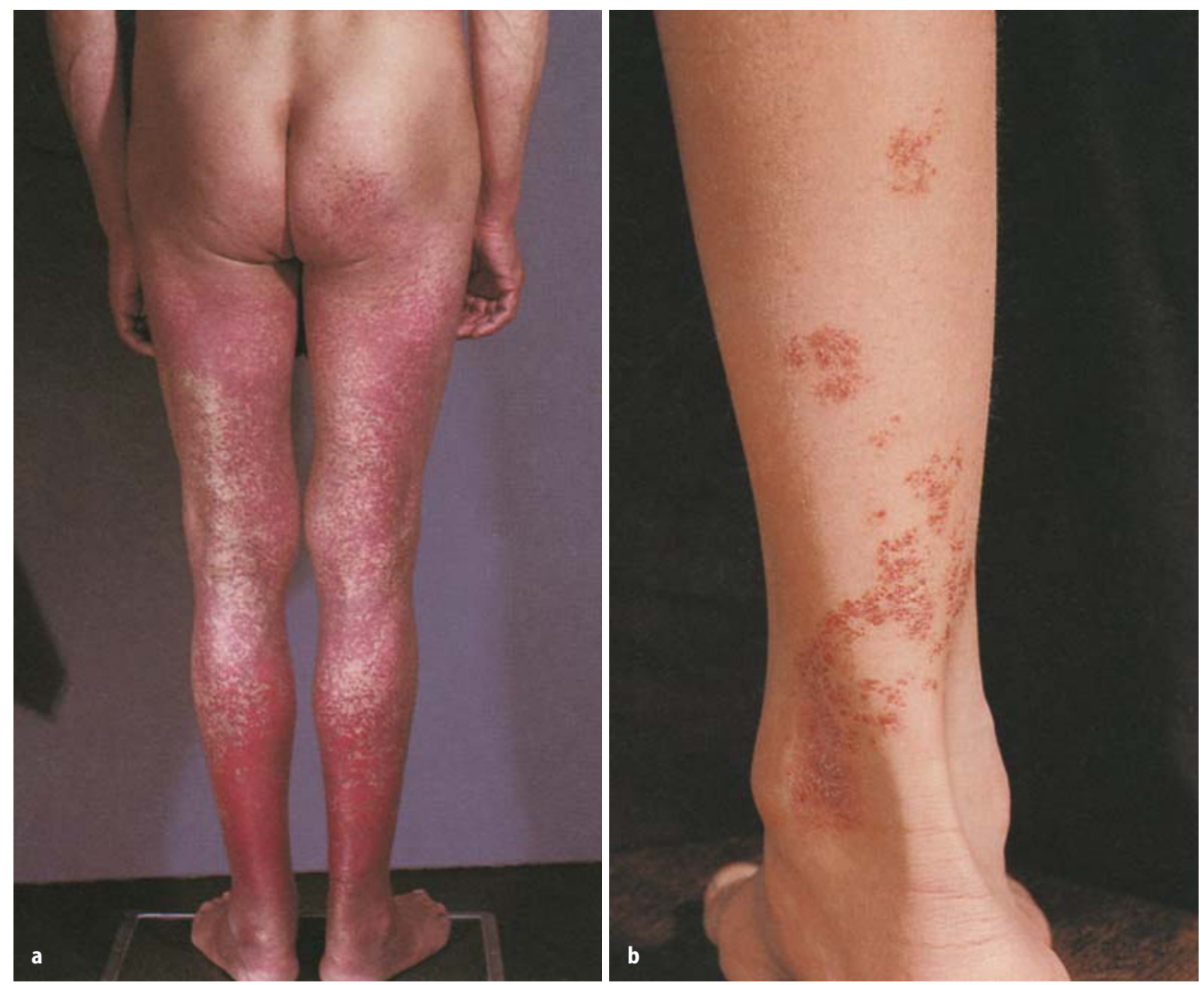

Fig. 5.22a,b. Clinical manifestations of allergic thrombocytopenic purpura 
ment of a new “autoantigen.” Autoimmune diseases of the blood may be triggered (e.g., hemolytic anemia by alphamethyldopa). Autoantibody formation continues after withdrawal of the drug and does not differ from idiopathic autoimmune hemolytic anemia of the heat type.

\subsubsection{Allergic Diseases of the Blood}

\subsubsection{Allergic Hemolytic Anemia}

The most important drugs eliciting different types of allergic hemolytic anemias are listed in Table 5.38. After high doses of penicillin (over 10 million U/day), slowly developing anemia of the hapten type occurs. The direct Coombs' test is positive. After withdrawal, hemoglobin normalizes. Antibodies (mostly IgG) do not react with normal erythrocytes. Quinine, chlorpromazine, and isoniazid are the most common elicitors of hemolytic anemia of the immune complex type.

Alpha-methyldopa, L-dopa, mefenamic acid, as well as methysergide may induce subacute heat-autoantibody-mediated anemia. After several months of treatment, $11 \%$ of patients develop a positive direct Coombs' test;

Table 5.38. Drugs eliciting allergic hemolytic anemia (selection)

\begin{tabular}{|c|c|}
\hline $\begin{array}{l}\text { Hapten type } \\
\text { Penicillin } \\
\text { Cephalosporin }\end{array}$ & $\begin{array}{l}\text { Rifampicin } \\
\text { Cisplatin }\end{array}$ \\
\hline \multicolumn{2}{|c|}{$\begin{array}{l}\text { Immune complex type } \\
\text { ("innocent bystander") }\end{array}$} \\
\hline Aminophenazone & Melphalan \\
\hline Acetylsalicylic acid & Metamizol \\
\hline Butizide & Paracetamol \\
\hline Quinidine & Phenacetin \\
\hline Quinine & Rifampicin \\
\hline Chlorpromazine & Streptomycin \\
\hline Ibuprofen & Salicylamide \\
\hline Insulin & Sulfonamide \\
\hline Isoniazid & Sulfonylurea \\
\hline \multicolumn{2}{|l|}{ Autoimmune type } \\
\hline Chlorpromazine & Latamoxef \\
\hline Glafenin & Levodopa \\
\hline Hydantoin & Mefenamic acid \\
\hline Ibuprofen & Methysergide \\
\hline Methyldopa & Procainamide \\
\hline
\end{tabular}

only in $0.7 \%$ of patients does anemia develop [23].

A common diagnostic criterion is the occurrence of hemoglobinemia and hemoglobinuria, a hemoglobin decrease with normal $\mathrm{MCHB}$, an increase in indirect bilirubin and a decrease in haptoglobin. In rare cases, renal insufficiency or diffuse intravascular coagulation can occur.

Pathophysiologically, mixed forms occur, e.g., after nomifensin or cianidanol [13, 22]. Withdrawal of the eliciting drug is the main therapy.

\subsubsection{Allergic Agranulocytosis}

Allergic agranulocytosis develops in highly acute form mostly via the hapten mechanism. A few days (in repeated treatments within hours) after intake of the eliciting drug (e.g., aminopyrine, metamizol, sulfonylurea, Table 5.39), leukocytes decrease, fever attacks occur, and putrid tonsillitis develops with glossitis, thrush, bronchitis and severe disease.

Differential diagnosis comprises toxic granulocytopenias due to bone marrow depression (e.g., cytostatics), which develop slowly over a subacute chronic stomatitis. A possible new type of drug reaction has been described as neutropenia after high toxic doses of penicillin (220 - 550 million U) [16].

Therapy consists in withdrawal of the drug, high-dose i.v. immunoglobulin, adequate antibiosis, possibly glucocorticosteroids, and intravenous G-CSF.

Table 5.39. Drugs eliciting allergic agranulocytosis (selection)

\begin{tabular}{ll}
\hline Aminophenazone & Methyldopa \\
Aminopyrine & Novobiocin \\
Aminosalicylic acid & Penicillins \\
Quinidine & Phenothiazines \\
Chloral hydrate & Phenylbutazone \\
Chlorpromazine & Procainamide \\
Diazepoxide & Propranolol \\
Ethacrynic acid & Mercury diuretics \\
Gold salts & Salazosulfapyridine \\
Hydantoin & Sulfonamide \\
Metamizol & Sulfonylurea \\
Methimazol & Thiouracil \\
\hline
\end{tabular}




\subsubsection{Allergic Thrombocytopenia}

The prototype of allergic hematologic disease is apronalid purpura, first described by Ackroyd [1] through an immune complex type reaction. Today, the most common elicitors are listed in Table 5.40. Figure 5.21 shows a typical course of a thrombocytopenia in allergy against quinine [20] in a mixed analgesic preparation. Clinically, apart from a non-inflammatory purpura (Fig. 5.22a,b), sweating attacks, dyspnea, fever with shivering, and mucosal bleeding together with lowered platelet counts are typical. The diagnosis can be confirmed in vitro using patients' serum together with the suspected drug and adding it to a platelet suspension and measuring changes in platelet function (e.g., aggregation, serotonin, or platelet factor 3 release) with the adequate controls.

Treatment consists of immediate withdrawal of the drug and high-dose glucocorticosteroids together with i.v. immunoglobulins $(0.4 \mathrm{~g} /$ $\mathrm{kg}$ over 5 days) [14]. Sometimes, fresh blood transfusion may be indicated. Continuation of therapy with vital drugs under systemic glucocorticoids has been reported [28].

In differential diagnosis, post-transfusion purpura should be considered developing mostly in $\mathrm{PL}^{\mathrm{Al}}$-negative women 1 week after

Table 5.40. Drugs eliciting allergic thrombocytopenia (selection)

\begin{tabular}{ll}
\hline $\begin{array}{l}\text { Alprenolol } \\
\text { Allylcarbamide } \\
\text { (e.g., Sedormid) }\end{array}$ & $\begin{array}{l}\text { Metamizol } \\
\text { Novobiocin }\end{array}$ \\
Aminopyrine & $\begin{array}{c}\text { Para-aminosalicylic acid } \\
\text { Acetacolamide }\end{array}$ \\
Acetylsalicylic acid & Penicillamine \\
Carbamazepine & Phenacetin \\
Cephalotin & Phensuximide \\
Quinine and quinidine & Phenylbutazone \\
Chloramphenicol & Procainamide \\
Chloroquine & Reserpine \\
Chlorothiazide & Rifampicin \\
Digitoxin & Salicylamide \\
Furosemide & Stibophen \\
Gold salts & Sulfonylurea \\
Heparin & Tetracycline \\
Hydantoin & Thiazide \\
Isoniazid & Tolbutamide \\
Levodopa & Trimethoprim \\
Meprobamate & Valproate \\
\hline
\end{tabular}

transfusion of $\mathrm{PL}^{\mathrm{A} 1}$-positive blood occurring with high antibody titers against $\mathrm{PL}^{\mathrm{A} 1}[14,26]$. Equally important is the exclusion of idiopathic thrombocytopenic purpura (ITP), where serum does not induce platelet changes in normals. Therapeutically, glucocorticosteroids together with high-dose immunoglobulins are given.

Besides allergic and toxic mechanisms, also enzyme defects can induce bone marrow depression via an idiosyncrasy (see also "Pseudoallergic Reactions," Sect. 5.7.3). It has been attempted to measure this in vitro by the inhibitory effect of certain substances on bone marrow stem cells [9].

\subsubsection{Heparin-Induced Thrombocytopenia}

The heparin-induced thrombocytopenia (HIT) is of major practical importance. Two types are differentiated [2]:

HIT 1, spontaneously reversible via inhibition of platelet adenylate cyclase activity and without major complications.

HIT 2, which is more dangerous, developing after 5-14 days and occurring with thrombocytopenia, but at the same time increasing the risk of thrombosis and embolization. Pathophysiologically, IgG antibodies against a multimolecular complex consisting of heparin and platelet factor 4 cause HIT $2[7,21]$. The size and degree of sulfatation of the heparin molecule seem to be crucial in the elicitation of HIT 2. The mechanism corresponds to an immune complex cytotoxic mechanism through an $\mathrm{Fc} \gamma$ RII activation.

The strong platelet-stimulating effect leads to microparticles from lysed platelets, which circulate in the blood and enhance thrombosis [21].

Immediate withdrawal of heparin is the first step of therapy! Changing to coumarin in the first few days is contraindicated since this will further increase risk of thrombosis. For therapy, low molecular and low sulfatized heparinoids may be tried such as danaparoid, recombinant hirudin or a synthetic thrombin inhibitor argatroban $[18,24]$. 


\subsubsection{Eosinophilia}

After certain drugs (Table 5.41), blood eosinophilia, sometimes without incompatibility symptoms, develops possibly due to increased interleukin-5 production from $\mathrm{T}$ lymphocytes. The prognostic relevance is unclear; for safety reasons, sometimes withdrawal of the drug is recommended.

Table 5.41. Drugs inducing eosinophilia

\begin{tabular}{ll}
\hline Allopurinol & Isoniazid \\
Aminosalicylic acid & Kanamycin \\
Cephalosporins & Nalidixic acid \\
Chloral hydrate & Nitrofurantoin \\
Dacarbazine & Penicillamine \\
Digitalis & Rifampicin \\
Erythromycin & Sulfonamides \\
\hline
\end{tabular}

Eosinophilia Myalgia Syndrome. The pathogenesis of the eosinophilia myalgia syndrome (EMS) described in 1989 after intake of L-tryptophan for depression and sleeplessness is not clear. In epidemiological studies comparing different batches of the drug, an impurity (peak E) with 1.1 ethylidene-bis-tryptophan was determined as elicitor. Apart from sclerodermalike changes and neuropathy, signs of myositis and in $50 \%$ autoantibodies with extremely elevated eosinophil counts in the peripheral blood were observed $(1,000-36,000 / \mu \mathrm{l})[3,27]$.

\subsubsection{Allergic Cytotoxic Organopathies}

\subsubsection{Drug-Induced Hepatitis}

After certain drugs, antibodies against liver cells and constituents (e.g., microsomes, cytochrome $\mathrm{P} 450$ isotypes) may develop with cytotoxic effects on hepatocytes detectable in vitro $[4,11,12,17]$. Drugs under discussion are halothane, chlorpromazine, some anticonvulsants, thyreostatics, as well as rarely antibiotics (sulfanomides, erythromycin estolate) [6].

\subsubsection{Drug-Induced Nephropathy}

After certain drugs, acute tubular disturbance of the kidney, sometimes occurring with exanthematous drug eruptions, has been reported; the mechanisms are unclear. Apart from classic immune complex nephritis (serum nephritis) (see Sect. 5.3), specific antibodies against altered renal antigens such as tubular basement membrane constituents [8] have been reported. Rarely, an allergic basis of nephrotic syndrome (gold, penicillamine, captopril, lithium) with positive lymphocyte transformation has been reported (see also Sect. 5.7.4 on "Drug-Induced Exanthematous Eruptions").

\section{References}

1. Ackroyd JF (1952) Sedormid purpura: An immunological study of drug hypersensitivity. Progr Allergy 3:531

2. Aster RH (1995) Heparin-induced thrombocytopenia and thrombosis. $\mathrm{N}$ Engl J Med 332: 1374-1376

3. Belongia EA, Hedberg CW, Gleich GJ (1990) An investigation into the cause of the eosinophilia myalgia syndrome associated with tryptophan use. N Engl J Med 323:357 - 365

4. Berg PA, Becker EW (1995) The lymphocyte transformation test - a debated method for the evaluation of drug allergic hepatic injury. J Hepatol 22:115-118

5. Brendel W, Ring J (1980) Transplantationsimmunologie. In: Filipp G (ed) Allergologie. Banaschewski, Munich, p 436

6. Dukes MNG (1998) Drug-induced hepatic injury. Elsevier, Amsterdam

7. Greinacher A, Potzsch B, Amiral J, Dummel V, Eichner A, Mueller-Eckhardt C (1994) Heparin in associated thrombocytopenia: isolation of the antibody and characterization of a multimolecular PF4-heparin complex as the major antigen. Thromb Haemost 71:247-251

8. Jäger L, Merk HF (1996) Arzneimittel-Allergie. Gustav Fischer, Jena

9. Kelton JG, Huang AT, Mold N (1979) The use of in vitro techniques to study drug-induced pancytopenia. N Engl J Med 301:621

10. Landsteiner K (1901) Wien Klin Wochenschr 14: 1132

11. Manns M (1989) Autoantibodies and antigens in liver diseases - updated. J Hepatol 9:272-280

12. Maria VAJ, Pinto L, Victorino RMM (1994) Lymphocyte reactivity to ex-vivo drug antigens in drug-induced hepatitis. J Hepatol 21:151 - 158

13. Mueller-Eckhardt C (1988) Ex vivo drug antigens. Are drug-induced immunoreactions such as immunohemolytic anemia related to genetic control? In: Estabrook RW, Lindenlaub E, Oesch F, Weck AL de (eds) Toxicological and immunological aspects of drug metabolism and environmental chemicals. Schattauer, Stuttgart, pp 329-342 
14. Mueller-Eckhart C, Kuenzlen E, Thilo-Korner D, Pralle H (1983) High-dose intravenous immunoglobulin for post transfusion purpura. N Engl J Med 308:287

15. Mueller-Eckhardt C, Salama A (1987) Immunhämolytische Anämien durch Medikamente. Dtsch Ärztebl 84:232-234

16. Neftel KA, Wälti M, Spengler H, Felten A von, Weitzmann SA, Bürgi H, Weck AL de (1981) Neutropenia after penicillins: toxic or immune-mediated? Klin Wochenschr 59:877

17. Pessayre D (1995) Mecanisme de hepatites medicamenteuses Gastroenterol. Clin Biol 19:47-56

18. Pihusch R (1998) Die Heparin-induzierte Thrombozytopenie. Phlebologie 27:111-116

19. Plötz G, et al. Hypereosinophilie-Syndrom. Hautarzt

20. Raif W, Schubothe H (1979) Durch körperfremde Substanzen induzierte immunhämatologische Erkrankungen. Allergologie 2:192

21. Raskob GE, George JN (1997) Thrombotic complications of antithrombotic therapy: a paradox with implications for clinical practice. Ann Intern Med 127:839-841

22. Salama A, Mueller-Eckhardt C (1985) The role of metabolite-specific antibodies in nomifensine-

\subsection{Allergic Diseases due to Immune Complexes}

\subsubsection{Immune Complex Anaphylaxis}

Binding of antigen by specific antibodies leads to immune complexes which generally have a protective function leading to clearance of the antigen from the organism through activation of the mononuclear phagocyte system [31]. Furthermore, immune complexes may have a regulating function in immune response, especially complexes from anti-idiotype antibodies and antibodies against environmental antigens (network theory according to Jerne).

However, circulating immune complexes may induce disease, when by activation of complement or $\mathrm{Fc} \gamma$ receptors pathogenic reactions are triggered $[17,28]$.

In the sensitized organism (IgG or IgM antibodies) antigen administration (mostly parenterally) may induce anaphylactic immediate reactions clinically manifesting sometimes even more acutely and dramatically than IgE-mediated reactions and described under the term "immune complex anaphylaxis" [1, 20, 26]. dependent immune hemolytic anemia. $\mathrm{N}$ Engl J Med 313:469-474

23. Salama A, Mueller-Eckhardt C (1992) Humanemediated blood cell dyscrasias related to drugs. Semin Hematol 29:54-63

24. Schiele F, Vuillemenot A, Kramarz P, Kieffer Y, Anguenot T, Bernard Y, Bassand JP (1995) Use of recombinant hirudin as antithrombotic treatment in patients with heparin induced thrombocytopenia. Ann J Hematol 50:20-25

25. Shulman NR, Aster RH, Leitner A, Hiller MC (1961) Immunoreactions involving platelets. V. Posttransfusion purpura due to a complementfixing antibody against a genetically controlled platelet antigen. J Clin Invest 40:1597

26. Shulman NR (1972) Immunologic reactions to drugs. N Engl J Med 286:508 - 512

27. Varga J, Uitto J, Jimenez SA (1992) The cause and pathogenesis of the eosinophilia-myalgia syndrome. Ann Int Med 116:140-147

28. Wanamaker WM, Wanamaker SJ, Celesia GG, et al. (1976) Thrombocytopenia associated with long-term levodopa therapy. J Am Med Assoc 235:2217

29. Zweiman B, Patten E (1982) Immunohematologic diseases. J Am Med Assoc 248:2677-2682

Clinical examples are dextran anaphylaxis (see Sects. 5.1.4, 5.7).

\subsubsection{Serum Sickness}

Serum sickness was first described by von Pirquet and Schick, giving rise to the term "allergy" in the following year (see Chap. 1), and represents the prototype of immune complex disease [16]. This has been forgotten by some younger allergists. Within $7-14$ days after antigen administration, circulating antigen antibody complexes $[5,12]$ lead to complement activation and activation of $\mathrm{Fc} \gamma$ receptors on inflammatory cells with release of mediators and proteases (Fig. 5.23) and clinical symptoms such as fever, urticaria, arthralgia, lymph node swelling, nephritis, endocarditis, and vasculitis $[1,6,16]$. In parallel with the decrease in concentration of free antigens and the increase in concentration of specific antibodies, the clinical symptoms occur in the phase of circulating immune complexes (Fig. 5.24). This principle was called "toxic body" by von Pirquet [16]. Crucial for the elicitation of serum sickness is the dose of antigen applied; after high doses of 


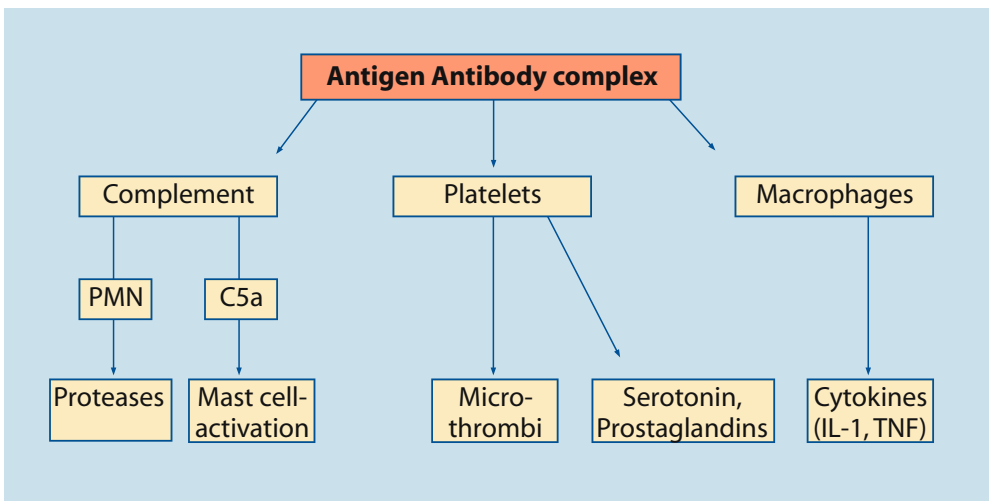

Fig. 5.23. Sequelae of the appearance of circulating immune complexes

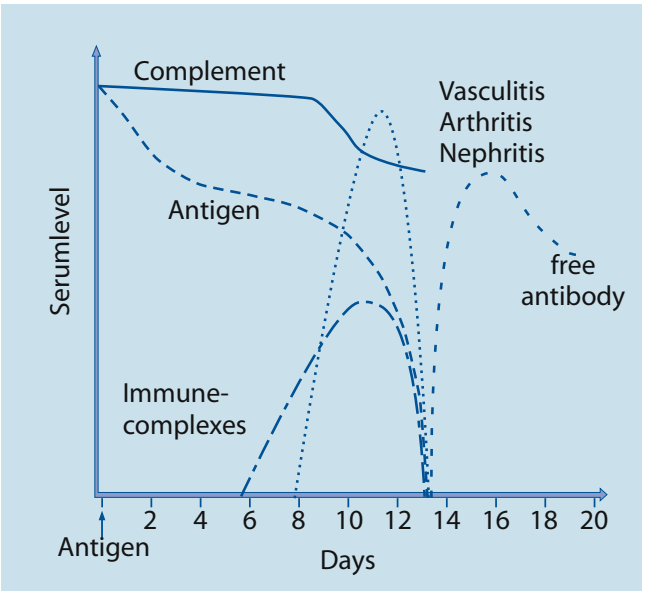

Fig. 5.24. Immunologic reaction in a patient with experimentally induced serum sickness (according to F. Dixon)

foreign serum in $80-100 \%$ of patients serum sickness can be expected.

Different types of immune complexes can be distinguished according to solubility $\left(<10^{6} \mathrm{D}=\right.$ soluble, $>10^{6} \mathrm{D}=$ hardly soluble complexes). For the mechanism of complement activation, refer to Chap. 2, "Pathophysiology."

The detection of activated complement products, complement consumption, or circulating immune complexes has diagnostic relevance $[12,24,30]$.

While serum sickness was a major problem at the beginning of the 20th century (animal sera as antitoxins), it has almost been forgotten in recent decades. However, today with the development of new biologicals of animal origin (monoclonal antibodies from the mouse) in di- agnosis and therapy, new problems have arisen. Major elicitors are drugs, especially xenogeneic proteins (e.g., antitoxins or antilymphocyte antibodies) [18, 19, 25]. Similar symptoms, however, may be observed due to bacterial, viral or tumor antigens. Serum sickness after insect stings and allergen-specific immunotherapy has been reported [10].

Circulating immune complexes are detectable under physiological conditions in healthy individuals (background value of $10-20 \mu \mathrm{g} / \mathrm{ml}$ aggregated gammaglobulin). These clinically silent immune complexes may represent idiotype-anti-idiotype complexes, as shown in healthy volunteers with cytotoxic antibodies against melanocytes and anti-idiotypic antibodies [14].

Commercial plasma protein solutions (human serum albumin, but also unmodified gammaglobulin) contain a high percentage of aggregated proteins able to elicit serum sickness-like symptoms [19]. By separation of these aggregates, the immunogenicity of xenogeneic protein solutions can be decreased and the compatibility dramatically improved [19]. Induction of immunological tolerance has been demonstrated against xenogeneic antilymphocyte globulin successfully using highly purified monomeric xenogeneic IgG [18].

In serum sickness by animal sera (e.g., snake venom), horse IgG has stronger immunogenicity than horse albumin as demonstrated in immune elimination by accelerated elimination in sensitized organisms [12, 25].

After serum sickness has subsided, often positive rheuma factors can be demonstrated 
(4-6 weeks), which, however, do not contain specific antigen in the cryoprecipitate possibly representing idiotype-anti-idiotype complexes.

The detection of antigen in the disease eliciting immune complexes would be of major diagnostic relevance; however, it is rarely achieved.

\subsubsection{Allergic (Immune Complex) Vasculitis}

Allergic (immune complex) vasculitis is elicited by an immunological type III reaction, when circulating immune complexes in mild antigen excess are not eliminated properly by the reticuloendothelial system and complement activation with local attraction and activation of neutrophil granulocytes occurs (experimental model of the Arthus phenomenon). Synonyms are "leukocytoclastic vasculitis," "anaphylactic purpura," "hypersensitivity angiitis," "arteriolitis allergica," and "vasculitis hyperergica." Histologically, a perivascular neutrophil infiltrate with occasional eosinophils and typical leukocytoclasia with nuclear fragments and fibrinoid degeneration of the vascular wall is typical (Fig. 5.25). In immunofluorescence or immune electron microscopy (Fig. 5.26), de-

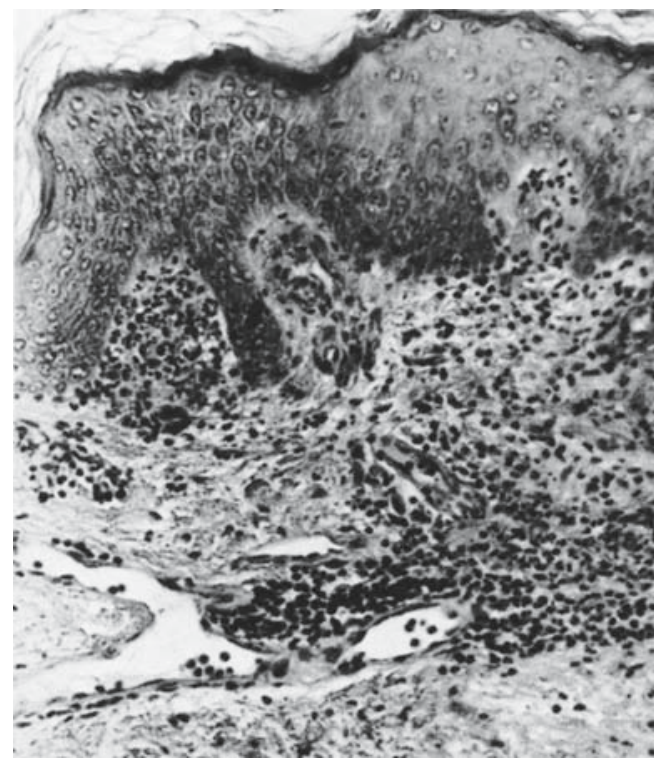

Fig. 5.25. Leukocytoclastic vasculitis. Postcapillary venules with infiltration of the vessel wall and perivascular infiltrate with neutrophils (1:650) (reprinted with the consent of Prof. Dr. H.H. Wolf [32])
Table 5.42. Classification of vasculitis according to pathophysiology (ANCA, antineutrophil cytoplasmic antibody)
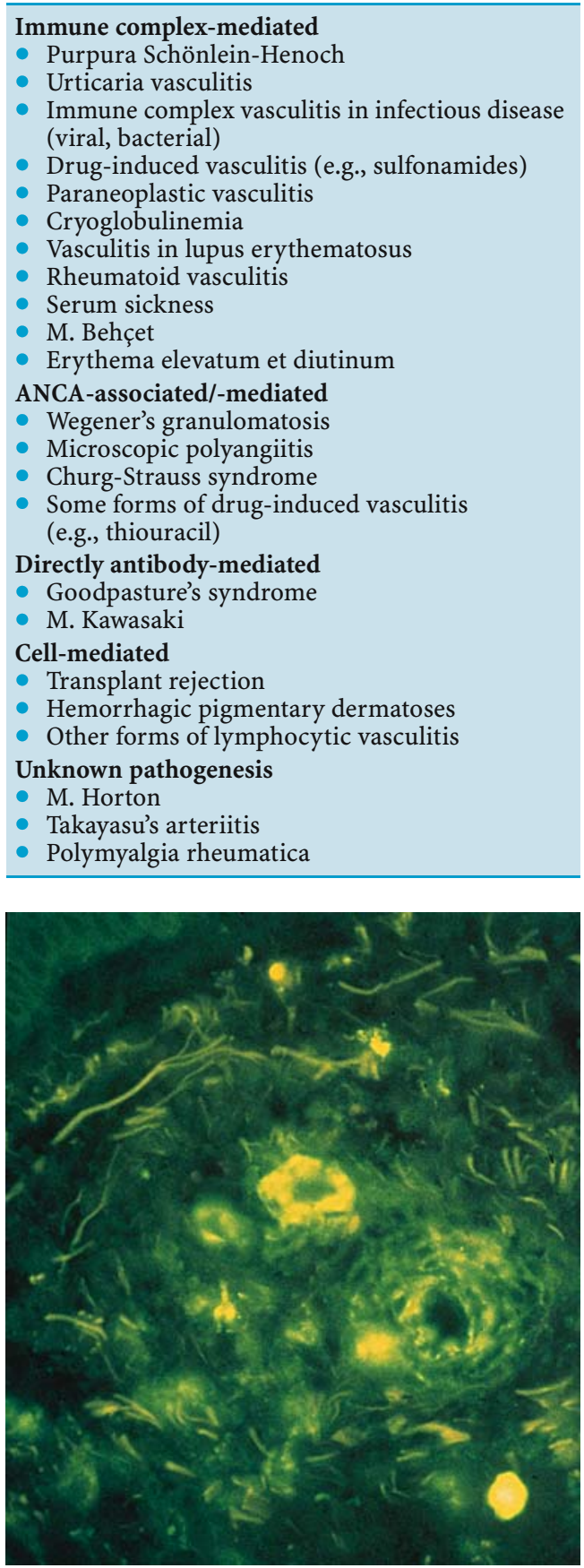

Fig. 5.26. Demonstration of C3 precipitates in the direct immunofluorescent antibody test performed on a patient with allergic vasculitis 
posits of C3, IgG, and IgM can be found. Immune complex vasculitis should be differentiated from other forms of allergic vasculitis (e.g., with lymphocytic infiltrates - as in progressive pigmentary purpura) (Table 5.42) [3, $9,12,27]$.

Clinically, three types of allergic vasculitis can be distinguished [32]:

- Hemorrhagic type (corresponding to purpura Schönlein-Henoch) (Fig. 5.27)

- Papulonecrotic type with necrotizing ulcers and scarring (Figs. 5.28, 5.29)

- Polymorphic nodular type with urticarial, maculopapular, and nodular skin lesions

A special form is "urticaria vasculitis" with long-persisting $(>24 \mathrm{~h})$ wheals with sometimes preceding lupus erythematosus $[12,13,27]$ (see Sect. 5.1.3 on "Urticaria").

The cardinal symptom is purpura (Fig. 5.27), characterized by erythrocyte extravasation, which does not disappear under pressure with

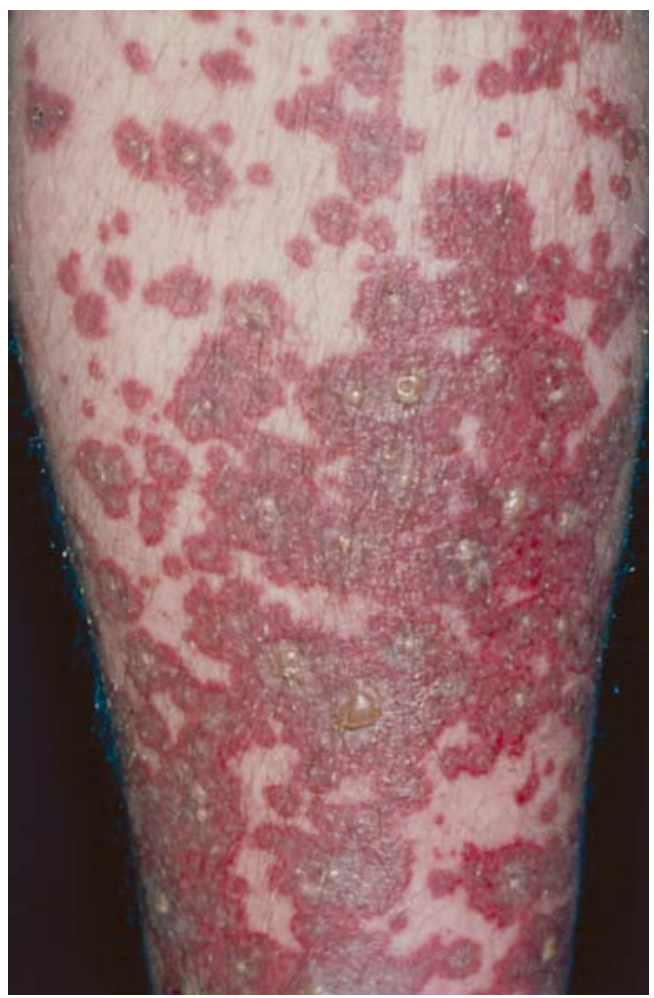

Fig. 5.27. Allergic vasculitis (hemorrhagic type) the diascope. Punctual extravasations (petechia) or fluctuating hemorrhages (ecchymosis, suggillation) occur. A pathophysiological classification of inflammatory versus non-inflammatory purpura is helpful (Table 5.43). Platelet function is normal, and the Rumpel-Leede test is positive.

The exanthema is symmetrical and often pronounced in the lower extremity (hydrostat-

Table 5.43. Inflammatory and non-inflammatory purpura

Inflammatory

Neutrophils: allergic vasculitis

ANCA-associated vasculitis

Lymphocytes: progressive pigmentary purpura

Granulomatous: granulomatous vasculitis

Non-inflammatory

Coagulopathy

Thrombocytopenia

Atrophy (age, corticosteroids)

Vitamin deficiency (vitamin C, scurvy)

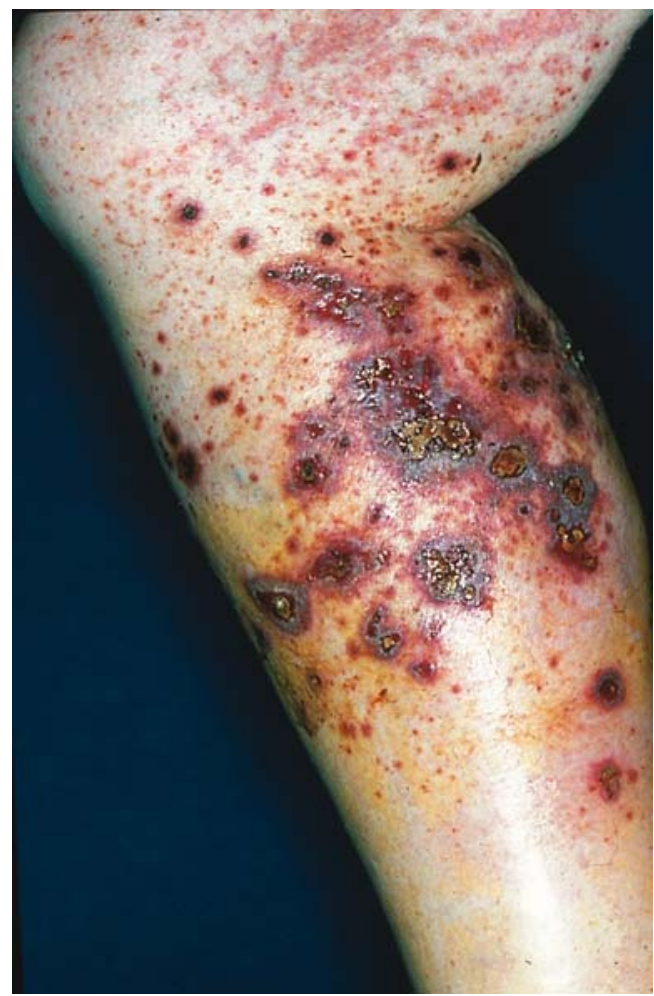

Fig. 5.28. Allergic vasculitis (papulonecrotic type) 


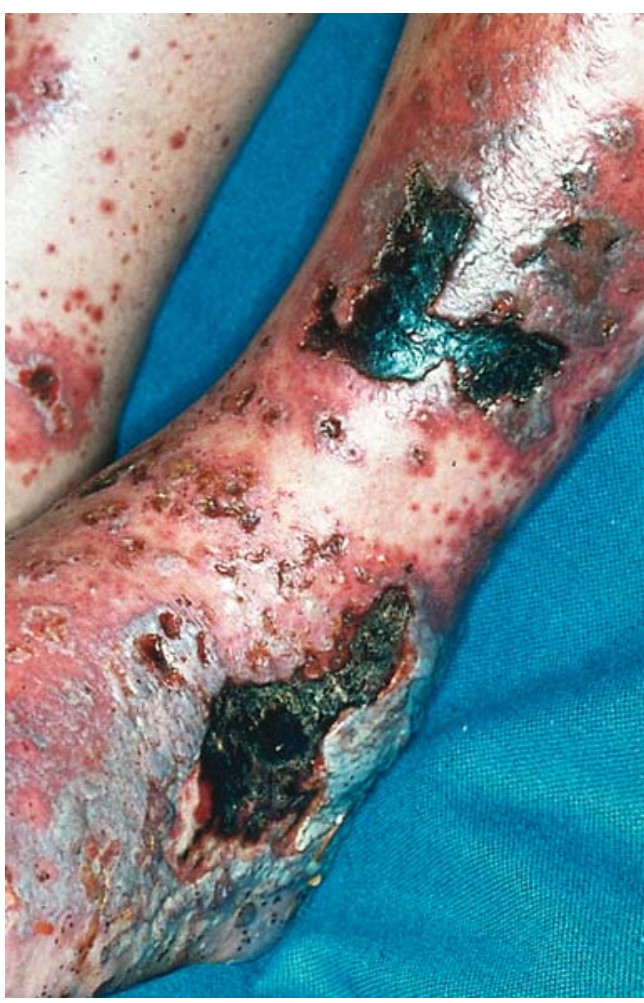

Fig. 5.29. Allergic vasculitis (necrotic type)

ic pressure). Erythrocyte sedimentation is elevated, and circulating immune complexes can be detected in the serum. In many cases, systemic manifestations of other organs (kidney, lung, CNS, gastrointestinal tract, and heart) may occur. Eliciting antigens may be viruses (e.g., hepatitis B), bacteria (e.g., streptococci), parasites (e.g., schistosoma), tumors (such as paraneoplastic syndrome), foods [2, 7] or drugs.

Therapy. The avoidance of eliciting noxious agents as well as treatment of the underlying disease is vital (Table 5.44).

Symptomatically, glucocorticosteroids are used; however, their use is controversial. The anti-inflammatory effect may be beneficial; on the other hand, the vasoconstrictive effect and the immunosuppressive action may prolong the disease.

Antihistamines are recommended by some authors to decrease endothelial permeability.
Table 5.44. Therapy of immune complex diseases

Antihistamines $\left(\mathrm{H}_{1}\right.$ and $\mathrm{H}_{2}$ antagonists combined, serotonin antagonists?)

Mast cell stabilizers

Glucocorticosteroids

Inhibitors of neutrophil function (e.g., colchicine, dapsone, clofazemine)

Inhibitors of TNF, pentoxiphyllin, infliximab

Prostaglandin $\mathrm{E}_{2}$ ?

Plasmapheresis

Cytostatics (cyclophosphamide, cyclosporin A)

Cytostatics (cyclophosphamide) can be used as well as immunosuppressives (cyclosporin). Agents with inhibitory effects on neutrophils are useful such as colchicine, dapsone, or clofazemine $[8,29]$.

Possible newer approaches comprise prostaglandin $\mathrm{E}_{2}$ or TNF-inhibiting pentoxyphyllin or infliximab [33].

\section{References}

1. Becker EL, Austen KF (1966) Mechanisms of immunologic injury of rat peritoneal mast cells. I. The effect of phosphonate inhibitors on the homcytotropic antibody-mediated histamine release and the first component of rat complement. J Exp Med 124:379-395

2. Brostoff J, Challacombe SJ (eds) (1987) Food allergy and intolerance. Tindall, London

3. Bruckbauer HR, Ollert M, Ring J (1997) Vaskulitiden der Haut. Bay Int 17:166-179

4. Burden AD, Tillman DM, Foley P, Holme E (1996) IgA class anticardiolipin antibodies in cutaneous leukocytoclastic vasculitis. J Am Acad Dermatol 35:411-415

5. Cochrane CG, Koftler D (1973) Immune complex disease in experimental animals and man. Adv Immunol 16:185

6. Dixon FJ, Vasquez JJ, Weigle WO, Cochrane CG (1958) Pathogenesis of serum sickness. Arch Pathol 65:18

7. Eisenmann A, Ring J, von der Helm D, Meurer M, Braun-Falco O (1988) Vasculitis allergica durch Nahrungsmittelallergie. Hautarzt 39:318-321

8. Fauci AS (1979) Cyclophosphamide therapy of severe systemic necrotizing vasculitis. $\mathrm{N}$ Engl J Med 301:235

9. Gross WL, Schmitt WH, Lotti T (1995) ANCA-assoziierte Vaskulitiden. Hautarzt 46:511-524

10. Hunt HJ, Valentine MD, Sobotha AK, Junginger JW, Lichtenstein LM (1976) Serum sickness associated with nonvenom protein in mixed hyme- 
noptera whole body extract. J Allergy Clin Immunol 57:246-254

11. Jenette CJ, Milling DM, Falk RJ (1994) Vasculitis affecting the skin. Arch Dermatol 130:899-906

12. Kohler PF (1983) Immune complexes and allergic disease. In: Middleton E, Ellis EF, Reed CE (eds) Allergy, principles and practice, 2nd edn. Mosby, St. Louis, pp 167-199

13. Meurer M (1981) Urticarial vasculitis. In: Ring J, Burg G (eds) New trends in allergy. Springer, Berlin Heidelberg New York, pp 148-151

14. Morgan AC Jr, Rossen R, Twomey JJ (1979) Naturally occurring circulating immune complexes: normal serum contains idiotype-anti-idotype complexes dissociable by certain IgG antiglobulins. J Immunol 122:1672

15. Ollert, deleted in production

16. Pirquet C v, Schick B (1905) Die Serumkrankheit. Deutike, Leipzig

17. Ravetch JV (1994) Fc receptors: Rubor redux. Cell 78:533- 560

18. Ring J, Seifert J, Lob G, Coulin K, Angstwurm H, Frick E, Brass B, Mertin I, Backmund H, Brendel W (1974) Intensive immunosuppression in the treatment of multiple sclerosis. Lancet II:1093

19. Ring J, Seifert J, Seiler F, Brendel W (1976) Improved compatibility of ALG therapy by application of aggregate free globulin. Int Arch Allergy Appl Immunol 52:227-234

20. Ring J (1978) Anaphylaktoide Reaktionen nach Infusion natürlicher und künstlicher Kolloide. Springer, Berlin Heidelberg New York

21. Ruzicka T, Burg G (1987) Effects of chronic intracutaneous administration of arachidonic acid and its metabolites. Induction of leukocytoclastic vasculitis by leukotriene B4 and 12-hydroxyeicosatetraenoic acid and its prevention by prostaglandin E2. J Invest Dermatol 88:120-123

22. Sais G, Vidaller A, Jucgla A, Gallardo F, Peyri J (1995) Colchicine in the treatment of cutaneous

\subsection{Hypersensitivity Pneumonitis (Allergic Alveolitis)}

\subsubsection{Definition}

Hypersensitivity pneumonitis (exogenous allergic alveolitis) (previously also classified under "pneumoconioses") represents an allergic disease of the alveoli and terminal bronchi against fine dusty, mostly organic material occurring with precipitating antibodies. Hypersensitivity pneumonitis has aspects of both type III and IV reactions with lymphocytic and granulomatous reactions. In $2 \%$ of airway dis- leukocytoclastic vasculitis. Results of a prospective, randomized controlled trial. Arch Dermatol 131:1399-1402

23. Scherer R, Wolff HH (1979) Vasculitis allergica. Allergologie 2:62

24. Sedlacek HH (1980) Pathophysiological aspects of immune complex diseases. Klin Wochenschr 58:543-593

25. Seifert J, Land W, Ring J, Lob G, Brendel W (1978) Antigen-Eliminationstechnik. Fortschr Med 96: 695-697

26. Smedegard G, Revenas B, Arfors KE (1979) Anaphylaxis in the monkey: hemodynamics and blood flow distribution. Acta Physiol Scand 106: $191-198$

27. Soter NA, Austen KF, Gigli I (1974) Urticaria and arthralgias as manifestations of necrotizing angiitis (vasculitis). J Invest Dermatol 63:485-490

28. Sylvestre DL, Ravetch JV (1994) Fc receptors initiate the Arthus reaction: Redefining the inflammatory cascade. Science 265:1095-1098

29. Theissen U, Luger TA, Schwarz T (1996) Erfolgreiche topische Anwendung von Cyclosporin A bei Pyoderma gangraenosum. Hautarzt 47:132135

30. Theofilopoulos AN, Dixon FJ (1980) Detection of immune complexes; techniques and implications. Hosp Pract 15:107

31. van Furth R, Cohn ZA, Hirsch JG, et al. (1972) The mononuclear phagocyte system: a new classification of macrophages, monocytes, and their precursor cells. Bull Wld Hlth Org 46:845

32. Wolff HH, Scherer R (1981) Allergic vasculitis. In: Ring J, Burg G (eds) New trends in allergy. Springer, Berlin Heidelberg New York, pp $140-$ 147

33. Zhang Y, Ramos BF, Jakschik BA (1992) Neutrophil recruitment by tumor necrosis factor from mast cells in immune complex peritonitis. Science 258:1957-1959

eases, hypersensitivity pneumonitis is not a rare disease $[6,7,12,13,17,34]$.

\subsubsection{Clinical Symptoms and Diagnosis}

The first description dates back to Ramazzini (1718) as pneumonia-like disease in merchants after contact with grain dust. As allergic disease, farmer's lung was classified by Pepys [24] and bagassosis by Salvaggio [28] in the 1960s after first reports by Gronemeyer in 1951.

An acute and chronic form are distinguished. In the acute form, 4-6 h after exposure dyspnea with tachypnea, coughing (some- 
Table 5.45. Symptoms and signs of hypersensitivity pneumonitis

\begin{tabular}{lr}
\hline Common cold & $91 \%$ \\
Dyspnea & $85 \%$ \\
Cough & $82 \%$ \\
Shivering & $56 \%$ \\
Sputum expectoration & $51 \%$ \\
Malaise & $47 \%$ \\
Tightness of chest & $42 \%$ \\
Weight loss & $31 \%$ \\
Nightly sweating & $29 \%$ \\
Headache & $25 \%$ \\
Nausea & $19 \%$ \\
Loss of appetite & $18 \%$ \\
Rhinitis/pharyngitis & $15 \%$ \\
Myalgia & $14 \%$ \\
Vertigo & $12 \%$ \\
Hemoptoe & $8 \%$ \\
Auscultatory noises & $73 \%$ \\
Fever & $40 \%$ \\
Leukocytosis & $76 \%$ \\
CRP elevation & $72 \%$ \\
ESR elevation & $46 \%$ \\
\hline
\end{tabular}

times itchy throat), fever, fatigue, myalgia, headache, tightness of the chest, as well as sputum (sometimes hemoptoe) develop. In the auscultation, a fine vesicular noise is heard, changing to rough basal noises and the typical end-expiratory rattling noise followed by fibrotic noises in inspiration (sclerosiphony) (Table 5.45).

Chest X-ray shows small patches of nodular shadows (1-3 mm) and milky opacification. Lung function shows restrictive ventilatory disturbance as well as disturbed diffusion capacity (diminished for $\mathrm{CO}_{2}$ ). Decreased arterial oxygen concentrations are found, especially after exercise [34].
Blood count shows leukocytosis with deviation, sometimes eosinophilia. The differential diagnosis (Table 5.46) includes bronchial asthma as type I reaction (sometimes elicited by similar exposure) which can be excluded by precipitating antibodies and negative IgE as well as lung function (no obstructive ventilatory disturbance). The family history of atopy is negative. In the bronchial provocation test, the reaction occurs after $4-6 \mathrm{~h}$ as diffusion disturbance.

More difficult to diagnose are chronic courses characterized by dry coughing, general malaise, weight loss, sometimes increased ESR, leukocytosis and hypergammaglobulinemia. In the X-ray, signs of lung fibrosis are found. Patients are often treated for long periods as having "common cold, bronchitis, etc." Other differential diagnoses are listed in Table 5.47.

Table 5.47. Differential diagnoses of hypersensitivity pneumonitis

Toxic lung disease
Organic toxic alveolitis
$\quad$ ("organic dust toxic syndrome," ODTS)
Byssinosis
Harvester's fever
Pig breeder's fever
Humidifier fever
Anorganic toxic alveolitis
$\quad$ Metal smoke fever
$\quad$ Polymer smoke fever
Silo worker's disease
Autoimmune alveolitis
Interstitial lung disease
e.g., sarcoidosis
Pneumoconioses (berylliosis, asbestosis, silicosis)

Table 5.46. Differential diagnosis between allergic bronchial asthma and hypersensitivity pneumonitis

$\begin{array}{lll}\text { Symptoms } & \text { Allergic asthma } & \text { Hypersensitivity pneumonitis } \\ \text { Symptoms } & \text { Wheezing, acute attacks } & \text { Dyspnea, fever, cough, general symptoms } \\ \text { Latency } & <1 \mathrm{~h} & 6-12 \mathrm{~h} \\ \text { Duration (after exposure) } & \text { Mostly hours } & \text { Days } \\ \text { History of atopy } & \text { Positive } & \text { Negative } \\ \text { Chest X-ray, acute } & \text { Lung inflation } & \text { Infiltrates } \\ \text { Chronic } & \text { Emphysema } & \text { Fibrosis } \\ \text { Lung function } & \text { Obstructive diffusion disturbance } & \text { Restrictive diffusion disturbance } \\ \text { Skin test } & \text { Immediate reaction (20 min) } & \text { Type III reaction }(8-24 \mathrm{~h}) \\ \text { Serology } & \text { RAST+ } & \text { Precipitating antibodies + } \\ \text { Bronchial provocation test } & \text { Immediate reaction } & \text { Delayed reaction (4-12 h) }\end{array}$

a Note the different parameters of lung function disturbance 


\begin{tabular}{lll} 
& ODTS & HP \\
\hline Exposure & Massive & Little to moderate \\
Selection & All exposed & Certain individuals \\
Course & 1 day & Days to weeks \\
Chest X-ray & Negative & Infiltrates \\
IgG antibodies & \pm & ++ \\
Lung function & Normal to mild restriction & Strong restriction \\
BAL & 3 d PMIV increased & Lymphocytosis \\
\hline
\end{tabular}

Table 5.48. Differential diagnosis between "organic dust toxic syndrome" (ODTS) and hypersensitivity pneumonitis (HP)
Table 5.49. Diagnostic criteria for hypersensitivity pneumonitis (German Society for Allergology and Clinical Immunology) [3]. For diagnosis of hypersensitivity pneumonitis, criteria $1-3$ plus 1 additional criterion have to be positive

1. Allergen exposure

2. Symptoms of alveolitis

3. IgG/IgA antibodies

4. Pathologic lung function (diffusion, hypoxemia)

5. Typical chest X-ray infiltrates

6. Typical BAL findings

7. Positive bronchial provocation

Toxic irritative processes through endotoxins or other irritants in organic materials can induce bronchoalveolar diseases $[7,11,13,20,21$, $22,27,34,38,41]$ (Table 5.48): byssinosis in cotton wool workers, grain dust (harvesting dust) disease, flax or hemp workers lung. In these cases, no relevant sensitization can be demonstrated immunologically or in provocation tests. Silo workers disease through toxic effects of nitric gases, furrier's disease with foreign body granulomas around animal hair in lung tissue as well as autoimmune alveolitis (in lupus erythematodes or scleroderma) need to be differentiated (see the diagnostic criteria for hypersensitivity pneumonitis of the German Society of Allergology and Clinical Immunology as well as the German Society for Pneumology in Table 5.49).

\subsubsection{Pathophysiology}

There are three phases in the histological changes (Fig. 5.30): In the acute phase $(4-30 \mathrm{~h})$, perivascular infiltrates of neutrophil and eosinophil granulocytes predominate, which transmigrate through the alveolar walls (type III reaction). In the further course ( $30 \mathrm{~h}$ to weeks), mononuclear infiltrates (type IV reaction) with the beginnings of granuloma formation and multinuclear giant cells are observed (see Sect. 5.8).

In chronic conditions, fibrotic changes are typical.

During bronchoalveolar lavage, a decreased CD4/CD8 ratio with increased lymphocytes of the $\mathrm{TH}_{1}$ secretion type is typical. Sometimes $\mathrm{TH}_{2}$ can be found [4]. In direct immunofluorescence, deposits of immunoglobulins in alveolar walls have been observed $[1,6,34]$.

In the blood, a high concentration of IgG antibodies (mostly as precipitins in immunodiffusion) against eliciting allergens can be detected. The immune complexes thus formed and deposited lead to activation of macrophages, maintaining further inflammatory processes. It is interesting that non-smokers have a higher incidence of hypersensitivity pneumonitis, possibly due to inhibition of macrophage functions in smokers $[16,39]$.

Antibodies may also be detected by complement fixation $[30,32,34]$ or using indirect immunofluorescence (e.g., bird feathers) or enzyme or radioimmunoassays.

The interpretation of antibody results is difficult since they also may be found in healthy exposed individuals, although in lower concentrations. More detailed investigations (longterm follow-up) and accidental autopsies of possibly asymptomatic exposed persons have yielded evidence that in many cases a clinically latent, but minimal form of alveolitis may be present in these individuals.

In the skin test - sometimes after an immediate reaction - the occurrence of a papule after $6-12 \mathrm{~h}$ up to $24 \mathrm{~h}$ is characteristic ( $80 \%$ in hypersensitivity pneumonitis, $50 \%$ in exposed individuals with demonstrable antibody, 10\% in non-exposed controls). Histologically, leu- 
Fig. 5.30. Pathophysiology of exogenous allergic alveolitis

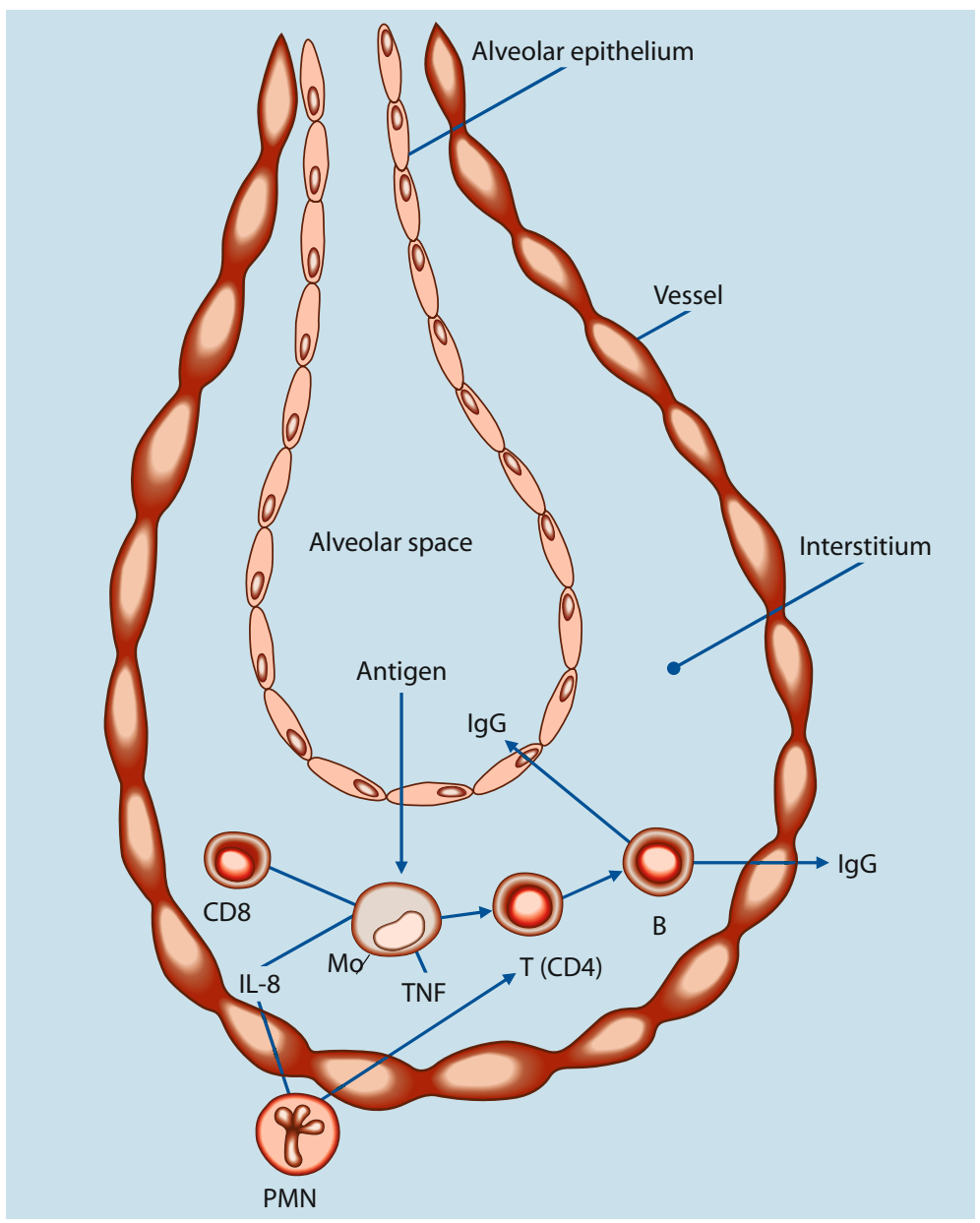

kocytoclastic vasculitis with immunoglobulin and complement deposits in direct immunofluorescence can be found. Unfortunately, skin tests are not often routinely performed since allergen extracts are poorly purified and standardized; false-positive reactions are common.

Bronchial provocation tests after exposure (mixing dust or using nebulizers) should be performed under inpatient conditions.

\subsubsection{Allergens and Common Forms of Hypersensitivity Pneumonitis}

Organic allergens of animal or plant origin, but also chemicals and drugs, are common elicitors of hypersensitivity pneumonitis (Table 5.50) $[2,8,9,10,11,19,25,28,29,31,33,34,40]$.
The classic example of hypersensitivity pneumonitis is farmer's lung elicited by bacteria, especially thermophilic actinomycetes with spores between 0.8 and $2 \mu \mathrm{m}$ in diameter, able to penetrate alveolar spaces. These microorganisms are especially dominant in moldy hay with high humidity and temperature (45\%). One gram of moldy hay may contain $10^{8}$ spores of Micropolyspora faeni. Farmer's lung is more common in humid regions in dairy farmers and late winter when the fresh hay has already been used.

In central Europe, hypersensitivity pneumonitis is common in bird breeders with antibodies against allergens in bird droppings (but also feathers, serum, and eggs), mostly gammaglobulins and albumin with cross-reactivi- 
Table 5.50. Hypersensitivity pneumonitis: allergens and diseases (according to [34])

\begin{tabular}{|c|c|c|}
\hline Allergen (most common) & Disease $^{a}$ & Allergen source \\
\hline $\begin{array}{l}\text { Bacteria } \\
\text { Micropolyspora faeni, } \\
\text { Thermoactinomyces vulgaris } \\
\text { Thermoactinomyces sacchari } \\
\text { "Multiple" microbial agents }\end{array}$ & $\begin{array}{l}\text { Humidifier lung } \\
\text { Water vapor lung bagassosis } \\
\text { Tobacco worker's lung }\end{array}$ & $\begin{array}{l}\text { Humidifiers and air conditioners } \\
\text { Moldy sugarcane } \\
\text { Tobacco leaves } \\
\text { Fungal waste } \\
\text { Moldy cotton }\end{array}$ \\
\hline $\begin{array}{l}\text { Enzymes } \\
\text { Alcalase, maxatase }\end{array}$ & Washing powder lung & Enzymes from B. subtilis \\
\hline $\begin{array}{l}\text { Fungi } \\
\text { Alternaria and others } \\
\text { Alternaria } \\
\text { Cryptostoma corticale } \\
\text { Penicillium frequentans } \\
\text { Penicillium casei } \\
\text { Penicillium brevicompactum } \\
\text { Aspergillus clavatus } \\
\text { Aspergillus fumigatus } \\
\text { Streptomyces olivaceus } \\
\text { Cephalosporium trochoderma } \\
\text { Botrytis cinerea } \\
\text { Various fungi } \\
\text { Pleurotus florida } \\
\text { Mixed fungi }\end{array}$ & $\begin{array}{l}\text { Wood cutter's lung } \\
\text { Paper worker's lung } \\
\text { Maplebark lung } \\
\text { Cork worker's lung (suberosis) } \\
\text { Cheese washer's lung } \\
\text { Tomato breeder's lung } \\
\text { Malt worker's lung } \\
\text { Espartosis } \\
\text { New Guinea lung } \\
\text { Textile worker's lung } \\
\text { Winemaker's lung } \\
\text { "Coptic lung" } \\
\text { Fungi worker's lung } \\
\text { Fruit farmer's lung } \\
\text { Moldy lung }\end{array}$ & $\begin{array}{l}\text { Moldy wood } \\
\text { Moldy paper mix } \\
\text { Moldy maple bark } \\
\text { Cork (Portugal) } \\
\text { Moist cheese storages } \\
\text { Tomatoes } \\
\text { Malt in breweries } \\
\text { Fiber production from esparto grass } \\
\text { Straw roofs } \\
\text { Textile fibers } \\
\text { Grapes } \\
\text { Mummies } \\
\text { Edible fungi (oyster mushroom) } \\
\text { Fruit in cooling rooms } \\
\text { Organic waste, moldy cotton }\end{array}$ \\
\hline $\begin{array}{l}\text { Plant allergens } \\
\text { Wood fiber }\end{array}$ & Wood dust alveolitis & Wood cutting dust \\
\hline $\begin{array}{l}\text { Animal allergens } \\
\text { Bird dust (feathers, feces, egg) } \\
\text { Bread beetle protein (Sitoph. gran.) } \\
\text { Fish proteins } \\
\text { Pig epithelium } \\
\text { Rat serum antigens } \\
\text { Pituitary extracts } \\
\text { Pancreatin } \\
\text { Silkworm proteins } \\
\text { Crustacea dust }\end{array}$ & $\begin{array}{l}\text { Bird breeder's lung } \\
\text { Bread beetle's lung } \\
\text { Fish flour lung } \\
\text { Pig hair lung } \\
\text { Animal keepers } \\
\text { Pituitary sniffer's lung } \\
\text { Pancreatin powder } \\
\text { Silk breeder's lung } \\
\text { Crustacean lung }\end{array}$ & $\begin{array}{l}\text { Bird droppings, bed feathers } \\
\text { Grain and flour } \\
\text { Miller's lung } \\
\text { Animal feeding } \\
\text { Rat urine } \\
\text { Pharmaceutical industry } \\
\text { Silkworm } \\
\text { Pearl oyster handling }\end{array}$ \\
\hline $\begin{array}{l}\text { Drugs } \\
\text { Nitrofurantoin } \\
\text { Hydrochlorothiazide } \\
\text { Carbamazepine } \\
\text { Amiodarone } \\
\text { Phenytoin } \\
\text { Gold salts }\end{array}$ & & \\
\hline $\begin{array}{l}\text { Chemicals } \\
\text { Isocyanates } \\
\text { Acid anhydrides } \\
\text { Silicon implants }\end{array}$ & $\begin{array}{l}\text { Isocyanate alveolitis } \\
\text { Chemicals }\end{array}$ & $\begin{array}{l}\text { Plastic production } \\
\text { Plastic, glues }\end{array}$ \\
\hline
\end{tabular}

a The term "alveolitis" should be preferred to the common term "lung" 
ties between various bird species (budgerigar, parrot, canary, etc.) $[6,34,37]$. The fine dust of dry pigeon feces seems to be especially allergenic. In Germany, there are an estimated 110,000 pigeon breeders. The prevalence of hypersensitivity pneumonitis is estimated at $0.2-10 \%$ of exposed individuals. In the United Kingdom, $12 \%$ of the population is supposed to keep birds (mostly budgerigars) without alarming figures of high prevalences of hypersensitivity pneumonitis. A study from the island of Gotland revealed among farmers a 10 - 100 times higher prevalence of IgE-mediated allergic diseases (especially against housedust and storage mites) than hypersensitivity pneumonitis [36].

In preparing lists of allergens and corresponding diseases, it has to be considered that not infrequently several allergens of various origin (bacteria, fungi, parasites) are involved together in the elicitation of the disease (e.g., humidifier lung) (Table 5.50).

Rare cases are observed under treatment with pituitary gland extracts, in the preparation of pancreatin, in fungi farming, under nitrofurantoin treatment (3 weeks after beginning), with ACE inhibitors, or with silicon implants.

Hypersensitivity pneumonitis can also occur in animals (e.g., horses) [33].

\subsubsection{Allergic Bronchopulmonary Mycosis}

The disease of allergic bronchopulmonary mycosis (mostly aspergillosis) needs to be distinguished from hypersensitivity pneumonitis; it develops mostly on the basis of a chronic bronchial asthma and consists of a combination of type I and III allergy together with intrabronchial colonization with molds. Relapsing lung infiltrates in patients with allergic bronchial asthma are characteristic [35]. In the diagnosis, precipitating antibodies together with specific IgE antibodies, dual skin reactions, as well as positive demonstration of molds in the sputum culture are relevant [34]. Other diseases due to aspergilli are aspergillus pneumonia as well as aspergilloma.

Besides allergic bronchopulmonary mycosis, there are true combinations of type I and III reactions such as exogenic allergic asthma and hypersensitivity pneumonitis through hay dust or isocyanates.

In this context, other forms of mold allergy together with an infection occurring in the paranasal sinuses should be mentioned such as the recently described "allergic fungal sinusitis" (see also Sect. 5.1.1 on "Rhinitis").

\subsubsection{Therapy of Hypersensitivity Pneumonitis}

Strict allergen avoidance is the primary commandment. Prophylactic measures include reduction of allergen concentrations through constructing better and drier storage rooms. With air masks, the amount of inhaled allergen can be reduced. The airstream helmet with an airflow passing through a filter can be used during work [18]. A new mask is the "Dust Master"; there are also half-masks (3M Co.). In highly sensitized individuals, a change of occupation or cessation of the exposed work is the only way.

Glucocorticosteroids may reduce the symptoms of hypersensitivity pneumonitis. Doses between 40 and $60 \mathrm{mg}$ prednisolone (in children $0.2 \mathrm{mg} / \mathrm{kg}$ body wt.) are given; steroid medication is, however, no alternative to allergen avoidance!

For therapy control, measurement of vital capacity, diffusion capacity, and $\mathrm{O}_{2}$ partial pressure under exercise are recommended.

The efficacy of cromoglycate is controversial. Allergen-specific immunotherapy in hypersensitivity pneumonitis is contraindicated. In severe cases, cytostatics and immunosuppressives are given [34, 42].

\section{References}

1. Allen DH, Basten A, Woolcock AJ (1977) Studies of cell and humoral immunity in birdbreeders hypersensitivity pneumonitis. Am Rev Resp Dis 115:45

2. Bäck O, Lindgren R, Wiman LG (1974) Nitrofurantoin induced pulmonary fibrosis and lupus syndrome. Lancet I:930

3. Bergmann KC, Costabel U, Knape H, Kroidl R, Müller-Wening D, Repp H, Rust M, Schwarz H, Sennekamp J (1990b) Empfehlungen zur Diagnosestellung einer exogen-allergischen Alveolitis. Allergologie 13:111

4. Boyd G, McSharry C, McLeod K, Sriram S, Boyd F (1999) Lymphocyte responses in pigeon breeders 
with extrinsic allergic alveolitis/hypersensitivity pneumonitis (EAA/HP) are predominantly $\mathrm{T}$ helper 2-type. Am J Resp Crit Care Med 159:A742

5. Doerr W (1953) Pneumokoniose durch Getreidestaub. Virchows Arch Pathol Anat 324:263

6. Fink JN (1992) Hypersensitivity pneumonitis. Clinics in chest Medicine 13:303

7. Fruhmann G (1988b) Pneumokoniosen durch organisches Material. Deutsches Ärzteblatt 85:3170

8. Fuchs A, Liebetrau G (1989) Die Vogelhalterlunge - eine Form der exogen allergischen Alveolitis. Z Klein Med 44:1407

9. Heiner DC, Snears JW, Kniker WT (1962) Multiple precipitins to cow's milk in chronic respiratory disease. Am J Dis Child 103:634

10. Hinojosa M (2001) Stipatosis or hypersensitivity pneumonitis caused by esparto (Stipa tenacissima) fibers. J Invest Allergol Clin Immunol 11:67-72

11. Jelke G (1986) Krank durch Fortschritt. Expositionelle Besonderheiten bei der exogen-allergischen Alveolitis. Allergologie 9:137

12. Kroidl RF, Nowak D, Seysen U (1994b) Exogenallergische Alveolitis: Probleme und Fehler bei der Begutachtung. Allergologie 17:75

13. Malmberg P, Rask-Andersen A (1993b) Organic dust toxic syndrome. Semin Resp Med 14:38

14. Marinkovich VA (1975) Hypersensitivity alveolitis. J Am Med Assoc 231:944

15. McCarthy DS, Pepys J (1971) Allergic bronchopulmonary aspergillosis. Clinical immunology: 1. Clinical features, 2. Skin, nasal and bronchial tests. Clin Allergy 1:261, 415

16. McSharry C, Banham SW, Boyd G (1985) Effect of cigarette smoking on the antibody response to inhaled antigens and the prevalence of extrinsic allergic alveolitis among pigeon breeders. Clin Allergy $15: 487$

17. Molina C (1984) Immunopathologie bronchopulmonaire. Masson, Paris

18. Müller-Wening D, Repp H (1989b) Investigation on the protective value of breathing masks in farmer's lung using an inhalation provocation test. Chest 95:100

19. Murray MJ, et al. (1965) Pulmonary reactions simulating cardiac pulmonary edema caused by nitrofurantoin. N Engl J Med 273:1185

20. Newman-Taylor A, Pickering CAC, Turner-Warwick M, Pepys J (1978) Respiratory allergy to a factor humidifier contaminant presenting as pyrexia of undetermined origin. Br Med J:II

21. Olenchock SA, May JJ, Pratt DS, et al. (1990) Presence of endotoxin in different agricultural environments. Am J Industr Med 18:279

22. Parkers WR (1994) Occupational lung disorders. Butterworth, London

23. Patterson R (1978d) Studies of hypersensitivity lung disease with emphasis on a solid-phase radioimmunoassay as a potential diagnostic acid. J Allergy Clin Immunol 61:216
24. Pepys J (1994) Farmer lung's - a needle in a haystack, and Pandora's box. Allergy Clin Immunol News 6:68

25. Pepys I, Jenkins P, Festenstein G, Gregory P, Lacey M, Skinner F (1963) Farmer's lung. Thermophilic actinomycetes as a source of "farmer's lung hay" antigen. Lancet II:607

26. Raulf M, Liebers V, Steppert C, Baur X (1994) Increased gamma/delta positive T-cells in pneumonitis. Eur Respir J 7:140

27. Rylander R, Malmberg P (1992a) Non-infectious fever: inhalation fever or toxic alveolitis? $\mathrm{Br} \mathrm{J}$ Industr Med 49:296

28. Salvaggio JE, Buechner HA, Seabury H (1966) Bagassosis I. Precipitins against extracts of crude bagasse in the serum of patients with bagassosis. Ann Intern Med 64:748

29. Sastre J, Ibanez MD, Lopez M, Lehrer SB (1990) Respiratory and immunological reactions among Shiitake (Lentinus edodes) mushroom workers. Clin Exp Allergy 20:13

30. Schatz M, Patterson R (1977) Immunopathogenesis of hypersensitivity pneumonitis. J Allergy Clin Immunol 60:27

31. Schulz KH, Felten G, Hausen BM, Noster U (1974) Allergy to spores of Pleurotus Florida. Lancet I:625

32. Schultze-Werninghaus G, Rust M (1988b) Asthma bronchiale und allergische Alveolitis durch Berufsallergene. Allergologie II:437

33. Seeliger HPR, Sühler H (1975) Farmerlunge beim Tier. Berl Münch Tierärztl Wochenschr 88:163

34. Sennekamp H-J (1998) Exogen allergische Alveolitis. Dustri, Munich

35. Slavin RG, Million L, Cherry J (1970) Allergic bronchopulmonary aspergillosis: characterization of antibodies and results of treatment. J Allergy Clin Immunol 46:150

36. van Hage-Hamsten M, Johansson SGO, Höglund S, Tüll P, Wirén A, Zetterström O (1985) Storage mite allergy is common in a farming population. Clin Allergy 15:555-564

37. Vogelmeier C, Krombach F, Münzing S, et al. (1993) Activation of blood neutrophils in acute episodes of farmer' lung. Am Rev Resp Dis 148:396

38. von Essen S, Robbins RA, Thompson AB (1990) Organic dust toxic syndrome. Clin Toxicol 28:389

39. Warren CPW (1977) Extrinsic allergic alveolitis: a disease commoner in non-smokers. Thorax 32:567- 569

40. Weck AL de, Gutersohn J, Bütikofer E (1969) La maladie des laveurs de fromage ("Käsewascherkrankheit"): une forme particulière du syndrome du poumon de fermier. Schweiz Med Wochenschr 99:872

41. Westphal O, Lüderitz O (1961) Bacterial endotoxins. J Med Pharma Chem 4:497

42. Wild LG, Lopez M (2001) Hypersensitivity pneumonitis: A comprehensive review. J Invest Allergol Clin Immunol 11:3-15 


\subsection{Dermatitis/Eczema}

\subsubsection{Definition and Classification}

The various forms of eczematous skin diseases are the most common skin diseases (approximately $5-10 \%$ of the population). The terms "dermatitis" and "eczema" are often used interchangeably to describe a disease best defined according to Miescher [42] (Table 5.51). Dermatitis/eczema is characterized by a strong itching sensation, a relapsing clinical course and a tendency to chronification.

The following different forms of eczematous diseases can be distinguished (Table 5.52). In the United States, the term "dermatitis" is often used identically to "eczema"; some want to stop using the term "eczema" [1]. The name "ecze-

Table 5.51. Definition of dermatitis/eczema

- Non-contagious epidermodermitis with typical

- clinical (itch, erythema, papule, seropapule, vesicle, desquamation, crusting, lichenification in the sense of synchronous or metachronous polymorphism) and

- dermatohistological (spongiosis, akanthosis, parakeratosis, lymphocytic infiltration into the epidermis) manifestation

mostly on the basis of hypersensitivity

Table 5.52. Classification of dermatitis/eczema

Contact dermatitis

- Allergic

- Irritative-toxic

Atopic and non-atopic eczema

Seborrheic dermatitis

Nummular (microbial) dermatitis

Unclassified dermatitis ma" in its 1,400 years of history has served a useful life and is understood by lay people $[2,7$, 49, 68]. The earliest definition by Aetius from Amida described something like "boiling, foaming" (ekzeo = I'm boiling) [2]. Interestingly, this idea illustrates very well the most modern pathophysiology of dermoepidermal inflammation with the subsequent intercellular edema formation (spongiosis).

The colorful spectrum of eczematous diseases may lead to confusion since definitions are given according to variable criteria (morphology, localization, route of contact, kinetics, etiology, or pathophysiology). It is most unfortunate that the term "contact dermatitis" only focuses on the route of elicitation and does not describe the actual difference in pathophysiology to atopic eczema, which also can be elicited by external contact (see below). Therefore the common classification as it is used in most textbooks (Table 5.52) is not very logical. Earlier the term "vulgar" eczema [28] was used for contact dermatitis; however, this is not an attractive diagnosis to give a patient today. Therefore one should focus on the different characteristics between "atopic eczema" and "contact dermatitis" both pathophysiologically and clinically (Table 5.53).

In the recent nomenclature consensus of the WAO, a new classification of "dermatitis" was proposed, restricting the term "eczema" to the forms of what has so far been called atopic eczema/dermatitis (Table 5.54). Thus only the allergic ("extrinsic" with IgE involvement) in contrast to the non-allergic ("intrinsic" without detection of IgE sensitization) variant should be named "atopic." The nummular form

Table 5.53. Differences between contact dermatitis and atopic eczema

\begin{tabular}{lll} 
& $\begin{array}{l}\text { Contact } \\
\text { dermatitis }\end{array}$ & Atopic eczema \\
Genetic disposition & - & + \\
Elicitation (route) & Contact & $?$ \\
Psychosomatic influence & - & ++ \\
Type of allergic reaction & IVa & I+IVb \\
Antibodies & - & IgE \\
T cells (elicitation) & TH1 & TH2 \\
Allergens & Haptens & Proteins \\
Amplifying cells & PMN? & EOS, mast cells \\
Role of allergens & Established & Controversial \\
Diagnosis & Patch test & Prick, specific IgE, atopy patch test \\
\hline
\end{tabular}




\begin{tabular}{|c|c|c|}
\hline Dermatitis & & \\
\hline Eczema & Contact dermatitis & Other forms \\
\hline Atopic Non-atopic & Irritative-toxic $>$ Allergic & $\begin{array}{l}\text { Nummular, } \\
\text { seborrheic, etc. }\end{array}$ \\
\hline
\end{tabular}

\begin{tabular}{|c|c|c|c|c|}
\hline Body area & \multicolumn{3}{|c|}{$\begin{array}{l}\text { Most common } \\
\text { form }\end{array}$} & Differential diagnosis \\
\hline Dorsum of hands & $\mathrm{CD}$ & $\mathrm{AE}$ & & \\
\hline Palms/soles & $\mathrm{AE}$ & $\mathrm{CD}$ & IT & Tinea \\
\hline Fingertips & $\mathrm{AE}$ & $\mathrm{CD}$ & IT & \\
\hline Scalp & SD & $\mathrm{CD}$ & $\mathrm{AE}$ & Psoriasis \\
\hline External ear & SD & $\mathrm{CD}$ & & Psoriasis \\
\hline Eyelid & $\mathrm{AE}$ & $\mathrm{CD}$ & SD & \\
\hline Lips & $\mathrm{AE}$ & $\mathrm{CD}$ & IT & \\
\hline Oral mucosa & IT & $\mathrm{CD}$ & & \\
\hline Mamilla & $\mathrm{AE}$ & $\mathrm{CD}$ & & Morbus Paget, scabies \\
\hline Anal & IT & CD & $\mathrm{AE}$ & Psoriasis \\
\hline Genital & IT & $\mathrm{AE}$ & & Scabies \\
\hline Lower leg & $\mathrm{CD}$ & $\mathrm{AE}$ & & Venous insufficiency ("stasis dermatitis"?) \\
\hline Post-traumatic & IT & $\mathrm{CE}$ & & \\
\hline
\end{tabular}

Table 5.54. Proposal of a new classification of dermatitis/eczema (according to WAO 2004; Chap. 1)

Table 5.55. Preferable characteristics of certain forms of dermatitis in various localizations ( $A E$, atopic eczema; $C D$, contact dermatitis; $I T$, irritative-toxic dermatitis; $S D$, seborrheic dermatitis)
- also called "dysregulative microbial" [31] - is still not well understood in its pathophysiology. In childhood, it seems to be a variant of atopic eczema.

Whether seborrheic dermatitis [65], first defined by Unna, really represents this type of inflammation or rather a superficial skin infection (e.g., P. ovale) is under discussion [20].

Contact dermatitis and atopic eczema are the most common forms, followed by nummular, seborrheic and other forms of dermatitis.

One can also classify according to localization (e.g., hand, lower leg dermatitis) for practical reasons. The prevalence of certain forms differs according to localization (Table 5.55). The entity of "stasis dermatitis" is controversial.

Clinical subtypes are "dyshidrotic dermatitis" (pompholyx), which often turns - when in chronification - into "hyperkeratotic-rhagadiform dermatitis" $[4,17,46,58]$.

\subsubsection{Contact Dermatitis}

\subsubsection{Pathophysiology}

Contact dermatitis can be either due to toxic or to allergic mechanisms (Table 5.56). Acute toxic contact dermatitis ("irritant contact derma-
Table 5.56. Clinical and histological distinctions between irritative-toxic and allergic contact dermatitis

\begin{tabular}{lll} 
& Irritative-toxic & Allergic \\
Clinical characteristics & \\
Margin & Sharp & Spreading \\
Polymorphism & + & +++ \\
Kinetic & Decrescendo & Crescendo \\
Pain & ++ & + - \\
Itch & + & +++ \\
Histology & & \\
Spongiosis & 0 & +++ \\
Exocytosis & ++ & ++ \\
Vesiculation & Non-spongiotic & Spongiotic \\
Keratinocyte & & \\
$\quad$ necrosis & ++ & 0 \\
Eosinophils & 0 & + \\
Neutrophils & + & 0 \\
Mononuclear & & \\
$\quad$ infiltrates & + & + \\
Edema & + & 0 \\
\hline
\end{tabular}

titis") develops after irritation, usually showing sharp margins and no spreading phenomena. It occurs in any individual without a peculiar genetic disposition. Special forms are diaper dermatitis in infants and intertrigo. The chronic (cumulative-toxic) form develops more slowly in disposed individuals (frequently atopics) and is due to skin barrier disturbance; it occurs most commonly in house- 
wives, hairdressers, metal workers, as well as health personnel. The most important noxious agents are: water, detergents, acids, alkali, solvents, secretions, mechanical factors, etc. A subtype can be classified as "exsiccation dermatitis" [8] after excessive washing.

Allergic contact dermatitis is due to an immunologic reaction of type IVa (sensitized T lymphocytes of TH1 type under IL-12 mediation) $[3,13,14,19,20,27,34,36,60,62,64]$. After skin contact, a specific hapten (e.g., chromate) is bound to an epidermal carrier protein, recognized by Langerhans cells $[9,19,26,27$, $37,38,56,61,62]$ in the epidermis. Metal ions (e.g., nickel) have been reported as possibly leading to a structural alteration of the HLADR complex [34]. In the regional lymph nodes [61], antigen is presented to $\mathrm{T}$ lymphocytes, which then circulate in the orgnism and after renewed antigen contact migrate as specifically sensitized $\mathrm{T}$ cells to the skin using the skin homing receptor CLA (cutaneous lymphocyte antigen) and secrete or release certain cytokines [13, 36, 64]. Apart from Langerhans cells, other dendritic cells in the epidermis may be involved during inflammation and tolerance induction $[6,27]$.

So-called "group allergy" develops when different haptens are transformed by coupling to the carrier into identical substances. "Coupling allergy" describes the common phenomenon of concomitant allergic sensitizations against different substances in the same patient due to common occurrence of allergens in the environment.

The molecular characteristics of contact allergenicity are better understood than that of protein allergens. A crucial characteristic is the binding of the hapten to proteins $[5,39]$, which can occur through electrophil haptens (covalent binding with certain protein structures, e.g., benzochinone), nucleophil haptens (e.g., mercaptobenzothiazole), and lipophil haptens, which directly integrate within the cell membrane (e.g., urushiol from poison ivy).

Certain haptens only become immunologically active under UV influence (see Sect. 5.6 on "Photoallergy").

Most contact allergens also have a certain irritative potency.

\subsubsection{Clinical Manifestations of Classic Contact Dermatitis}

Usually in contact dermatitis, sensitization and elicitation occur through epidermal contact; but there are also systemically elicited forms ("hematogenous") where either sensitization or elicitation occur via systemic allergen administration $[29,35,48]$ mostly via the gut. The most common elicitors of systemic contact dermatitis are drugs as well as foods and aromatic substances (flavors).

The clinical symptoms (Figs. 5.31-5.40) in the acute stage are of exsudative character (erythematous, vesicular, crusted), and in the chronic stage more infiltrative (papules, lichenification, hyperkeratosis).

The most common contact allergens (see Sect. 3.2.2) are metals (nickel, chromate, cobalt), rubber accelerators (used during vulcanization as antioxidants or stabilizers, not rubber proteins themselves!), ointment vehicles (e.g., lanolin, woolwax, emulsifiers, etc.), epoxy resins (solvents, hardeners in resins, sensitizing agents mostly are monomers and dimers, not

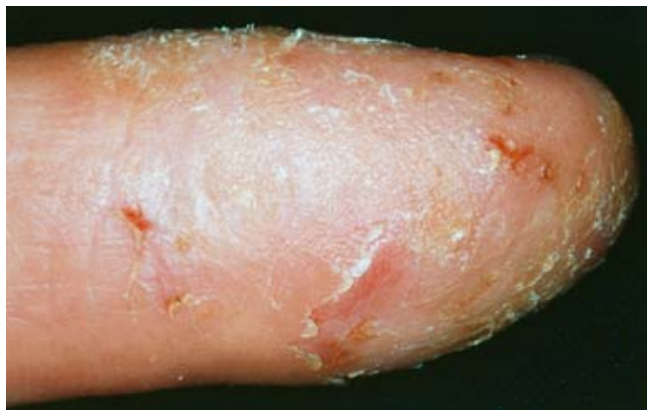

Fig. 5.31. Fingertip dermatitis seen in a dentist

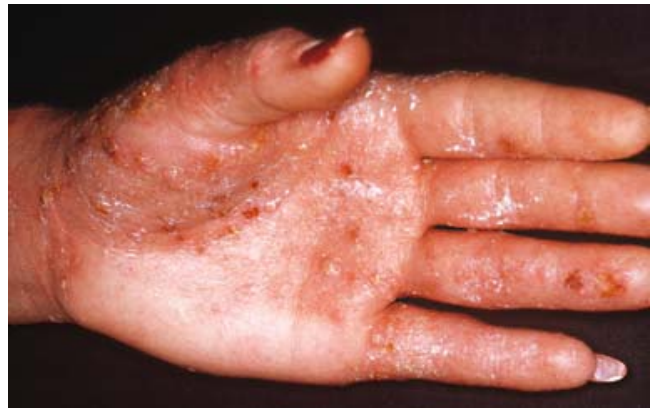

Fig. 5.32. Dyshidrotic hand dermatitis 


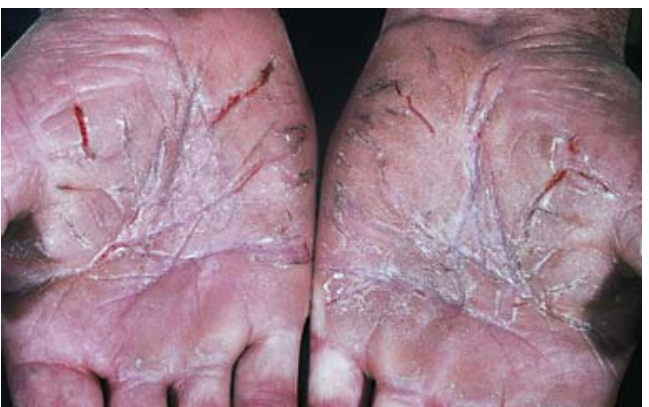

Fig. 5.33. Cumulative toxic hand dermatitis

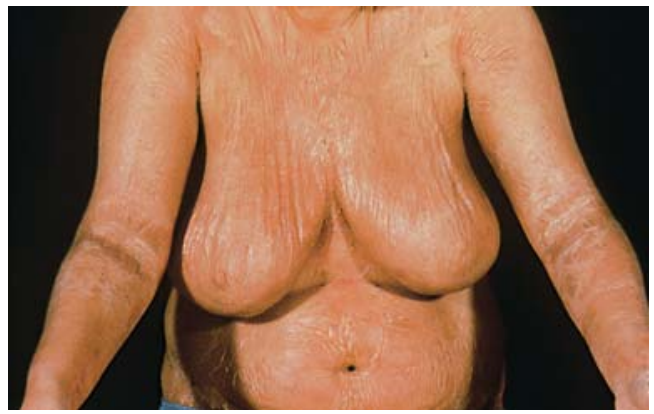

Fig. 5.35. Irritative contact dermatitis due to artificial application of a disinfectant

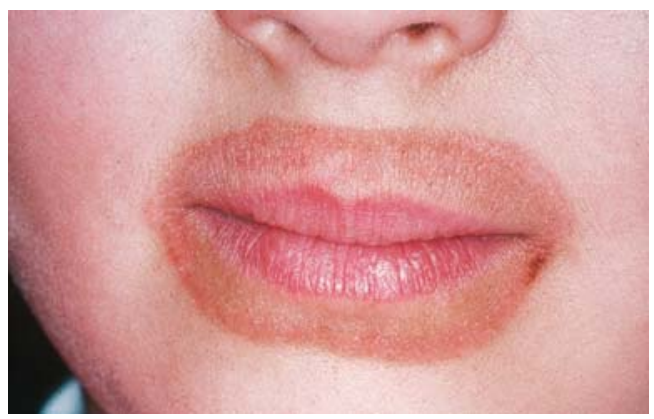

Fig. 5.37. Dermatitis caused by excessive licking of the lips

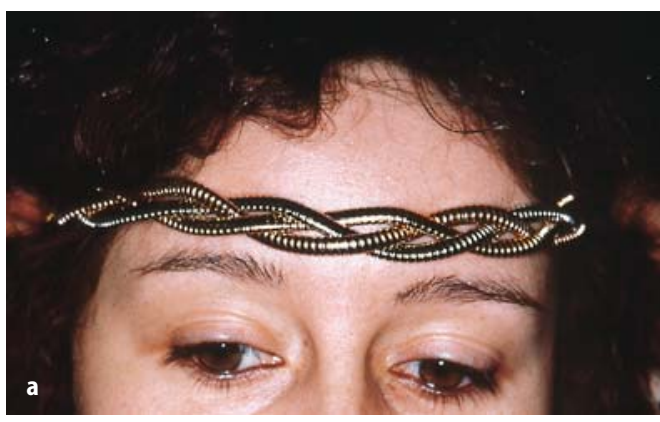

Fig. 5.39a,b. Nickel allergy (dermatitis caused by a headband)

Fig. 5.34. Foot dermatitis (allergy to antimycotic medication)

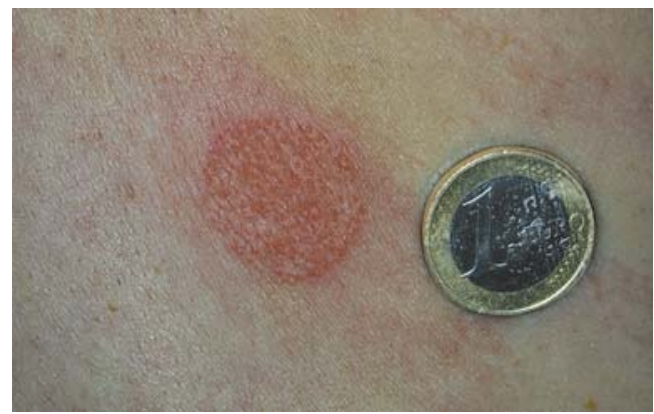

Fig. 5.36. Allergy to coins containing nickel

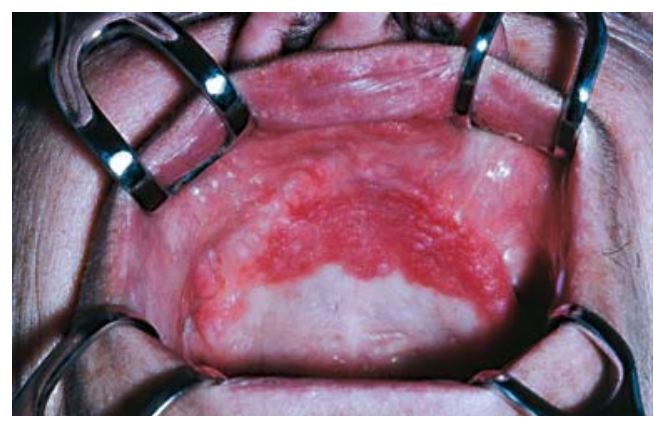

Fig. 5.38. Contact stomatitis

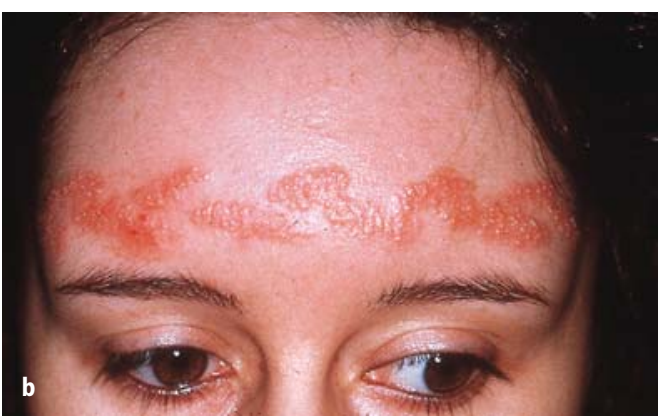



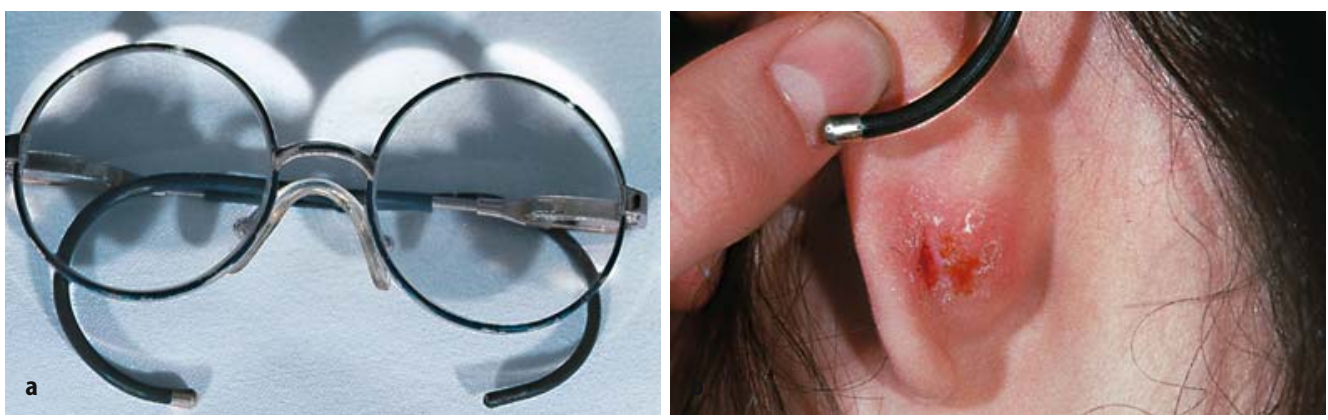

Fig. 5.40a,b. Nickel allergy (dermatitis caused by eyeglass frames)

the polymers), disinfectants (formaldehyde, parabens), drugs (there is a strong increase in iatrogenic sensitizations through rheuma and venous insufficiency ointments) as well as plants; the most common phytoallergens are sesquiterpenlactones from composites (= Asteraceae) such as chrysanthemum, arnica, chamomile, mugwort, as well as chinoid eczematogens from exotic woods $[5,30]$. There is no allergen cross-reaction to the pollen of the respective plants!

Contact dermatitis can also be elicited via the air ("airborne contact dermatitis"), which often is confused with photoallergy.

\subsubsection{The Patch Test}

Since the first description of the patch test by J. Jadassohn in 1895 [33], the patch test is the classical method for diagnosis of contact dermatitis $[4,10,15,18,20,52,55,56]$. The allergen is diluted properly (adequate concentrations have to be determined first in healthy volunteers in order to avoid toxic reactions) in an indifferent vehicle (mostly petrolatum) and fixed to a patch on the skin. Patches either are fixed in aluminum foil or aluminum chambers (Finn chambers). A new technique uses allergen-coated thin layer foils (TRUE test, thin layer rapid use epicutaneous test) [21]. After 1 or 2 days, the patch is removed. The test reaction is read after $24 / 48$ and after $72 \mathrm{~h}$ and graded from 0 to $+++[0=$ negative, $(?)=$ questionable (erythema), $+=$ weakly positive (erythema and infiltration, single papules),$++=$ strongly positive (erythema, infiltrate, papules, and vesicles),$+++=$ very strongly positive (erythema,

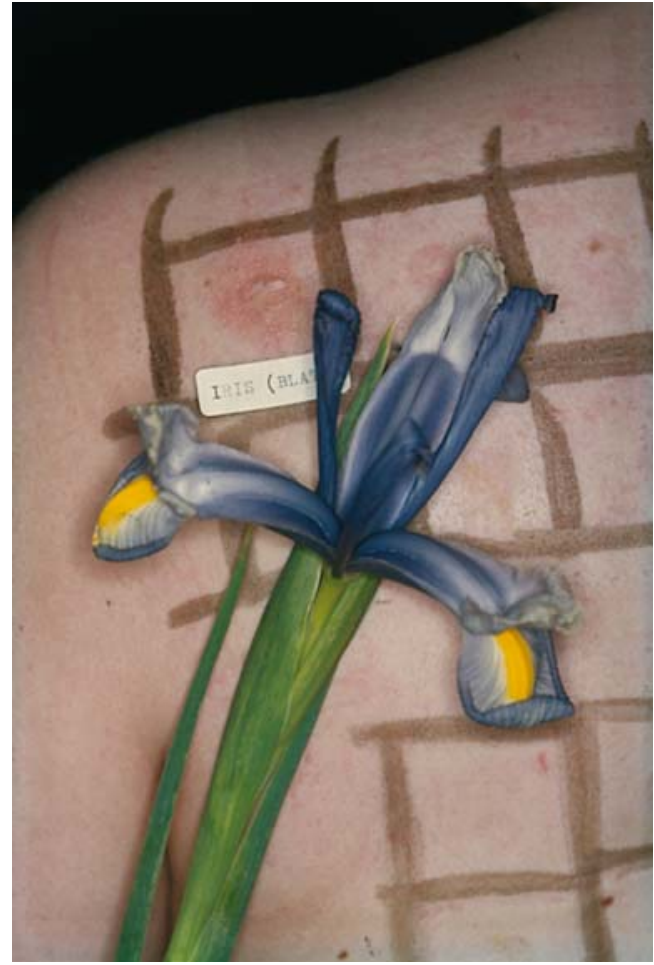

Fig. 5.41. Positive test reaction to phytoallergens (iris)

papules, confluent vesicles, erosion), IR = irritative reaction (Figs. 5.41, 5.42)]. In special cases, a third reading after 1 or 2 weeks may be indicated.

The open patch test (reading after $20 \mathrm{~min}$ ) is used in the diagnosis of contact urticaria (see Sect. 5.1.3).

The "contact allergy time" (CAT) as the time interval needed to become sensitized against neoantigens through epidermal contact deter- 


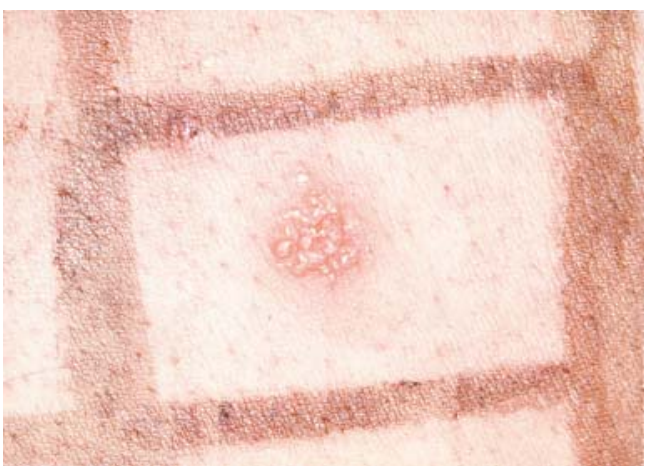

Fig. 5.42. Positive epidermal test

mines the afferent part of the cellular immune response quantitatively [11].

Allergic and toxic reactions can be distinguished: toxic reactions are sharply marginated, reach their maximum earlier $(24-48 \mathrm{~h})$ and are also positive in normal individuals (>20\%). Besides toxic reactions, false-positive test results may occur through other factors of irritation such as adhesive tape irritation, too high concentrations, allergy against test materials, or concomitant to other very strong reactions ("angry back" or "excited skin syndrome") [12, 40, 42, 44]. Substances with a tendency to elicit false-positive reactions are: chromate, formaldehyde, thiomersal, and fragrance mix. Primary toxic substances may only be tested in very special cases with a clear-cut history (e.g., tear gas) and in high dilution.

False-negative test results occur under longterm glucocorticoid treatment or with too low concentrations (see Sect. 4.2). External steroid therapy should be stopped 1 week prior to patch tests. On the day of patch testing, no ointments at all should be applied. Antihistamines, beta-adrenergics, and xanthins do not influence patch test reactions. Strong UV radiation should be avoided 4 weeks prior to testing.

Even if carefully performed and read, the reproducibility of patch test reactions (especially of weakly positive reactions) remains unsatisfactory in some cases $[23,25,55]$. Unfortunately, there is no routine in vitro test for type IV allergies!

Positive patch test reactions should be evaluated regarding their relevance for the disease.
This requires a high degree of expertise on the part of the physician and cooperation from the patient. Nevertheless, some test reactions remain unexplained when the substance is ubiquitous or when the occurrence is unrecognized.

In unclear cases, an epidermal provocation test (repeated open application test $=$ ROAT) is used [32]: the substance suspected (e.g., cosmetic) is applied twice daily over 7 days into the elbow flexure, the volar forearm or the cheek. The open application avoids the risk of falsepositive reactions.

When there are more than five positive test reactions - except group allergies - "angry back syndrome" should be suspected (see above). Substances should be retested in single small groups, especially in forensic, occupational situations or if lifesaving drugs are concerned $[8,59]$.

The selection of substances to be tested follows a careful history. There are standard selections through national or international contact dermatitis research groups (ICDRG) and additional specific "blocks" for special situations (occupation, localization, etc.) $[4,5,8,10,18$, $22,23,52,55,59]$.

Only clear-cut positive and well-defined allergens (no ointment mixtures!) should be documented in the allergy passport! Weakly positive or possibly irritative or "angry back"-induced test results should not be included because of potential lifelong and forensic consequences [8]. However, they should be recorded in the files.

Particular problems occur with questionable allergies against dental prosthetic materials where often psychosomatic influences play a role or against metal implant materials after orthopedic surgery (often positive nickel patch test reactions are not relevant for the implanted material situation) as well as against cosmetics due to the high number of possible substances (Table 5.57). Most common elicitors of cosmetic incompatibility are (in decreasing sequence): facial creams, antiperspirants/deodorants, eye make-up, nail cosmetics, hair colorings, soap [45]. The testing of individual products is crucial (Table 5.58). For the evaluation of positive patch test reactions, adequate controls are required. 
Table 5.57. Possible ingredients of a simple "moisturizer cream" (BHA, butylhydroxyanisol)

\begin{tabular}{llc} 
Ingredient & Examples & $\begin{array}{c}\text { Possible number } \\
\text { of substances }\end{array}$ \\
\hline Fat & Lanolin, paraffin & 500 \\
Polyalcohol & PEG & 20 \\
Emulsifier & Tween & 1,000 \\
Solvent & Alcohol, acetone & 30 \\
Thickening & Starch, traganth & 30 \\
"Moisturizer" & Mannit, inositol & 50 \\
Color & Azo dyes, pigments & 500 \\
Preservatives & Benzylalcohol, formaldehyde & 150 \\
Antioxidants & Tocopherol, BHA & 40 \\
Fragrance & Citronellal, eugenol & 3,500 \\
Sum & & $\sim 6,000$ \\
\hline
\end{tabular}

Table 5.58. Recommended concentrations for patch testing of patient's cosmetics

\begin{tabular}{ll}
\hline Cream & Undiluted \\
Make-up & Undiluted \\
Mascara & Undiluted \\
Mascara (dry) & Undiluted \\
Lipstick & Undiluted \\
Perfume & $20-100 \%$ \\
Deodorant & $20-100 \%$ \\
Hairspray & $20 \%$ \\
Hair coloring & $10 \%$ \\
Hair bleaching & $20 \%$ (separated!) \\
Nail polish & $10 \%$ \\
Cold perm materials & $2 \%$ \\
Toothpaste & $2 \%$ \\
Soap & $1 \%$ \\
Shampoo & $1 \%$ \\
\hline
\end{tabular}

\subsubsection{Therapy}

Acute dermatitis is treated with moist cooling wraps, lotio alba and short-term topical glucocorticosteroids. For long-term success, allergen avoidance is crucial. Contact sensitization is lifelong in most cases.

Attempts to perform specific hyposensitization against contact allergens have been published (e.g., by oral administration) without convincing success for the clinical routine. Nevertheless, in many cases "hardening" occurs together with adequate skin care. Chronic forms of dermatitis with hyperkeratotic skin lesions require the use of keratolytics prior to glucocorticosteroids. They may be very therapy resistant. In severe cases of, e.g., dyshidrotic dermatitis, PUVA (psoralen plus UVA) therapy may be helpful.

The use of new topical immunosuppressants (tacrolimus or pimecrolimus) in these cases may be helpful.

\section{References}

1. Ackermann AB, Ragaz A (1982) A plea to expunge the word eczema from the lexicon of dermatology and dermatopathology. Am J Dermatopathol 4:315-326

2. Aetius von Amida (1549) Tetrabiblos (V.4, Sermo 1, Kap. 128). Froben, Basel, p 730

3. Akdis M, Klunker S, Schliz M, Blaser K, Akdis CA (2000) Expression cutaneous lymphocyte-associated antigen on human $\mathrm{CD} 4^{+}$and $\mathrm{DC} 8^{+} \mathrm{Th} 2$ cells. Eur J Immunol 30:3533 - 3541

4. Bandmann HJ, Dohn W (1967) Die Epicutantestung, 2nd edn. Bergmann, Munich

5. Benezra C (1986) Molecular recognition in allergic contact dermatitis. In: Ring J, Burg G (eds) New trends in allergy II. Springer, Berlin Heidelberg New York, pp 218-224

6. Bergstresser PR, Tigelaar RE, Dees JH, Streilein JW (1983) Thy-1 antigen-bearing dendritic cells populate murine epidermis. J Invest Dermatol 81:286

7. Bloch I (1911) Der älteste Gebrauch des Wortes "Eczema". Mh Prakt Dermatol 53:69-71

8. Borelli S (1980) Gewerbedermatosen, einschließlich Begutachtung. In: Korting GW (ed) Dermatologie in Praxis und Klinik, vol II. Thieme, Stuttgart

9. Braathen LR, Thorsby E (1983) Human epidermal Langerhans cells are more potent than blood monocytes in inducing some antigen-specific $\mathrm{T}$ cell-responses. Br J Dermatol 108:139- 146

10. Brasch J, Geier J, Schnuch A (1998) Differenzierte Kontaktallergenlisten dienen der Qualitätsverbesserung. Hautarzt 49:184-191

11. Burg G, Przybilla B, Bogner J (1986) Contact - allergy time. In: Ring J, Burg G (eds) New trends in allergy II. Springer, Berlin Heidelberg New York, pp 230-239

12. Bruynzeel DP (1983) Angry back or excited skin syndrome. Thesis, Amsterdam

13. Cavani A, Albanesi C, Traidl C, Sebastiani S, Girolomoni $G$ (2001) Effector and regulatory T cells in allergic contact dermatitis. Trends Immunol 22: $118-120$ 
14. Chase MW (1946) Inhibition of experimental drug allergy by prior feeding of the sensitizing agent. Proc Soc Exp Biol Med 61:257-259

15. Cronin E (1980) Contact dermatitis. Churchill Livingstone, Edinburgh

16. De Groot AC (1994) Patch testing. Elsevier, Amsterdam

17. Diepgen TL, Coenraads PJ (1999) The epidemiology of occupational contact dermatitis. Int Arch Occup Environ Health 72:496-506

18. Enders F, Przybilla B, Ring J (1988) Epikutantest mit einer Standardreihe. Ergebnisse bei 12026 Patienten. Hautarzt 39:779-786

19. Enk AH, Angeloni VL, Udey MC, Katz SI (1993) An essential role for Langerhans cell-derived IL$1 \beta$ in the initiation of primary immune responses in skin. J Immunol 150:3698-3703

20. Faergemann J (1993) Pityrosporum ovale-assoziierte Dermatosen. In: Braun-Falco O, Plewig GK, Meurer M (eds) Fortschritte prakt. Derm Venereol, vol 14. Springer, Berlin Heidelberg New York, pp 234-237

21. Fischer T, Bellberg K, Bruynzeel DP, Ducombs G, Hannuksela M, Lachapelle IM, Ring J, White IR, Wilkinson J (1988) European multicenter study of TRUE test. Contact Dermatol 19:91 - 97

22. Foussereau J, Benezra C, Maibach HI (1982) Occupational contact dermatitis, clinical and chemical aspects. Munksgaard, Copenhagen

23. Frosch P, Rustemeyer T, Schnuch A (1996) Kontaktdermatitis, parts I and II. Hautarzt 47:874882, 945-961

24. Fuchs T, Aberer W (eds) (2004) Kontakteczema. Dustri, Deisenhofen (in press)

25. Gollhausen R, Ring J, Przybilla B (1987) Der iterative Test zur Unterscheidung kontaktallergischer oder irritativer Epikutantestreaktionen. Allergologie 10:427

26. Grabbe S, Kämpgen E, Schuler G (2000) Dentritic cells: multi-lineal and multi-functional. Immunol Today 21:431-433

27. Granstein RD, Askari M (1986) Cutaneous cells in activation of immunologic reactions: further characterization. J Invest Dermatol 87:141

28. Halter S (1959) Das vulgäre Eczema. In: Gottron A, Schönfeld W (eds) Dermatologie und Venerologie, vol III/1. Thieme, Stuttgart

29. Happle R (1994) Paraptisches Eczema. Hautarzt $45: 1-3$

30. Hausen B, Vieluf I (1998) Allergie-Pflanzen. Pflanzen-Allergene. Ecomed, Landsberg

31. Hornstein OP (1986) Anmerkungen und Vorschläge zur Definition und Klassifikation der Eczemakrankheiten. Z Hautkr 61:1281 - 1296

32. Hannuksela M, Salo H (1986) The repeated open application test (ROAT). Contact Dermatol 14: $211-227$

33. Jadassohn J (1895) Verhandl Dtsch Derm Gesellschaft 5. Kongreß 1896, p 103

34. Kapsenberg ML, Bos JD, Wierenga EA (1992)
Cells in allergic responses to haptens and proteins. Springer Semin Immunopathol 13:303 - 314

35. Klaschka F (1987) Hämatogenes Kontakteczema durch Nahrungsmittel. Allergologie 10:93-97

36. Knop J, Malorny U, Macher E (1984) Induction of $\mathrm{T}$ effector and $\mathrm{T}$ suppressor lymphocytes in vitro by haptenized bone marrow-derived macrophages. Cell Immunol 88:411 - 420

37. Kripke ML, Munn CG, Jeevan A, Tang MM, Bucana C (1990) Evidence that cutaneous antigen-presenting cells migrate to regional lymph nodes during contact sensitization. J Immunol 145: $2833-2842$

38. Langerhans $P$ (1868) Über die Nerven der menschlichen Haut. Virchows Arch A (Path Anat) 44:325

39. Lepoittevin J-P, Benezra C, Sigman CC, Baheri D, Fraginals R, Maibach HI (1995) Molecular aspects of allergic contact dermatitis. In: Rycroft RJG, Menné T, Frosch P (eds) Textbook of contact dermatitis. Springer, Berlin Heidelberg New York, pp 105-119

40. Luderschmidt C, Heilgemair G, Ring J, Burg G (1982) Polyvalente Kontaktallergie versus "Angry-back-Syndrom”. Allergologie 5:262-268

41. Magnussen B, Kligman AM (1977) Usefulness of guinea pig tests for detection of contact sensitizers. In: Marzulli FN, Maibach HI (eds) Dermatotoxicology and pharmacology. Wiley, London, pp $551-560$

42. Maibach HI (1981) The ESS, excited-skin-syndrome (alias the "angry-back"). In: Ring J, Burg G (eds) New trends in allergy. Springer, Berlin Heidelberg New York, pp 206-216

43. Miescher G (1962) In: Marchionini A (ed) Handbuch der Haut- und Geschlechtskrankheiten, supplementary vol 11/1. Springer, Berlin Heidelberg New York, p 1

44. Mitchell JC (1975) The angry back syndrome: eczema creates eczema. Contact Dermatol 1: $193-194$

45. Nater JP, De Groot AC (1983) Unwanted effects of cosmetics and drugs used in dermatology, 2nd edn. Elsevier, Amsterdam

46. Odia S, Vocks E, Rakoski J, Ring J (1996) Successful treatment of dyshidrotic hand eczema using tap water iontophoresis with pulsed direct current. Acta Derm Venereol 76:472-474

47. Rietschel RL, Fouler JF (2001) Fisher's contact dermatitis, 5th edn. Lippincott-Williams, Philadelphia

48. Ring J (ed) (1990) Endogenous and exogenous eczema. Semin Dermatol 9:195-246

49. Ring J ((1996) Zum Wandel des Eczema-Begreiffes: Klassisches versus atopisches Eczema. Z Hautkr 10:752 - 756

50. Römpp H (1982) Chemielexikon, 8th edn. Franckh'sche Verlagshandlung, Stuttgart

51. Ross R, Gillitzer R, Kleinz J, Schwing H, Kleinert U, Förstermann AB, Reske-Kunz (1998) Involve- 
ment of NO in contact hypersensitivity. Int Immunol 10:61-69

52. Rycroft RJG, Menné T, Frosch P (eds) (1995) Textbook of contact dermatitis. Springer, Berlin Heidelberg New York

53. Schäfer T, Böhler E, Ruhdorfer S, Weigl L, Wessner D, Filipiak B, Wichmann HE, Ring J (2004) Epidemiology of contact allergy in adults. Allergy (in press)

54. Schnuch A, Geier J, Uter W, et al. (1997) National rates and regional differences in sensitization to allergens of the standard series. Contact Dermatitis 37:200-209

55. Schnuch A, Aberer W, Agathos M, Brasch J, Frosch PJ, Fuchs T, Richter G (2001) Leitlinien der Deutschen Dermatologischen Gesellschaft (DDG) zur Durchführung des Epikutantests mit Kontaktallergenen. Hautarzt 52:864-866

56. Schulz KH, Fuchs T (1993) Der Epikutantest. Manuale allergologicum, IV, 4. Dustri, Deisenhofen, pp 1-39

57. Schuler G, Steinman RM (1985) Murine epidermal Langerhans cells mature into potent immuno-stimulatory dendritic cells in vitro. J Exp Med 161:526-546

58. Schwanitz HJ (1986) Das atopische Palmoplantareczema. Springer, Berlin Heidelberg New York

\subsubsection{Atopic Eczema}

Atopic eczema is one of the most common inflammatory skin diseases (found in $9-20 \%$ of German children!) with a chronic or relapsing course, and strong itching [20, 21, 30, 36, 40, 48, $49,64,68$ ]. The multitude of names ("atopic dermatitis," "neurodermitis diffusa," "neurodermitis constitutionalis," "neurodermitis atopica," "prurigo Besnier," "endogenous eczema," "neurodermatitis," etc.) reflects the various pathophysiological concepts $[5,10,20,27,40$, $48,49,65,68]$. We prefer the term "atopic eczema" (or "atopic dermatitis") since it implies neither pathomechanisms (e.g., neurologic abnormalities) nor routes of contact (exogenous or endogenous), but focuses on the familial atopic trait.

\subsubsection{Clinical Manifestation}

Atopic eczema most often starts in childhood or adolescence; sometimes the first manifestation is cradle cap in infants (also called "crusta lactea" because of its similarity with burnt milk in a pan); it affects the face and extensor sur-
59. Schwanitz HJ, Szliska C (eds) (2001) Berufsdermatosen. Dustri, Munich

60. Scott P (1993) IL-12: initiation cytokine for cellmediated immunity. Science 260:496-497

61. Silberberg I, Baer RI, Rosenthal SA (1974) The role of Langerhans cells in contact allergy. I. An ultrastructural study in actively induced contact dermatitis in guinea pigs. Acta Derm Venereol (Stockh) 54:321-331

62. Stingl G (1980) New aspects of Langerhans cell function. Int J Dermatol 19:189

63. Török I (1989) Eczema s betegsegek. Medicina, Budapest

64. Traidl C, Merk HF, Cavani A, Hunzelmann N (2000) New insights into the pathomechanisms of contact dermatitis by the use of transgenic mouse models. Skin Pharmacol Appl Skin Physiol 13:300-312

65. Unna PG (1887) Seborrhoeal eczema. J Cutan GU Dis 5:449-459

66. Uter W, Schnuch A, Geier J, et al. (1998) Epidemiology of contact dermatitis. The information network of Department of Dermatology (IVDK) in Germany. Eur J Dermatol 8:36-40

67. Willan (1808) On cutaneous diseases. Johnson, London

faces of infants, while later the large flexures, hands, and neck are most commonly involved. The eczema becomes drier with increasing age, the skin shows lichenification, and in adulthood excoriated nodules (prurigo-like) (Figs. 5.43-5.51) are common [30, 50]. Unfortunately, atopic eczema - contrary to common opinion - does not clear regularly before puberty, but two-thirds of affected children will also suffer from the disease as adults [26] (Fig. 5.52). Atopic eczema may also first appear in adulthood, sometimes even in elderly persons.

Atopic eczema occurs with so-called "stigmata" or "minimal variants" [30, 33, 38, 49, 52] (Table 5.59, Figs. 5.53, 5.54). There is still controversy regarding the primary skin lesion, which is described as erythema, flush, papule, seropapule, or vesicle. In the tradition of St. John or J.W. von Goethe and together with the French school [5], we say: "In the beginning there was the itch." In many cases all skin lesions can be explained as secondary reactions to the itch. In children undergoing oral provocation, I have often observed that they com- 

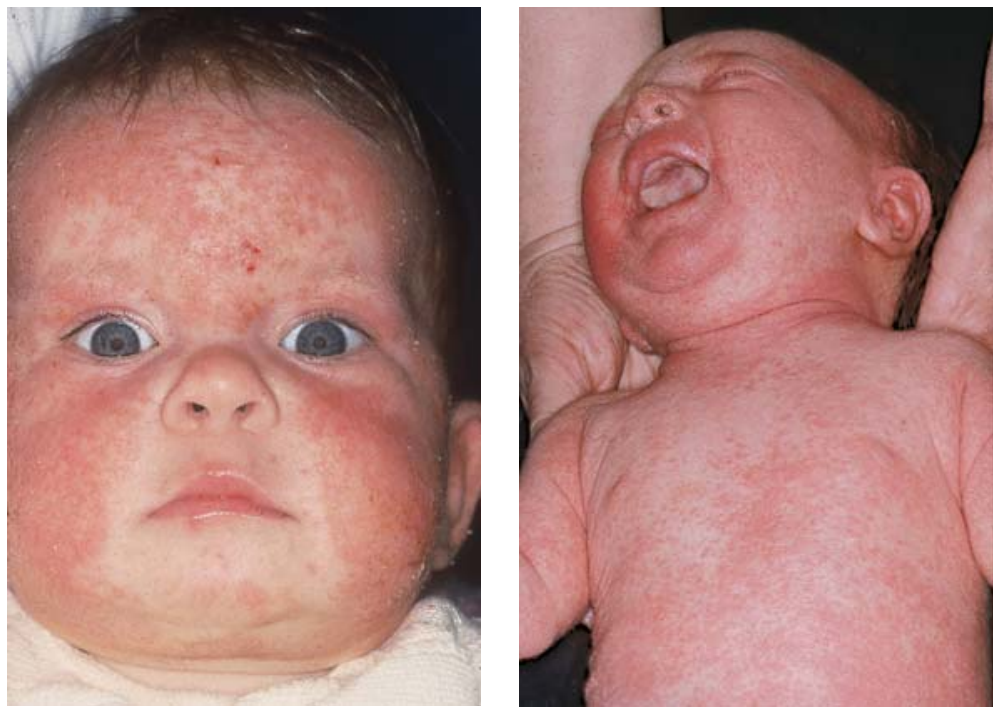

Fig. 5.43. (left) Atopic eczema in an infant (“cradle cap")

Fig. 5.44 (right). Atopic eczema in a newborn
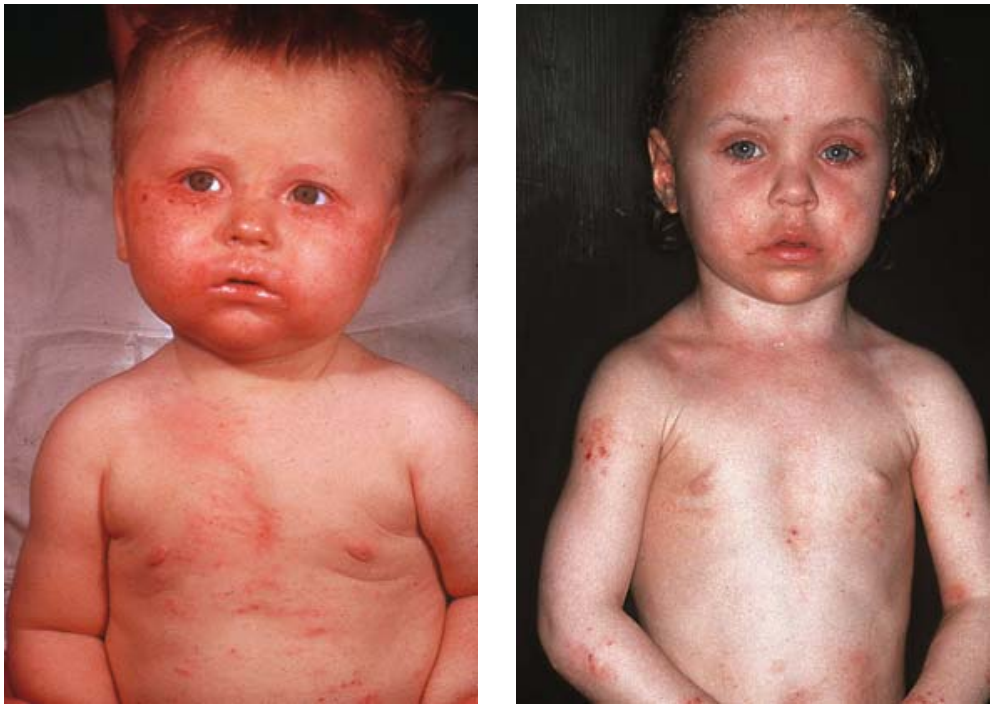

Fig. 5.45. (left) Atopic eczema in an older baby

Fig. 5.46. (right) Atopic eczema in a toddler

Table 5.59. Stigmata of atopic eczema

Sebostasis (dry skin)
Ichthyotic palms/soles
Linear grooves on the fingertips
Atopy lid fold (Dennie-Morgan)
Rarefication of lateral parts of eyebrows (Hertoghe)
Cap-like temporal hair growth (small distance
between lateral eyebrow and temporal scalp hair)
Facial pallor with periorbital halo
White dermographism
Delayed blanch after acetylcholine

plain about itching without any visible skin lesion and start scratching, and only 15-20 min later do eczematous changes occur. For the diagnosis of atopic eczema, classically the criteria of Hanifin and Rajka [21] (Table 5.60) are cited, but are rarely used in practice. 
Fig. 5.47. (left) Itching as the primary symptom of atopic eczema

Fig. 5.48. (right) Atopic eczema on dark skin
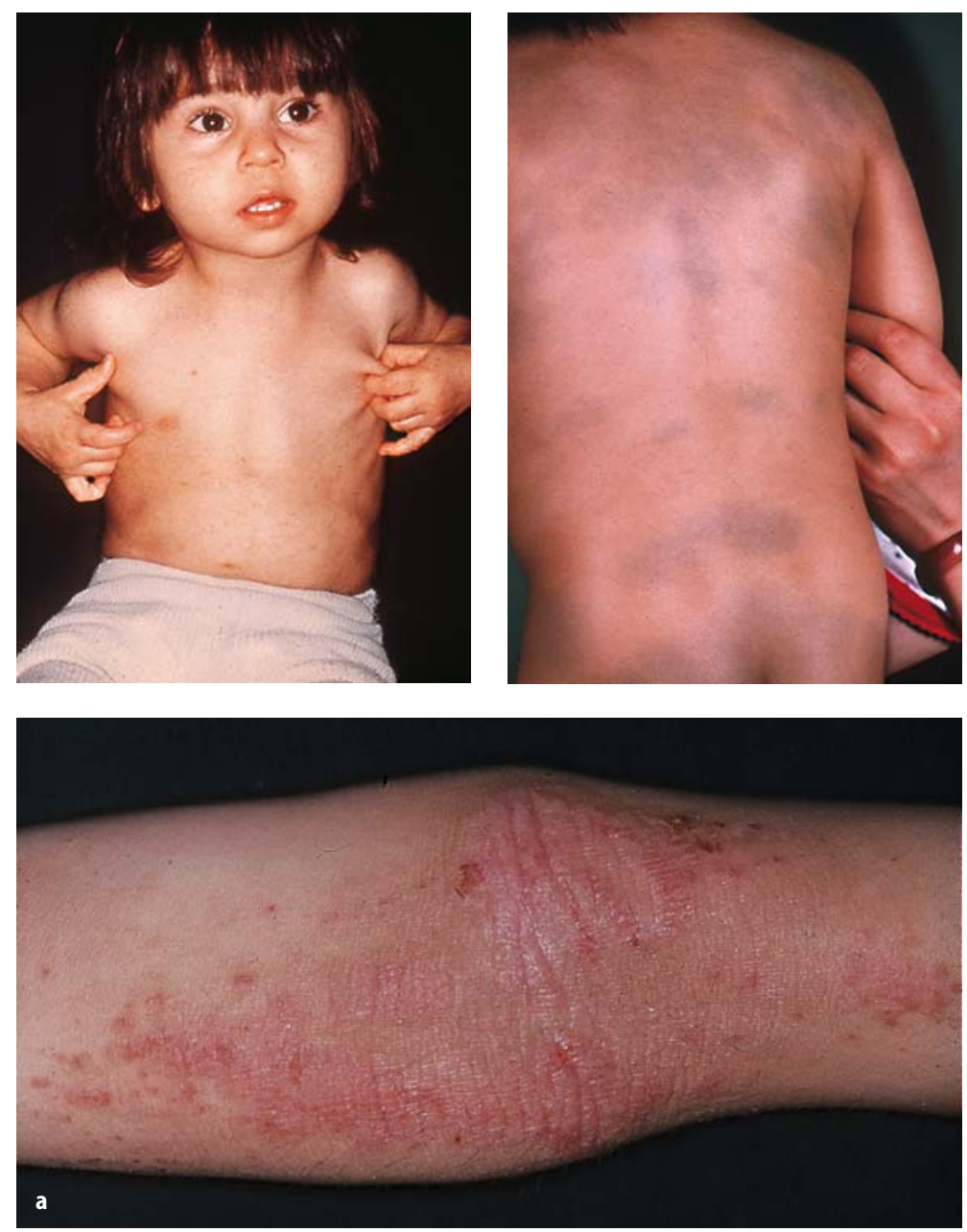

Fig. 49a,b. Elbow eczema

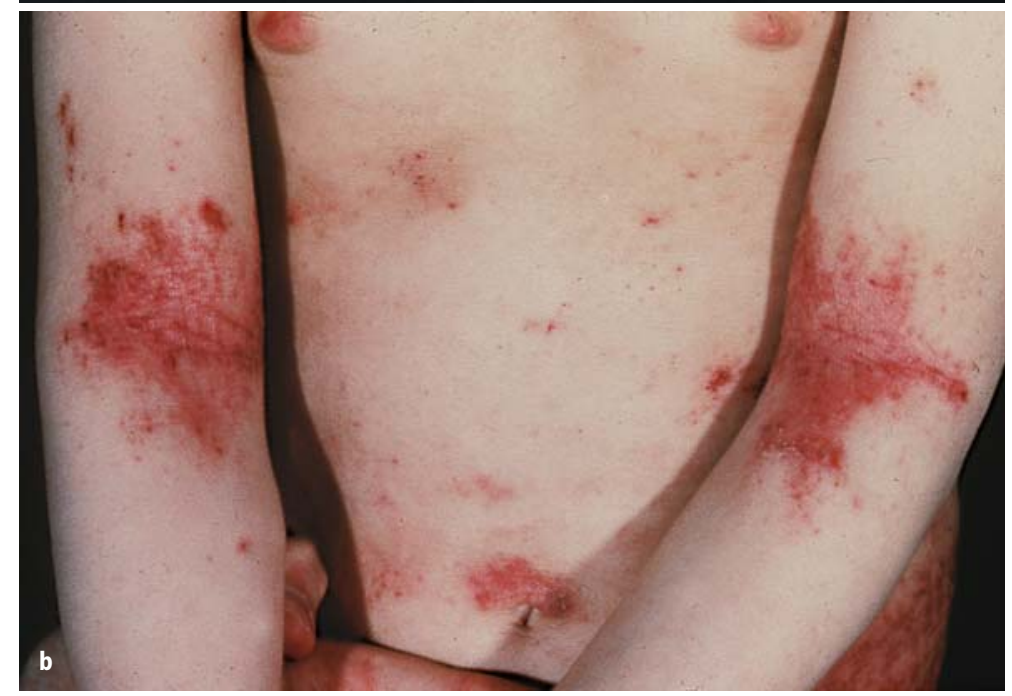



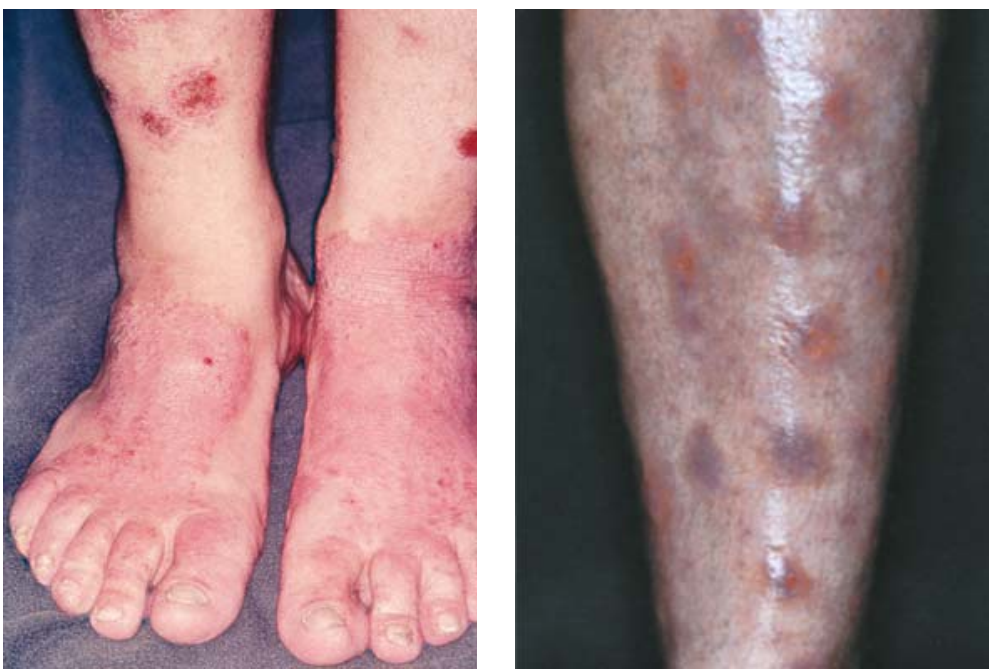

Fig. 5.50. (left) Atopic eczema on the lower legs and feet

Fig. 5.51. (right) Prurigo form of atopic eczema

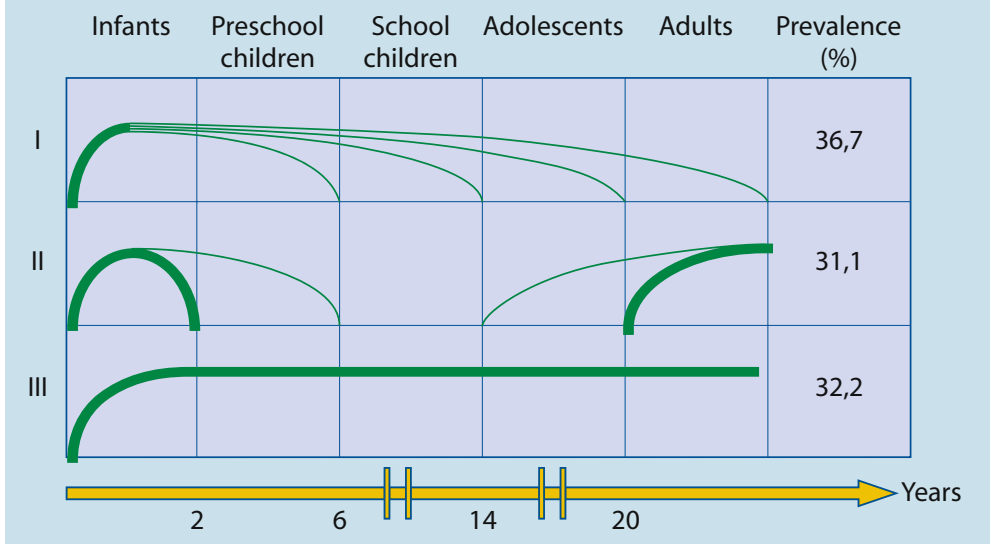

Fig. 5.52. Occurrence and course of atopic eczema at different ages (modified according to [26])

Table 5.60. Diagnosis of atopic eczema: criteria of Hanifin and Rajka [21] (three major and minor criteria each have to be positive)

\begin{tabular}{|c|c|}
\hline $\begin{array}{l}\text { Major } \\
\text { criteria }\end{array}$ & $\begin{array}{l}\text { Itch } \\
\text { Typical morphology and distribution } \\
\text { (lichenification in flexures of adults, } \\
\text { face and extensor surfaces of children) } \\
\text { Chronic relapsing eczema } \\
\text { Personal and family history of atopy }\end{array}$ \\
\hline $\begin{array}{l}\text { Minor } \\
\text { criteria }\end{array}$ & $\begin{array}{l}\text { Sebostasis } \\
\text { Ichthyosis } \\
\text { Ichthyotic palm/sole } \\
\text { Keratosis follicularis } \\
\text { Type I sensitization (prick test) } \\
\text { Elevated total serum IgE } \\
\text { Early onset of disease } \\
\text { Tendency to cutaneous infections } \\
\text { (Staph. aureus, HSV) } \\
\text { Tendency to unspecific hand and foot } \\
\text { eczema }\end{array}$ \\
\hline
\end{tabular}

\begin{tabular}{ll}
\hline $\begin{array}{l}\text { Minor } \\
\text { criteria }\end{array}$ & Mamillar eczema \\
(cont.) & Relapsing conjunctivitis \\
& Dennie-Morgan fold \\
& Keratoconus \\
& Subcapsular cataract \\
& Periocular halo \\
& Facial pallor \\
& Facial erythema \\
& Pityriasis alba \\
& Folding in the neck \\
& Itch when sweating \\
& Wool and solvent incompatibility \\
& Perifollicular accentuation \\
& Adverse food reactions \\
& Dependence of environmental and \\
& psychological factors \\
& White dermographism \\
&
\end{tabular}


Fig. 5.53. Ichthyosis hands as a stigma of atopic eczema
Fig. 5.54. Atopic "winter feet"
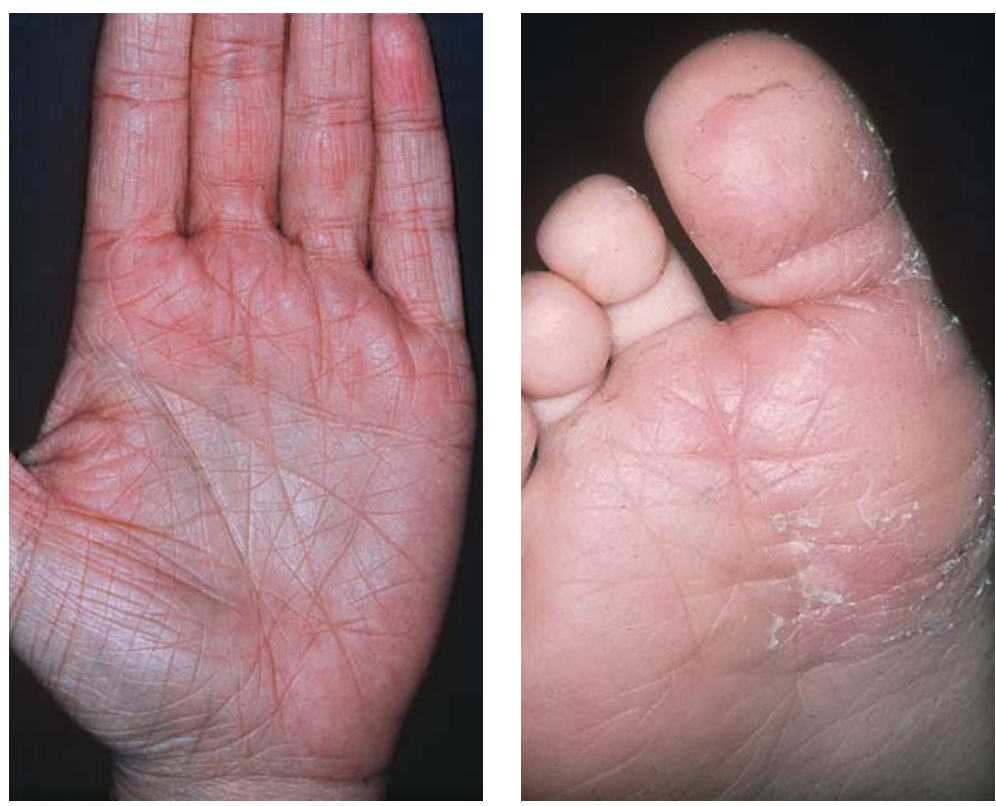

Table 5.61. Atopic eczema: diagnostic criteria (Ring 1982). With four or more positive findings, the diagnosis "atopic eczema" can be made (note that by this criterion, the diagnosis "atopic eczema" is possible without history or laboratory tests for atopy)

Eczema morphology (age-dependent)

Itch

Typical localization (age-dependent)

Atopy stigmata

Atopy in personal or family history

IgE sensitization

Table 5.61 shows our diagnostic criteria from 1982: with four out of six positive parameters, the diagnosis atopic eczema can be made. Similarly in the 1990s, the "UK-refined criteria" [64] or the "Millennium criteria" [9] were developed.

Particular manifestations of eczema comprise so-called "sandbox dermatitis," "atopic winter feet," and "patchy lichenoid infiltrates" of Kitamura-Zazagawa-Takahashi and others $[20,22,30,38,48,49]$, some of them also included under minimal variants (for instance, infra-auricular fissures). For the determination of severity of actual eczematous skin lesions, the SCORAD (scoring system atopic dermatitis), developed by the European Task Force
Table 5.62. Dermatohistopathology in atopic eczema

\section{Acute}

Acanthosis, hyperkeratosis, parakeratosis

Spongiosis, exocytosis, mild dermal lymphohistocytic infiltrate

\section{Chronic-lichenified}

Acanthosis, enlarged rete ridges, hyperkeratosis, parakeratosis, dense dermal infiltrate (mononuclear cells), increased mast cells, increase in capillaries and thickening of capillary walls, endothelial cell hyperplasia, fibrosis

Atopic Dermatitis ETFAD [71], has proven valuable (Fig. 5.55).

In dermatohistology, patterns differ between acute and chronically lichenified lesions (Table 5.62) [59].

\subsection{Genetics}

Atopic eczema, allergic bronchial asthma, and allergic rhinoconjunctivitis are genetically closely linked [52]. Sixty percent of patients with eczema have other atopic diseases in their family history. The concordance rate of homozygous twins is $85 \%$ compared to $30 \%$ in heterozygous twins [54]. Inheritance is multifactorial: $\operatorname{IgE}$ formation in general (total $\operatorname{IgE}$ ), the 
Patient: Name/Vorname

Eingesetztes topisches Steroid

Wirkstoff (Handelsname, Konzentration)

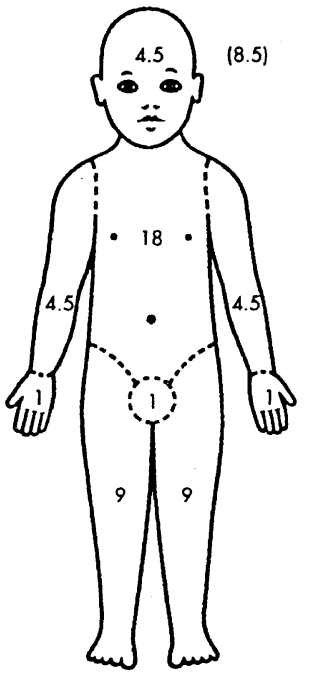

Geburtsdatum

(g)

Menge/Monat

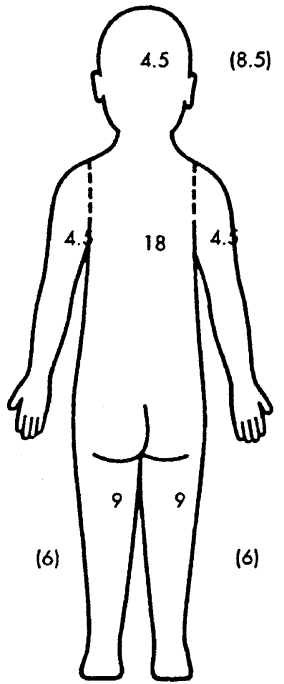

\section{A: AusmaB}

Ziffern in Klammern für Kinder unter 2 Jahren

Besuchsdatum

Anzahl der Erytheme/Monat

Bitte geben Sie die Summe der betroffenen Hautareale an.

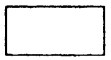

\section{B: Intensitäł}

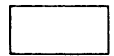

\section{Bemessungswerte}

Angaben zur Intensität (üblicherweise typische Stellen)

Kriterien

Intensität

$0=$ keine

$1=$ leicht

$2=m a ̈ ß i g$

$3=$ stark

Erythem

Kriterien

Intensität

Ödem/Papelbildung

Exkoriation

Lichenifikation

Nässen/Krustenbildung

Trockenheit

\section{C: Subjektive Symptome}

Die Hauttrockenheit wird an nicht betroffenen Stellen bewertet

\section{Pruritus und Schlaflosigkeit}

Visuelle Analog-Skala (Durchschnitt für die letzten drei Tage oder Nächte)

SCORAD A $/ 5+7 B / 2+C$

Pruritus (0-10)

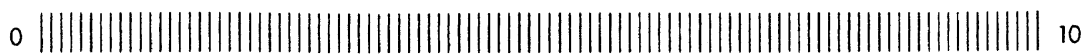

Schlaflosigkeit (0-10)

Behandlung

Anmerkungen

Fig. 5.55. SCORAD (scoring for atopic dermatitis) index for assessing the severity of eczema 
specificity of IgE antibodies and organ manifestations are influenced separately (see Sect. 3.1). There is no significant association between the diagnosis "atopic eczema" and HLA haplotypes [15].

\subsubsection{Pathophysiology}

\subsection{Genetics}

Recently, a close link of infantile atopic eczema with a gene on chromosome 3 q21 was reported [31]. A second genome screen revealed an association with loci on chromosomes 1q21, 17q25, and $20 \mathrm{p}$ [15]. While the genes for the costimulatory $\mathrm{CD} 80 / 86$ molecules are found in the region of chromosome 3q21, the other loci do not reveal known relations to atopy. It is interesting that all four gene loci are also linked to psoriasis [15]. It may be speculated that these genes encode for general markers of skin inflammation independent of "atopy."

\subsection{Increased IgE Production}

Few diseases are characterized by elevated IgE values in the serum similarly to atopic eczema $[36,40,42,48,49,68]$. These IgE antibodies are directed against environmental allergens, in central Europe in adults most commonly against cat epithelia, housedust mite, and grass pollen, in infants against hen's eggs and cow's milk. The evaluation of the relevance of IgE sensitization for the induction or elicitation of eczema may be difficult. It is achieved by careful history and provocation tests. The detection of IgE and IgEreceptors on epidermal Langerhans cells (Fig. $5.56)[6,12,55,66]$ opens new perspectives for an understanding of the pathogenesis of atopic eczema (Table 5.63). Positive epidermal test reactions induced by typical aeroallergens (e.g., housedust mites) help to show the relevance of an IgE response for the eczematous skin lesions ("atopy patch test," APT) [16, 46] (Fig. 5.57). Compared to the prick test and RAST, the APT has a much higher specificity (Table 5.64).

There is no doubt that for a large group of eczema patients, IgE-mediated allergy plays a decisive role in the disease ("extrinsic" form). There are, however, (as in respiratory atopy) patients without IgE elevation or positive prick
Table 5.63. Langerhans cells, IgE and atopic eczema

IgE on Langerhans cells
IgE receptors [low- and high-affinity (CD23 and
FceR I) as well as IgE-binding protein]
Housedust mite allergen (Der p 1) next to IgE in
doublestaining on Langerhans cell surface
Langerhans cells may present allergen via IgE
T-cell clones from atopy patch test reactions show
TH2 characteristics and allergen specificity
Particularly increased expression of FceR I in atop-
ic eczema in lesional skin (contrary to contact der-
matitis and other inflammatory skin diseases)

Table 5.64. Comparison of different allergy tests in atopic eczema (Darsow et al. [16])

\begin{tabular}{lll} 
Test & Sensitivity $^{\mathrm{a}}$ & Specificity \\
\hline Skin prick test & $69-82 \%$ & $44-53 \%$ \\
RAST & $65-94 \%$ & $42-64 \%$ \\
Atopy patch test & $42-56 \%$ & $69-92 \%$ \\
\hline
\end{tabular}

a Allergen-dependent (related to specific history)

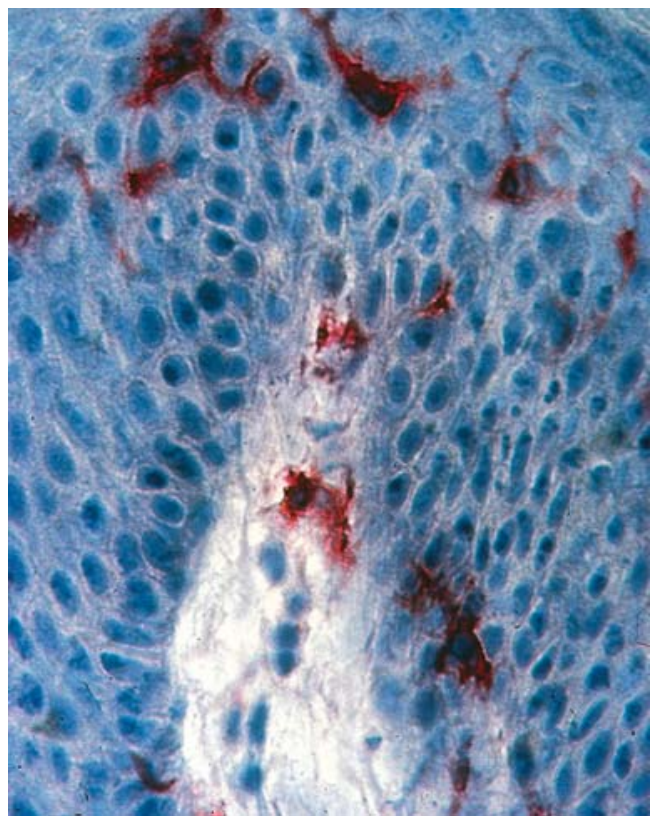

Fig. 5.56. IgE-positive Langerhans cells (reprinted by permission of T. Bieber)

test reactions ("intrinsic" form or "non-atopic" eczema) [69].

Recently, in very severe cases of atopic eczema, autoantibodies of IgE class against epider- 


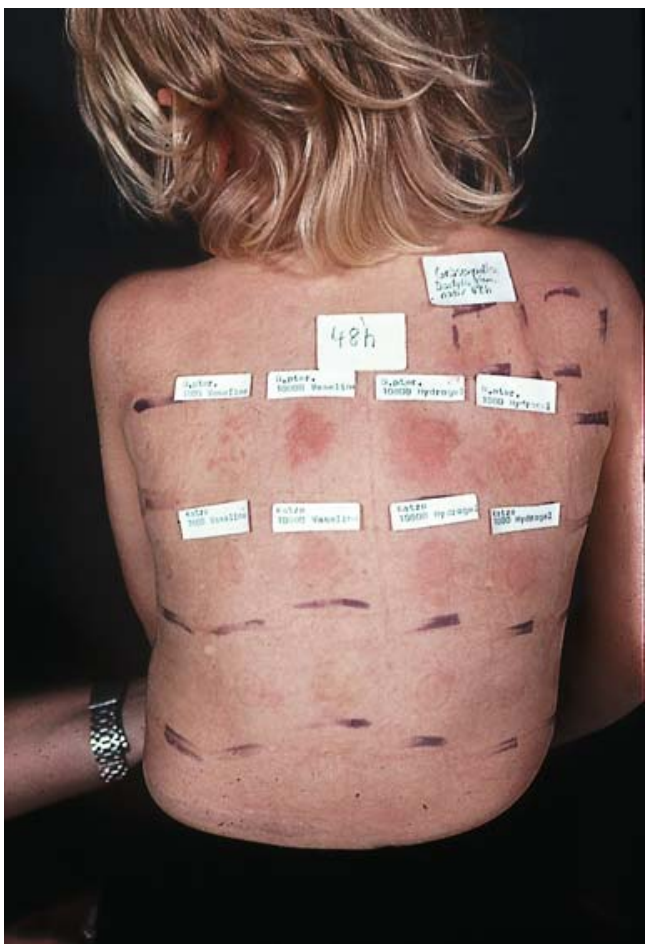

Fig. 5.57. Atopy patch test (APT)

mal proteins (Hom s 1) have been detected [60]; we see an increasing dynamic of eczema elicitation and maintenance via TH2 over TH1 to IgE autoantibodies, explaining the phenomena of chronification and resistance to therapy.

\subsection{Disturbed T-Cell Regulation}

Patients with eczema are often suffering from infections of fungal, bacterial, or viral origin (e.g., Kaposi's varicelliform eruption, or eczema herpeticum as well as increased staphylococcal colonization and infection of the skin; Fig. 5.58). Increased $\mathrm{TH} 2$ reaction occurs with decreased TH1 phenomena [14, 25, 53], which are most prominent in the so-called "hyper-IgE syndrome," which in its dermatological manifestation may be regarded as a maximal variant of atopic eczema [49].

Recent phenomena of spongiosis have been elucidated: activated CLA-positive T cells in the skin secrete beside other cytokines Fas-ligand, leading to apoptosis of keratinocytes and

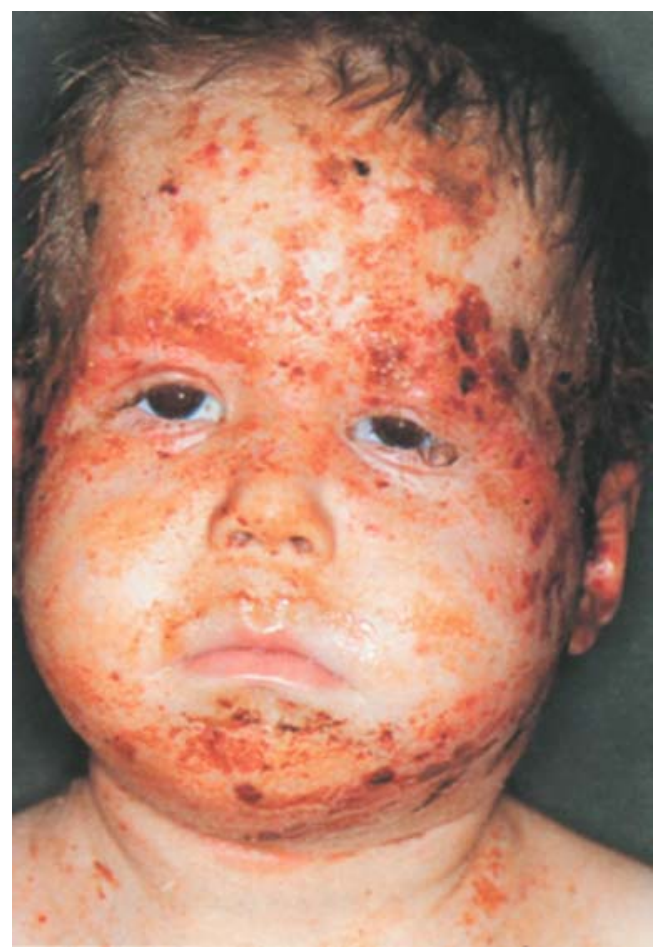

Fig. 5.58. Atopic eczema with massive superinfection by Staphylococcus aureus

breaking up of intercellular E-cadherin junctions, while desmosomes stay intact and the inflammatory edema induces the picture of spongiosis $[3,58]$.

\subsection{Autonomic Nervous System Dysregulation}

Many patients show a dysbalance in autonomic nervous system reactivity [27], mostly in the sense of decreased $\beta$-adrenergic and increased $\alpha$-adrenergic and cholinergic reactivity $[3,42]$ (see also "Stigmata"). In a Japanese study, patients with atopic eczema less frequently had hypertension than normals [Uehara, personal communication).

The imbalance of enhancing and inhibitory influences on mediator secretion can lead to an increased releasability of mediator secreting cells in atopic eczema. Patients with atopic eczema have increased plasma histamine levels as well as enhanced releasability of other mediators (e.g., leukotriene) [44]. These mediators 
not only have proinflammatory activity, but also - as histamine via histamine receptors on lymphocytes - regulatory effects in the immune response (see also Chap. 2), thus favoring IgE production and promoting a "circulus vitiosus" [42].

The well-known psychosomatic interactions fit into this concept very well $[10,18,45]$. Psychologic events may influence the disease positively and negatively through the action of nervous transmitters. In stress or anxiety, the same mediators are liberated as during itch or allergic inflammation (see Chap. 7, "Psyche and Allergy").

\subsection{Dry Skin}

The phenomenon of "dry skin" is complex in nature $[7,10,11,23]$ and describes at least three different dimensions ("rough" versus "smooth"; "fat" versus "lipid-poor"; "moist" versus "waterpoor"); it can be better described as a barrier disturbance of the epidermis. In eczema, the following findings have been shown:

- Stratum corneum water content is not
decreased
- Transepidermal water loss is increased
- Epidermal permeability is increased
- Skin roughness is increased
- Surface lipids are decreased
- Sebaceous glands are smaller
- Microscopically inflammatory reactions

Therefore, some authors regard "dryness" as a minimal inflammatory reaction [59] with the involvement of keratinocytes [19].

Previously, dryness was interpreted as decreased sebaceous gland activity ("sebostasis"); today alterations in intercellular lipid bilayer are seen as the basis of the epidermal barrier (the "bricks and mortar" model according to P. Elias). The chemical basis is a mixture of ceramides, which are decreased in atopic eczema and possibly qualitatively altered [7]. Ceramide synthesis follows a subtle balance of different enzymes such as sphingomyelinase, $\beta$ glucocerebrosidase, ceramidase, and sphingomyelindeacylase [23].

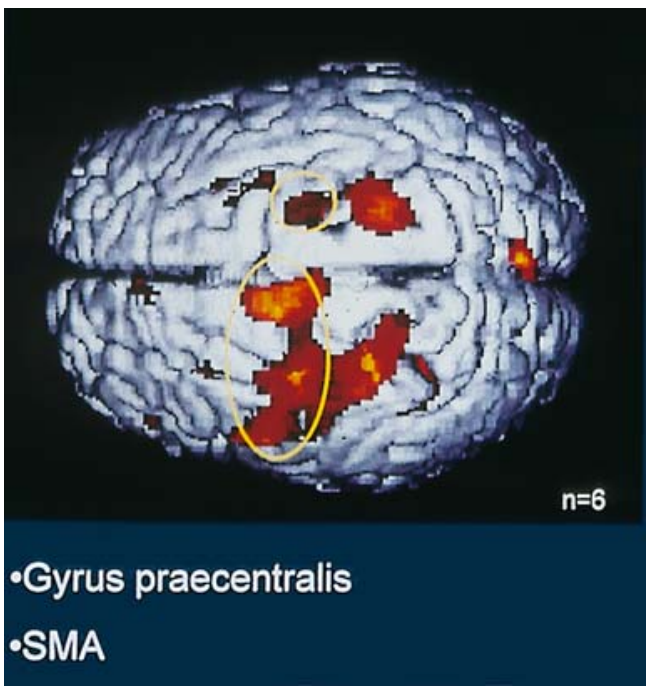

Fig. 5.59. Visualization of pruritus with the aid of positron emission tomography (PET). The red areas are significantly activated. Motor-associated areas are additionally marked (yellow circles). (From Darsow et al. [17])

\subsection{Itch}

Itch and dryness are closely related. Any skin exsiccated too much (e.g., by excessive showering) starts to itch and gives rise via scratching to eczematous lesions. On the basis of "hypersensitive" skin, patients react more strongly to a variety of stimuli and irritants (e.g., wool).

Recently, the itch sensation has been visualized with positron emission tomography (PET) [17] (Fig. 5.59). Atopic itch has several components, only some of them depending on skin inflammation.

\subsubsection{Therapy}

Individual treatment is the major principle, considering the patient's actual skin characteristics in the course of the disease [2, 11, 47]. There is no "miracle" pill or ointment, nor is there a general diet against atopic eczema! Monomania should be avoided; the disease is neither only allergic nor only sebostatic nor only psychologic in origin!

The basis of any therapeutic strategy is careful dermatologic basic skin care, especially during remission [11]. The individual selection 
of emollients (different for different body areas and different individuals) including bath or showering oils (a distinction should be made between emulsion and spreading type bath oils) is critical; avoid showering at too hot a temperature or for too long.

Acceptance by the patient is important; many patients do not like ointments which are too greasy although their skin looks very dry. Hydrophilic ointments (unguentum emulsificans aquosum) have been found helpful as basic vehicles.

Consistent avoidance of all eliciting factors detected during the diagnostic work-up is crucial (irritants, allergens, infection, food reactions) $[36,39,47]$. The inflamed skin manifesting as eczema is treated with anti-inflammatory drugs, preferably with topical glucocorticosteroids in the acute phase (see Sect. 5.5.4).

A new method of anti-inflammatory treatment of atopic eczema without glucocorticoids is available with the new topical immunosuppressives or calcineurin antagonists, which act topically. These substances (tacrolimus and pimecrolimus) inhibit like cyclosporin A activation of calcineurin phosphatase in T cells and also mast cells and basophil leukocytes by binding to a cytosolic immunophyllin (cyclophyllin, FK506 binding protein or macrophyllin 12). The intracellular signal transduction is thereby inhibited and the transcription of many proinflammatory cytokines is reduced [41, 57, 69]. (see also Sect. 6.3.2).

In contrast to glucocorticosteroids, these substances do not have atrophogenic effects in the skin. The two preparations available are tacrolimus in a relatively fatty ointment in $0.1 \%$ and $0.03 \%$ concentrations as well as the more aqueous cream pimecrolimus in a $1 \%$ cream. The place of these new compounds in the management of atopic eczema will be seen in the years to come.

For prophylaxis, avoidance of irritants and allergens (Table 5.65) also includes recommendations for breast feeding of the newborn infant, the use of encasings at home or rehabilitation under climatic therapy conditions (e.g., North Sea, high altitude in Davos, Switzerland) [10].

Frequent superinfections of the skin sometimes require antimicrobial therapy, best done
Table 5.65. Atopic eczema: irritants and elicitors

\begin{tabular}{ll}
\hline Physical & $\begin{array}{l}\text { Mechanical stimuli, dryness, } \\
\text { UV radiation, temperature }\end{array}$ \\
Chemical & $\begin{array}{l}\text { Detergents, solvents, acids, } \\
\text { alkali }\end{array}$ \\
Pharmacological & $\begin{array}{l}\text { Vasoactive substances (alcohol, } \\
\text { nicotine, amines) }\end{array}$ \\
Infectious & Superantigens \\
Psychological & Stress, emotional conflict \\
\hline
\end{tabular}

with disinfectants (clioquinol, triclosan, gentian violet). In severe cases, systemic antibiotic or antimycotic (in head and neck dermatitis) treatment may help.

Wet wraps ("moist pyjamas"), cooling baths, topical steroids, lotio alba, and systemic antihistamines are used against severe itching (see Sect. 6.3.2 on "Pharmacotherapy").

The well-known psychosomatic interactions in atopic eczema sometimes require careful psychosomatic counseling of the patient and relatives [10, 18, 45].

UV therapy as adjuvant strategy has a good effect with different modalities, especially as long-wave UVA-1 $[1,28,29]$.

Unsaturated fatty acids have been recommended as well as traditional Chinese herbs [2] or leukotriene antagonists [13].

The role of allergen-specific immunotherapy is controversial [70]; however, considering the new results with the atopy patch test and the clear-cut role of allergy in some patients, it should be investigated by control studies.

There is no need for desperation or pessimism when we look at the spectrum of therapeutic modalities available for atopic eczema (Fig. 5.60). All these treatment modalities require the active cooperation of the informed patient over months and years (Table 5.66). Therefore, "eczema school" programs have been developed, which after adequate training (eight atopic eczema academies in Germany) are offered in an interdisciplinary setting (allergy, dermatology, pediatrics, nutritionists, psychosomatics) for children, parents, and adults [18]. 
Table 5.66. Leaflet for patients with (atopic) eczema

- Your disease is based partly on inherited factors which can either lead to eczema, conjunctivitis, rhinitis, or bronchial asthma. This genetic predisposition, however, does not necessarily lead to disease. There is a genetic predisposition to increased hypersensitivity of skin and mucous membranes.

- In eczema, the skin is dry, looks rough, the hair sometimes looks rigid, a variety of factors from the environment (both irritant and allergic) can give rise to the development of eczematous skin lesions (red, itchy, sometimes oozing or crusted skin lesions), preferably on the big flexures elbow, knee, neck, hands, and face.

- The skin of patients with eczema (children and adults) needs constant care.

Skin care:

- Avoid too frequent bathing or showering (especially too hot or too foamy)!

- Use alkali-free soaps or syndets for cleaning your skin (mild products).

- When taking a bath or showering, restoration of the skin lipid is important. This can be done by adding a bath oil and/or by creaming after taking a bath or a shower with emollients (lotion, cream, etc.), especially on arms, legs, and hands.

- Take yourself time for skin care every morning and evening. Let the cream penetrate your skin (at least $5 \mathrm{~min}$ ) before dressing. Don't change your ointments too often, stick to the products you tolerate. Thus, you can avoid additional allergies.

\section{Clothing:}

- Avoid wool or irritating textiles. Direct contact to the skin is best tolerated with cotton, silk, or linen.

- Wash underwear before first wearing, especially dark colored products.

- In changing T-shirts on your baby, watch the ears (avoid fissures under the earlobes!). Your favorite sweater may scratch your neck where there is no cotton underneath. Then use a silk scarf.

- During acute exacerbations, keep your baby dressed; an uncovered body surface starts itching and will be scratched.

\section{Treatment of itch:}

- The itch-scratch cycle deserves utmost attention. Often itch is the primary event inducing the new flare.

- Scratching often occurs as a reflex, it is not a matter of will. You should not forbid scratching! Rather treat the itch!

- Keep the nails cut short (scratching occurs also during sleep).

- Itch can be treated topically (anti-inflammatory creams, wet wraps, cooling procedures) or systemically (e.g., antihistamines; the sedating effect of old preparations may be helpful during night time). Topical therapy does less harm to the skin than pronounced scratching!

- Teachers and colleagues should know about the problem. People suffering from intense itch sometimes behave strangely (most of these children are not "hyperactive/hyperkinetic").

\section{Allergen avoidance:}

- According to the results of your allergy diagnosis, avoidance strategies should be implemented. These always have to be specific. Don't change your apartment into a prison-like environment with only glass and concrete. In housedust mite allergy, the bedroom and the mattress are most important and encasings are helpful.

- Some patients benefit from a longer stay in a different climate (sea level or high altitude; talk about this with your specialist).

- In high-risk families, pets should not be kept for allergy prevention. Tobacco smoke and indoor chemicals (cleaning, hobby activities) should be avoided.

\section{Diet:}

- There is no general anti-allergy diet. Patients with atopic eczema can principally eat what they want except for those foods detected as elicitors in careful allergy diagnosis including provocation tests. Positive skin prick or blood tests do not necessarily tell you whether this allergy is relevant for your skin disease. You may use these results as markers for self-observation.

- For allergy prevention, newborns from atopic parents should be breast-fed over 3-6 months; solid food should be only introduced after 6 months. If breastfeeding is not possible, use a hypoallergenic formula.

- Avoid ear-piercing in young children (nickel allergy!).

- If you are pollen-allergic wash your hair before going to bed. 


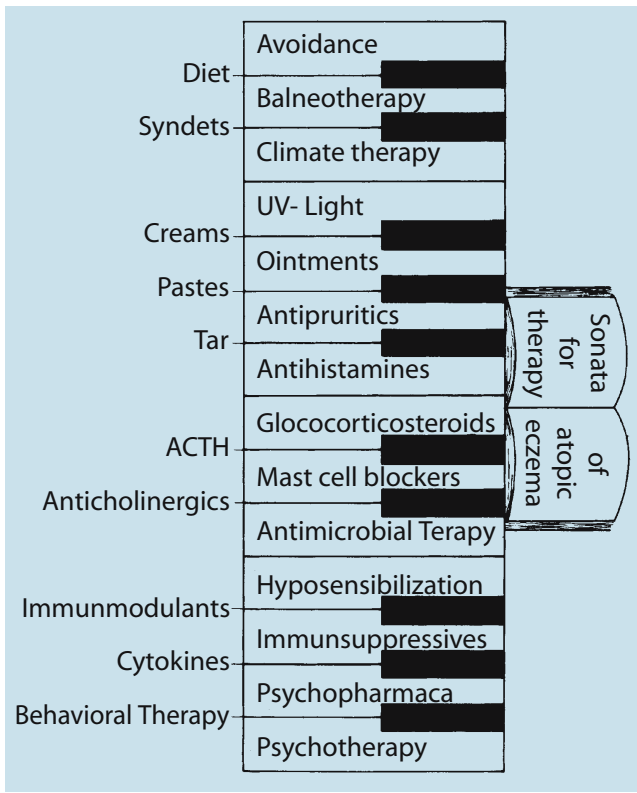

Fig. 5.60. "Therapeutic keyboard"

\section{References}

1. Abeck D, Schmidt T, Fesq H, Strom K, Mempel M, Brockow K, Ring J (2000) Long-term efficacy of medium-dose UVA1 phototherapy in atopic dermatitis. J Am Acad Dermatol 42:254-257

2. Abeck D, Ring J (eds) (2002) Atopisches Eczema (Neurodermitis) im Kindesalter. Steinkopff, Darmstadt

3. Akdis CA, Akdis M, Trautmann A, Blaser K (2000) Immune regulation in atopic dermatitis. Curr Opin Immunol 12:641-646

4. Atherton DJ (1981) Allergy and atopic eczema. Clin Exp Dermatol 6:317 - 325

5. Besnier E (1892) Premiere note et observations preliminaires pour servir d'introduction a l'etude des prurigos diathesiques (dermatites multiformes prurigineuses chroniques exacerbantes et paroxystiques, du type du prurigo de Hebra). Ann Derm Syph (Paris) 3,3:634-648

6. Bieber T (1994) FceR1 on human Langerhans cells: a receptor in search of new functions. Immunol Today 15:52-53

7. Bleck O, Abeck D, Ring J, Hoppe U, Vietzke J, Wolber R, Brandt O, Schreiner V (1999) Two ceramide subfractions detectable in Cer(AS) position by HPTLC in skin surface lipids on non-lesional skin of atopic eczema. J Invest Dermatol 113:894-900

8. Boguniewicz M, Leung DYM (1998) Atopic dermatitis: A question of balance. Arch Dermatol 134:870-871
9. Bos JD, Van Leent EJ, Sillevis Smitt JH (1998) The millennium criteria for the diagnosis of atopic dermatitis. Exp Dermatol 7:132-138

10. Borelli S, Schnyder UW (1962) Neurodermitis constitutionalis sive atopica, part II: Atiologie, Pathophysiologie, Pathogenese, Therapie. In: Miescher G, Storck H (eds) Entzündliche Dermatosen I. Handbuch der Haut- und Geschlechtskrankheiten [Suppl 11/1]. Springer, Berlin Heidelberg New York, pp 254-319

11. Braun-Falco O, Ring J (1984) Zur Therapie des atopischen Eczemas. Hautarzt 35:447-454

12. Bruynzeel-Koomen C, Van Wichen DF, Toonstra J, Berrens L, Bruynzeel PLB (1986) The presence of IgE molecules on epidermal Langerhans cells in patients with atopic dermatitis. Arch Dermatol Res 278:199-205

13. Carucci JA, Washenik K, Weinstein A, Shupack J, Cohen DE (1998) The leukotriene antagonist zafirlukast as a therapeutic agent for atopic dermatitis. Arch Dermatol 134:785-786

14. Cooper KD, Stevens SR (2001) T cells in atopic dermatitis. J Am Acad Dermatol 45:510 - 512

15. Cookson WO, Ubhi B, Lawrence R, Abecasis GR, Whalley AJ, Cox HE, et al. (2001) Genetic linkage of childhood atopic dermatitis to psoriasis susceptibility loci. Nat Genet 27:372-373

16. Darsow U, Vieluf D, Ring J for the APT Study Group (1999) Evaluating the relevance of aeroallergen sensitization in atopic eczema with the atopy patch test: a randomized, double-blind multicenter study. J Am Acad Dermatol 40:187-193

17. Darsow U, Drzezga A, Frisch M, Munz F, Weilke F, Bartenstein P, Schwaiger M, Ring J (2000) Processing of histamine-induced itch in the human cerebral cortex: a correlation analysis with dermal reactions. J Invest Dermatol 115:1029-1033

18. Fartasch $M$, Abeck D, Werfel $T$, Diepgen $T$, Schmid-Ott G, Ring J, Gieler U (2000) Aktueller Stand des interdisziplinären Modellprojektes "Neurodermitis-Schulung für Kinder und Jugendliche". Hautarzt 51:299-301

19. Giustizieri ML, Mascia F, Frezzolini A, De Pita O, Chinni LM, Gianetti A, Girolomoni G, Pastore S (2001) Keratinocytes from patients with atopic dermatitis and psoriasis show a distinct chemokine production profile in response to T cell-derived cytokines. J Allergy Clin Immunol 107: $871-877$

20. Hanifin JM (1982) Atopic dermatitis. J Am Acad Dermatol 8:1-13

21. Hanifin JM, Rajka G (1980) Diagnostic features of atopic dermatitis. Acta Derm Venereol 114: $146-148$

22. Herzberg J (1973) Wenig bekannte Formen der Neurodermitis. Hautarzt 24:407-501

23. Imokawa $G$ (2001) Lipid abnormalities in atopic dermatitis. J Am Acad Dermatol 45:S29-32

24. Jakob T (2002) Mechanismen der Aktivierung und Mobilisation dentritischer Zellen in der 
Haut. Habilitationsschrift, Technische Universität München

25. Jung T (2002) Zytokindysregulation bei atopischer Dermatitis. Dustri, Munich

26. Kissling S, Wüthrich B (1994) Dermatitis in young adults: personal follow-up 20 years after diagnosis in childhood. Hautarzt 45:368-371

27. Korting GW (1954) Zur Pathogenese des endogenen Eczemas. Thieme, Stuttgart

28. Kowalzick L, Kleinheinz A, Weichenthal M, Neuber K, Köhler I, et al. (1995) Low dose versus medium dose UVA1 treatment in severe atopic eczema. Acta Derm Venereol 75:43 - 45

29. Krutmann J, Czech W, Diepgen T, Niedner R, Kapp A, Schöpf E (1993) Highdose UVA1 therapy in the treatment of patients with atopic dermatitis. J Am Acad Dermatol 26:225 - 230

30. Kunz B, Ring J (1999) Clinic diagnostic features of atopic eczema. In: Oranje A, et al. (ed) Pediatric dermatology, vol 2. Blackwell, Oxford

31. Lee Y-A, Wahn U, Kehrt R, Tarani L, Businco L, Gustafsson D, Andersson F, Oranje AP, Wolkertstorfer A, Berg A v, Hoffmann U, Küster W, Wienke T, Rüschendorf F, Reis A (2000) A major susceptibility locus for atopic dermatitis maps to chromosome 3q21. Nature Genetics 26:470

32. Leung DYM (2001) Atopic dermatitis and the immune system: The role of superantigens and bacteria. J Am Acad Dermatol 45:S13 - 16

33. Leutgeb C, Bandmann HJ, Breit R (1972) Handlinienmuster, ichthyosis vulgaris und dermatitis atopica. Arch Derm Forsch 244:244-354

34. Neuber K (2002) Atopisches Eczema und Staphylococcus aureus. Dustri, Munich

35. Olesen AB (2001) Role of the early environment for expression of atopic dermatitis. J Am Acad Dermatol 45:37 - 40

36. Oranje AP (2000) Atopic dermatitis (AD): Evaluation and therapy. Pediatr Dermatol 17:75-83

37. Platts-Mills TAE, Mitchell EB, Rowntree S, Chapman MD, Wilkins SR (1983) The role of dust mite allergens in atopic dermatitis. Clin Exp Dermatol $8: 233-247$

38. Przybilla B, Ring J, Enders F, Winkelmann $\mathrm{H}$ (1991) Stigmata of atopic constitution in patients with atopic eczema or atopic respiratory disease. Acta Derm Venereol 71:407-410

39. Przybilla B, Eberlein-König B, Rueff F (1994) Practical management of atopic eczema. Lancet 343:1342-1346

40. Rajka G (1989) Essential aspects of atopic dermatitis. Springer, Berlin Heidelberg New York

41. Reitamo S, Rissanen J, Remitz A, Granlund H, Erkko P, Elg P, Autio P, Lauerma A (1998) Tacrolismus ointment does not affect collagen synthesis: results of a single-center randomized trial. J Invest Dermatol 111:396-398

42. Ring J (1979) Atopic dermatitis: a disease of general vasoactive mediator dysregulation. Int Arch Allergy Appl Immunol 59:233-239
43. Ring J (1991) Atopy: condition, disease, or syndrome? In: Ruzicka T, Ring J, Przybilla B (eds) Handbook of atopic eczema. Springer, Berlin Heidelberg New York, pp 3-8

44. Ring J, Bieber T, Vieluf D, et al. (1991) Atopic eczema. Langerhans cells and allergy. Int Arch Allergy Appl Immunol 94:194-201

45. Ring J, Schröpl F (1985) Das atopische Eczema. Medizinisches Hörspiel, Frankfurt (Audio-Kassette mit Begleitheft)

46. Ring J, Kunz B, Bieber T, Vieluf D, Przybilla B (1989) The "atopy patch test" with aeroallergens in atopic eczema. J Allerg Clin Immunol 82:195

47. Ring J, Brockow K, Abeck D (1996) The therapeutic concept of "patient management" in atopic eczema. Allergy 51:206-215

48. Ring J (ed) (1998) Neurodermitis. Ecomed, Landsberg

49. Ruzicka T, Ring J, Przybilla B (eds) (1991) Handbook of atopic eczema. Springer, Berlin Heidelberg New York

50. Saurat J-H (1985) Eczema in primary immunedeficiencies. Clues to the pathogenesis of atopic dermatitis with special reference to the WiskottAldrich syndrome. Acta Derm Venereol (Stockh) 114:125-128

51. Schäfer T, Krämer U Vieluf D, Abeck D, Behrendt H, Ring J (2000) The excess of atopic eczema in East Germany is related to the intrinsic type. $\mathrm{Br}$ J Dermatol 143:992-998

52. Schnyder UW (1960) Neurodermitis, Asthma, Rhinitis, eine genetisch allergologische Studie. Karger, Basel

53. Schöpf E, Kapp A, Kim CW (1978) T-cell function in atopic dermatitis. Controlled examination of concanavalin A. Dose-response relations in cultured lymphocytes. Arch Dermatol Res 262:37 44

54. Schultz-Larsen F (1985) Atopic dermatitis. Etiological studies based on a twin population. Laegeforeningens, Copenhagen

55. Stingl G (2001) IgE-mediated, $F c_{\varepsilon}$ RI-dependent allergen presentation: A pathogenic factor in atopic dermatitis? J Am Acad Dermatol 45:S517-S520

56. Taieb A (1999) Hypothesis: from epidermal barrier dysfunction to atopic disorders. Contact Dermatitis 41:177-180

57. Thestrup-Pedersen K, Ring J (1999) Atopic dermatitis: summary of the 1st Georg Rajka Symposium 1998 and a literature review. Acta Derm Venerol 79:257-264

58. Trautmann A, Akdis M, Kleemann D, Altznauer F, Simon HU, Graeve T, Noll M, Brocker EB, Blase K, Akdis CA (2000) T cell-mediated Fas-induced keratinocyte apoptosis plays a key pathogenetic role in eczematous dermatitis. J Clin Invest 106:25-35

59. Uehara M (1985) Clinical and histological features of dry skin in atopic dermatitis. Acta Derm Venereol (Stockh) [Suppl] 114:8246

60. Valenta R, Seiberler S, Natter S, Mahler V, Mossabeb R, Ring J, Stingl G (2000) Autoallergy: A 
pathogenetic factor in atopic dermatitis? J Allergy Clin Immunol 105:432-437

61. Wahlgren CF, Scheynius A, Hagermark O (1990) Antipruritic effect of oral cyclosporin A in atopic dermatitis. Acta Derm Venereol 70:323 - 329

62. Wakim M, Alazard M, Yajima A, Speights D, Saxon A, Stiehm E (1998) High dose intravenous immunoglobulin in atopic dermatitis and hyper-IgE syndrome. Ann Allergy Asthma Immunol 81: $153-158$

63. Werfel T (2000) Allergenspezifische T-Zell-Antwort bei Eczemakrankheiten. Dustri, Munich

64. Williams HC (ed) (2000) Atopic dermatitis. The epidemiology, causes and prevention of atopic eczema. Cambridge University Press, Cambridge

65. Wise F, Sulzberger MB (1933) Footnote on problem of eczema, neurodermatitis and lichenification. In: Wise F, Sulzberger MB (eds) The 1933 Year book of dermatology and syphilology. Year Book Publishers, Chicago, pp 38-39

\subsubsection{Topical Glucocorticosteroid Therapy}

Glucocorticosteroids have a central place in the treatment of inflammatory skin disease. They can be regarded as the greatest advance in topical dermatotherapy in the second half of the 20 th century [28]. In Germany in the year 2001, there were 263 different preparations in various application forms including 70 combination preparations on the market (systemic substances not included).

\subsubsection{Mechanisms of Action}

Glucocorticosteroids have a variety of wellknown effects due to control of synthesis of several enzymes at the chromosome level [2, 5, $9,11]$. The steroid is bound to a cytoplasmic receptor leading to a conformation change of the receptor complex [6], which then binds in the nucleus to chromatin and influences the transcription of messenger RNA. Steroids may both stimulate and inhibit transcription. The exact mechanisms are still not known; however, they enhance the activity of RNA polymerases at certain positions in the chromatin [2].

Glucocorticoids have a variety of metabolic effects; the best known (hence the name!) affects the glucose metabolism with the mobilization of muscular glycogen and neoglycogenesis from amino acids. This protein catabolism with a negative nitrogen balance maybe
66. Wollenberg A, Wen S, Bieber T (1999) Phenotyping of epidermal dendritic cells - clinical applications of a flow cytometric micromethod. Cytometry 37:147-155

67. Wright S, Burton JL (1982) Oral-evening-primrose-seed oil improves atopic eczema. Lancet 2:1120-1122

68. Wüthrich B (1975) Zur Immunpathologie der Neurodermitis constitutionalis. Huber, Bern

69. Wüthrich B (ed) (1999) The atopic syndrome in the third millennium. Karger, Basel

70. Zachariae H, Cramers M, Herlin T, Jensen J, Kragballe K, Ternowitz T, Thestrup-Pedersen K (1985) Non-specific immunotherapy and specific hyposensitization in severe atopic dermatitis. Acta Derm Venereol (Stockh) [Suppl] 114:48-54

71. Stalder R, Taieb A, et al. (1993) Consensus Report of the European Task Force on Atopic Dermatitis. Severity scoring of atopic dermatitis: the SCORAD index. Dermatology 186:23-31

plays a role in the well-known immunosuppression and affects wound healing. In fatty tissue, lipolysis is enhanced, and in the kidney a mild mineralocorticoid effect exists, although it is $1,000 \times$ weaker than aldosterone. In some tissues, glucocorticoids induce involution, especially in lymphatic tissues, the bone and the skin, most likely due to inhibition of DNA synthesis.

Furthermore, gestagenic effects (such as progesterone) have been described as well as psychic alterations (depression, sleeplessness, euphoria, alteration in behavior, and others).

In the skin, glucocorticosteroids inhibit the proliferation of epidermal, inflammatory, and lipid cells, the synthesis of collagen tissue, the liberation of mediators from mast cells, and pigment formation by melanocytes. They normalize altered cornification of epidermis cells, inhibit migration of inflammatory cells, and induce vasoconstriction [5] (Table 5.67).

The anti-inflammatory effect is of particular interest in dermatology, affecting almost all kinds of inflammation (infectious, allergic, physical, chemical, etc.). Apart from formation of lipocortin, inhibition of phospholipase plays a role which in the cell membrane is important in the formation of arachidonic acid from phospholipids. From arachidonic acid, highly active prostaglandins and leukotrienes are formed $[2,4,6]$. The anti-inflammatory effect 
Table 5.67. Action of glucocorticosteroids on skin cells

\begin{tabular}{|c|c|}
\hline Cells & Effects \\
\hline \multirow[t]{2}{*}{ Keratinocytes } & Inhibition of proliferation \\
\hline & $\begin{array}{l}\text { Normalization of keratiniza- } \\
\text { tion }\end{array}$ \\
\hline Fibroblasts & $\begin{array}{l}\text { Inhibition of collagen and } \\
\text { proteoglycan synthesis }\end{array}$ \\
\hline Lymphocytes & $\begin{array}{l}\text { Inhibition of proliferation } \\
\text { and cytokine secretion }\end{array}$ \\
\hline Granulocytes & $\begin{array}{l}\text { Inhibition of chemotaxis } \\
\text { and activation }\end{array}$ \\
\hline Mast cells/basophils & $\begin{array}{l}\text { Inhibition of liberation of } \\
\text { vasoactive mediators }\end{array}$ \\
\hline Vascular system & Vasoconstriction \\
\hline Melanocytes & $\begin{array}{l}\text { Inhibition of pigment for- } \\
\text { mation }\end{array}$ \\
\hline Fatty tissue & Inhibition of proliferation \\
\hline
\end{tabular}

can be shown as inhibitory function on various cells (neutrophils, macrophages, lymphocytes) with additional vasoconstriction.

Pharmacologic effects of glucocorticosteroids depend on specific structures in the molecule (Fig. 5.61), the introduction of a fluor atom in position $9 \alpha$ increases the biological activity, and substitution in position $6 \alpha$ increases antiinflammatory effects. Esterification, acetonide formation as well as introduction of methyl or halogen groups in positions $16-21$ lead to a variety of topically effective steroid preparations, which have been tested in various experimental systems (e.g., vasoconstriction assay) [1].

Table 5.68 shows the most common topical glucocorticoids, roughly classified according to pharmacologic potency.

New developments with fewer side effects include prednicarbate, methylprednisolonaceponide, and mometasone furoate.

For therapeutic efficacy, dermal resorption of the applied substance is necessary; this can be influenced by certain factors, such as:

- Stratum corneum thickness (tape stripping)

- Age (infant skin has higher permeability)

- Blood flow (increased skin blood flow increases resorption)

- Hydration (occlusion increases permeation by a factor of 10!) (Table 5.69)<smiles>CCC1CCC2(C)C1(C)CCC1(C)C3(C)CCCCC3(C)CCC21C</smiles>

a) Pregnane

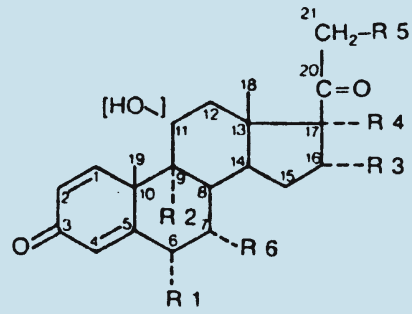

b) Structure of natural and synthetic Glucocorticosteroides<smiles>CC12CCC(=O)C=C1CCC1C2C(O)CC2(C)C1CCC2(O)C(=O)CO</smiles>

c) Cortisol

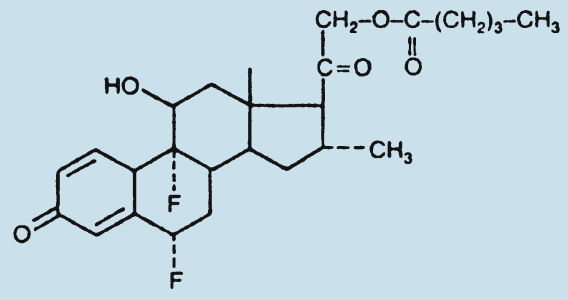

d) Diflucortolon-21-valerate

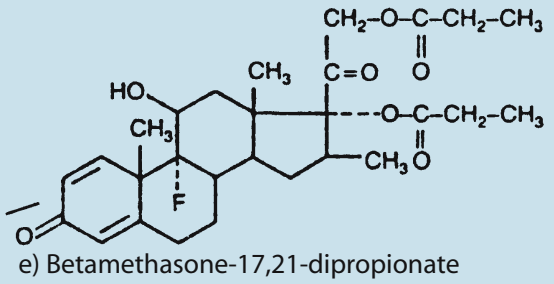

Fig. 5.61. Natural and synthetic glucocorticosteroids as pregnane derivatives [21] 
Table 5.68. Topical glucocorticosteroids of different potency (arbitrary selection) (according to $[9,17,21]$ )

$\begin{array}{ll}\text { Potency } & \text { Substance } \\ \text { (group) } & \\ & \\ & \text { Non-halogenated glucocorticosteroids } \\ & \text { Hydrocortisone } \\ & \text { Hydrocortisone-17-butyrate } \\ & \text { Hydrocortisone acetate } \\ & \text { Desonid } \\ & \text { Hydrocortisone buteprate } \\ & \text { Methylprednisolone aceponide } \\ & \text { Prednisolone } \\ \text { II }=\quad \text { Prednicarbate } \\ \text { Weakly fluorinated glucocorticosteroids } \\ \text { Alclomethasone } \\ \text { Clobetasol butyrate } \\ \text { Fluocortin butylester } \\ \text { Moderate glucocorticosteroids } \\ \text { Betamethasone-17-valerate } \\ \text { Betamethasone-17-benzoate } \\ \text { Betamethasone-17-pentanoate } \\ \text { Desoximethasone } \\ \text { Momethasone fuorate } \\ \text { Triamcinolone-16-17-acetonide } \\ \text { Flumethasone-21-pivalate } \\ \text { Fludroxycortide } \\ \text { Fluticasone-17-propionate } \\ \text { Dexamethasone } \\ \text { Strong glucocorticosteroids } \\ \text { Betamethasone-17-21-dipropionate } \\ \text { Fluocinolone acetonide } \\ \text { Diflorasone-17-21-diacetate } \\ \text { Diflucortolone-21-valerate } \\ \text { Very strong glucocorticosteroids } \\ \text { Amcinonide } \\ \text { Fluocinonide } \\ \text { Halcinonide } \\ \text { Clobetasol-17-propionate }\end{array}$

Table 5.69. Excretion of hydrocortisone into the urine after local administration of $5.2 \mathrm{mg} / \mathrm{cm}^{2}$ in acetone under different conditions (according to [7])

\begin{tabular}{|lc|} 
& $\begin{array}{c}\% \text { of dose } \\
\text { applied }\end{array}$ \\
\hline Normal skin & 0.46 \\
Under occlusion & 4.48 \\
After corneal stripping & 0.91 \\
After corneal stripping plus occlusion & 14.91 \\
\hline
\end{tabular}

- Skin temperature (increasing temperature increases permeation, part of the occlusion effect)

- Influence of vehicle (optimal solution of the effective agent, but not too high an affinity to the vehicle)
- Interaction of drugs (e.g., addition of $3 \%$ salicylic acid enhances the steroid penetration)

- Skin metabolism (biotransformation by oxidation, methylation, sulfatation, glucuronidation, etc.). Fluocortin butylester is hydrolyzed in the skin to the inactive steroid acid, leading to decreased efficacy, but also fewer side effects.

\subsubsection{Practical Application of Topical Glucocorticoids}

Topical glucocorticosteroids have to be indicated. They can suppress inflammation, but rarely are curative, which has to be considered in chronic disease.

If there is an indication for topical glucocorticosteroid therapy, the weakest effective preparation should be selected in order to avoid side effects. Maximally, apply twice daily, generally once daily (depot in the stratum corneum). Occlusion should never be longer than $12 \mathrm{~h}$ to avoid side effects!

After 1 week of therapy, the situation should be monitered by a physician (sometimes even daily). If there is no immediate rapid response within a week, the patient should consult a dermatologist.

Long-term steroid therapy never should be stopped abruptly (rebound phenomenon), slow dose reduction can be done either by changing to a less potent product or, preferably, by interval therapy ( 3 days steroid, 4 days vehicle only) $[3,10,12,13,14]$. Tachyphylaxis phenomena have been observed and may be overcome by changing the product.

With regard to epidermal proliferation kinetics (with a minimum at 6.00 p.m. in the daily rhythm), some authors recommend the application of topical steroids in the evening; we follow the individual itch intensity.

Crucial in the selection of topical steroid preparations is the vehicle [3]. Figure 5.62 shows a rough schedule of critical criteria (clinical course, skin type, body area for the selection of the vehicle) [21]. In chronic inflammation, fatty preparations are preferred while acute lesions should be treated with solutions and cooling wraps. In intertrigenous areas, 
Fig. 5.62. Application forms of topical therapy. Guidelines for selecting the proper application form for topical glucocorticoid therapy according to the clinical course and the location and condition of the affected skin area

\begin{tabular}{l|lll} 
& dry & fat \\
\cline { 2 - 3 } Indication & $\begin{array}{l}\text { Wraps } \\
\text { Suspensions } \\
\text { Lotions } \\
\text { Powder }\end{array}$ & $\begin{array}{l}\text { hydrophilic } \\
\text { ointments } \\
\text { (creams) } \\
\text { Hydropastes }\end{array}$ & $\begin{array}{l}\text { Fatty } \\
\text { ointments } \\
\text { Occlusion }\end{array}$ \\
\hline Course & \\
\hline acute & \\
\hline subacute & \\
\hline chronic & \\
\hline Skin type & \\
\hline Sebostasis \\
Seborrhea
\end{tabular}

greasy ointments need to be avoided, whereas on the extensor surfaces and in chronic lesions they are indicated.

Corticoid preparations are available in all forms: greasy ointment (no water), water in oil ointments, oil in water (creams), lotio (suspension mixtures), lotion (milk), gel, paste (powder in ointment), alcoholic solutions (tinctura), plasters, sprays, foams, etc. The vehicles comprise substances of mineral (petrolatum, paraffin), animal (wool wax alcohols), plant (oils, wax, starch), and synthetic origin (propylene glycol) together with emulsifiers, preservatives, fragrances, etc. These constituents are important for potential contact allergy.

Combination preparations of glucocorticoids with antibiotics or antimycotics should be considered critically and only in occasional cases are they indicated. The "ex iuvantibus" practice often prevents correct diagnosis.

For individual prescriptions of mixtures, the galenic compatibility has to be considered to avoid instability of emulsions, loss of efficacy, and incompatibilities between substances. Many companies offer the vehicle ointment alone in addition to the steroid-containing compound.

\subsubsection{Side Effects of Topical Glucocorticosteroids}

The most relevant side effects of topical steroid therapy are listed in Table 5.70. The risk of systemic steroid therapy generally is much higher. However, sometimes after very intense topical steroid application (especially under occlusion) systemic side effects may occur $[5,9,11$, $16,17,21]$.

Almost all undesired side effects of corticoids are somehow related to the desired pharmacological effect and therefore in most cases dose dependent. Disturbance of ostiofollicular keratinization leads to comedo formation and steroid acne. Inhibition of proliferation and regeneration of the epidermis induces thinning and atrophy. The degeneration of collagen and 
Table 5.70. Side effects of glucocorticosteroids

\begin{tabular}{l} 
Systemic administration \\
Endocrinology \\
Diabetes mellitus \\
Catabolic metabolism \\
Osteoporosis \\
Hyperlipidemia \\
Alkalosis (sodium retention potassium excretion) \\
Suppression of pituitary gland (growth suppres- \\
$\quad$ sion in children) \\
Cushing's syndrome \\
Hypertension \\
Immune system \\
Inhibition of lymphocyte and granulocyte func- \\
$\quad$ tion, immunosuppression \\
Gastrointestinal \\
Peptic ulcer \\
Neurological \\
Myopathy \\
Neuropathy \\
Psychic alteration \\
Ophthalmological \\
Cataract \\
Glaucoma \\
Thromboembolic complication \\
Anaphylactoid reaction (very rare) \\
Topical application on skin \\
Striae distensae \\
Atrophy \\
Fatty tissue atrophy \\
Embolia cutis (after i.m. crystal suspension) \\
Increased photosensitivity \\
Pseudo-anetoderma \\
Cutis punctata linearis colli \\
Teleangiectasias \\
Rubeosis steroidica \\
Pigment changes \\
Perioral rosacea-like dermatitis \\
Granuloma gluteale infantum \\
Hypertrichosis \\
Contact allergy \\
\hline
\end{tabular}

elastic fibers (also vessels) leads to senile elastosis, teleangiectasia, purpura, ecchymosis and striae distensae (Fig. 5.63).

A special form of topical corticoid side effect is the so-called perioral rosacea-like dermatitis, developing after long-term application of mostly fluorinated glucocorticoids (especially in atopics) and mostly in the face; it manifests as fine sharp papules and occasional pustules (Fig. 5.64). The indication for steroid treatment

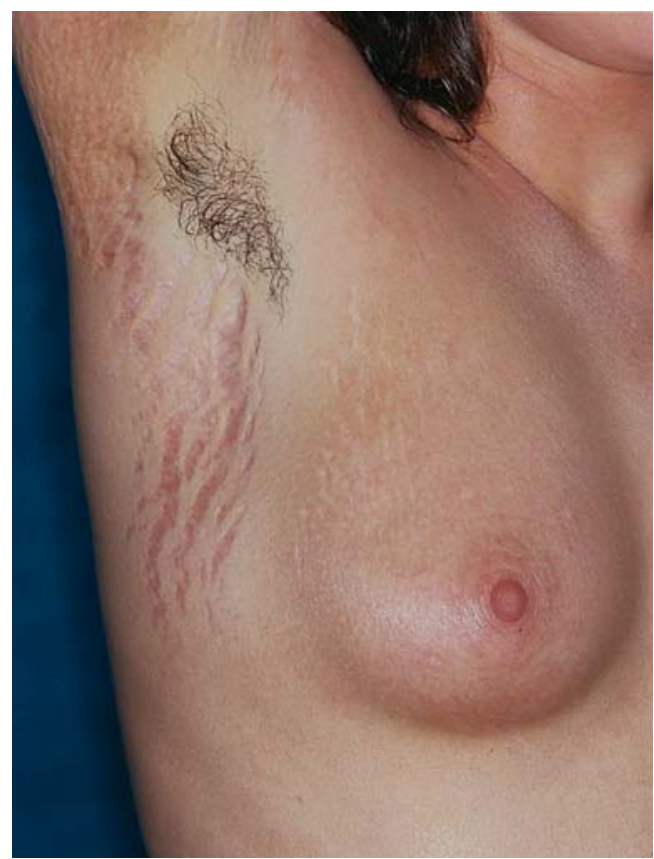

Fig. 5.63. Striae distensae after long-term application of glucocorticoids

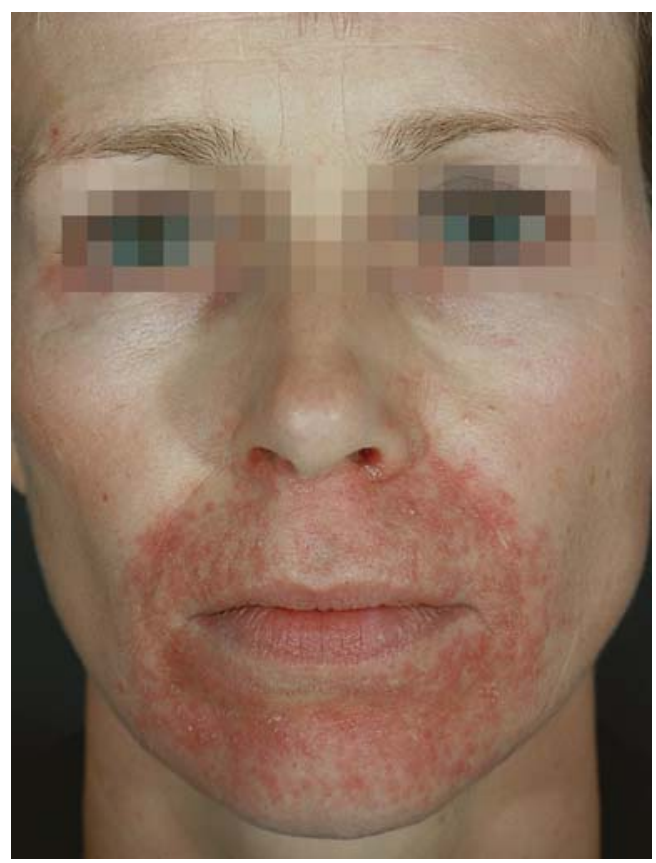

Fig. 5.64. Rosacea-like perioral dermatitis appearing in a patient who had used a fluoridated topical glucocorticoid preparation for several weeks 
mostly remains trivial or unknown. The antiinflammatory effect of the steroid induces improvement again and again, but is followed by heavy rebounds after withdrawal. Therefore, the patient will never learn the causal interactions. Only authoritative guidance of the patient can break this vicious cycle (I tell my patients: "Your skin is addicted to cortisone and we have to perform withdrawal!").

There are also allergic reactions (contact allergy) to cortisone preparations, mostly against constituents of the vehicle, but also against the steroid molecule itself.

After intramuscular application of corticoid crystal suspensions, partly irreversible local reactions may occur (embolia cutis, lipid or muscular atrophy) (Figs. 5.65, 5.66).

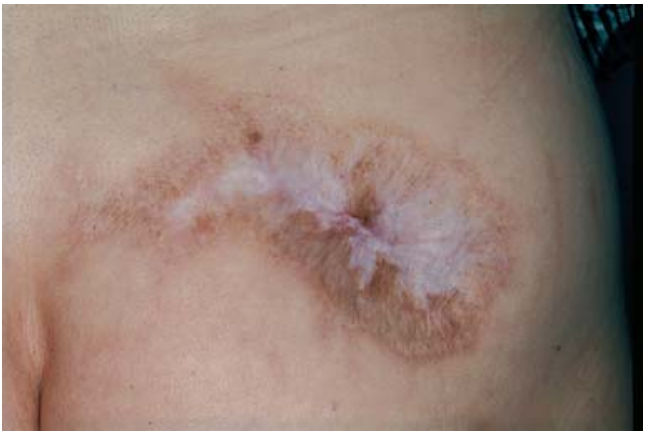

Fig. 5.65. Lipoatrophy occurring after the intramuscular administration of a glucocorticoid crystalline suspension
Practical Conclusions. Glucocorticosteroids are, even if applied topically, very active drugs, the use of which should be well indicated; it requires experience of skin diseases and steroid actions and side effects. The good doctor uses as little cortisone as necessary and as much indifferent vehicle therapy (emollients, lotio alba, paste, etc.) as possible!

\section{References}

1. Alpermann HG, Sandow J, Vogel HG (1982) Tierexperimentelle Untersuchungen zur topischen und systemischen Wirksamkeit von Prednisolon17-ethylcarbonat-21-propionat. Arzneimittelforschung/Drug Res 32:633

2. Barnes PJ, Adcock I (1993) Anti-inflammatory actions of steroids: molecular mechanisms. Trends Pharmacol Sci 14:436-440

3. Braun-Falco O, Ring J (1984) Zur Therapie des atopischen Ekzems. Hautarzt 35:447-454

4. Carnuccui R, di Rosa M, Guerrasio B, Iuvone T, Sautebin L (1987) Vasocortin: a new glucocorticoid-induced anti-inflammatory protein. $\mathrm{Br} \mathrm{J}$ Pharmacol 90:443 - 445

5. Claman WN (1984) Antiinflammatory effects of corticosteroids Immunol. Allergy Practice 4: 317-329

6. Clark CR (1985) Intracellular localisation of steroid receptors. In: Sluyser M (ed) Interaction of steroid hormone receptors with DNA. Ellis Horwood, Chichester, pp 7-56

7. Flower RJ, Rothwell NJ (1994) Lipocortin-I: cellular mechanisms and clinical relevance. Trends Pharmacol Sci 15:71-76
Fig. 5.66. Cutaneous atrophy following longterm treatment with a topical glucocorticoid

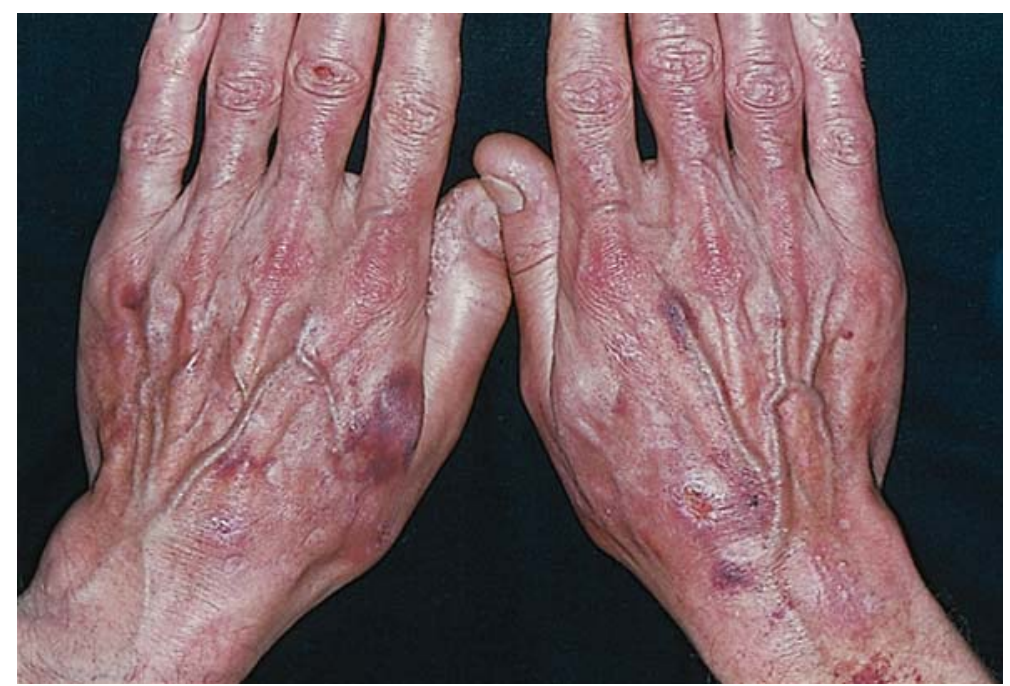


8. Guin JD (1984) Contact sensitivity to topical corticosteroids. J Am Acad Dermatol 10:773 - 782

9. Hatz H (1998) Kortison und Kortikoide. Deutscher Apothekerverlag, Stuttgart

10. Hornstein OP, Nürnberg E (eds) (1985) Externe Therapie von Hautkrankheiten. Pharmazeutische und medizinische Praxis. Thieme, Stuttgart

11. Kaiser H (1977) Cortisonderivate in Klinik und Praxis. Thieme, Stuttgart

12. Kligman AM (1986) Topical steroids: Perspectives and retrospectives. In: Ring J, Burg G (eds) New trends in allergy. II. Springer, Berlin Heidelberg New York, pp 342-352

13. Lubach D, Kietzmann M (1992) Dermatokortikoide - Pharmakologie und Therapie. In: Marghescu S, Wolff HH, Zaun H (eds) Kohlhammer, Freiburg

14. Maibach H, Stougthon RB (1973) Topical corticosteroids. Med Clin N Am 57:1253

15. Marghescu S (1983) Externe Kortikoidtherapie: Kontinuierliche versus diskontinuierliche Anwendung. Hautarzt 34:114-117

16. Miyachi Y (1982) Adrenal axis suppression caused by a small dose of a potent topical corticosteroid. Arch Dermatol 118:451

17. Niedner R, Ziegenmeyer J (eds) (1992) Dermatika - Therapeutischer Einsatz, Pharmakologie und Pharmazie. Wiss Verlagsgesellsch, Stuttgart

18. Poulsen J, Rorsman H (1980) Ranking of glucocorticoid creams and ointments. Acta Derm Venereol 60:57

19. Ponec M, Kempanaar SA, DeKloet ER (1981) Corticosteroids and cultured human epidermal keratinocytes. J Invest Dermatol 76:211 - 214

\subsection{Photoallergy/Photosensitization}

\subsubsection{Classification}

Incompatibility reactions in connection with exposure to UV light represent a special type of photobiologic reaction. In the following the term "light" is used for "non-ionizing electromagnetic radiation" in general. When light reaches the skin, part of the energy is reflected, another part affecting the organism after absorption to body constituents $[3,8,16$, 17, 42]. Substances increasing the sensitivity against light are called "photosensitizers" (Table 5.71).

Photosensitization can be either phototoxic or photoallergic in nature $[8,17,24,38]$.

Phototoxic effects occur through formation of pyrimidine adducts within the DNA, leading to cross-links within the double-helix (e.g.,
20. Przybilla B, Ring J (1983) Äußerliche Behandlung mit Glukokortikosteroiden. Med Monatsschr Pharm 6:192-205

21. Ring J, Fröhlich HH (1985) Wirkstoffe in der dermatologischen Therapie, 2nd edn. Springer, Berlin Heidelberg New York

22. Schaefer H, Zesch A, Schalla W, Stüttgen G (1980) Pharmakokinetik externer Glucocorticoide. Allergologie 3:194

23. Schell H, Hornstein OP (1980) Endogener Kortisolrhythmus und Epidermisproliferation. Akt Derm 6:27-33

24. Schleimer RP (1993) An overview of glucocorticoid anti-inflammatory actions. Eur J Clin Pharmacol 45 [Suppl]:1

25. Schmutzler W (1999) Antiallergische und antientzündliche Pharmakotherapie. In: Heppt W, Renz H, Röcken M (eds) Allergologie. Springer, Berlin Heidelberg New York, pp 160-174

26. Schöpf E (1972) Nebenwirkungen externer Corticoidtherapie. Hautarzt 23:295

27. Schöpf E (1980) Kortikosteroide in der Dermatologie. Allergologie 3:306

28. Sulzberger MB, Witten VH (1952) The effect of topically applied compound $\mathrm{F}$ in selected dermatoses. J Invest Dermatol 19:101

29. Wendt H, Frosch PJ (1982) Klinisch-pharmakologische Modelle zur Prüfung von Corticoidexterna. Karger, Basel

30. Wilckens T (1995) Glucocorticoids and immune function: hormonal dysfunction. Trends Pharmacol Sci 16:193-197

Table 5.71. Terminology of photobiologic reactions

\begin{tabular}{|c|c|}
\hline $\begin{array}{l}\text { Photobiologic } \\
\text { reaction }\end{array}$ & $\begin{array}{l}\text { Effect of light }{ }^{\mathrm{a}} \text { on biological } \\
\text { systems }\end{array}$ \\
\hline $\begin{array}{l}\text { Light incompatibi- } \\
\text { lity }\end{array}$ & Reaction after light exposure \\
\hline Photosensitization & $\begin{array}{l}\text { Increased sensitivity to light } \\
\text { by defined endogenous or } \\
\text { exogenous substances }\end{array}$ \\
\hline Photosensitizer & $\begin{array}{l}\text { Substance inducing photo- } \\
\text { sensitization }\end{array}$ \\
\hline $\begin{array}{l}\text { Photoallergic } \\
\text { reaction }\end{array}$ & $\begin{array}{l}\text { Immunologically mediated } \\
\text { photosensitization }\end{array}$ \\
\hline Phototoxic reaction & $\begin{array}{l}\text { Non-immunologic photo- } \\
\text { sensitization }\end{array}$ \\
\hline $\begin{array}{l}\text { Photohypersensi- } \\
\text { tivity }\end{array}$ & $\begin{array}{l}\text { Increased sensitivity against } \\
\text { light exposure }\end{array}$ \\
\hline Photodermatosis & $\begin{array}{l}\text { Skin disease provoked or } \\
\text { aggravated by light }\end{array}$ \\
\hline
\end{tabular}

a "Light" in this context means "non-ionizing electromagnetic radiation" 
Table 5.72. Differential diagnosis of phototoxic and photoallergic reactions

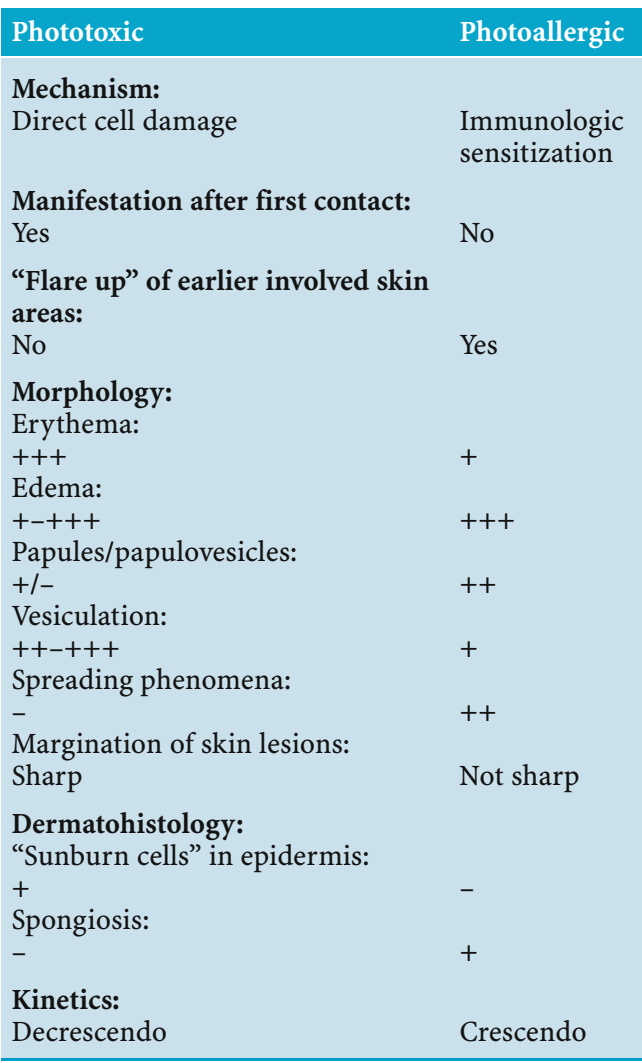

psoralen phototoxicity) or via oxygen radicals affecting cell membranes [8, 15, 42].

Photoallergic reactions are due to immunological sensitization directed against a new photoallergen induced by action of UV radiation. Theoretically, phototoxic and photoallergic reactions can be well differentiated (Table 5.72), although in individual patients this may be difficult in practice.

\subsubsection{Clinical Manifestations of Photo- hypersensitivity}

Photohypersensitivity reactions should be distinguished from well-known adverse reactions induced by UV radiation, either acutely (sunburn) or chronically (atrophy, elastosis, carcinogenesis), which occur dose dependently in all individuals with normal sensitivity. Hypersensitivity against UV light may occur in meta-
Table 5.73. Classification of photohypersensitivity diseases

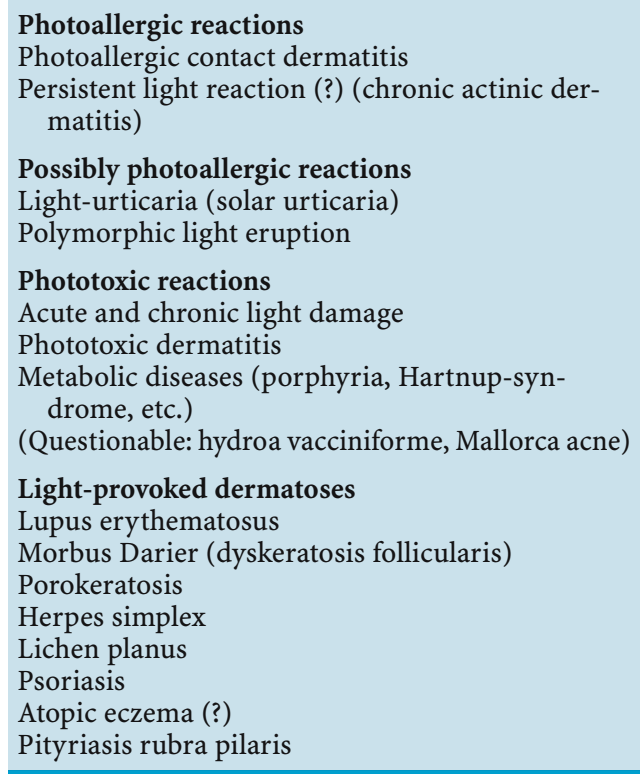

bolic disturbances or enyzme defects (e.g., various forms of porphyria) with endogenous photosensitizers or contact with exogenous photosensitizers (e.g., weeds in dermatitis pratensis or drugs).

Photoallergic reactions manifest mostly as photoallergic contact dermatitis. Photohypersensitivity reactions with an unknown elicitor (Table 5.73) comprise some forms of solar urticaria and so-called polymorphic light eruption (lay people often call it "sun allergy"), which differs from patient to patient in morphology, but is rather monomorphous in the individual patient $[2,3,13,24,28,36]$.

Photoallergic contact dermatitis is a relatively common form of photohypersensitivity (Fig. 5.67). Some patients under the combined influence of light and photoallergen develop a chronification, the so-called persistent light reaction, occurring with thickened erythematous lichenoid plaques and a strong itching or burning pain. Persistent light reaction is characterized by a general increase in photosensitivity in different parts of the UV spectrum. Persistent light reaction can further develop into chronic actinic dermatitis ("actinic reticuloid"), which may sometimes turn into cutaneous lymphoma $[8,17,24]$. 


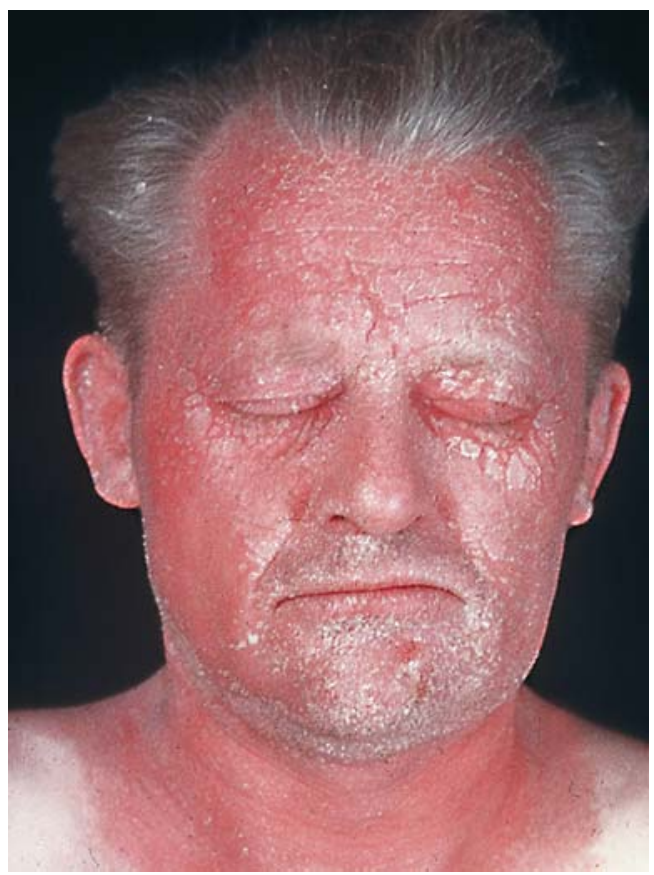

Fig. 5.67. Photoallergic contact eczema

In patients with persistent light reaction the minimal erythema dose (MED) is generally decreased, mostly in the UVB but also in the UVA range. Rarely there is also hypersensitivity against visible light. These patients develop inflammatory skin lesions after exposure to light, independent of allergen contact.

In the rare solar urticaria, UV radiation (mostly UVA) is the elicitor. The detection of the eliciting wavelength is important. In photoprovocation tests $0.2-5.0 \mathrm{~J} / \mathrm{cm}^{2}$ UVA will elicit reactions within 10-20 min. Anaphylactic shock in the solarium has been described. By pretreatment with other wavelengths hardening may be achieved [12, 32, 34].

In polymorphic light eruption photoprovocation may be possible in previously involved, but at the time of testing symptom-free, skin areas not exposed to light. This has to be done on three subsequent days with doses of $3 \times 60-100 \mathrm{~J} / \mathrm{cm}^{2}$ UVA or UVA1, or $3 \times 1.5 \times$ MED UVB or UVA+UVB.

The very rare disease of hydroa vacciniformia can sometimes be treated with UVA; the cause is unknown, vitamin B deficiency has been discussed.
Suspected systemic photosensitization may be detected by measuring the MED during a systemic administration (oral or parenteral) of a suspected agent, UV irradiation and demonstration of increased photosensitivity $[1,9,25]$.

\subsubsection{Photosensitizers}

Photosensitizing agents are widely distributed in nature. They are found in tar (polyaromatic hydrocarbons, acridine derivatives) or colorings (eosin, fluorescein, methylene blue).

Many plants contain photosensitizers (Table 5.74), giving rise to phototoxic reactions after epidermal contact or after oral intake [26, 43]. The furocoumarins contained in many etheric oils or fragrances in cosmetics (Breloque dermatitis) are also the active agents in the elicitation of meadow grass dermatitis (dermatitis pratensis) [21, 26] (Fig. 5.68). Chlorophyll derivatives have been described as inductors of photodermatoses [18].

Various drugs (mostly after systemic administration) act as photosensitizers (Table 5.75). Photosensitizers eliciting clear-cut allergic reactions are also called "photoallergens." In the office the distinction is often difficult, since many photoallergens also have phototoxic potential.

Recently non-steroidal anti-inflammatory drugs have been shown to act as photosensitizers, especially the propionic acid derivatives (Fig. 5.69) [25, 32, 35, 39].

Table 5.74. Photosensitizors from plants

Umbelliferae
Heracleum, Angelica, Daucus carota (carrot),
Ammi majus, Apium graveolens (celery), Pastinaca
Rutaceae
Citrus bergamia (bergamot), Citrus sinensis
(orange), Ruta graveolens, Dictamnus albus
Moraceae
Ficus carica (fig)
Leguminosae
Psoralea corylifolia
Rosaceae
Compositae


Table 5.75. Photosensitizers in drugs and cosmetics (examples)

Disinfectants (e.g., halogenated salicylanilides,
hexachlorophen, chlorhexidine, bithionol)
Antimycotics (buclosamide)
Chemotherapeutics (sulfonamides, tetracyclines,
nalidixic acid, quinolones)
Sedatives (phenothiazine)
Diuretics (hydrochlorothiazide, furosemide)
Non-steroidal anti-inflammatory drugs (e.g.,
ibuprofen, ketoprofen, piroxicam, diclofenac)
Antiarrhythmics (quinidine, amiodarone)
Fragrances (musk ambrette, 6-methylcoumarin)
Sunscreen substances (e.g., para-aminobenzoic
acid, benzophenones, isopropyldibenzoylmethane)
Antidiabetics (sulfonyl urea)

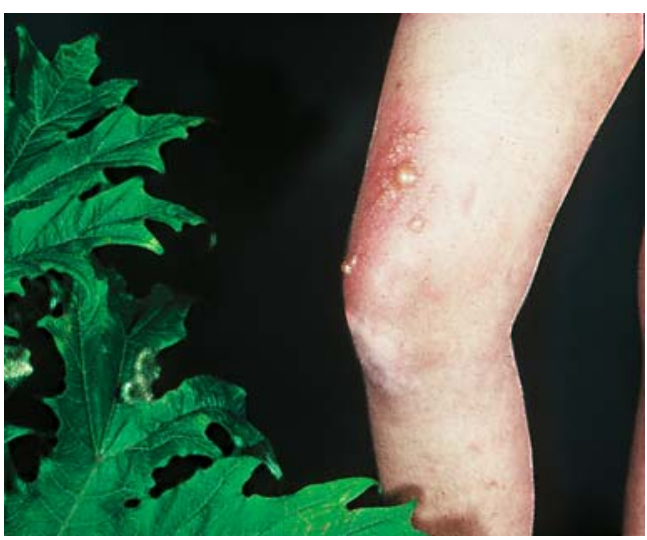

Fig. 5.68. Meadow grass dermatitis caused by furocoumarins - in this case by contact with the giant hogweed (Heracleum mantegazzianum)

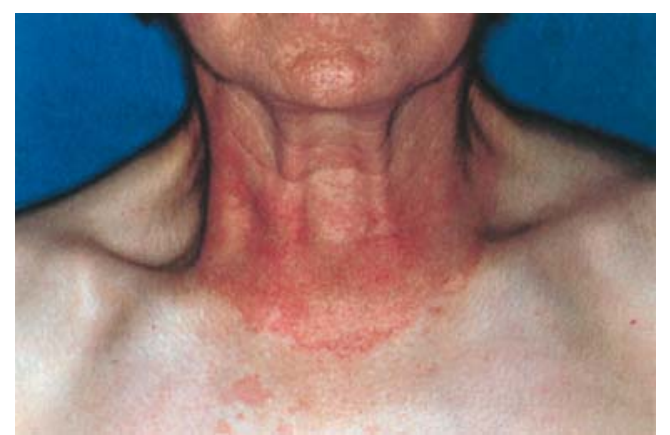

Fig. 5.69. Light-induced drug exanthema following the administration of carprofen

\subsubsection{Diagnosis}

In the diagnosis of photoallergic or phototoxic reactions, not only the eliciting substance but also the eliciting wavelength has to be determined [33]. Most of the eliciting wavelengths in photohypersensitivity are found in the UVA range, but sometimes also in the UVB range or visible light. With a clear-cut history and negative test results different wavelengths should be used. There is no general concordance between the absorption spectrum of a substance and the eliciting wavelength of the adverse reaction. UV radiation penetrates through certain textiles; affection of covered body areas does not exclude photosensitization.

A variety of genuine skin diseases can be provoked by light which are not currently understood pathophysiologically $[24,28]$.

Photo-patch Test. The most important technique with which to diagnose photoallergic reactions is the photo-patch test $[14,19,23,24$, 30 ], when two samples each of the suspected substance are applied to the back skin. After $24 \mathrm{~h}$ the patch over one testblock is removed and the skin radiated with $10 \mathrm{~J} / \mathrm{cm}^{2}$ (when radiated with UVB with the half minimal erythema doses). After 48 and $72 \mathrm{~h}$ both testblocks are read. Under certain conditions a late reading after 3 weeks (labeling of test areas with a polaroid camera) is recommended.

For quantitative analysis photo-patchthreshold testing can be performed and the series of substances is irradiated with increasing doses (geometric increase) of UV. For differentiation of phototoxic and photoallergic test reactions dermatohistology is sometimes required.

Photo-prick Test. Concordant with the photopatch test, other skin test procedures can be performed with and without irradiation (e.g., in solar urticaria).

Systemic Photo-provocation Test. For evaluation of the clinical relevance of a positive photo-patch-test reaction against drugs or foods, a systemic photo-provocation test can be performed $[9,25,30]$. Before and after systemic 
administration of the suspected substance various areas are irradiated at different time intervals (e.g., $50 \mathrm{~J} / \mathrm{cm}^{2} \mathrm{UVA}$ ).

\subsubsection{Prophylaxis and Therapy}

Information from the patient and recommendations for careful sun exposure are the basis of any treatment. Avoidance of elicitation agents is crucial. In patients with unknown photosensitizers the selection of the sunscreen is very important. Most of the commercial sunscreens describe the sun protection factor for UVB radiation only (rarely also for UVA), which, however, is the decisive wavelength for most patients with photosensitization. One should know that many of the common light filter substances in sunscreens can act as photoallergens $[38,39]$.

In patients with polymorphic light eruption as well as chronic photoallergic contact dermatitis with transition to persistent light reaction, PUVA therapy as well as UVA1 or small spectrum UVB (311 nm) can be used as conditioning $[13,15,28]$. In experimental models inhibitory effects of UV radiation on allergy-relevant reactions have been demonstrated $[3,6,22,32]$.

Prior to the production of new substances as drugs or cosmetics, screening tests for possible photosensitizing properties should be performed. There are various in vivo (guinea pig, rat, mice) and in vitro procedures (Candida albicans inhibition test, photohemolysis test) [5, $12,14]$. We have detected the photosensitizing properties of non-steroidal anti-inflammatory drugs using a photo-basophil-histamine-release test $[31,35]$.

\section{References}

1. Bergner T, Przybilla B (1992) Photosensitization caused by ibuprofen. J Am Acad Dermatol 26:114-116

2. Breit R (1987) Rötung und Bräunung der Haut durch UVA. Zuckschnverdt, Munich

3. Eberlein-König B, Fesq H, Abeck D, Przybilla B, Placzek M, Ring J (2000) Systemic vitamin C and vitamin $\mathrm{E}$ do not prevent photoprovocation test reactions in polymorphous light eruption. Photodermatol Photoimmunol Photomed 16:50-52
4. Epstein S (1939) Photoallergy and primary photosensitivity to sulfanilamide. J Invest Dermatol $2: 43-51$

5. Ferguson J, Johnson BE (1993) Clinical and laboratory studies of the photosensitizing potential of norfloxacin, a 4-quinolone broad-spectrum antibiotic. Br J Dermatol 128:185-195

6. Fjellner B (1981) Experimental and clinical pruritus. Studies on some putative peripheral mediators. The influence of ultraviolet light and transcutaneous nerve stimulation. Thesis, Stockholm

7. Fotiades J, Soter NA, Lim HW (1995) Results of evaluation of 203 patients for photosensitivity in a 7.3-year period. J Am Acad Dermatol 33: 597-602

8. Frain-Bell W (1986) Cutaneous photobiology. Oxford University Press, New York

9. Galosi A, Przybilla B, Ring J, Dorn M (1984) Systemische Photoprovokation mit Surgam. Allergologie 7:143 - 144

10. Gigli I, Lim HW (1981) Release of proinflammatory peptides by complement in porphyrin-induced photosensitivity. In: Ring J, Burg G (eds) New trends in allergy. Springer, Berlin Heidelberg New York, p 5848

11. Gollhausen R, Przybilla B, Galosi A, Köhler K, Ring J (1987) Environmental influences of UVB erythema. Photodermatology 4:148-153

12. Hasei K, Ichihashi M (1982) Solar urticaria. Determinations of action and inhibition spectra. Arch Dermatol 118:346-350

13. Hölzle E, Plewig G, Kries R v, Lehmann P (1987) Polymorphous light eruption. J Invest Dermatol 88:32-38

14. Hölzle E, Neumann N, Hausen B, Przybilla B, Schauder S, Hönigsmann H, Bircher A, Plewig G (1991) Photopatch testing: The 5-year experience of the German, Austrian and Swiss photopatch test group. J Am Acad Dermatol 25:59-68

15. Hönigsmann H, Stingl G (eds) (1986) Therapeutic photomedicine. Karger, Basel

16. Horio T (1975) Chlorpromazine photoallergy. Arch Dermatol 111:1469-1471

17. Ippen H (1973) Photochemie der Haut. In: Herrmann F, Oppen H, Schaefer H, Stüttgen G (eds) Biochemie der Haut. Thieme, Stuttgart, p 146

18. Jitsukawa K, Suizu R, Hidano A (1984) Chlorella photosensitization, a new phytophotodermatosis. Int J Dermatol 23:263

19. Jung EG (1981) Die belichtete Epikutantestung. Akt Derm 7:163-165

20. Jung EG, Hardmeier T (1967) Zur Histologie der photoallergischen Testreaktion. Dermatologica 135:243-252

21. Kavli G, Volden G (1984) Phytophotodermatitis. Photodermatology 1:65-75

22. Kripke ML (1986) Photoimmunology, the first decade. Curr Probl Dermatol 15:164-175

23. Lehmann P (1990) Die Deutschsprachige Arbeitsgemeinschaft Photopatch-Test (DAPT). Hautarzt 41:295-297 
24. Lischka G, Jung EG (1982) Lichtkrankheiten der Haut, 2nd edn. Perimed, Erlangen

25. Ljunggren B, Bjellerup M (1986) Systemic drug photosensitivity. Photodermatology 3:26-35

26. Ljunggren B (1990) Severe phototoxic burn following celery ingestion. Arch Dermatol 126: $1334-1336$

27. Maurer T (1983) Contact and photocontact allergens. A manual of predictive test methods. Dekker, New York

28. Plewig G, Hölzle E, Roser-Maaß E, Hofmann C (1985) Photoallergy. In: Ring J, Burg G (eds) New trends in allergy. Springer, Berlin Heidelberg New York, pp 152-169

29. Przybilla B, Ring J, Schwab U, Galosi A, Dorn M, Braun-Falco O (1987) Photosensibilisierende Eigenschaften nicht-steroidaler Antirheumatika im Photopatch-Test. Hautarzt 38:18-25

30. Przybilla B (1987) Phototestungen bei Lichtdermatosen. Hautarzt 38:S23-S28

31. Przybilla B, Schwab-Przybilla U, Ruzicka T, Ring J (1987) Phototoxicity of non-steroidal antiinflammatory drugs demonstrated in vitro by a photobasophil-histamine-release test. Photodermatology 4:73-78

32. Przybilla B, Ring J, Eberlein B (1988) Inhibition of in vitro basophil histamine release by UVA irradiation. J Allergy Clin Immunol 83:302

33. Przybilla B, Bergner T (1992) Diagnostik von lichtallergischen Exanthemen im erscheinungsfreien Intervall. Hautarzt 43:100-101

34. Przybilla B, Eberlein-König B (2000) Photoprovokationstests. In: Przybilla B, Bergmann K, Ring J (eds) Praktische allergologische Diagnostik. Steinkopff, Darmstadt

35. Ring J, Przybilla B, Ruzicka T (1987) Nonsteroidal antiinflammatory drugs induce UV-dependent

\subsection{Adverse Drug Reactions}

\subsubsection{Drug Allergy: General Procedures}

\subsubsection{Classification}

Adverse drug reactions are unexpected undesired reactions to drugs in normal doses [26] and represent an increasing problem in clinical medicine. Approximately $3-5 \%$ of hospitalizations are due to drug reactions [39], and $10-15 \%$ of hospitalized patients suffer from adverse drug reactions during their hospital stay.

Drug allergies are a serious problem: $0.32 \%$ of hospital patients die from adverse drug reactions in the United States, corresponding to histamine and leukotriene release from peripheral human leukocytes. Int Arch Allergy Appl Immunol 82:344-346

36. Ring J, Przybilla B (1990) UV irradiation and allergy. Allergologie 12(Suppl EAACI):75-79

37. Ruzicka T, Walter JF, Printz MP (1983) Changes in arachidonic acid metabolism in ultraviolet irradiated hairless mouse skin. J Invest Dermatol $81: 300-303$

38. Schauder S, Ippen H (1986) Photoallergic and allergic contact dermatitis from dibenzoylmethanes. Photodermatology 3:140 - 147

39. Schauder S, Schrader A, Ippen H (1996) Göttinger Liste 1996. Sonnenschutzkosmetik in Deutschland, 4th edn. Blackwell, Berlin

40. Schmidt T, Abeck D, Ring J (1998) Photoallergic contact dermatitis due to combined UVB-(4-methylbenzylidene camphor/octyl methoxy-cinnamate) and UVA-(benzophenone-3/butyl-methoxy-dibenzoylmethane) absorber. Dermatology 196:354-357

41. Schulz KH, Wiskemann K, Wolf K (1956) Klinische und experimentelle Untersuchungen über die photodynamische Wirksamkeit von Phenotiazinderivaten, insbesondere Megaphen. Arch Klin Exp Dermatol 202:285-298

42. Terui T, Okuyama R, Tagami H (2001) Molecular events occurring behind ultraviolet-induced skin inflammation. Curr Opin Allergy Clin Immunol 1:461-467

43. Wessner D, Hofmann H, Ring J (1999) Phytophotodermatitis due to Ruta graveolens applied as protection against evil spells. Contact Dermatitis $41: 232-233$

44. Wucherpfennig V (1931) Biologie und praktische Verwendbarkeit der Erythemschwelle des UV. Strahlentherapie 40:201-243

106,000 estimated fatalities in 1994 (the fourth commonest cause of death in the United States) $[4,31]$.

Apart from severe bullous reactions (Lyell's syndrome, etc.) (see Sect. 5.7.3), the vasculitic "hypersensitivity syndrome" as well as organ damage to liver, lung, or kidney, anaphylactoid reactions are the most dangerous and most frequently lethal adverse drug reactions. A study from the United Kingdom reported a marked increase in prevalence of anaphylactic reactions leading to hospitalization (1:10,000 in 1995) [42]. In a hit list of elicitors of fatal anaphylactic reactions, anesthetics, relaxants, antibiotics, and radiographic contrast media are on top.

The frequency of fatal drug allergy is estimated to be 1:10,000 [56]; for most drugs aller- 
gy prevalences are lower (0.1-1\%). Some groups of drugs, however, have a higher risk (over 2\%), e.g., foreign proteins (xenogeneic protein, allergen extracts, organ extracts, vaccines, transfusions, enzymes, and hormones) and antibiotics (penicillin, ampicillin, sulfonamides, erythromycin). It is unlikely that there are drugs which under guarantee will never elicit an allergy! Anaphylactoid reactions to corticosteroids have been reported. Precise studies to compare the prevalences of side effects are difficult to perform. The term "frequent" implies different aspects such as an actual increased prevalence of side reactions (relative percentage) as well as an absolutely increased usage of the drug (absolute numbers).

The classification of adverse drug reactions can be done according to clinical symptoms (e.g., anaphylactoid reaction, fever, exanthematous eruption, organ disease) and suggested or proven pathomechanism time course kinetics (acute 0-60 min, subacute 1-24 h, delayed or accelerated for more than $24 \mathrm{~h}$ ) (according to [23]).

\subsubsection{Pathophysiology}

Drug allergies can be classified like all other allergic diseases (modified classification of
Coombs and Gell) (Table 5.76). In order to elicit an allergy, the drug has to be immunogenic; this holds true for proteins and peptides $(>7$ amino acids). Low molecular drugs are haptens and need binding to body carrier proteins to gain immunogenicity. The chemical basis of sensitization is known for very few drugs; for penicillin, we know the critical antigenic determinants: the penicilloyl group as "major determinant" (that is most frequent, not most dangerous!) and the "minor determinants" (less frequent) of penicillenate and penicillamine [62]. Similar molecules can show "cross-reactions"; small molecules can elicit a reaction when they have capacity for at least divalent binding to the antibody molecule.

Metabolism of drugs is important for the induction of incompatibility reactions. In the balance between activation and detoxification, disturbances may be crucial, involving especially the enzymes of the cytochrome P450 system as well as $\mathrm{N}$-acetyltransferase (NAT) [34, 35]. In cutaneous drug reactions, keratinocytes also play a role with metabolizing enzymes [45].

For the frequency of sensitization, the route of administration is essential: the risk of allergy induction increases in the following sequence: oral, intravenous, intramuscular, subcutaneous, and topical.

Table 5.76. Drug allergy: different pathomechanisms

\begin{tabular}{lll} 
Mechanism (type) & Symptoms & Example \\
\hline I (IgE) & Anaphylaxis & Penicillin, allergen extracts, insulin \\
II (Cytotoxic) & Agranulocytosis & Metamizol \\
& Anemia & Penicillin, cephalosporin \\
& Thrombocytopenia & Carbamazepine \\
III (Immune complex) & Anaphylaxis & Xenogeneic serum, dextran \\
& Serum sickness & Xenogeneic serum, penicillin \\
& Vasculitis & Allopurinol, phenylbutazone \\
& Alveolitis & Pituitary extracts, nitrofurantoin \\
IV (Cell mediated) & Eczema (also systemic!) & Antibiotics, disinfectants \\
& Photoallergy & Halogenated salicylanilides, nalidixic acid \\
& (Fixed drug eruption) & Barbiturates, quinine \\
& (Maculopapular) & Penicillin, gold, barbiturates, $\beta$-blockers \\
& (Toxic epidermal necrolysis) & Sulfonamides, NSAIDs, allopurinol \\
V (Granulomatous) & Granuloma & Allergen extracts, soluble collagen \\
VI (Neutralizing/stimulating) & (Drug-induced LE?) & Hydralazine, procainamide \\
& Insulin resistance & Anti-insulin IgG antibodies \\
\hline
\end{tabular}




\subsubsection{Risk Factors}

The risk of a drug allergy depends both on the characteristics of the substance and on the patient (Table 5.77). Risk factors from the patient can be seen in underlying diseases (immunodeficiency, infectious disease, metabolic defects such as decreased or slow acetylators). Whether drug allergies are more frequent in atopics is controversial. Most studies have not differentiated according to reaction types and have given controversial results. There is evidence that IgE-mediated reactions may be more frequent in atopics compared to normals.

Table 5.77. Risk factors for drug allergy

\begin{tabular}{l} 
1. Risk factors from the drug \\
Duration of administration \\
Frequency of administration \\
Dose \\
Route of administration \\
Dose of reactive metabolites \\
2. Risk factors from the patient \\
Underlying disease (immunodeficiency, metabolic \\
disturbance) \\
Age \\
Genetic disposition (polymorphisms, HLA) \\
Atopy (?) \\
Previous incompatibility of the same drug \\
\hline
\end{tabular}

With increasing age and more frequent underlying diseases, the intensity of clinical symptoms of drug reactions is also increasing.

\subsubsection{General Diagnosis of Drug Allergy}

The diagnosis of adverse drug reactions follows the same principles used for classical allergy diagnosis:

- History and clinical symptoms

- Skin test

- In vitro diagnostics

- Provocation test

\subsection{History and Clinical Symptoms}

History is the most important part of allergy diagnosis! In most cases of adverse drug reactions, however, the allergist has not seen the clinical symptoms of the incompatibility reac- tion himself and needs information from the patient or from colleagues (questionnaires have proven useful). Therefore, every physician should carefully document all the symptoms together with the suspected drug when there is a suspicion of adverse drug reaction. It is not enough to write down the general class of drug (e.g., "penicillin" is often used as a wide term for any antibiotic), but the individual substance, the brand name, the producer, the formula, the batch number (especially in intravenous solutions and biologicals) should be recorded. If possible, single substances of combination drugs should be documented since the drug content may change over the years under the same brand name (Table 5.78). The allergist also needs the "physician's desk reference" from previous years!

Sometimes the intensity of a reaction can be evaluated from the treatment given. The time course is especially important; some patients suffer from a mild anaphylactic reaction, which only becomes serious after administration of epinephrine. In anesthesia-related complications, the anesthesia protocol is of the utmost importance for allergy diagnosis.

According to clinical symptoms, rough information for suspected pathomechanisms can be found with large overlaps. No single symptom is characteristic for a certain pathomechanism (urticaria can be induced by IgE antibodies, but also by immune complex reactions, or pseudo-allergic reactions).

Sometimes fever reactions occur together with other complaints in the sense of serum sickness; however, they can also be due to toxic

Table 5.78. Important information from the history of adverse drug reactions

\begin{tabular}{ll}
\hline Substance & $\begin{array}{l}\text { Effective agents, additives } \\
\text { Brand name, producer } \\
\text { Administration formula, batch } \\
\text { number } \\
\text { Possible incompatibilities }\end{array}$ \\
Reaction type & $\begin{array}{l}\text { Clinical symptoms } \\
\text { Time course (in surgery also an- } \\
\text { esthesia protocol!) } \\
\text { Severity }\end{array}$ \\
Therapeutic procedures performed
\end{tabular}


effects. Hematologic complications are common in cytotoxic reactions (e.g., allergic agranulocytosis) (see Sect. 5.2). Central nervous symptoms (cramps, paresthesia, cognitive failure) are seen in pseudo-allergic reactions (e.g., with local anesthetics).

In the literature, a hypersensitivity syndrome is described as a very severe drug reaction with sepsis-like symptoms, high fever with or without skin involvement and frequent hypereosinophilia in the peripheral blood. Anticonvulsants as elicitors are known. The mechanism of these reactions - in earlier textbooks also called "drug fever" - is not clear. Lymphocyte transformation tests may be helpful [5].

\subsection{Skin Test}

Two to 3 weeks after remission of symptoms or withdrawal of systemic glucocorticoid or antihistamine therapy, skin tests should be performed, if possible not later than after 3 months. Certain drugs able to inhibit skin reactions should be withdrawn (see Sect. 4.2). Skin tests stay positive over longer periods of time compared to in vitro tests. However, they also bear the risk of systemic reactions. Fatalities after simple scratch tests in highly sensitized patients have been reported [14].

The general problem of all drug allergy tests is the haptenic nature of the low molecular substances which have to bind in the body to proteins to gain antigenic properties. Therefore, real progress in the field of drug allergy is only possible when haptens can be coupled to high molecular carriers, for instance penicillin to penicilloyl polylysine (PPL) [62].

Prior to testing of unknown substances, concentrations used need to be evaluated carefully [51] in order to avoid toxic reactions. The choice of solvent in water-insoluble drugs is important. Drug test solutions should be freshly made up more often than allergen extracts. Positive test reactions should be evaluated together with controls in healthy volunteers (in order to exclude irritative reactions).

Patch tests with topical preparations must include vehicles and other ingredients. In positive reactions the single substances need to be tested in adequate concentrations; this is only possible with confidential cooperation from the pharmaceutical industry (confidentiality agreement!) and the informed patient.

In pseudo-allergic reactions skin tests are usually negative; they should, however, be performed in order to detect rare true allergies and in order to avoid dramatic immediate type reactions.

\subsection{In Vitro Diagnosis}

The development of reliable in vitro tests for allergy diagnosis of adverse drug reaction is a major endeavor in research in order to save patients from having to undergo unnecessary provocation tests. Unfortunately, only for a few drugs (e.g., penicillin) are standardized RAST procedures available for routine diagnosis.

Besides RAST, IgE-mediated reactions may be detected by in vitro histamine release, sulfidoleukotriene formation (CAST-ELISA) [63] or basophil activation (CD63) from peripheral leukocytes after stimulation with the suspect drug. In these tests, the problem of hapten coupling to protein is inherent.

The diagnosis of non-IgE-mediated reactions requires the measurement of other antibody classes, e.g., with passive hemagglutination, immunodiffusion, or specific RIA or EIA assays. Immune complex anaphylaxis due to dextran is mediated by high titers of specific IgG antibodies against dextran (see Sect. 5.3). In this model, the importance of time points for taking blood samples for investigation has been elucidated. The highest antibody titers were found in serum samples drawn prior to the administrations of the drug [46]; immediately after the clinical reaction, antibody titers were markedly reduced or not measurable; only after several days or weeks were antibodies again increased. The retrospective asservation of samples (laboratory or blood bank) may be decisive for final diagnosis!

Some authors recommend the lymphocyte transformation test (LTT) as an in vitro test for adverse drug reactions [5, 40, 53]. In our experience, the LTT can be helpful in the diagnosis of cell-mediated reactions while immediate-type reactions only rarely show reliable results. 
A major difficulty of all cellular procedures is the high variance of the test results. In adverse drug reactions, the problem of standardization (vehicle, concentration, metabolites, controls) causes difficulty; many procedures (e.g., use of liver microsomes) [34] are not available for routine tests and are only possible in specialized laboratories.

\subsection{Provocation Test}

The provocation test, e.g., the exposure of the patient to the specific relevant substance under controlled conditions, often remains the only reliable method in the diagnosis of adverse drug reactions; this holds especially true for pseudo-allergic reactions $[43,48]$.

Prior to the provocation test, the other diagnostic procedures need to be performed in order to gain information about the intensity of the patient's sensitization. Any provocation test bears a certain risk and has to be performed with the utmost caution (sometimes under inpatient conditions).

In the diagnosis of adverse drug reactions, oral provocation is the commonest test. The oral provocation test (OPT) should not only include the suspected agent from the patient's history but also a selection of standard substances as possible alternatives. The recommendation of an alternative drug on the basis of the literature only without actual proof of tolerability in an OPT may be dangerous $[43,48]$.

For example, we have observed several sometimes severe - anaphylactoid reactions after administration of acetaminophen in patients with a history of anaphylaxis to analgesics.

The evaluation of OPT results can sometimes be difficult, especially with regard to the "allergy passport" (Table 5.79). In contrast to the procedure for contact allergy and patch test
Table 5.79. Documentation for an "allergy passport"

Criteria for registration of a substance:

- The substance can be avoided

- The clinical relevant sensitization usually persists over longer periods

- High allergenic potency

- Risk of systemic reactions (anaphylaxis)

- Alternative drug tested in provocation tests

- The allergy passport should contain the following information:

- Location and date, name of the allergist

- Clinical symptomatology and severity of the adverse reaction

- Eliciting substance

- Information regarding the diagnostic test procedures

- Tested alternatives (e.g., information regarding the dose tolerated in OPT)

results (only clear-cut positive patch test reactions are recorded in the allergy passport!), we also document the so-called "allergy suspicion" in adverse drug reactions (Table 5.80). However, in the allergy passport, both test results and diagnostic considerations should be documented (e.g., "suspicion by history," "skin test positive," "RAST positive") [60]. So-called prophetic testings (without a history of adverse reactions) are rarely indicated.

The most common mistakes in the diagnosis of adverse drug reactions are listed in Table 5.81.

Table 5.81. Common mistakes in the diagnosis of adverse drug reactions
- Insufficient history
- Wrong substance tested
- Wrong test procedure
- Wrong interpretation of skin test reactions (especially intradermal)
- Insufficient precautions for skin tests and prov- ocation tests
- Wrong interpretation of psychic factors (under- and overestimation)
- Inadequate allergy passport
- Testing under therapy with antiallergic drugs

Table 5.80. Allergy diagnosis in adverse drug reaction: Score for inclusion in allergy passport (together with B. Przybilla). $0-1$ point $=$ no allergy passport, 2 points = "allergy suspicion," 3 or more points $=$ allergy passport necessary

\begin{tabular}{llll} 
Criterion & Score points & & \\
& 0 & 1 & 2 \\
\hline Clinical symptoms (history) & Negative & Doubtful & Clear-cut \\
Provocation test & Negative & $\begin{array}{l}\text { Doubtful } \\
\text { Skin test (epidermal) }\end{array}$ & Clear-cut \\
Skin test (cutaneous) $^{\mathrm{a}}$ & Negative or & $(+)$ & + \\
\hline
\end{tabular}

a A positive in vitro test may replace a positive cutaneous skin test 
Often doctors advise the patient with adverse drug reactions: “Just don't take this drug any more." This advice is as intelligent as the recommendation for a patient with abdominal pain: "Don't press on it again!"

\subsubsection{Hyposensitization in Drug Allergy}

In spite of multiple alternative substances, it may occur that the patient is allergic to a lifesaving drug and the possibility of hyposensitization should be discussed. This has been done successfully for various drugs although the mechanism of this "hyposensitization" (also called "adaptive deactivation" or "tolerance induction") is by no means clear.

Principally, one has to distinguish between anaphylactic reactions and cutaneous drug eruptions. The best experiences date from immediate reactions to penicillin, antibiotics and insulin (Table 5.82). Hyposensitization can be performed orally or intravenously. In patients with anaphylaxis, the dose increase is done at 15-30 min intervals. According to the severity of the history, $0.1-1 \%$ of a usual dosis is the starting dose. Tables 5.82 and 5.83 show successful schedules for penicillin and insulin. "Hyposensitization" in cutaneous drug eruptions usually does not induce lasting tolerance. After renewed administration, the drug has to be carefully started with a low dose.

Contraindications for drug hyposensitizations comprise severe and life-threatening conditions without adequate possible therapy such as severe bullous skin diseases (Stevens-Johnson syndrome, Lyell's syndrome, necrotic vasculitis), severe organopathies (hepatitis, nephritis), as well as cytotoxic reactions (agranu-

Table 5.82. Schedule for hyposensitization in penicillin allergy (oral)

\begin{tabular}{cccc} 
Steps & Dose (units) & Steps & Dose (units) \\
\hline 1 & 100 & 9 & 24,000 \\
2 & 200 & 10 & 48,000 \\
3 & 400 & 11 & 80,000 \\
4 & 800 & 12 & 160,000 \\
5 & 1,600 & 13 & 320,000 \\
6 & 3,200 & 14 & 640,000 \\
7 & 6,400 & 15 & $1,000,000$ \\
8 & 12,000 & & \\
\hline
\end{tabular}

Table 5.83. Successful hyposensitization in drug eruptions

\begin{tabular}{ll}
\hline Antibiotics & Virostatiics \\
Penicillin & Zidovudine \\
Ciprofloxacin & Nevirapine \\
Ethambutol & Anticonvulsives \\
Rifampicin & Carbamazepine \\
Sulfonamides & Phenobarbital \\
Cotrimoxazole & Cytostatics \\
Sulfadiazine & Azathioprine \\
Dapsone & 6-Mercaptopurine \\
Antimycotics & Carboplatin \\
Itraconazole & Other \\
Antiparasitics & Allopurinol \\
Pyrimethamine & Insulin \\
\hline
\end{tabular}

locytosis, thrombocytopenia, anemia). Maybe this should be reconsidered after future studies using granulocyte colony-stimulating factor (G-CSF) or erythropoietin as emergency treatment.

Severe underlying diseases may also represent a contraindication. In suspected IgE-mediated allergy, beta-blocking agents and angiotensin-converting enzyme inhibitors should be withdrawn prior to hyposensitization.

\subsubsection{Adverse Reactions to Special Drugs}

\subsection{Penicillin and Betalactam Antibiotics}

Penicillin allergy may manifest in many reaction types $(\mathrm{I}-\mathrm{V})$. The prevalence of all reactions is between $5 \%$ and $10 \%$ [16]. The incidence of anaphylactic reactions is approximately $1 \%$, of lethal cases 1:50,000. Regarding the common use of penicillin (80 million penicillin administrations per year in the United States), this is a great practical problem: 32 of 43 fatal anaphylactic reactions in the US army were penicillin mediated (see Sect. 5.1.4). Attempted suicide through the elicitation of anaphylaxis by a penicillin-allergic individual has been reported [55]. Often penicillin allergy is observed after the first therapeutic administration of penicillin; here sensitization may have occurred unnoticed via food (cow's milk, chicken, etc.), conjunctival prophylaxis at birth or penicillin-containing wound ointments. $A$ 
positive reaction against Penicillium notatum in the standard allergy test is not of relevance for penicillin allergy!

The skin test (always begin with a prick or scratch!) is performed with penicilloyl polyly$\sin (\mathrm{PPL})$ in a concentration of $50 \mathrm{nM} / \mathrm{ml}$ to $500 \mathrm{nM} / \mathrm{ml}$ (major determinant) as well as penicillin $\mathrm{G}(200,000 \mathrm{U} / \mathrm{ml})$, benzylpenicillin or benzylpenicillenate $\left(10^{-2} \mathrm{mM}\right.$ ) (minor determinants).

If negative, intradermal tests are started: PPL 25-250 nM/ml, penicillin G 10-1,000 U/ $\mathrm{ml}$.

The frequency of positive skin test reactions in patients with a history of penicillin allergy is approximately $30 \%$. Negative skin tests do not exclude penicillin allergy; positive tests do not $100 \%$ predict adverse reactions at the next penicillin administration! However, the risk of penicillin allergy in patients with a positive skin test is significantly higher $(30 \%)$, while provocation tests in patients with a negative skin test in spite of a positive history have only shown $3 \%$ positive reactions [20]. The experience with RAST is similar: a positive RAST does not necessarily imply adverse reactions, and negative RASTs do not exclude allergy [29]. In the single patient, the synopsis of skin test, in vitro test results, and history should be evaluated in a risk-benefit consideration towards the desired therapeutic effect. Penicillin allergy is not life-long. Skin test studies in penicillinallergic patients show that allergy to penicillin $\mathrm{G}$ as well as PPL decreases over the years.

Penicillin and cephalosporins of the first generation have shown a cross-reactivity of $10 \%$; this does not hold true for the newer cephalosporins (third generation].

$\beta$-Lactam antibiotics (penicillin and cephalosporin) differ by various side chains of the $\beta$ lactam ring structure whereby cephalosporins have an additional substitution at the 3-position of the dihydrothiazine ring.

While 10 years ago the most frequent IgE-mediated sensitizations were due to the penicilloyl group, in recent years the spectrum has changed towards an increasing number of reactions to minor determinants and amoxicillin [34].

If penicillin treatment is life-saving, hyposensitization can be attempted with slowly in- creasing doses with the utmost caution [54]. Fortunately, penicillin can be replaced for most indications by alternative antibiotics. Very special indications remain: streptococcal endocarditis, life-threatening Pseudomonas infection, sepsis with serratia or neurosyphilis.

\subsection{Analgesics}

Anaphylactoid reactions after analgesics represent the major problem in allergy due to the wide use of these drugs. They may be elicited via different mechanisms: opiates are direct histamine liberators. The most commonly used agents in "mild" analgesics are salicylates, para-aminophenol derivatives, pyrazolones, as well as other contents like vitamins or codeine $[28,43,59]$. Combination drugs are commonly used in many countries as well. The identification of the eliciting substance is the major aim of allergy diagnosis. Skin test procedures have limited sensitivity. However, strongly positive $(+++)$ prick reactions often have diagnostic relevance. Intradermal reactions are more difficult to evaluate; adequate controls are crucial! Positive skin test reactions after codeine- or opioid-containing analgesics are a sequel of direct histamine liberation. Rarely, IgE-mediated reactions against opiates have been reported (e.g., morphine) [19].

The relevance of positive prick tests increases with increasing severity of the anaphylactoid reaction in history. Twenty-five percent of patients with grade III anaphylactic reactions (shock) had positive prick test reactions in our study, while in patients with skin symptoms only (grade I) there were positive skin tests in only $7 \%$ [43].

For most cases, OPTs are required for final diagnosis to avoid life-threatening reactions in the future and offer tolerable alternatives. OPT has to be performed under emergency conditions. A slow increase in dose from $10 \%$ via $50 \%$ to $100 \%$ of a usual single dose of a substance has been proven useful; in very severe reactions (e.g., propyphenazone anaphylaxis) starting with $1 \%$ or $2.5 \%$ of a single dose is recommended. Provocation tests have to be performed blinded and placebo controlled in order to avoid psychosomatic interactions. The 
results of OPT with analgesics show characteristic reaction patterns: $40 \%$ of our patients reacted to acetylsalicylic acid with concomitant reactions to other analgesics. These patients had negative skin tests and possible pseudo-allergic mechanisms. In contrast, $50 \%$ of patients only reacted to pyrazolone compounds, with occasional positive skin reactions suggesting allergic mechanisms. It was interesting that there was no cross-reaction between different pyrazolones such as metamizol (dipyrone) and propyphenazone [43]. Eight percent of our patients also reacted to para-aminophenol derivatives such as acetaminophen. The common practice of avoiding OPTs and just recommending acetaminophen as alternative is not justified.

We use a standard block of analgesics for OPT comprising acetylsalicylic acid (ASA), acetaminophen, dipyrone, propyphenazone, tramadol, ibuprofen, and sometimes nefopam or dextropropoxyphen. For the special problem of ASA idiosyncrasy, see Sect. 5.7.3.

It should be stressed that with other substances suspected in a mixed preparation these also have to be tested including also additives.

\subsection{Insulin}

With increasing purity of insulin preparations, the previously frequent incompatibility reactions have become rare. Insulin of different species shows pronounced cross-reactivity. Even after the introduction of recombinant human insulin, allergic reactions have been observed. The unusual route of administration (subcutaneous), possible impurities, additives (depot substances such as protamine, zinc, preservatives such as surfen, phenolcresol, or glycerin acetate), as well as unphysiological molecular structures (aggregates of insulin) have been discussed [57]. A genetic association with HLA-D 3 has been suggested.

Interestingly, some patients with type I diabetes have insulin autoantibodies, without ever having been treated with insulin, persisting for years and sometimes occurring with antibodies against cytoplasmic island cell antigens [57].

The clinical symptoms of insulin allergy vary; there are many different types of allergic reactions to insulin. Granulomatous reactions in patients allergic to surfen at the injection site need to be mentioned. Maybe the lipatrophy sometimes observed after insulin injection is also immunologically mediated $[18,57]$.

Almost half of patients under insulin treatment form antibodies of $\operatorname{IgE}$ and IgG class against insulin without clinical incompatibility. Sometimes high titers of neutralizing IgG antibodies against insulin give rise to insulin resistance [18], a phenomenon that may be classified under type VI reactions (see Table 5.76).

Anaphylactic reactions to insulin represent the major problem; for diagnosis, skin tests (start with $0.01 \mathrm{U}$ in a prick or $0.0001 \mathrm{U}$ intradermally) as well as RAST and histamine release are used.

When insulin allergy is diagnosed, the indication for insulin therapy should be evaluated. If this is given, hyposensitization under inpatient conditions can be attempted (see above). If the patient has received insulin within the previous $24 \mathrm{~h}$, the dose is reduced to one-tenth of the last dose and increased daily by $5 \mathrm{U}$.

If the last insulin injection dates back further, hyposensitization with human recombinant insulin is performed as rush hyposensitization (Table 5.84). The starting dose represents $1 / 100$ of the last positive prick test concentration.

\subsection{Heparin}

Heparin and heparinoids are glucosaminoglycans (molecular weight 3,000 to 40,000) and are

Table 5.84. Schedule of rush hyposensitization in insulin allergy

\begin{tabular}{llllrl} 
Day & Dose & $\begin{array}{l}\text { Adminis- } \\
\text { tration }\end{array}$ & Day & Dose & $\begin{array}{l}\text { Adminis- } \\
\text { tration }\end{array}$ \\
\hline 1 & 0.0001 & i.c. & 4 & 8.0 & s.c. \\
& 0.001 & i.c. & & 12.0 & s.c. \\
& 0.01 & i.c. & & 16.0 & s.c. \\
& 0.1 & i.c. & 5 & 20.0 & s.c. \\
& 0.5 & i.c. & 6 & 25.0 & s.c. \\
& 1.0 & i.c. & 7 & 30.0 & s.c. \\
& 2.0 & s.c. & 7 & & \\
& 4.0 & s.c. & & & \\
& 6.0 & s.c. & & & \\
\hline
\end{tabular}


used for anticoagulation. Mostly, they are prepared from mucosa of pig intestine or beef lung. Allergic reactions against heparin may be mediated via different mechanisms (type I to type IV). Anaphylactic reactions are rare but have been reported (cited by Zürcher and Krebs; Sect. 5.7.3). Cytotoxic reactions in the sense of heparin-induced thrombocytopenia have been covered in Sect. 5.2.

More frequent are local reactions manifesting either as the Arthus reaction with leukocytoclastic vasculitis or as a recently more commonly occurring indurating dermatitis type IV reaction $[33,37]$. Apart from the exclusion of allergic sensitization against xenogeneic animal proteins, testing is done by prick and intradermal tests as well as subcutaneous provocation testing. There are considerable cross-reactions, sometimes also with low molecular heparinoids, which should always be tested as possible alternatives.

In some cases, recombinant hirudin (Lepirudin) can be recommended after negative provocation testing in patients with severe heparin allergy and contraindication for coumarin derivatives.

\subsubsection{Rare Drug Reactions}

With the new development of recombinant drugs and gene technology, also new side effects of drugs should be expected such as against:

- Recombinant drugs

- Monoclonal antibodies (even if hybrids with human immunoglobulin form large parts of the protein and mouse sequences are only small)

- Reactions against viral vectors during gene therapy

In the United States, a fatal case in a gene therapy study with adenovirus as the vector has been brought to public attention. The precise mechanisms are not clear; overstimulation of the innate immune system with massive secretion of various cytokines, especially interleukin-6 and TNF, leading to shock lung [acute respiratory distress syndrome (ARDS) and multiorgan failure] have been discussed.

\subsubsection{HIV Infection and Drug Allergy}

Adverse drug reactions are a major problem for HIV patients, especially exanthematous drug eruptions, which are a hundred times more frequent in HIV patients than in the general population [11]. Maculopapulous eruptions, unspecific "hypersensitivity syndrome" and rare complications such as "metabolic lipodystrophy syndrome" have been observed under combined highly active antiretroviral therapy (HAART) [38].

While previously sulfonamides and other antimicrobials were the most frequent eliciting agents of adverse drug reactions, recently nucleoside reverse transcriptase inhibitors (e.g., abacavir), non-nucleoside reverse transcriptase inhibitors (e.g., delavirdin, efavirenz, nevirapine, etc.) as well as protease inhibitors (like amprenavir) have become common [38]. The reasons for the increased prevalence of exanthematous drug eruptions in HIV infections are not clear. Besides the immanent challenge due to the multiple pharmacotherapy with drugs to be taken continuously, the use of very different and new substances with ill-defined side reactions needs to be discussed. Also rather high doses and possible metabolic interactions may be considered as well as the general situation of an overstimulated immune system with upregulation of co-stimulatory molecules, cell surface receptors, and cytokine secretion. 


\section{References}

1. Aberer W, Kränke B (1997) Überempfindlichkeitsreaktionen auf Impfstoffe. Allergologie 20:407-411

2. Adkinson NF (1998) Drug allergy. In: Middleton E, Reed CE, Ellis EF, Adkinson NF, Yunginger JW, Busse WW (eds) Allergy: principles and practice. CV Mosby, St. Louis, pp 1212-1224

3. Baldo BA (2000) Diagnosis of allergy to penicillins and cephalosporins. Structural and immunochemical considerations. Allergy Clin Immunol Int 12:206-212

4. Bates DW, Cullen DJ, Laird N, et al. (1995) Incidence of adverse drug events and potential adverse drug events. JAMA 274:29-34

5. Berg PA, Daniel PT, Brattig N (1987) Immunologie und Nachweis medikamentöser Allergien. In: Fuchs E, Schulz KH (eds) Manuale allergologicum IV, 11. Dustri, München-Deisenhofen, pp $1-13$

6. Bircher AJ (1996) Arzneimittelallergie und Haut. Thieme, Stuttgart

7. Bircher AJ (2001) Hyposensibilisierung bei Arzneimittelallergie. In: Ring J, Darsow U (eds) Allergie 2000. Dustri, München-Deisenhofen, pp 219-228

8. Brockow K, Romano A, Blanca M, Ring J, Pichler W, Demoly P (2002) General considerations for skin test procedures in the diagnosis of drug hypersensitivity. Allergy 57:45-51

9. Classen DC, Pestotnik SL, Evans RS, Burke JP (1991) Computerized surveillance of adverse drug events in hospital patients. JAMA 266: 2847-2851

10. Coleman JW, Blanca M (1998) Mechanisms of drug allergy. Immunol Today 19:196-198

11. Demoly P, Bousquet J (2001) Epidemiology of drug allergy. Curr Opin Allergy Clin Immunol 1:305-310

12. Demoly P, et al. (2004) Provocative testing. Allergy (in press)

13. DeShazo RD, Kemp SF (1997) Allergic reactions to drugs and biologic agents. JAMA 278:1895-1906

14. Dogliotti M (1968) An instance of fatal reaction to the penicillin scratch test. Dermatologica 136: 489-496

15. Eapen SS, Connor EL, Gern JE (2000) Insulin desensitization with insulin lispro and an insulin pump in a 5-year-old child. Ann Allergy Asthma Immunol 85:395-397

16. Eichler G, Merk HF (1997) Unerwünschte Arzneimittelreaktionen durch Antibiotika. Allergologie $20: 368-374$

17. Fam AG, Dunne SM, Iazzetta J, Paton TW (2001) Efficacy and safety of desensitization to allopurinol following cutaneous reactions. Arthritis Rheum 44:231 - 238

18. Federlin K (1974) Insulinallergie. Dtsch Med Wochenschr 99:535-537
19. Fisher MM, Baldo BA (2000) Immunoassays in the diagnosis of anaphylaxis to neuromuscular blocking drugs: the value of morphine for the detection of IgE antibodies in allergic subjects. Anaesth Intens Care 28:167-170

20. Gadde J, Spence M. Wheeler B, Adkinson NF (1993) Clinical experience with penicillin skin testing in a large inner-city STD clinic. JAMA 270:2456-2463

21. Gall H, Merk H, Scherb W, Sterry W (1994) Anticonvulsiva-Hypersensitivitätssyndrom auf Carbamazepin. Hautarzt 45:494-498

22. Hedin H, Richter W, Ring J (1976) Dextran-induced anaphylactoid reactions in man: role of dextran reactive antibodies. Int Arch Allergy Appl Immunol 52:145-152

23. Hoigné R (1965) Arzneimittel-Allergien. Klinische und serologisch-experimentelle Untersuchungen. Huber, Bern

24. Hoigné R, Schlumberger HP, Vervloet D, Zoppi M (1993) Epidemiology of allergic drug reactions. In: Burr ML (ed) Epidemiology of clinical allergy. Monogr Allergy 31. Karger, Basel, pp $147-170$

25. Jäger L, Merk HF (1996) Arzneimittel-Allergie. Gustav Fischer, Jena

26. Karch FE, Lasagna L (1975) Adverse drug reactions. A critical review. JAMA 234:1236-1241

27. Kelkar PS, Li JT-C (2001) Cephalosporin allergy. N Engl J Med 345:804-811

28. Kleinhans D (1985) Reaktionen vom Soforttyp auf Analgetika-Wirkstoffe. Allergie und Intoleranz. Allergologie 8:254-259

29. Kraft D, Wide L (1976) Clinical patterns and results of radioallergosorbent test (RAST) and skin tests in penicillin allergy. Br J Dermatol 94: 593-601

30. Lasagna L (1986) The placebo effect. J Allergy Clin Immunol 78:161 - 165

31. Lazarou J, Pomeranz BH, Corey PN (1998) Incidence of adverse drug reactions in hospitalized patients. A meta-analysis of prospective studies. JAMA 279:1200 - 1205

32. Maucher OM, Fuchs A (1983) Kontakturtikaria im Epikutantest bei Pyrazolonallergie. Hautarzt 34:383-386

33. Menzel SH, Vente C, Fuchs T (1997) Heparin-Allergie. Allergo J 6:372-376

34. Merk H (1989) Arzneimittelallergie: Einfluß des Fremdstoff-Metabolismus. Allergologie 12:171173

35. Merk HF (1998) Skin metabolism. In: Lepoittevin JP, Basketter DA, Goossens KA, Karlberg AT (eds) Allergic contact dermatitis. Springer, Berlin Heidelberg New York, pp 68-80

36. Moneret-Vautrin D, Laxenaire MC (1993) The risk of allergy related to general anaesthesia. Clin Exp Allergy 23:629-633

37. O’Donnell BF, Tan CY (1993) Delayed hypersensitivity reaction to heparin. Br J Dermatol 129: $634-636$ 
38. Pallela FJ, Delaney KM, Moorman AC, et al. (1998) Declining morbidity and mortality among patients with advanced human immunodeficiency virus infection. HIV Outpatient Study Investigators. N Engl J Med 338:853 - 860

39. Parker CW (1975) Drug allergy. N Engl J Med 292:511- 521

40. Pichler WJ (1993) Diagnostische Möglichkeiten bei Medikamentenallergien. Schweiz Med Wochenschr 123:1183-1192

41. Pichler WJ, Yawalkar N (2000) Allergic reactions to drugs: involvement of T cells. Thorax 55 [Suppl 2]:S61-S65

42. Pouyanne P, Haramburu F, Imbs JL, Bégaud B (2000) Admissions to hospital caused by adverse drug reactions: cross incidence study. $\mathrm{Br}$ Med J 320:1036

43. Przybilla B, Bonnländer AR, Ring J (1986) Anaphylactoid reactions to mild analgesics. In: Ring J, Burg G (eds) New trends in allergy. II. Springer, Berlin Heidelberg New York, pp 262-271

44. Przybilla B, Fuchs T, Ippen H, et al. (1991) Empfehlungen für die Aufklärung von Überempfindlichkeitsreaktionen auf Arzneimittel. Allergologie 14:58-60

45. Reilly TP, Lash LH, Dollo MA, et al. (2000) A role for bioactivation and covalent binding within epidermal keratinocytes in sulfonamide-induced cutaneous drug reactions. J Invest Dermatol 114:1164-1173

46. Ring J (1978) Anaphylaktoide Reaktionen nach Infusion natürlicher und künstlicher Kolloide. Springer, Berlin Heidelberg New York

47. Ring J (1986) Exacerbation of eczema by formalin-containing hepatitis B vaccine in a formaldehyde-allergic patient. Lancet 2:522 - 523

48. Ring J (1987) Diagnostik von Arzneimittel-bedingten Unverträglichkeiten. Hautarzt 38:516-522

49. Schaub N, Bircher AJ (2000) Severe hypersensitivity syndrome to lamotrigine confirmed by lymphocyte stimulation in vitro. Allergy 55: 191-193

50. Schnyder B, Pichler WJ (2000) Skin laboratory tests in amoxicillin- and penicillin-induced morbilliform skin eruption. Clin Exp Allergy 30: $590-595$

\subsubsection{Pseudo-allergic Drug Reactions}

\subsubsection{Definition and Elicitors}

Adverse reactions mimicking clinically allergic diseases without detectable immunologic sensitization are called "pseudo-allergic" reactions $[9,13,15,28]$. In principle, pseudo-allergic reactions exist for all types of allergic reactions (see Table 5.85); the most frequent pseudo-allergic reactions, however, are immediatetype reactions resembling anaphylaxis [23].
51. Schulz KH, Kasemir HD (1990) Arzneimittelallergie. In: Fuchs E, Schulz KH (eds) Manuale allergologicum, vol 3. Dustri, München-Deisenhofen, pp $1-71$

52. Solensky R, Earl HS, Gruchalla RS (2000) Clinical approach to penicillin-allergic patients: a survey. Ann Allergy Asthma Immunol 84:329-333

53. Stejskal VDM, Olin RG, Forsbeck M (1986) The lymphocyte transformation test for diagnosis of drug-induced occupational allergy. J Allergy Clin Immunol 77:411 - 426

54. Sullivan TJ (1982) Antigen-specific desensitization of patients allergic to penicillin. J Allergy Clin Immunol 69:500-508

55. Templeton B (1965) Suicide by anaphylaxis attempted with penicillin. JAMA 192:264

56. Van Arsdel PP Jr (1982) Allergy and adverse drug reactions. J Am Acad Derm 6:833-845

57. Velcovsky H-G, Federlin K (1987) Unverträglichkeitsreaktionen gegenüber Insulin, auch Humaninsulin, bei Diabetikern. Allergologie 10:287-296

58. Vervloet D, Durham S (1998) Adverse reactions to drugs. Br Med J 316:1511 - 1514

59. Vieluf D (2000) Arzneimittelreaktionen. In: Przybilla B, Bergmann K, Ring J (eds) Praktische allergologische Diagnostik. Steinkopff, Darmstadt, pp 224-242

60. Vieluf D, Ring J (2001) Der Allergie-Paß. MMW Fortschr Med 143:608-610

61. Vittorio CC, Muglia JJ (1995) Anticonvulsant hypersensitivity syndrome. Arch Intern Med 155:2285-2290

62. De Weck AL, Bundgaard M (eds) (1984) Allergic reactions to drugs. Handbook of experimental pharmacology, vol 63. Springer, Berlin Heidelberg New York

63. De Weck AL (1997) Zellulärer Allergen-Stimulierungstest (CAST). Allergologie 20:487 - 502

64. Weiss ME, Adkinson NF (1991) Allergy to protamine. Clin Rev Allergy 9:339-355

65. Zanni MP, von Greyerz S, Schnyder B, et al. (1998) HLA-restricted, processing- and metabolism-independent pathway of drug recognition by human ab T lymphocytes. J Clin Invest 102:1591 1598

The most common drugs eliciting pseudo-allergic anaphylactic reactions are radiographic contrast media, local anesthetics, i.v. anesthetics, volume substitutes, acetylsalicylic acid, and other non-steroidal anti-inflammatory drugs (Table 5.86). The case of a severe anaphylactic reaction after infusion of a colloid volume substitute (hydroxyethyl starch HES) is shown in Fig. 5.70.

Asthma and urticaria are the most common clinical manifestations of acetylsalicylic acid 


\begin{tabular}{|c|c|c|}
\hline Clinical symptoms & Allergy & Pseudo-allergy \\
\hline Anaphylactic reaction & $\begin{array}{l}\text { IgE } \\
\text { IgG }\end{array}$ & $\begin{array}{l}\text { Direct mediator release } \\
\text { Direct complement activation } \\
\text { Neuropsychogenic reflexes } \\
\text { Embolic-toxic reaction }\end{array}$ \\
\hline Cytotoxic reaction & IgG, IgM & G6PDH deficiency \\
\hline $\begin{array}{l}\text { Serum sickness, } \\
\text { vasculitis }\end{array}$ & IgG, IgM & $\begin{array}{l}\text { Shwartzman-Sanarelli phenomenon } \\
\text { Aggregate-induced reaction } \\
\text { Jarisch-Herxheimer reaction } \\
\text { Embolia cutis }\end{array}$ \\
\hline Eczema, exanthema & T lymphocytes & $\begin{array}{l}\text { Phototoxic dermatitis } \\
\text { B-cell stimulation (ampicillin), } \\
\text { lichen planus (gold) }\end{array}$ \\
\hline Granuloma & $\begin{array}{l}\text { T lymphocytes }+ \\
\text { macrophages }\end{array}$ & Foreign body granuloma \\
\hline $\begin{array}{l}\text { Organopathy or } \\
\text { autoallergy }\end{array}$ & $\begin{array}{l}\text { Autoantibodies } \\
\text { (drug-induced LE) }\end{array}$ & Cholestasis \\
\hline
\end{tabular}

Table 5.85. Mechanisms of different types of drug-induced allergy and pseudo-allergy (examples)
Table 5.86. Drugs eliciting pseudo-allergic anaphylactic reactions (examples)

- Radiographic contrast media

- Colloidal volume substitutes

- Gammaglobulins

- Antibiotics

- Intravenous anesthetics

- Opioids

- Muscle relaxants

- Local anesthetics

- Cyclooxygenase inhibitors

- Drugs increasing microcirculatory flow

idiosyncrasy. These patients are often also suffering from nasal polyps and chronic sinusitis (Samter's triad) [30]. Certain forms of drug-induced hepatopathy possibly may be regarded as pseudo-allergic reactions, such as cholestatic (phenothiazine, imipramine) or hepatocellular icterus (amphotericin B, furosemide, isoniazid).

Hemolytic anemias in patients with specific enzyme deficiencies (glucose-6-phosphate dehydrogenase or glutathione reductase) occur after administration of certain drugs, corresponding to "pseudo-allergic" reactions of type II (Table 5.87).

The pathophysiology of pseudo-allergic reactions is variable and not well understood (Table 5.88): Besides direct complement activation, direct mediator liberation as well as enzyme deficiencies, also embolic-toxic reac-

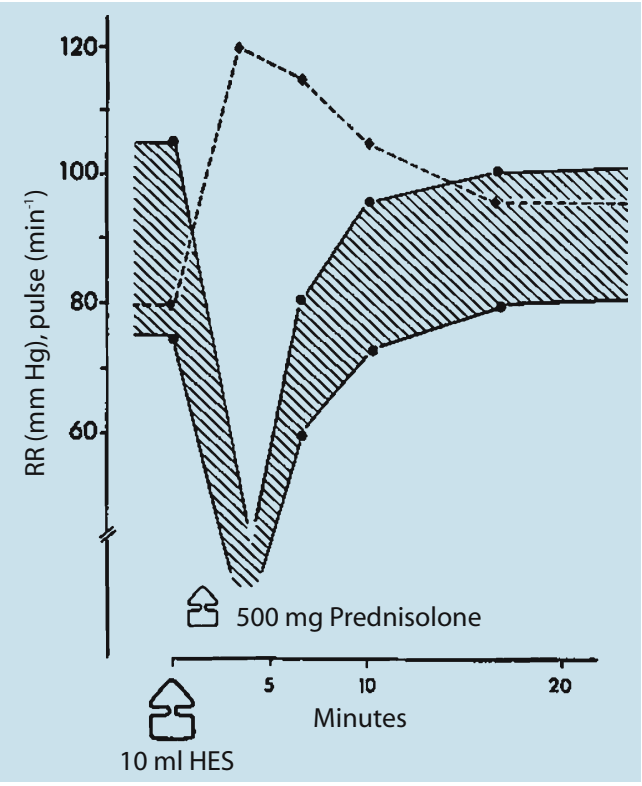

Fig. 5.70. Clinical symptoms of an anaphylactic reaction following the infusion of hydroxyethyl starch (HES)

tions, neuropsychogenic mechanism reflex reactions, and Jarisch-Herxheimer reaction may be mentioned here. For only a few drugs are the pathomechanisms established. The situation is complicated by the fact that one and the same drug may elicit both allergic and pseudo-allergic reactions! Table 5.89 gives some rules for 
Table 5.87. Drugs and other substances able to induce hemolysis in patients with enzyme deficiency (from [11])

\begin{tabular}{|c|c|c|c|}
\hline Glucose-6-phosphate dehydrog & ase deficiency & Glutathione reduct & deficiency \\
\hline Drug & Food & Drug & Other substances \\
\hline Primaquine & Fava beans & Nitrofurantoin & Nitro solvent \\
\hline Atebrin & Leguminosae & Primaquine & Thallium \\
\hline Anilin derivatives & Red- and black currants & & Resochin \\
\hline Acetanilide & & Azulfidine & \\
\hline Naphthalene and derivatives & & Dapsone (DADPS) & \\
\hline Phenylhydrazine & & Chloramphenicol & \\
\hline Acetylphenylhydrazine & & Phenacetin & \\
\hline Methylene blue & & Pentazolidine & \\
\hline Phenacetin & & Coumarin & \\
\hline Aminopyrine & & & \\
\hline p-Aminosalicylic acid & & & \\
\hline Sulfones and Sulfonamides & & & \\
\hline Chloramphenicol & & & \\
\hline Vitamin $\mathrm{K}$ and analogues & & & \\
\hline Azulfidine & & & \\
\hline Dimercaprol & & & \\
\hline
\end{tabular}

Table 5.88. Examples of possible mechanisms of pseudo-allergic reactions

Table 5.89. Rough criteria for distinction of allergic from pseudoallergic reactions

$\begin{array}{ll}\begin{array}{l}\text { Direct complement activation } \\ \text { (Classic) }\end{array} & \begin{array}{l}\text { Gammaglobulin (standard) (aggregated } \\ \text { IgG) } \\ \text { Plasmaprotein solutions (aggregated IgG) } \\ \text { Radiographic contrast media } \\ \text { Intravenous anesthetics } \\ \text { (Bypass activation) }\end{array} \\ \text { Gelatin } \\ \text { Radiographic contrast media } \\ \text { Relaxants } \\ \text { Intravenous anesthetics } \\ \text { Antibiotics (polymyxin) } \\ \text { (Acetylsalicylic acid?) }\end{array}$

\begin{tabular}{ll} 
Allergy & Pseudo-allergy \\
\hline Sensitization & No sensitization \\
Reaction after repeated contact & Reaction at first contact \\
Rare $(<5 \%)$ & $\begin{array}{l}\text { Frequent }(>5 \%) \\
\text { "Unspecific" symptoms }\end{array}$ \\
Typical clinical symptoms & $\begin{array}{l}\text { Dose dependent (speed dependent in } \\
\text { infusions) }\end{array}$ \\
Fow eliciting doses & $\begin{array}{l}\text { Family history negative (exception: } \\
\text { enzyme defects) }\end{array}$ \\
Moderate psychologic influence & Strong psychologic influence \\
\hline
\end{tabular}


the differentiation of pseudo-allergic and allergic reactions (cum grano salis).

In the following, some clinically common pseudo-allergic reactions will be discussed.

\subsubsection{Radiographic Contrast Media}

The majority of adverse reactions after radiographic contrast media (RCM) are non-immunologic in origin. Occasional cases of true allergy have been published. In recent years, late or delayed reactions (4-8 h) after RCM infusion have been reported, which may correspond to a true type IV reaction (positive patch tests) [1, 32]. RCM are direct histamine and serotonin liberators [25] as well as complement activators [38]. Interactions with the coagulation and kallikrein-kinin system have been reported [17, 28].

While 20 years ago toxic effects of ionic contrast media as well as high osmolarity were considered pathophysiologically important, we now know that even after non-ionic solutions with physiological osmolarity, severe side reactions (even fatalities) may occur.

There is no reliable method of predicting the risk of an RCM reaction in the individual patient. Iodine allergy is a type IV reaction in the sense of a classic allergic contact dermatitis and is not primarily linked to anaphylactic reactions after iodinated RCM, where iodine is bound within the benzoic acid ring structure! Occasional cases of systemic contact dermatitis may be elicited by iodine since in some RCM solutions minute amounts of free iodine (picogram range) have been detected.

According to our experience, the risk of an RCM reaction is not increased in atopics or patients with other drug reactions. Only in patients with a clear-cut history of severe anaphylactic reactions after RCM infusion is the risk significantly elevated to $30 \%$ (normal individuals around $10 \%$ ) (cited in [24]).

Some patients may react to a prick test with systemic reactions. Therefore, we perform skin tests as a minimum variant of provocation under emergency conditions. The occasional intravenous provocation testing with RCM is a matter of clinical research.

Uncontrolled "test injections" of small volumes may elicit severe anaphylactic reactions.
For prophylaxis, antihistamines and glucocorticosteroids, beta-adrenergics, antidepressives, as well as hypnotic suggestion have been recommended.

In a prospective placebo-controlled study of our own, we were able to show a significant prophylactic effect of a combined $\mathrm{H}_{1}$ and $\mathrm{H}_{2}$ antagonist intravenous pretreatment (clemastine + cimetidine $5 \mathrm{~min}$ prior to RCM infusion) [26].

\subsubsection{Plasma Protein Solutions}

After intravenous injection of standard gammaglobulin, severe anaphylactic reactions may occur; therefore, these preparations are only applied intramuscularly. Gammaglobulin aggregates present in the solutions activate the complement system via the classic pathway (reverse immune complex reaction). Protein aggregates are also present in other plasma protein solutions and severe systemic reactions have been observed [23]. The liberation of kinins and kinin-activating substances present in some human serum albumin batches is discussed. The common intravenous gammaglobulins are chemically or physically modified on the Fc part, thus preventing aggregate formation and complement activation. Therefore, they are generally well tolerated.

\subsubsection{Gelatine Volume Substitutes}

After infusion of gelatine volume substitutes especially the urea-linked modification using di-isocyanate (Haemaccel) - a dose- and speed-dependent histamine liberation has been described $[8,19]$. Anaphylactic reactions after gelatine infusion were very frequent in the 1980 s (up to $30 \%$ !), but have been reduced by better production with lower isocyanate concentrations. Pretreatment with histamine $\mathrm{H}_{1}$ and $\mathrm{H}_{2}$ antagonists is an effective prophylaxis. Occasional true IgE-mediated reactions to gelatine have been reported [42].

\subsubsection{Intravenous Anesthetics}

Intravenous anesthetics (Table 5.90) have pharmacological effects, giving rise to complica- 
Table 5.90. Intravenous anesthetics

\begin{tabular}{ll}
\hline Barbiturates & Opiates \\
- Thiopental & Morphine \\
- Methohexital & - Fentanyl \\
- Hexobarbital & Alfentanil \\
Dhiobutabarbital & Droperidol \\
Diazepines & Others \\
- Diazepam & - Propanidide \\
& - Ketamine \\
& - Etomidate \\
\hline
\end{tabular}

tions like hypotension or tachycardia or have central stimulating effects such as ketamine and propanidide, or sedative effects like barbiturates.

Various mechanisms have been discussed to explain anaphylactic reactions. Besides classic IgE-mediated reactions (barbiturates), pseudo-allergic mechanisms with direct complement activation and histamine liberation may play a role (especially opioids) $[8,24]$. Recently, IgE-mediated reactions to opiates and relaxants have been reported [19].

A careful history is the mainstay of diagnosis of these adverse reactions. The allergist needs the cooperation of the anesthetist, who should record the exact time sequence of the substances administered! When skin tests are performed, the histamine-liberating properties of certain anesthetics need to be considered.

\subsubsection{Muscle Relaxants}

The most important side effects of muscle relaxants are:

- Prolonged muscle relaxation

- Anaphylactic reaction

- Malignant hyperthermia

Prolonged muscle relaxation mostly is due to a genetic or drug-induced inhibition of cholinesterase (e.g., neostigmine, organophosphates, hexafluronium, quinidine, cyclophosphamide, aprotinin) or a muscular disease (myasthenia gravis).

Muscle relaxants are direct histamine liberators. It is under discussion whether this property is connected with the frequently observed tachycardia and hypotension. However, in se- vere anaphylactic reactions, true IgE-mediated allergies against muscle relaxants have been observed with cross-reactivity related to the quarternary ammonium group [39].

If a depolarizing relaxant (e.g., succinylcholine) is not tolerated, a non-depolarizing agent (e.g., alcuronium) may be tolerated.

Malignant hyperthermia occurs in patients with myopathy due to increased calcium influx and contractility with rapid increase in body temperature without shivering, tachycardia, tachypnea, muscle rigidity, and cardiac arrhythmia. The disease is familiar. For diagnosis, muscle biopsy with in vitro stimulation and contractility study is available. Molecular genetic tests found a relevant mutation in the ryanodin receptor 1 gene (RYR-1) [38]. Effective therapy uses the hydantoin derivative dantrolen (1 mg/kg body wt. i.v.), oxygen, and slow reduction of body temperature.

\subsubsection{Local Anesthetics}

So-called allergic reactions against local anesthetics are common in the allergist's office; however, true allergies are rare, except for the type IV reactions in classic allergic contact dermatitis [29]. Most anaphylactic reactions are non-immunologic in origin with unspecific symptoms. Intradermal tests cannot be related to clinical manifestation [14]. As pathomechanism, psychoneurogenic reflex mechanisms with vasovagal components have been suggested. In practice, the procedure of "subcutaneous provocation testing" (Table 5.91) is recommended with slowly increasing doses under careful observation in emergency conditions subcutaneously.

The role of preservatives contained in some solutions, especially in larger bottles, has to be

Table 5.91. Local anesthetics: provocation tests, 20-min interval

\begin{tabular}{llll}
\hline $\begin{array}{l}\text { Prick test } \\
\text { if negative: }\end{array}$ & & \\
$\qquad$ & 1. I.d. & $1: 10$ & $0.1 \mathrm{ml}$ \\
& 2. S.c. & $1: 10$ & $0.1 \mathrm{ml}$ \\
& 3. S.c. & Undiluted & $0.1 \mathrm{ml}$ \\
& 4. S.c. & Undiluted & $0.5 \mathrm{ml}$ \\
& 5. S.c. & Undiluted & $1.0 \mathrm{ml}$ \\
6. S.c. & Undiluted & $2.0 \mathrm{ml}$ \\
\hline
\end{tabular}


Table 5.92. Local anesthetic (LA) incompatibility: "reverse placebo provocation" (in patients reacting to placebo and psychological influence)

\begin{tabular}{ll} 
Procedure & $\begin{array}{l}\text { Patient } \\
\text { information }\end{array}$ \\
\hline 1. Skin test & $\begin{array}{l}\text { Open } \\
\text { 2. S.c. provocation with LA 1 }\end{array}$ \\
"with LA" \\
3. S.c. provocation with LA 2 & "another LA" \\
5. S.c. provocation with NaCl & "another LA" \\
5. S.c. provocation with LA 1 & "NaCl" \\
6. S.c. provocation with LA 1 & LA 1 \\
\hline
\end{tabular}

evaluated by testing preservative-free substances (mostly in ampules).

If there is psychologic influence and patients also react to placebo, we use the procedure of "reverse placebo provocation" (Table 5.92), giving the patient "verum" under the label "placebo." If the local anesthetic then is well tolerated, the patient is completely informed and the same procedure is repeated on the next day openly.

\subsubsection{Acetylsalicylic Acid and Non-steroidal Anti-inflammatory Drugs (NSAIDs)}

Toxic effects of NSAIDs such as gastric irritation and inhibition of platelet aggregation need to be differentiated from pseudo-allergic hypersensitivity reactions with variable manifestation (Table 5.93).

The pathomechanism of acetylsalicylic acid (ASA) idiosyncrasy ( $15 \%$ of asthma patients) has not yet been clearly elucidated. Direct mediator liberation $[3,4,5,15,21,27,36,40,41]$ has been discussed as well as direct complement activation, platelet stimulation and a shift in eicosanoid metabolism (Table 5.94). The

Table 5.93. Clinical manifestations of NSAID incompatibility

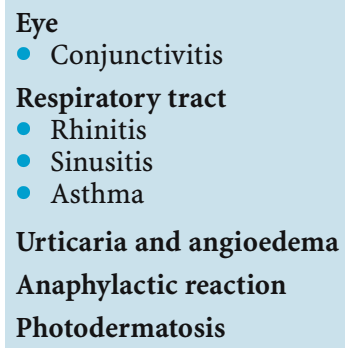

Table 5.94. Hypothetical concepts for pathophysiology of ASA idiosyncrasy

- Cyclooxygenase inhibition leads to diminished protective prostaglandins

- Cyclooxygenase inhibition leads to increased formation of lipoxygenase products

- Cyclooxygenase 1-inhibition is decisive

- Direct release of vasoactive mediators

- Activation of complement system

- Activation of coagulation and/or kallikreinkinin system

- Increased platelet reactivity

- Immune reaction against ASA metabolites or impurities

concomitant administration of NSAIDs and allergen can lead to increased reactions (ASA augmentation [20]) (see Sect. 5.1.4 on "Anaphylaxis").

The most prominent feature of analgesic idiosyncrasy (sometimes also called "intolerance syndrome" $[20,40]$ is the lack of immunologic cross-reactivity with other chemically related substances. However, there are pharmacologic cross-reactivities with similarly acting substances, e.g., other NSAIDs, but also chemicals such as food colorings (tartrazine) and preservatives (see Sect. 5.1.5 on "Food Allergy").

For diagnosis the provocation test is most important (see Sect. 5.7.1). Caveat: with too high doses of ASA, patients with aspirin-asthma may develop acute severe asthma attacks! We recommend beginning according to the intensity of symptoms in the history with 5-50 mg ASA and increasing doses at 2-h intervals to $100,200-500$ and eventually $500 \mathrm{mg}$.

Patients with chronic urticaria often react to ASA as well as other additives and colorings (see Sect. 5.1.6 on "Urticaria").

Several in vitro diagnostic techniques have been attempted in ASA idiosyncrasy; however, the observed effects (e.g., histamine release by ASA) have also been observed in patients tolerating ASA [3, 5, 27, 39]. Recently the cellular allergen stimulation test (CAST) has been favored, when after stimulation with $\mathrm{C} 5 \mathrm{a}, \mathrm{PAF}$ or F-Met-Leu-Phe increased leukotriene secretion is measured in patients with chronic urticaria and a positive ASA provocation test $[5,43]$. Direct stimulation with ASA in vitro, however, has yielded controversial results $[5,21,43]$. 
For therapy, avoidance is the primary principle: in nasal polyposis polypectomy is indicated; equally infectious sinusitis has to be treated.

By administrations of slowly increasing doses of ASA, in some patients "adaptive deactivation" is possible, leading to ASA tolerance, which makes the daily intake of $500 \mathrm{mg}$ or $650 \mathrm{mg}$ ASA necessary $[34,27,40]$. In some patients a decrease in relapses of nasal polyposis has been observed [34].

Adaptive deactivation with ASA in patients with chronic urticaria or anaphylactic reactions has not been convincingly achieved.

After the introduction of cyclooxygenase (COX) 2 inhibitors [10], many people were hopeful of having safe alternatives for patients with ASA idiosyncrasy $[6,31,36,37,45]$. There are, however, patients who react particularly to COX 2 inhibitors [12]. COX 2 inhibitors, therefore, cannot generally be regarded as safe alternatives in ASA idiosyncrasy.

\subsubsection{Additives}

Adverse drug reactions may not only be elicited by the active substance but also by additives in the preparation. Most additives have been added for galenic reasons (preservatives, antioxidants, stabilizers, filling substances, etc.); however, undesired ingredients may also be considered [16, 23, 28]. Some may be legal (such as high molecular residues or small particles $<30 \mu \mathrm{m}$ in infusion solutions) or illegal such as bacterial contaminants or pyrogens (Table 5.95).

Table 5.95. Additives in drugs as elicitors of anaphylactic reactions (examples)

\begin{tabular}{ll}
\hline - Depot mediators & (Penicillin preparations) \\
- Micell formers & (Cremophor EL) \\
(Injection solutions, \\
local anesthetics) \\
- Pulfites & (Protein solutions) \\
- Protein stabilizers & (Injection solutions, \\
- Benzylalcohol & (In tablets) $\mathrm{H}_{2} \mathrm{O}$ or saline) \\
- Colorings & (Dialysis) \\
\hline
\end{tabular}

\subsubsection{Other Pseudo-allergic Reactions}

For the sake of completeness the classical Jarisch-Herxheimer reaction should be mentioned in a chapter on pseudo-allergic reactions; by cell destruction (penicillin in syphilis), pyrogenic or vasoactive substances may be released and activate the complement system.

After administration (mostly intramuscular) of depot-penicillins occasional pseudo-allergic reactions have been observed with central nervous disturbances and cardiovascular symptoms, which have been called "embolic-toxic reactions" (Hoigné syndrome) [13]. Oily material of the depot emulsion may reach the intravasal lumen after injection and lead to microemboli. Whether a direct pharmacologic effect of procaine - sometimes also contained in these preparations - plays a pathogenic role remains open.

For the mechanisms of ampicillin rash see Sect. 5.7.3.

Generally, contaminants and impurities have to be considered whenever an adverse reaction remains unclear.

\subsubsection{Therapy and Prophylaxis}

The treatment of pseudo-allergic anaphylactic reactions follows the principles of anti-anaphylactic regimens (see Sect. 5.1.4). In unclear cases and with a history of pseudo-allergic reactions the prophylactic administration of histamine $\mathrm{H}_{1}$ - and $\mathrm{H}_{2}$-antagonists (intravenously $5 \mathrm{~min}$ prior to the drug) or orally together with glucocorticosteroids ( $18 \mathrm{~h}$ prior to administration) is recommended.

\section{References}

1. Brockow K, Ring J (1996) Mechanisms of pseudoallergic reactions due to radiographic contrast media. Allergy Clin Immunol Int 8:123-125

2. Brockow K, Vieluf D, Püschel K, Grosch J, Ring J (1999) Increased postmortem serum mast cell tryptase in a fatal anaphylactoid reaction to nonionic radiocontrast medium. J Allergy Clin Immunol 104:237-238

3. Capron A, Ameisen J, Joseph M, Auriault C, Tarnel $A B$, Caen J (1985) New functions for platelets and their pathological implications. Int Arch Allergy Appl Immunol 77:107-114 
4. Conroy MC, de Weck AL (1981) Effect of aspirin and indomethacin on histamine release from leukocytes of patients with suspected intolerance to aspirin. Int Arch Allergy Appl Immunol 66 [Suppl 1]:152-153

5. Czech W, Schöpf E, Kapp A (1995) Release of sulfidoleukotrienes in vitro: Its relevance in the diagnosis of pseudoallergy to acetylsalicylic acid. Inflamm Res 44:291 - 295

6. Dahlen B, Szczeklik A, Murray JJ (2001) Celecoxib in patients with asthma and aspirin intolerance (letter). N Engl J Med 344:142

7. Denborough MA, Lovell RRH (1960) Anaesthetic deaths in a family. Lancet II:362

8. Doenicke A, Koenig UD (eds) (1983) Immunologie in Anästhesie und Intensivmedizin. Sertürner Workshops Einbek. Springer, Berlin Heidelberg New York

9. Dukor P, Kallos P, Schlumberger HD, West GB (eds) (1980) Pseudo-allergic reactions, 3 vols. Karger, Basel

10. Fitzgerald GA, Patrono C (2001) The coxibs, selective inhibitors of cyclooxygenase-2. N Engl J Med 345:433-442

11. Gaetani GF, Luzatto L (1980) Haemolytic reactions induced by drugs and other agents: the role of red cell enzyme abnormalities and of abnormal haemoglobins. In: Dukor P, Kallos P, Schlumberger HD, West GB (eds) Pseudo-allergic reactions; involvement of drugs and chemicals. vol. 2, Karger, Basel, pp 1 - 19

12. Grimm V, Rakoski J, Ring J (2004) Selective COX2 inhibitors also can elicit symptoms in patients with aspirin idiosyncrasy. J Allergy Clin Immunol (in press)

13. Hoigné R (1962) Allergische und pseudo-allergische Reaktionen auf Penicillinpräparate. Acta Allergol 17:521

14. Incaudo G, Schatz M, Patterson R, Rosenberg M, Yamamoto E, Hamburger RN (1978) Administration of local anesthetics to patients with a history of prior adverse reaction. J Allergy Clin Immunol 61:339-345

15. Kallos P, Kallos L (1980) Histamine and some other mediators of pseudo-allergic reactions. In: Pseudo-allergic reactions: involvement of drugs and chemical, vol. 1. Karger, Basel, p 28

16. Kleinhans D, Galinsky T (1982) Zur möglichen Provokation eines Bronchialasthmas und einer Urtikaria durch Natriumdisulfit. Allergologie 4:120-121

17. Lasser EC, Lang JH, Lyon SG, Hamblin AE, Howard MM (1981) Prekallikrein-kallikrein conversion rate as a predictor of contrast media catastrophes. Radiology 140:11-15

18. Lorenz W, Doenicke A (1978) Histamine release in clinical conditions. Mt Sinai J Med N Y 45:357-386

19. Meßmer K, Lorenz W, Sunder-Plassmann L, Klövekorn WP, Hutzel M (1970) Histamine release as cause of hypotension following rapid colloid infusion. Arch Pathol Pharm 267:433 - 439

20. Paul E, Gall H-M, Mechlin A, Möller R, Müller I (2001) Acetylsalicylic acid (ASA)-augmentation in relation to ASA-intolerance. Allergo J 10: $269-272$

21. Pierzchalska M, Mastalerz L, Sanak M, et al. (2000) A moderate and unspecific release of cysteinyl leukotrienes by aspirin from peripheral blood leucocytes preludes its value for aspirin sensitivity in asthma. Clin Exp Allergy 30:1785 - 1791

22. Przybilla B, Ring J (1987) Pseudo-allergische Arzneimittelreaktionen: Pathophysiologie und Diagnostik. Z Hautkr 62:430 - 443

23. Ring J (1978) Anaphylaktoide Reaktionen nach Infusion natürlicher und künstlicher Kolloide. Springer, Berlin Heidelberg New York

24. Ring J, Brockow K (2004) Pseudo-allergische Arzneimittelreaktionen. In: Schultze-Werninghaus $\mathrm{G}$, et al. (eds) Manuale allergologicum, 2nd edn. Dustri, Munich (in press)

25. Ring J, Arroyave CM, Fritzler MJ, Tan EM (1978) In vitro histamine and serotonin release by radiographic contrast media (RCM). Complement dependent and independent release reaction and changes in ultrastructure of human blood cells. Clin Exp Immunol 32:105-118

26. Ring J, Rothenberger KH, Clauß W (1985) Prevention of anaphylactoid reactions after radiographic contrast media in fusion by combined histamine $\mathrm{H}_{1}$ - and $\mathrm{H}_{2}$-receptor antagonists: results of a prospective controlled trial. Int Arch Allergy Appl Immunol 78:9-14

27. Ring J, Walz U (1985) Indomethacin enhances in vitro histamine release induced by anti-IgE and Ca-Ionophore but inhibits $\mathrm{C} 5 \mathrm{a}$-induced release reactions from basophils of atopics and normals. Int Arch Allergy Appl Immunol 77:225 - 227

28. Ring J (1992) Pseudo-allergic reactions. In: Korenblat $\mathrm{PE}$, Wedner $\mathrm{HJ}$ (eds) Allergy: theory and practice. Saunders, Philadelphia, pp 243-264

29. Ruzicka T, Gerstmeier M, Przybilla B, Ring J (1987) Allergy to local anesthetics: comparison of patch test with prick and intradermal test results. J Am Acad Dermatol 16:1202-1208

30. Samter M, Beers RF (1968) Intolerance to aspirin. Clinical studies and consideration of its pathogenesis. Ann Intern Med 68:975-983

31. Sánchez-Borges M, Capriles-Hulett A, CaballeroFonseca F (2001) NSAID hypersensitivity in the COX-2 inhibitor era. ACI Int 13:211-218

32. Schick E, Weber L, Gall H (1996) Delayed hypersensitivity reaction to the non-ionic contrast medium iopromide. Contact Dermatitis 35:312

33. Simon RA (1984) Adverse reactions to drug additives. J Allergy Clin Immunol 74:623

34. Stevenson DD (1984) Diagnosis, prevention, and treatment of adverse reactions to aspirin and nonsteroidal antiinflammatory drugs. J Allergy Clin Immunol 74:617-622 
35. Stevenson DD, Simon RA (2001) Lack of cross-reactivity between rofecoxib and aspirin in aspirinsensitive patients with asthma. J Allergy Clin Immunol 108:47-51

36. Szczeklik A, Sanak M (2000) Genetic mechanisms in aspirin-induced asthma. Am J Resp Crit Care Med 161:S142-146

37. Szczeklik A, Nizankowska E, Sanak M, Swierczynska M (2001) Aspirin-induced rhinitis and asthma. Curr Opin Allergy Clin Immunol 1:27 - 33

38. Till G, Rother U, Gemsa D, Gerhardt P (1977) Aktivierung des Komplementsystems bei Zwischenfällen nach Kontrastmittelinjektionen. Verh Dtsch Ges Inn Med 83:1589-1591

39. Vervloet DL, Dor P, Arneud A, Senft M, Alazia M, Charpin J (1985) Anaphylactic reactions to succinylcholine. Prevention of mediator release by choline. J Allergy Clin Immunol 75:150

40. Virchow C (ed) (1986) Analgetika, Asthma. Medidact 6. Programmed, Frankfurt

\subsubsection{Exanthematous Drug Eruptions}

\subsubsection{Prevalence}

Adverse drug reactions occur preferably on the skin. Three percent of all drug treatments give rise to adverse drug reactions on the skin $[3,10$, 62], not including contact allergic reactions after external application of topicals (see Sect. 5.5.2). Exanthematous drug eruptions occur after systemic administration of a drug, manifesting mostly symmetrically with a predilection of the
41. Voigtländer V, Walter E, Siess R, Rother U (1981) Acetylsalicylic acid intolerance: a possible role of complement. Int Archs Allergy Appl Immunol 66 [Suppl 1]:154-155

42. Wahl R, Kleinhans D (1989) IgE-mediated allergic reactions to fruit gums and investigation of cross-reactivity between gelatine and modified gelatine-containing products. Clin Exp Allergy 19:77-80

43. Wedi B, Kapp A (2000) Aspirin induced adverse skin reactions: new pathophysiological aspects. Thorax 55 [Suppl 2]:S70-S71

44. Wüthrich B (1983) Allergische und pseudo-allergische Reaktionen der Haut durch Arzneimittel und Lebensmitteladditiva. Schweiz Rdsch Med (Praxis) 72:691-699

45. Yoshida S, Ishizaki Y, Onuma K, Shoji T, Nakagawa $\mathrm{H}$, Amayasu H (2000) Selective cyclo-oxygenase 2 inhibitor in patients with aspirin-induced asthma. J Allergy Clin Immunol 106:1203-1204

extensor surfaces of extremities [10, 12, 24, 35, 53, $56,62]$. The morphology of exanthematous drug eruptions is very colorful. Skin reactions mostly are not specific but may be elicited through allergic, toxic, or infectious processes. There are, however, conditions which are elicited more frequently by certain drugs than by others $[10,60,62]$. Knowledge of these facts is crucial in the causal diagnosis $[3,10,25,39,62]$ (Tables 5.96, 5.97).

On the other hand, an underlying disease of the patient does influence the occurrence of

Table 5.96. Prevalence of drug-induced allergic skin reactions (from [3])

\begin{tabular}{llll} 
& Prevalence (\%) & & Prevalence (\%) \\
\hline Cotrimoxazole & 5.90 & Trimethobenzamide & 0.66 \\
Ampicillin & 5.20 & Phenazopyridine & 0.65 \\
Other semisynthetic penicillins & 3.60 & Methenamine & 0.64 \\
Corticotropin & 2.80 & Cyanocobalamin & 0.62 \\
Erythromycin & 2.30 & Barbiturate & 0.47 \\
Salicylazosulfapyridine & 2.10 & Glutethimide & 0.45 \\
Sulfisoxazole & 1.70 & Indomethacin & 0.44 \\
Penicillin G & 1.60 & Chlordiazepoxide & 0.42 \\
Gentamycin & 1.60 & Metoclopramide & 0.40 \\
Practolol & 1.60 & Diazepam & 0.38 \\
Cephalosporin & 1.30 & Propoxyphene & 0.34 \\
Quinidine & 1.20 & Isoniazid & 0.30 \\
Metamizol (dipyrone) & 1.10 & Nystatin & 0.29 \\
Mercury diuretics & 0.95 & Chlorothiazide & 0.28 \\
Nitrofurantoin & 0.91 & Furosemide & 0.26 \\
Heparin & 0.77 & Insulin & 0.13 \\
Chloramphenicol & 0.68 & Phenytoin & 0.11 \\
& & Phytonadione & 0.09 \\
\hline
\end{tabular}


Table 5.97. Common elicitors of certain cutaneous drug eruptions

\begin{tabular}{|c|c|}
\hline Morphology & Elicitor (examples) \\
\hline $\begin{array}{l}\text { Urticarial } \\
\text { eruptions }\end{array}$ & $\begin{array}{l}\text { see Sect. 5.1.3 on "Urticaria" } \\
\text { and Sect. 5.1.4 on "Anaphylaxis" }\end{array}$ \\
\hline $\begin{array}{l}\text { Erythematovesi- } \\
\text { cular eruptions }\end{array}$ & see Sect. 5.5.2 on "Dermatitis" \\
\hline $\begin{array}{l}\text { Purpura/hemor- } \\
\text { rhagic eruptions }\end{array}$ & $\begin{array}{l}\text { see Sect. } 5.2 \text { on "Cytotoxic } \\
\text { Reactions" and Sect. } 5.3 \text { on } \\
\text { "Immune Complex Reactions" }\end{array}$ \\
\hline $\begin{array}{l}\text { Erythema } \\
\text { multiforme }\end{array}$ & $\begin{array}{l}\text { Barbiturates } \\
\text { Sulfonamides } \\
\text { Hydantoin } \\
\text { Hydralazine } \\
\text { Carbamazepine } \\
\text { Diuretics } \\
\text { NSAIDs }\end{array}$ \\
\hline $\begin{array}{l}\text { Erythema } \\
\text { nodosum }\end{array}$ & $\begin{array}{l}\text { Anticonceptives } \\
\text { Halogens } \\
\text { Sulfonamides }\end{array}$ \\
\hline $\begin{array}{l}\text { Macular and } \\
\text { maculopapular }\end{array}$ & $\begin{array}{l}\text { Penicillin } \\
\text { Ampicillin } \\
\text { Allopurinol } \\
\text { Sulfonamides } \\
\text { NSAIDs }\end{array}$ \\
\hline $\begin{array}{l}\text { Exfoliative } \\
\text { dermatitis }\end{array}$ & $\begin{array}{l}\text { Antiepileptics } \\
\text { Phenylbutazone } \\
\text { Heavy metals (e.g., arsenic) }\end{array}$ \\
\hline $\begin{array}{l}\text { Fixed drug } \\
\text { eruption }\end{array}$ & $\begin{array}{l}\text { Barbiturates } \\
\text { Analgesics } \\
\text { NSAIDs } \\
\text { Tetracyclines } \\
\text { Sulfonamides } \\
\text { Anticonceptives } \\
\text { Hydantoin } \\
\text { Laxants } \\
\text { Metronidazole }\end{array}$ \\
\hline $\begin{array}{l}\text { Lichenoid drug } \\
\text { eruptions }\end{array}$ & $\begin{array}{l}\text { Thiazides } \\
\text { Phenothiazine } \\
\text { Captopril } \\
\text { Gold } \\
\text { Sulfonamides }\end{array}$ \\
\hline $\begin{array}{l}\text { Acneiform drug } \\
\text { eruptions }\end{array}$ & $\begin{array}{l}\text { Steroid hormones } \\
\text { Halogens } \\
\text { Lithium } \\
\text { Isoniazin } \\
\text { Vitamins (B) } \\
\text { Hydantoin }\end{array}$ \\
\hline $\begin{array}{l}\text { Lymphocytic } \\
\text { infiltration }\end{array}$ & Analgesics (plus alcohol?) \\
\hline $\begin{array}{l}\text { Psoriasiform } \\
\text { eruptions }\end{array}$ & $\begin{array}{l}\text { Beta-blockers } \\
\text { Gold salts } \\
\text { Lithium }\end{array}$ \\
\hline
\end{tabular}

drug eruptions: Increased prevalences of drug eruptions are common in HIV infection and AIDS (sulfonamides, etc.) while in early stages of HIV, IgE-mediated reactions may be diminished $[36,47]$.

\subsubsection{Clinical Classification of Exanthematous Drug Eruptions}

The prevalences of the most important types of drug eruptions from a Finnish study are shown in Table 5.98.

Urticarial Drug Eruptions. These represent mostly allergic reactions due to IgE-mediated phenomena (urticaria, anaphylaxis) (see Sects. 5.1.3, 5.1.4) or IgG/IgM immune complexes as serum sickness (after $8-14$ days!) (see Sect. 5.3.2).

Erythematovesicular Drug Eruptions. These correspond clinically to systemic contact dermatitis whereby the allergens are administered systemically (e.g., sulfonamides, metal ions) (see Sect. 5.5.2).

Hemorrhagic Drug Eruptions. Some exanthematous drug eruptions may become hemorrhagic in nature when they are very intense or

Table 5.98. Prevalence of clinical types of drug eruptions in 446 patients (from Kauppinnen and Stubb [26])

\begin{tabular}{lc} 
Type & $\begin{array}{c}\text { Number of } \\
\text { patients }\end{array}$ \\
\hline $\begin{array}{l}\text { Macular und maculopapular } \\
\quad \text { eruptions }\end{array}$ & 189 \\
Fixed eruptions & 92 (16 multi- \\
& 57 \\
Urticaria/angioedema & 47 \\
Eczema & 18 \\
Erythema multiforme & 8 \\
Stevens-Johnson syndrome & \\
Lyell's syndrome (toxic epidermal & \\
$\quad$ necrolysis) & 8 \\
Photosensitization & 5 \\
Purpura & 4 \\
Lupus erythematosus-like lesions & 2 \\
Erythema nodosum & 1 \\
Fever & 5 \\
Total & 436 \\
\hline
\end{tabular}




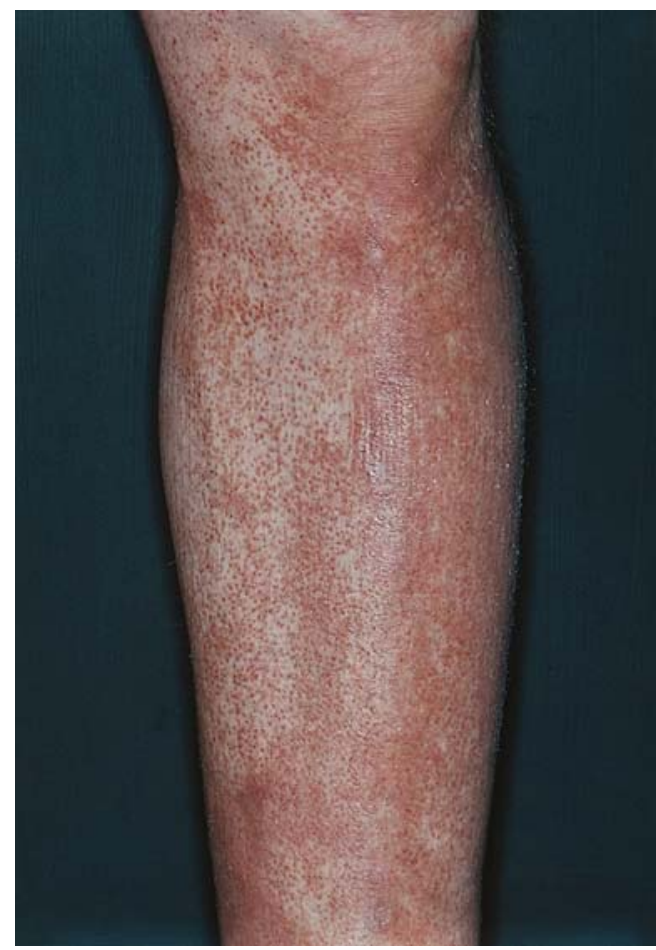

Fig. 5.71. Clinical manifestation of purpura chronica progressiva (Schamberg's disease)

due to hydrostatic pressure (legs). There is, however, primary drug-induced purpura corresponding to cytotoxic reactions (allergic thrombocytopenic purpura) (see Sect. 5.2) or as immune complex vasculitis (see Sect. 5.3).

Purpura chronica progressiva (M. Schamberg) is characterized by small petechial bleedings with a reddish-brownish (Cayenne pepper) skin lesion and is elicited by drugs (bromide carbamide) or additives (Fig. 5.71).

Histologically, lymphocytic infiltration around the vessels is seen; sometimes patch tests are positive. Some authors regard progressive pigmentary purpura as the vascular type IV reaction ("dermatitis of the vessels") [35].

Macular and Maculopapular Drug Eruptions. These are the most common exanthematous drug eruptions with histologically perivascular lymphocytic infiltrates. The skin lesions manifest 8-12 days after the first treatment (Fig. 5.72), in repeated treatment much faster. Pathogenetically, a type IVc reaction is proba-

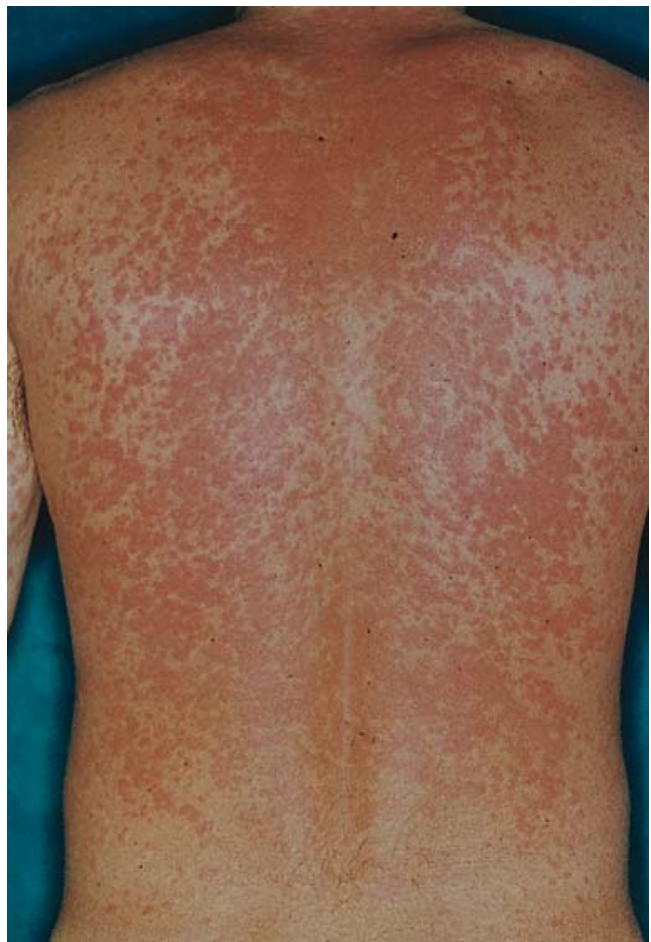

Fig. 5.72. Measles-like drug exanthema following the oral administration of penicillin

ble (CD8 cells), which can be demonstrated as delayed-type reactions in the intradermal or patch test $[14,35,42,54]$. Infectious diseases (measles, rubeola) are a differential diagnosis.

A special problem is ampicillin exanthema, which occurs in $10 \%$ of ampicillin-treated patients and is probably due to unspecific B-cell stimulation as it occurs with certain viral infections (e.g., Epstein-Barr virus). Infection and drug effect may potentiate in the example of infectious mononucleosis where $90-100 \%$ of ampicillin-treated patients develop ampicillin rash (almost pathognomonic).

Exfoliative Dermatitis. Some drugs elicit generalized exfoliative dermatitis (Fig. 5.73) ranging up to erythroderma (e.g., sulfonamides, antimalarials, penicillin, mercury-containing diuretics, barbiturates). The pathomechanism is not clear; in the differential diagnosis, toxic shock syndrome should be considered $[15,23$, 58]. 


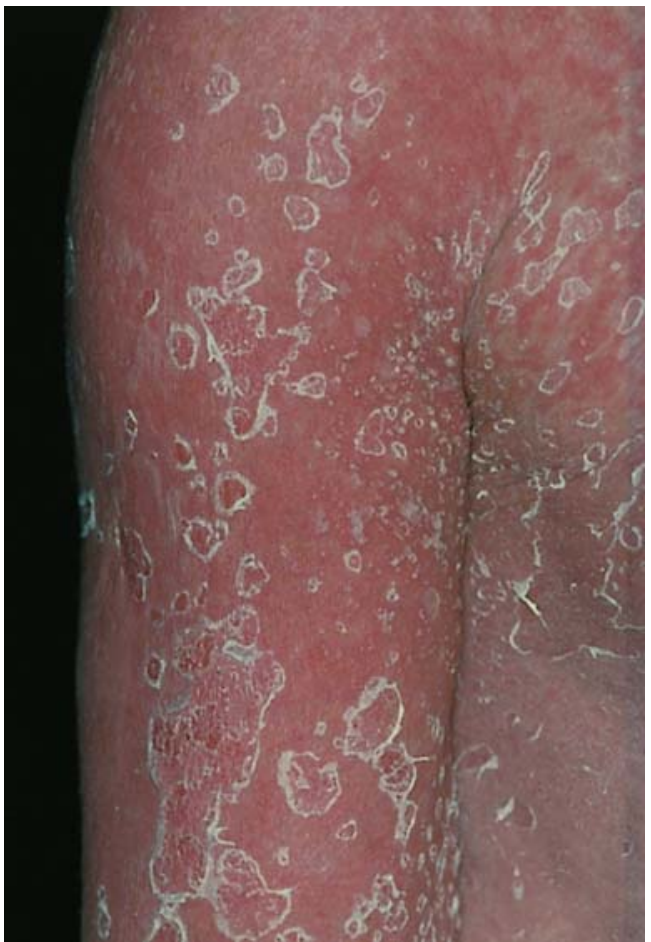

Fig. 5.73. Drug exanthema: exfoliative dermatitis

Drug-Induced Erythema Nodosum. Erythema-nodosum-like skin lesions may be drug induced (anticonceptives, sulfonamides, phenylbutazone) (Fig. 5.74). In the pathogenesis, immune complexes but also cellular reactions have been discussed.

Lymphohistiocytic Reaction. This is a localized reaction mostly in the face with livid-red infiltrates (Fig. 5.75), sometimes occurring $12-24 \mathrm{~h}$ after intake of analgesics together with alcohol. Histologically, perivascular infiltrates of lymphocytes and histiocytes together with edema of the dermis are characteristic.

\section{Bullous Drug Eruptions}

Fixed Drug Eruptions. These are sharply marginated dark red to livid macules, which can be blistering with predominant acral localization (hands, feet, glans penis) $24-48 \mathrm{~h}$ after drug intake (Figs. 5.76, 5.77). The characteristic feature is the occurrence on exactly the same skin

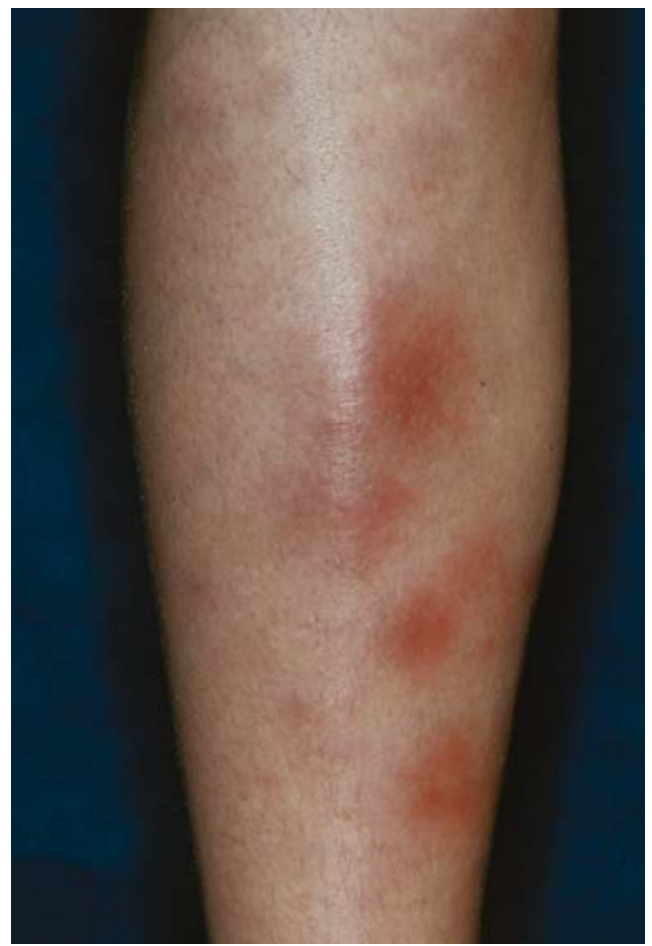

Fig. 5.74. Drug-induced erythema with nodosum-like skin lesions

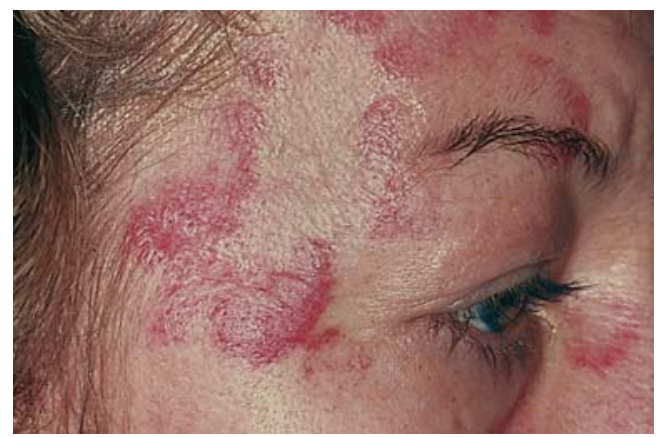

Fig. 5.75. Lymphohistiocytic reaction

area after repeated administration. With increasing number of relapses, skin lesions may be more brownish. Specifically sensitized lymphocytes may stay over longer periods of time in the area. Patch tests only will be positive in loco during remission (Fig. 5.78). New investigations describe an early vascular phase with CD4 infiltrates followed by an epidermal phase with CD8 cells and HLA-DR-expressing, partly destroyed keratinocytes [41]. 


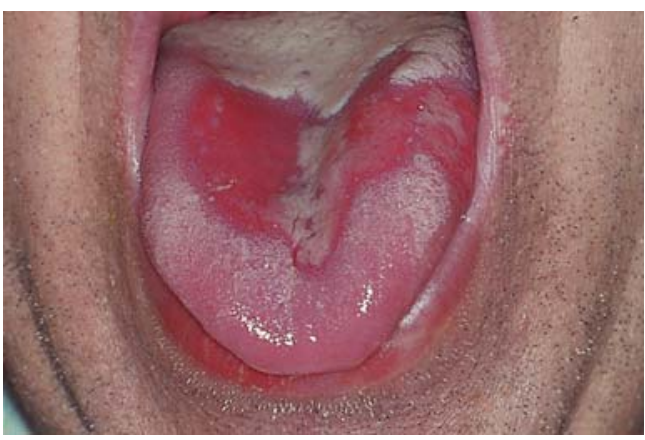

Fig. 5.76. Fixed drug-induced exanthema of the oral mucosa

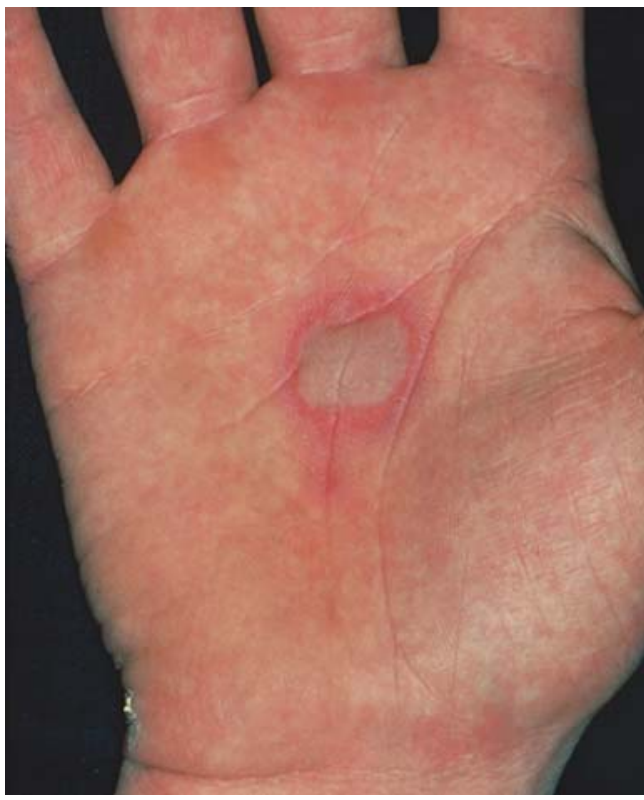

Fig. 5.77. Fixed drug-induced exanthema following the oral administration of phenylbutazone

Erythema Multiforme. Erythema multiformelike skin lesions with typical target formations (Fig. 5.79) may be triggered by viral, bacterial infection or drugs. Sulfonamides and barbiturates are common, also tetracyclines. Pathogenetically, type IV reactions but also immune complex mechanisms are suspected [27]. In the histology, subepidermal blistering is characteristic.

A serious complication of erythema multiforme is mucosal involvement (conjunctival, oral, genital) (Figs. 5.80, 5.81) such as in Stevens-Johnson syndrome. In rare cases, there is

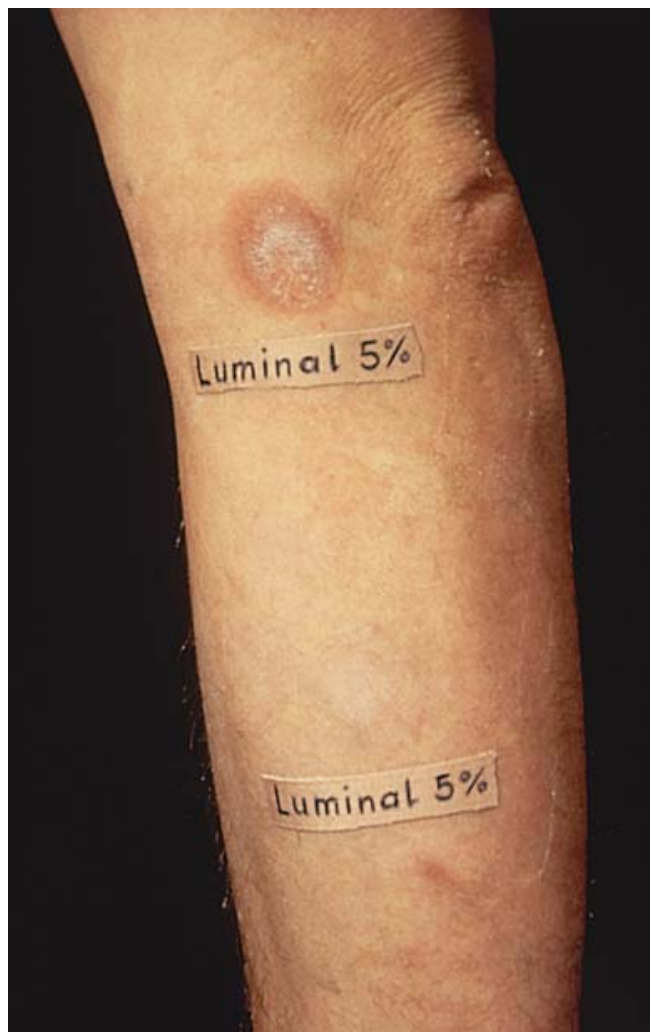

Fig. 5.78. Positive epidermal reaction to patch test in loco during remission (K.H. Schulz)

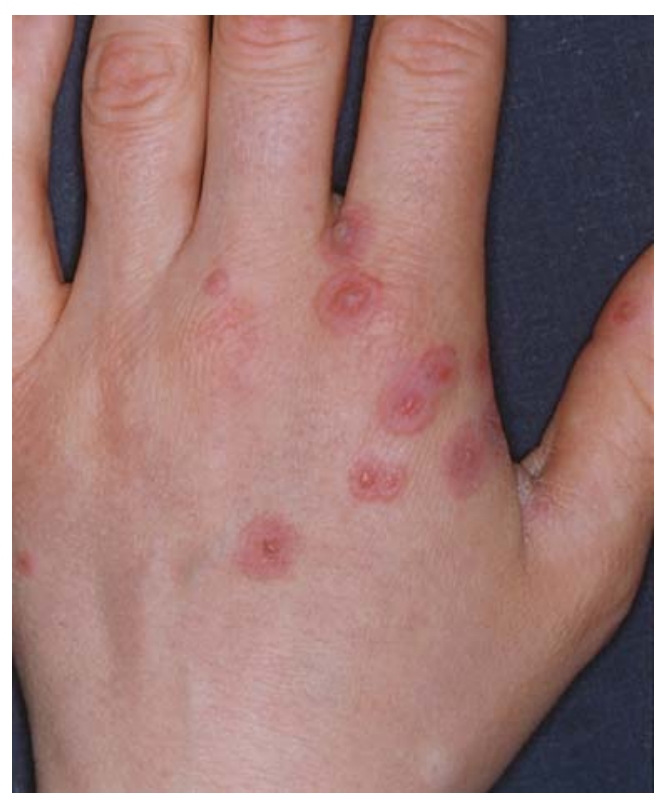

Fig. 5.79. Exudative erythema multiforme 


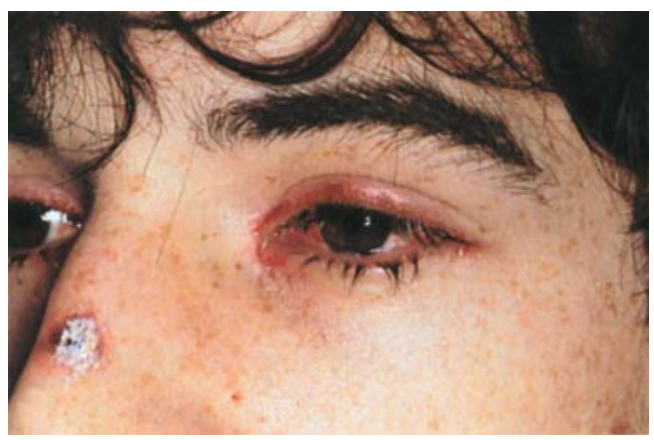

Fig. 5.80. Exudative erythema multiforme with mucosal involvement

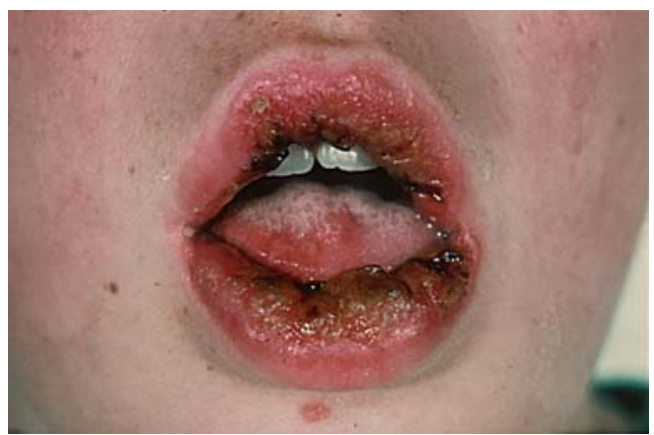

Fig. 5.81. Erosive reaction of the oral mucosa (Stevens-Johnson syndrome) transition possible into drug-induced Lyell's syndrome (toxic epidermal necrolysis) (see below). Clinical and dermatopathological characteristics (Table 5.99), however, argue for the individual entity of the different diseases $[39,51]$.

Toxic Epidermal Necrolysis (Drug-Induced Lyell's Syndrome). Drug-induced Lyell's syndrome ("toxic epidermal necrolysis" or "syndrome of burnt skin") represents the maximal variant of bullous drug eruptions.

In 1956, Allen Lyell coined the term "toxic epidermal necrolysis" (TEN) for diseases which had been published earlier under different names (Table 5.100). In a retrospective study of 1967, Lyell postulated four subgroups of TEN [34]: drug-induced, staphylococcal-induced, miscellanea (sepsis, viral infections, vaccination, $\mathrm{GVH}$, or malignancy) as well as idiopathic TEN.

Today two forms of Lyell's syndrome can be well differentiated clinically and pathophysiologically (Table 5.101): staphylococcal Lyell's syndrome, also staphylococcal scalded skin syndrome (SSSS) $[10,12,39]$, whereas TEN in the actual definition comprises diseases where

Table 5.99. Clinical characteristics of various bullous drug eruptions (according to [39]). SJS, Stevens-Johnson syndrome; TEN, toxic epidermal necrolysis

\begin{tabular}{llllll} 
& $\begin{array}{l}\text { Extent } \\
\text { (\% body surface) }\end{array}$ & Target lesions & Macules & $\begin{array}{l}\text { Large } \\
\text { erythemas }\end{array}$ & $\begin{array}{l}\text { Mucosal } \\
\text { involvement }\end{array}$ \\
Erythema multiforme & $<10 \%$ & ++ & - & - & - \\
SJS & $<10 \%$ & - (atypical) & + & - & ++ \\
SJS/TEN (mixed) & $10-30 \%$ & - (flat) & ++ & - & ++ \\
TEN with macules & $>30 \%$ & - (flat) & +++ & + & ++ \\
TEN & $>10 \%$ & - & - & +++ & ++ \\
\hline
\end{tabular}

Exfoliative dermatitis

Erythrodermie avec epidermolyses

Toxicoderma bullosum

Pemphigus aigu febrile

Toxic epidermal necrolysis

Universelle epidermolysis acuta toxica

Syndrome de Lyell

Syndrom der verbrühten Haut

Lyell's syndrome

Staphylococcal scalded skin syndrome

Acute disseminated epidermal necrolysis

(type III)
Rittershain 1878

Debré 1939

Guszman 1940

Griveaud and Mitarb 1946

Lyell 1956

Korting and Holzmann 1960

Dugois and Mitarb 1961

Braun-Falco and Geissler 1962

Jung and Mitarb 1964

Melish and Glasgow 1970

Ruiz-Maldonado 1985
Table 5.100. History and terminology of Lyell's syndrome (from [45]) 
Table 5.101. Differences between staphylococcal and drug-induced Lyell's syndrome (from [28])

\begin{tabular}{lll} 
& Staphylococcal & Drug-induced \\
\hline History & Mostly first episode & $\begin{array}{l}\text { Sometimes previous } \\
\text { incompatibility }\end{array}$ \\
Family history & S. aureus in family & $\varnothing$ \\
Drugs & Variable & Obligatory \\
Age & Newborn babies & Elderly \\
Skin pain & +++ & \pm \\
Mucosal involvement & ++ & ++ \\
Conjunctival involvement & + & ++ \\
Blister formation & Subcorneal & Junctional \\
\hline
\end{tabular}

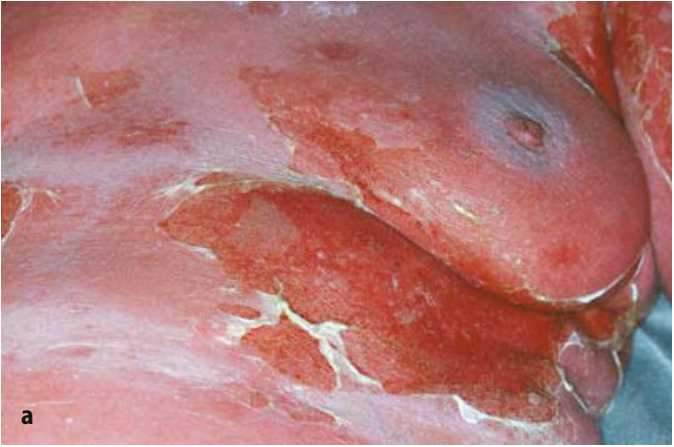

Fig. 5.82a,b. Detachment of large areas of the epidermis in a patient with a drug-induced Lyell's syndrome

the whole epidermis is filled with necrotic keratinocytes in the blister roof [39].

Clinical Symptoms and Dermatopathology. The clinical symptoms of Lyell's syndrome are dramatic in nature. After a prodromal phase with fever and unspecific complaints of the upper respiratory tract, often misinterpreted as a viral infection, macular eruptions occur, sometimes confluent and leading to large areas of epidermolysis (Fig. 5.82a,b). Nikolski I and II signs are positive. The patient is "swimming in his own skin." Mucous membranes are involved, and sometimes hair loss occurs.

After successful therapy, skin will heal within 2-4 weeks with large scaling of epidermal components. Finger- and toenails may be lost. Postinflammatory hyperpigmentation is common. Mucosal changes heal more slowly, especially in the eye, giving rise to synechia (Fig. 5.83). Generally, there is a severe disease (high fever!). Through the fluid loss, hypovolemia occurs, leading to shock. Superinfection may compromise other organs (pneumonia). Mucosal involvement gives rise to intestinal
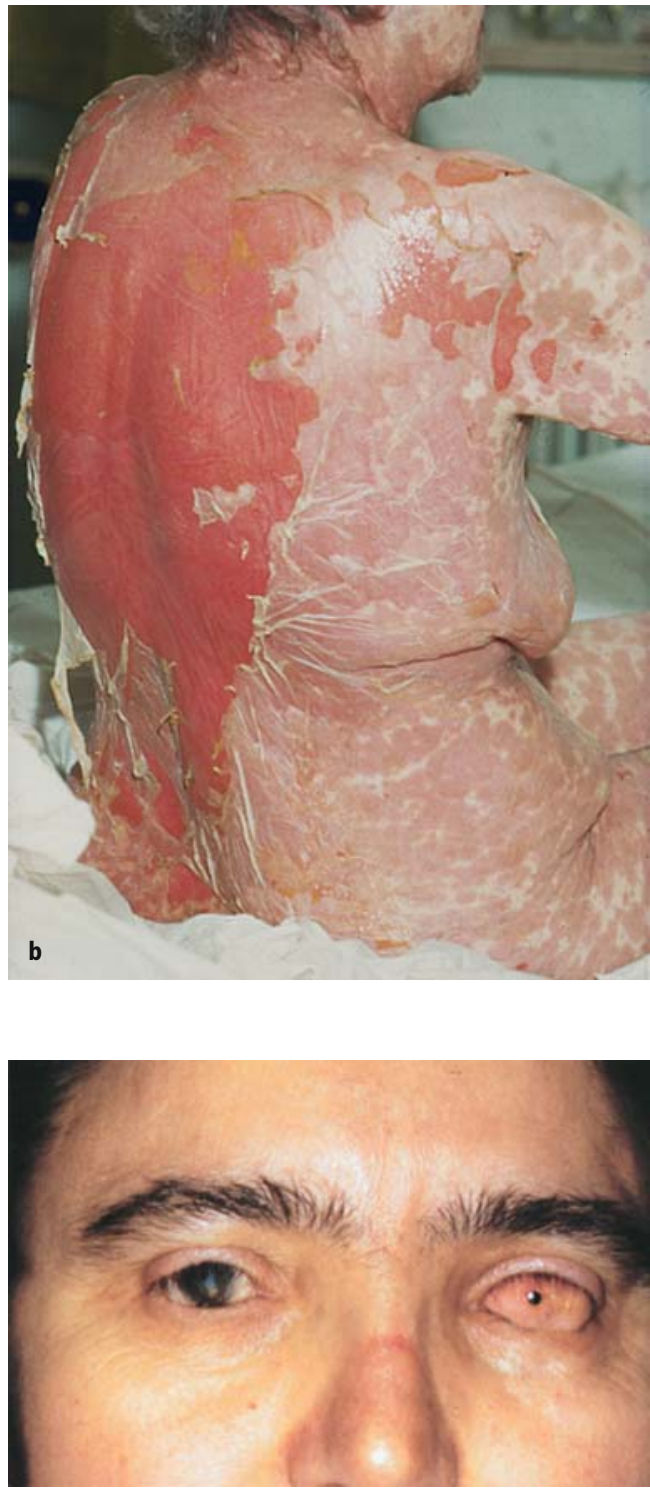

Fig. 5.83. Status post-Lyell's syndrome with scarified conjunctival lesions 
bleeding. Toxic changes of the liver (dystrophy, toxic fattening) and the kidneys (tubular necrosis, interstitial nephritis) have been described as well as endocarditis, myocarditis, or central nervous involvement (cerebral edema, encephalomalacia) [11].

In dermatopathology, there is necrosis of the whole epidermis with only minimal inflam-

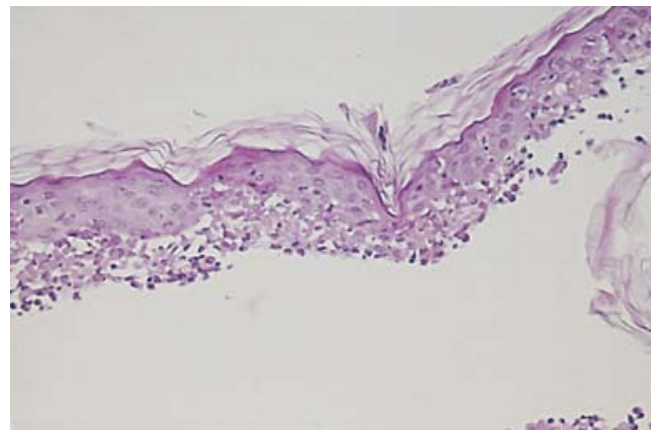

Fig. 5.84. Histological picture of a drug-induced Lyell's syndrome. The entire epidermis with necrotic keratinocytes is in the blister roof matory changes in the dermis ("empty corium"). Monoclonal antibodies may detect an increase in monocytoid cells in the epidermis $[20,51]$, which is in the blister roof (Fig. 5.84), in contrast to staphylococcal scalded skin syndrome with subcorneal blistering (Fig. 5.85, Table 5.102). The blister formation is junctional with the destruction of basal cells (Fig. 5.86).

Higher age groups are more often affected with female sex predilection (2:1). Rarely, there is a history of allergy. In France, a linkage to the HLA haplotypes A2, B12, and DR4 has been found [49].

Prognostic infaust factors include advanced age, late hospitalization, extent of blister formation, early leukopenia, initial renal insufficiency, as well as increased glucosemia. Lethality is around $30 \%$ in spite of the availability of most modern therapeutic modalities (15-50\% in the literature) [45].

According to Schöpf, the risk of drug-induced Lyell's syndrome in the total population is 0.7 per 1 million inhabitants [53].

\begin{tabular}{llll} 
& SSSS & TSS & TEN \\
Etiology & S. aureus (II) & S. aureus (I) & Drug (?) \\
Toxin & Exfoliatin & TSST-1 & $?$ \\
Blister formation & Subcorneal & Subgranular & Junctional \\
Mucosal involvement & \pm & ++ & ++ \\
Organ involvement & & ++ & ++ \\
\hline
\end{tabular}

Table 5.102. Comparison between staphylococcal scalded skin syndrome (SSSS), toxic shock syndrome (TSS), and toxic epidermal necrolysis (TEN)

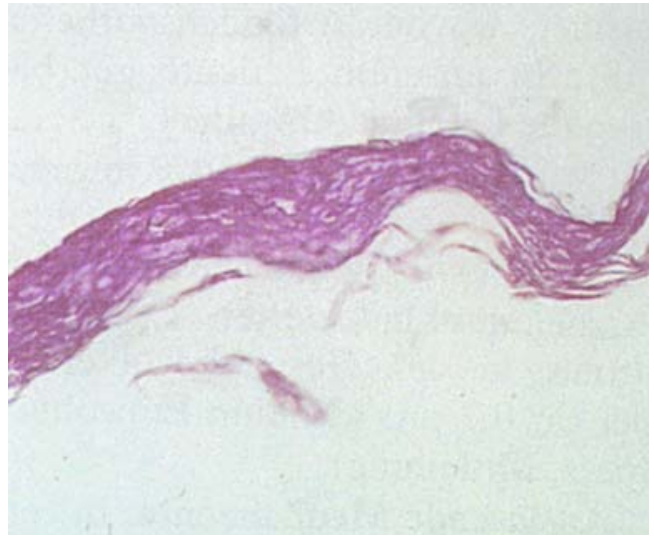

Fig. 5.85. Histological picture of a staphylogenic Lyell's syndrome: subcorneal blistering

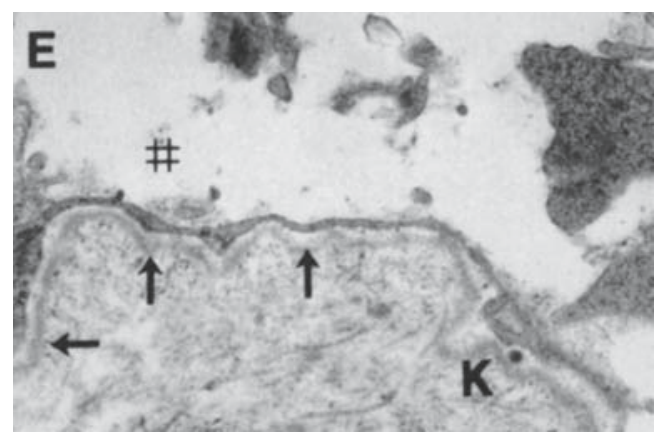

Fig. 5.86. Drug-induced Lyell's syndrome. The basement membrane (arrow) remains intact at the base of the continuity boundary. Above the lamina lucida there are cytoplasmic residues of necrotic keratinocytes (electron microscope magnification: 25,000:1). E, epidermis; $K$, corium; $\uparrow$ basement membrane; \#, cytoplasmic residue of a necrotic keratinocyte (reprinted with the consent of Prof. Dr. C. Luderschmidt) 
Eliciting Drugs. Many textbooks contain "hit lists" based on the literature, naming sulfonamides, analgesics, CNS-active drugs such as barbiturates and phenytoin besides many other drugs. The causal relation is difficult and sometimes arbitrary. Often, drugs are administered simultaneously (especially in elderly patients with 15 and more different drugs). The danger of "tautology" following reports from the literature is evident, leading to increased mentions of certain substances which have been mentioned before.

In a study of our own evaluating 306 cases, in only 67 patients, clear-cut evidence for a suspected drug was found (criterion: single or only recently introduced drug or proved by reexposure). However, we have seen a patient who reacted to carbamazepine, which he had been taking over 4 years as a single drug prior to TEN [45].

In a critical evaluation, there is no totally safe drug. We observed a case elicited by a herbal tea (devil's claw) as well as cases elicited by eyedrops (Borelli, personal communication), isoproterenol powder or tonic water $[11,18,45]$.

In Germany, the documentation center for severe cutaneous reactions has been recording for 10 years all bullous drug eruptions occurring in Germany. Evaluation and classification is done through an expert committee leading to a list of eliciting drugs (Table 5.103).

Diagnostic Procedures in TEN. Besides the clinical and dermatopathological diagnosis (Table 5.104), allergy tests may be helpful in single cases. Positive skin tests or in vitro lymphocyte transformation tests have revealed sensitizations [54]. We observed positive skin tests in two out of four tested persons with severe TEN $[32,45]$. Looking through the litera-

Table 5.103. Suspected drugs as elicitors of TEN
Sulfonamides
Aminopenicillins
Quinolones
Chlormezanone
Carbamazepine
Phenobarbital
Phenytoin
Valproic acid
NSAIDs
Allopurinol

Table 5.104. Diagnosis of Lyell's syndrome

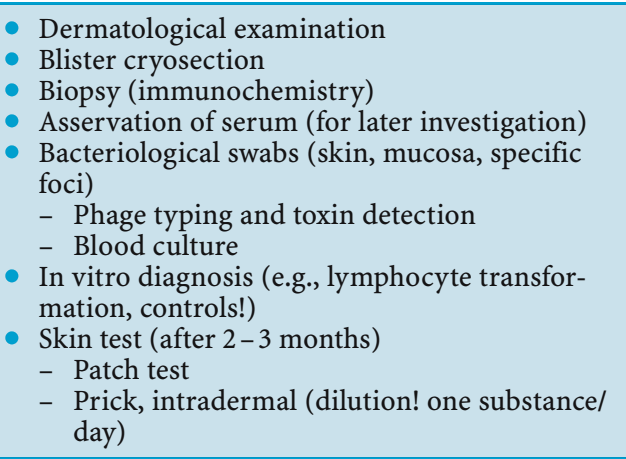

ture, there is no evidence that a careful skin test (prick or patch test) may induce generalized TEN symptoms.

Rarely oral provocation has been tried [28] successfully. Many authors, however, do not recommend it. If there is an indication, one should use an extremely low starting dose $(1 / 1,000$ of a single dose and lower) and apply only one substance per day under inpatient conditions.

Therapy of TEN. Therapy consists of general, local, and systemic procedures (Table 5.105), as well as the observation of certain items to avoid (Fig. 5.87). Local therapy includes early ophthalmologic counseling for prevention of synechia with hourly application of eyedrops!

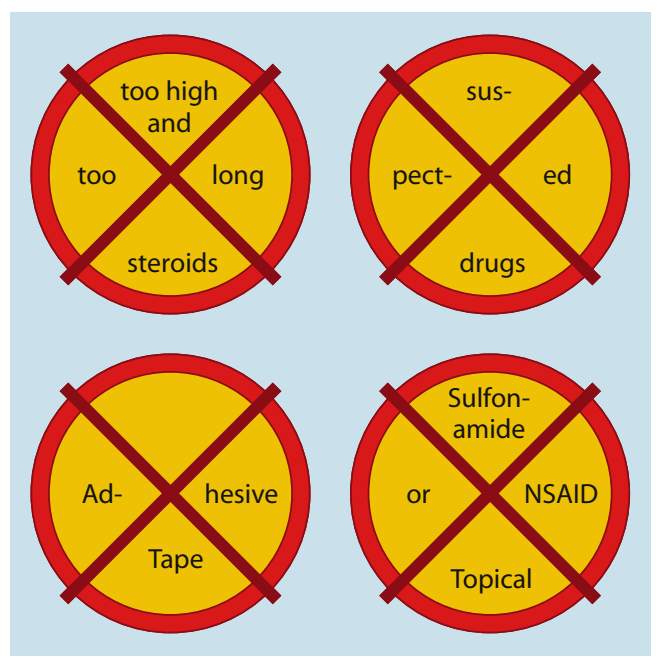

Fig. 5.87. Four important "Don'ts" when treating Lyell's syndrome 
Table 5.105. Drug-induced Lyell's syndrome therapy

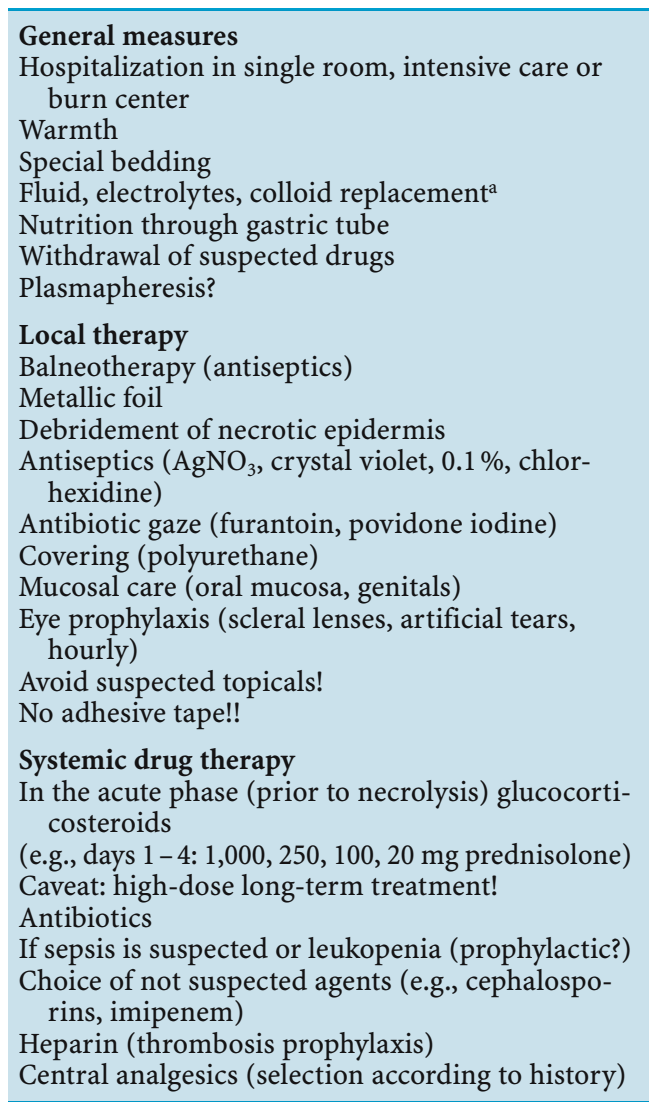

a Not only according to the "rule of 9" but controlled according to excretion, body weight, urine, and serum electrolytes, etc.

Systemic glucocorticosteroids are controversial $[30,49,50]$. We give steroids only in the early exanthematous phase prior to appearance of large areas of necrolysis (maximal 4 days of high-dose therapy). If epidermolysis has occurred, glucocorticosteroids may rather have a negative effect.

Avoidance of the eliciting drug is the focus of immediate treatment as well as general lifesaving measures.

According to the extent of bullous erosive skin lesions, patients may be treated in special institutions for burn injury or intensive care units. Volume replacement, parenteral nutrition, temperature application, and special bedding (Clinitron) are crucial. Medium-severe cases have been treated successfully isolated under hygienic conditions in a single room.
In order to influence the immune reaction, the following drugs have been tried:

- Cyclophosphamide

- Cyclosporin A

- Thalidomide as TNF inhibitor

- Intravenous immunoglobulin G

- Protease inhibitors (ulinastatin)

- Plasmapheresis

But only case reports or small numbers have been published [13, 17, 25, 30, 45, 49, 56, 59].

The immediate and adequate general therapy is the performance of life-saving measures. Due to pathophysiologic considerations and possible involvement of microbial toxins as well as the avoidance of sepsis, prophylactic antibiotics with unsuspicious agents are recommended by some authors.

\subsubsection{Pathophysiology of Cutaneous Drug Eruptions}

While urticarial reactions may often be due to IgE-mediated or pseudo-allergic reactions, thrombocytopenic purpura represents a cytotoxic reaction, hemorrhagic vasculitic phenomena an immune complex reaction. The mechanisms of the colorful spectrum of exanthematous drug eruptions, however, are not well established (Table 5.106).

In dermatopathology, superficial perivascular mononuclear cell infiltrate is seen sometimes with eosinophils. Often a so-called interface dermatitis with lymphocytes at the dermoepidermal junction is seen [61].

Immunohistochemistry shows a predominant T-cell $(\mathrm{CD} 3+)$ infiltrate with both $\mathrm{CD} 4$ and CD8 cells. CD1a+ dendritic cells and CD68 macrophages are also increased as well as CD56+ natural killer cells. Major basis protein from eosinophils can be detected.

Activated T cells are also CLA positive and may maintain inflammatory reactions through cytokines (IL-5, IL-6, TNF $\alpha$ ) or chemokines (eotaxin, RANTES) $[19,36,43]$.

Furthermore, cytotoxic T cells may directly destroy keratinocytes either via Fas/Fas ligand (rather unlikely) or more probably via a cytotoxic mechanism through perforin and granzyme B. 
Table 5.106. Pathophysiology of various forms of drug eruptions

\begin{tabular}{|c|c|c|}
\hline Clinical manifestations & Suspected pathomechanism & Differential diagnosis \\
\hline Urticarial eruption & IgE, serum sickness & Focus (infection, tumor) \\
\hline Erythematovesicular & Systemic contact & Toxic dermatitis, eczema atopic eczema \\
\hline \multicolumn{3}{|l|}{ Purpura } \\
\hline - Thrombopenic & Type II & Coagulation defect \\
\hline - Vasculitic & Type III & Infection, tumor \\
\hline - Purpura chronica progressiva & $?$ & \\
\hline - Purpura senilis & Cortisone effect & Atrophy, vitamin deficiency \\
\hline $\begin{array}{l}\text { Macular and maculopapular } \\
\text { (special case: ampicillin rash) }\end{array}$ & $\begin{array}{l}\text { Type IV? } \\
\text { (B-cell stimulation?) }\end{array}$ & Viral exanthema \\
\hline $\begin{array}{l}\text { Exfoliative dermatitis, scarlatini- } \\
\text { form eruption }\end{array}$ & Type IV? & Scarlet fever (toxic shock syndrome) \\
\hline $\begin{array}{l}\text { Bullous drug eruption (erythema } \\
\text { exsudativum multiforme, EEM) }\end{array}$ & Type III/type IVc & Postherpetic EEM \\
\hline Erythema nodosum & Type III? & Sarcoidosis, infection \\
\hline Fixed drug eruption & Type IVc & \\
\hline Toxic epidermal necrolysis & Type IVc & Staphylococcals, scalded \\
\hline \multicolumn{3}{|l|}{ Skin syndrome } \\
\hline Lichenoid eruption & $?$ & Lichen planus \\
\hline Acneiform eruption & $?$ & Acne vulgaris \\
\hline Psoriasiform eruption & ? & Psoriasis vulgaris \\
\hline Lymphohistocytic reaction & Type IV & Pseudolymphoma \\
\hline
\end{tabular}

The role of proinflammatory cytokines is supported by the common coincidence of concomitant infections in the eliciting phase. It may be that different cell populations (CD4 or CD8 cells) with different activation mechanisms induce different clinical symptoms. The metabolism of the drug via different routes (acetylation, glutathione transferase, cytochrome P450, etc.) is important [22, 37].

Table 5.107 lists some possible immunologic and non-immunologic reactions which play a role in the pathogenesis of TEN (hypothetical). Animal experiments have shown similarities between GVH and TEN [38].

The differential diagnosis between TEN and toxic shock syndrome (TSS) may be difficult $[23,58]$. TSS is defined by: fever, exanthema (diffuse, sometimes with erythroderma or vesiculation), mucous membrane involvement, hypotension, multiorgan affection, as well as exclusion of other infectious diseases [15].

TEN and TSS have some things in common: prodromi, certain laboratory findings (liver enzymes), mucosal involvement, multiorgan affection. However, in the majority of TSS patients, no large epidermolysis occurs, but rather desquamative exfoliative dermatitis (especially palmoplantar) after $8-10$ days (similar to scarlet fever).
Table 5.107. Toxic epidermal necrolysis: pathophysiological concepts

Immunologic reactions

Allergy (type II): antibodies or cytotoxic T cells against keratinocytes?

Allergy (type III): immunoglobulin and complement deposits

Allergy (type IV): positive patch tests and lymphocyte transformation

Graft versus host reaction: altered self?

Monocyte-mediated cytotoxicity?

Combination of infection and drug

Photosensitization

Non-immunologic reaction

Pharmacotoxicity in enzyme deficiency

Enzyme activation

Activated oxygen species

Combination: virus/drug?

Combination: UV/drug?

Microbial toxins (prodromi through toxin, interleukin-1)?

The staphylococcal toxin of TSS (TSST-1) induces necrosis in the stadium granulosum in animal experiments with keratinocyte necrosis in contrast to the exfoliatin of staphylococcal Lyell's syndrome with subcorneal blisters. Dermatologically, TEN can be clearly differentiated from other bullous drug eruptions (Table 5.108). 
Table 5.108. Dermatopathological patterns of bullous drug eruptions

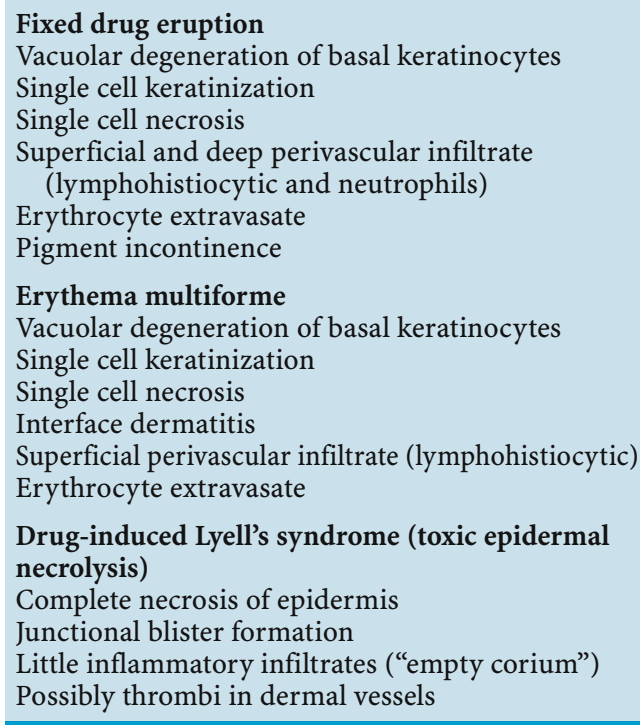

\subsubsection{Special Forms of Drug-Induced Skin Diseases}

After intake of some drugs, specific dermatologic symptoms may be induced (Table 5.109).

Some genuine dermatoses may be provoked by drugs such as lichen planus by gold and sul-
Table 5.110. Genuine skin diseases provoked by drugs

\begin{tabular}{ll}
\hline $\begin{array}{l}\text { Acanthosis nigricans } \\
\text { Acne vulgaris }\end{array}$ & $\begin{array}{l}\text { Gestagens } \\
\text { Androgens, gestagens }\end{array}$ \\
$\begin{array}{l}\text { Dermatitis herpeti- } \\
\text { formis }\end{array}$ & $\begin{array}{l}\text { Furosemide, salazosul- } \\
\text { fapyridine }\end{array}$ \\
Lichen planus & Halogens, progesterone \\
Lupus erythematosus & $\begin{array}{l}\text { Gold, arsenic, quinine, } \\
\text { sulfonamides } \\
\text { procainamide, phenyto- }\end{array}$ \\
Pemphigus vulgaris & $\begin{array}{l}\text { in, phenylbutazone } \\
\text { D-Penicillamine } \\
\text { Porphyria cutanea tarda }\end{array}$ \\
$\begin{array}{l}\text { Alcohol, analgesics, an- } \\
\text { drogens, barbiturates, } \\
\text { contraceptives, sulfon- } \\
\text { amides }\end{array}$
\end{tabular}

fonamides, lupus erythematosus by hydralazine and procainamide, or psoriasiform drug eruptions by beta-blockers (Table 5.110).

Many cases are characterized by mucosal membrane involvement only ("stomatitis medicamentosa") [2]. These conditions need to be distinguished from contact-allergic reactions (against dental prostheses) as well as the toxic effects of some drugs as cytostatics. Drugs inducing stomatitis medicamentosa include

\begin{tabular}{|c|c|}
\hline Morphology & Example \\
\hline Exanthematous drug eruptions & (see Table 5.98) \\
\hline Pruritus & Opioids, belladonna, laxatives \\
\hline Sebostasis & Retinoids \\
\hline Pigmentary changes & $\begin{array}{l}\text { Metals (silver, gold, bismuth, mercury), anti- } \\
\text { malarials (gray-yellow), clofazimine (red), } \\
\text { gestagens, estrogens (melasma) }\end{array}$ \\
\hline Atrophy/striae & Glucocorticosteroids \\
\hline Keratoses, tumors & Arsenic, cytostatics, levodopa (melanoma?) \\
\hline Nail changes & Cytostatics, photosensitization, beta-blockers \\
\hline Alopecia & Cytostatics, steroids, anticoagulants, retinoids \\
\hline Skin color changes & Chloroquine, mephenesin, bleomycin \\
\hline Hypertrichosis & Diazoxide, minoxidil, cyclosporin \\
\hline Iododerma/bromoderma & Halogens \\
\hline Palmoplantar pustulosis & Lithium \\
\hline Pseudolymphoma & Phenytoin, analgesics, menthol \\
\hline Photosensitization & See Sect. 5.6 \\
\hline Granuloma & See Sect. 5.8 \\
\hline Embolia cutis & Antirheumatics, steroids \\
\hline Necroses & $\begin{array}{l}\text { Coumarin, barbiturates, ergotaminine, see } \\
\text { vasculitis allergica (Sect. 5.3) }\end{array}$ \\
\hline Mucosal changes & See Sect. 5.5 \\
\hline
\end{tabular}

Table 5.109. Skin changes due to drugs (selection) 
heavy metals (mercury, gold), antibiotics (sulfonamides, chloramphenicol, streptomycin), local anesthetics, hypnotics (barbiturates, hydantoin), and analgesics (phenylbutazone, aminopyrine) [2].

\section{References}

1. Aberer W, Stingl G, Wolff K (1982) Stevens-Johnson-Syndrom und toxische epidermale Nekrolyse nach Sulfonamideinnahme. Hautarzt 33:484-490

2. Archard HO (1979) Stomatologic disorders of an internal and integumental nature. In: Fitzpatrick TB, Eisen AZ, Wolff K, Freedberg IM, Austen KF (eds) Dermatology in general medicine. McGraw Hill, New York, p 834

3. Arndt KA, Jick H (1976) Rate of cutaneous reactions to drugs. J Am Med Assoc 235:918

4. Bachot N, Roujeau J-C (2001) Physiopathology and treatment of severe drug eruptions. Curr Opin Allergy Clin Immunol 1:293-298

5. Barreiro P, Soriano V, Casas E, et al. (2000) Prevention of nevirapine-associated exanthema using slow dose escalation and/or corticosteroids. AIDS 14:2153-2157

6. Behrendt H, Gollnick H, Bonnekoh B (2000) Upregulated perforin expression of $\mathrm{CD} 8+$ blood lymphocytes in generalized non-anaphylactic drug eruptions and exacerbated psioriasis. Eur J Dermatol 10:365-369

7. Bergner T, Przybilla B, Ring J (1989) Anaphylactoid reaction to the coloring agent Erythrosine in an antiallergic drug. Allergy Clin Immunol News $1: 177-179$

8. Bigby M, Stern R (1985) Cutaneous reactions to nonsteroidal anti-inflammatory drugs. J Am Acad Dermatol 12:866-876

9. Billingham RE, Streilein JW (1968) Toxic epidermal necrolysis and homologous disease in hamsters. Arch Dermatol 98:528

10. Bork K (1985) Kutane Arzneimittelnebenwirkungen. Unerwünschte Wirkungen systemisch verabreichter Medikamente an Haut und hautnahen Schleimhäuten bei Erwachsenen und Kindern. Schattauer, Stuttgart

11. Braun-Falco O, Bandmann HJ (eds) (1970) Das Lyell-Syndrom. Das Syndrom der verbrühten Haut. Huber, Bern

12. Braun-Falco O, Plewig G, Wolff HH (1998) Dermatologie und Venerologie, 4th edn. Springer, Berlin Heidelberg New York

13. Craven NM (2000) Management of toxic epidermal necrolysis. Hosp Med 61:778-781

14. Crowson AN, Magro CM (1999) Recent advances in the pathology of cutaneous drug eruptions. Dermatol Clin 17:537-560

15. Davis JP, Chesney PJ, Wand PJ, LaVenture M
(1980) Toxic-shock syndrome: Epidemiologic features, recurrence, risk factors and prevention. N Engl J Med 303:1429-1435

16. Fellner MJ, Prutkin L (1970) Morbilliform eruptions caused by penicillin. A study by electron microscopy and immunologic tests. J Invest Dermatol 55:390-395

17. French LE, Tschopp J (2000) Fas-mediated cell death in toxic epidermal necrolysis and graft-versus-host disease; potential for therapeutic inhibition. Schweiz Med Wochenschr 130:1656-1661

18. Goerz G, Ruzicka T (1978) Lyell-Syndrom. Grosse, Berlin

19. Gutierrez-Ramos JC, Lloyd C, Gonzalo JA (1999) Eotaxin from an eosinophilic chemokine to a major regulator of allergic reactions. Immunol Today 20:500-504

20. Hari Y, Frutig-Schnyder K, Hurni M, Yawalkar N, Zanni MP, Schnyder B, Kappeler A, von Greyerz S, Braathen LR, Pichler WJ (2001) T cell involvement in cutaneous drug eruptions. Clin Exp Allergy 31:1398-1408

21. Hofmann C, Burg G, Jung C (1986) Kutane Nebenwirkungen der Goldtherapie. Klinische und histologische Ergebnisse. Z Rheum 45:100-106

22. Hertl M, Jugert F, Merk HF (1995) CD8 ${ }^{+}$dermal T cells from a sulphamethoxazole-induced bullous exanthem proliferate in response to drug-modified liver microsomes. Br J Dermatol 132: 215 220

23. Hurwitz M, Rivera HP, Gooch MH, Slama TG, Handt A, Weiss J (1982) Toxic shock syndrome or toxic epidermal necrolysis? J Am Acad Dermatol 7:246-254

24. Kaplan AP (1984) Drug induced skin disease. J Allergy Clin Immunol 74:573 - 579

25. Kasemir H, Kerp L (1980) Arzneimittel-Allergene und Arzneimittel-Allergien. In: Filipp G (ed) Allergologie, vol 1. Ätiopathogenese. Werk-Verlag, Gräfelfing, p 144

26. Kauppinen K, Stubb S (1984) Drug eruptions: Causative agents and clinical types. A series of inpatients during a 10-year period. Acta Derm Venereol (Stockh) 64:320-324

27. Kazmierowski JA, Wuepper KD (1981) Erythema multiforme: Clinical spectrum and immunopathogenesis. Springer Semin Immunopathol 4:45

28. Kleinhans D, Fuchs T (1984) Orale Provokation bei einem durch Barbitursäure verursachten Lyell-Syndrom. Akt Derm 10:122-124

29. Knowles SR, Uetrecht J, Shear NH (2000) Idiosyncratic drug reactions: the reactive metabolite syndromes. Lancet 356:1587-1591

30. Konstantinow A, Mühlbauer W, Balda BR, Ring J (2001) Toxische epidermale Nekrolysen (Arzneimittel-induziertes Lyell-Syndrom). Dtsch Med Wochenschr 126:141 - 144, 177-179

31. Le Cleach L, Delaire S, Boumsell L, et al (2000) Blister fluid $\mathrm{T}$ lymphocytes during toxic epidermal necrolysis are functional cytotoxic cells 
which express human natural killer (NK) inhibitory receptors. Clin Exp Immunol 119:225-230

32. Luderschmidt C, Linderkamp O, Ring J (1985) Drug-induced toxic epidermal necrolysis (Lyell's syndrome) in a 4-year-old girl. Eur J Pediatr $14: 91-93$

33. Lyell A (1956) Toxic epidermal necrolysis: an eruption resembling scalding of the skin. Br J Dermatol 68:355-361

34. Lyell A (1967) A review of toxic epidermal necrolysis in Britain. Br J Derm 79:662-671

35. Marghescu S (1978) Allergische Arznei-Exantheme. Pathomechanismus - Klinik - Testung - Therapie. Perimed, Erlangen

36. Merk H, Gerecke D (1986) Arzneimittelnebenwirkungen bei Patienten mit LAV/HTLV-III-Infektion. AIDS-Bericht 2. Grosse, Berlin, pp $139-142$

37. Merk HF, Hertl M (1996) Immunologic mechanisms of cutaneous drug reactions. Semin Cutan Med Surg 15:228-235

38. Merot Y, Saurat JH (1985) Clues to pathogenesis of toxic epidermal necrolysis. Int J Dermatol 24:165- 168

39. Mockenhaupt M, Norgauer J (2001) Schwere arzneimittelinduzierte Hautreaktionen. Allergologie 24:419-432

40. Mougdil A, Porat S, Brunnel P, Jordan SC (1995) Treatment of Stevens-Johnson syndrome with pooled human intravenous immune globulin. Clin Pediatrics 34:47-51

41. Murphy GF, Guillén FJ, Flynn TC (1985) Cytotoxic $\mathrm{T}$ lymphocytes and phenotypically abnormal epidermal dendritic cells in fixed cutaneous eruptions. Hum Pathol 16:1264-1271

42. Pichler WJ, Yawalkar N (2000) Allergic reactions to drugs: involvement of T cells. Thorax 55 [Suppl 2]:S61-S65

43. Pichler WJ, Zanni M, von Greyerz S, et al. (1997) High IL-5 production by human drug-specific T cell clones. Int Arch Allergy Immunol 113: $177-180$

44. Ring J (1987) Diagnostik von Arzneimittel-bedingten Unverträglichkeitsreaktionen. Hautarzt 38:16-22

45. Ring J (1989) Drug-induced Leyell's syndrome (toxic epidermal necrolysis). In: Pichler WJ, et al. (eds) Progress in allergy and clinical immunology. Hogrefe \& Huber, Toronto, pp 455-461

46. Ring J, Przybilla B, Gollhausen R (1989) Progressive pigmentary purpura provoked by a phytotherapeutic drug containing Echinacea extract. Allergy Clin Immunol News 114:108-109

47. Ring J, Kraus K, Fröschl M, Brunner R, Przybilla B, Burg G, Braun-Falco O (1987) AIDS, HIV-Infektion und allergische Reaktionen. AIDS Forschung 2:643-646

48. Roujeau JC, Kelly JP, Naldi L, et al. (1995) Medication use and the risk of Stevens-Johnson syn- drome or toxic epidermal necrolysis. N Engl J Med 333:1600-1607

49. Roujeau J-C, Stern RS (1994) Severe cutaneous adverse reactions to drugs. $\mathrm{N}$ Engl J Med 331: $1272-1285$

50. Ruiz-Maldonado R (1985) Acute disseminated epidermal necrosis types 1,2, and 3: Study of sixty cases. J Am Acad Dermatol 13:623-635

51. Rzany B, Hering O, Mockenhaupt M, et al. (1996) Histopathological and epidemiological characteristics of patients with erythema exudativum multiforme major, Stevens-Johnson syndrome and toxic epidermal necrolysis. Br J Dermatol 135:6-11

52. Sachs B, Merk H (2001) Demonstration and characterization of drug-specific lymphocyte reactivity in drug allergies. Allergy Clin Immunol Int 13:91-98

53. Schöpf E, Stühmer A, Rzany B, Victor N, Zentgraf R, Kapp JF (1991) Toxic epidermal necrolysis and Stevens-Johnson syndrome. An epidemiologic study from West Germany. Arch Dermatol $127: 839-842$

54. Schulz KH (1966) Stellenwert und Aussagekraft von Testmethoden bei allergischen Arznei-Exanthemen. In: Braun-Falco O, Wolff HH (1979) Fortschritte der praktischen Dermatologie und Venerologie, vol 9. Springer, Berlin Heidelberg New York, p 71

55. Steigleder GK (1966) Haut. In: Heintz R (ed) Erkrankungen durch Arzneimittel. Diagnostik, Klinik, Pathogenese und Therapie. Thieme, Stuttgart, pp $103-130$

56. Schulz JT, Sheridan RL, Ryan CM, et al. (2000) A 10-year experience with toxic epidermal necrolysis. J Burn Care Rehabil 21:199-204

57. Smith CL, Brown I, Torraca BM (1997) Acetylator status and tolerance of high-dose trimethoprimsulfamethoxazole therapy among patients infected with human immunodeficiency virus. Clin Infect Dis 25:1477-1478

58. Todd J, Fishaut M, Kapral F, Welch T (1978) Toxicshock syndrome associated with phage-group-I staphylococci. Lancet II:1116-1118

59. Viard I, Wehrli P, Bullani R, et al. (1998) Inhibition of toxic epidermal necrolysis by blockade of CD95 with human intravenous immunoglobulin. Science 282:490-493

60. Stern RS, Wintroub BU (1999) Cutaneous reactions to drugs. In: Freedberg IM, Eisen AZ, Wolff $\mathrm{K}$, et al. (eds) Fitzpatrick's dermatology in general medicine, 5th edn. McGraw Hill, New York, pp $1633-1642$

61. Wolff HH, Winzer M (1986) Histopathological patterns of drug eruptions. In: Ring J, Burg G (eds) New trends in allergy II. Springer, Berlin Heidelberg New York, pp 240-253

62. Zürcher K, Krebs A (1992) Cutaneous drug reactions. Karger, Basel 


\subsection{Granulomatous Reactions}

In some textbooks, type IV reactions include both allergic contact dermatitis and tuberculin reactions under the common pathophysiology of sensitized T-lymphocyte reaction with a difference of route of administration (epidermal versus intradermal). The kinetics of tuberculin correspond to a maximum between 48 and $72 \mathrm{~h}$ after intradermal administration of allergen to those with epidermal patch test reactions.

Quite different kinetics (3-5 weeks) are characteristic of the lepromin reaction as well as some other granulomatous infectious diseases characterized by typical histopathology with epithelioid cell granulomas $[6,11,26]$. The clear-cut differences in clinical symptomatology, dermatohistopathology, and kinetics $[3,29$, 30] justify a separate classification of granulomatous hypersensitivity reactions as type $\mathrm{V}$ (see Chap. 1).

Granulomatous reactions are inflammatory changes occurring with slow development over 3-5 weeks and long-lasting persistence; histologically, they are characterized by typical epithelioid cell granuloma formation in the upper and mid dermis. In the skin brownish-red or livid nodules are characteristic, sometimes showing a "lupoid" infiltrate under the diascope [6].

\subsubsection{Clinical Examples}

Common clinical examples of allergic reactions of the granulomatous type $\mathrm{V}$ are the zirconium granuloma after application of zirconium-containing deodorants with histologically typical epithelioid cell granulomas without necrosis together with lymphocytic infiltrates with foreign bodies in polarization microscopy [30].

Rare subcutaneous granuloma formations after allergen-specific subcutaneous immunotherapy can equally be classified as type $\mathrm{V}$, especially after application of aluminum hydroxide adsorbed allergen extracts [2]. In some cases, these granulomas may change into subcutaneous pseudolymphomas [15].

After repeated intradermal administration of procaine polyvinylpyrrolidone (PVP) for back pain, one of our patients developed multi-

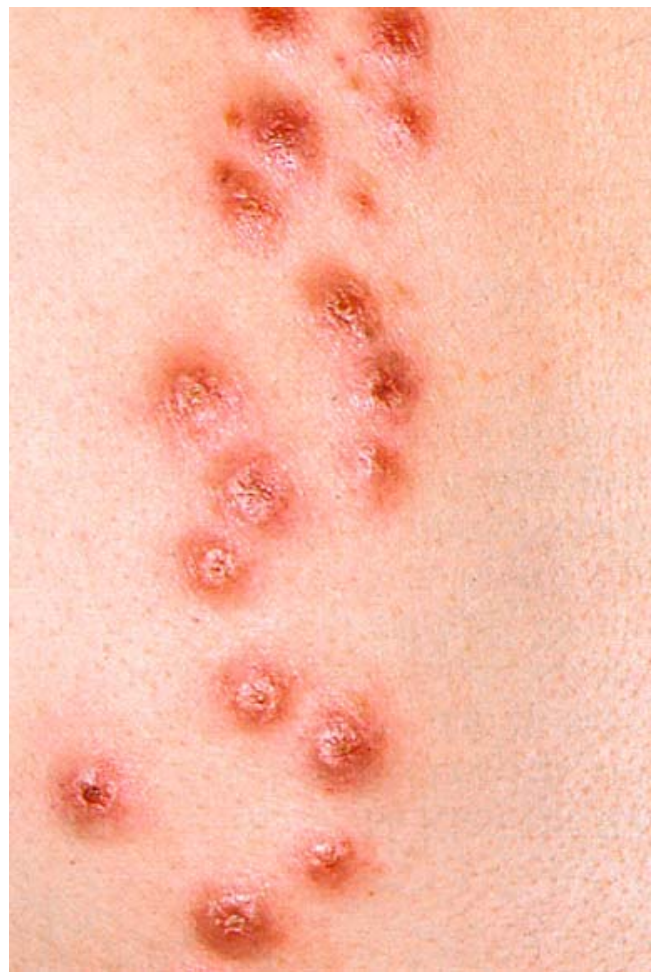

Fig. 5.88. Multiple circumscribed brownish-red nodules at the injection site following the repeated intradermal administration of procaine polyvinylpyrrolidone (PVP) to alleviate back pain (from [3])

ple brownish-red sharply margined nodules at the injection sites, histologically resembling sarcoid granuloma without clinical evidence for sarcoidosis (Figs. 5.88, 5.89). Earlier administrations had been tolerated without adverse reaction. In the intradermal test, a positive granulomatous reaction was observed [3]. Similar granulomas have been described after administration of other PVP-containing substances [4], whereby often clear storage processes were evident in contrast to the hypersensitivity reaction to minute amounts as observed in our patient.

In dermatological practice, granulomatous reactions have gained relevance against soluble bovine collagen used for the correction of scars and wrinkles $[7,8,12,16-20,27,29]$. Therefore, prior to such treatment, a test injection needs to be performed, which can lead to clinically visible nodule formation in $0.3 \%$ of the 


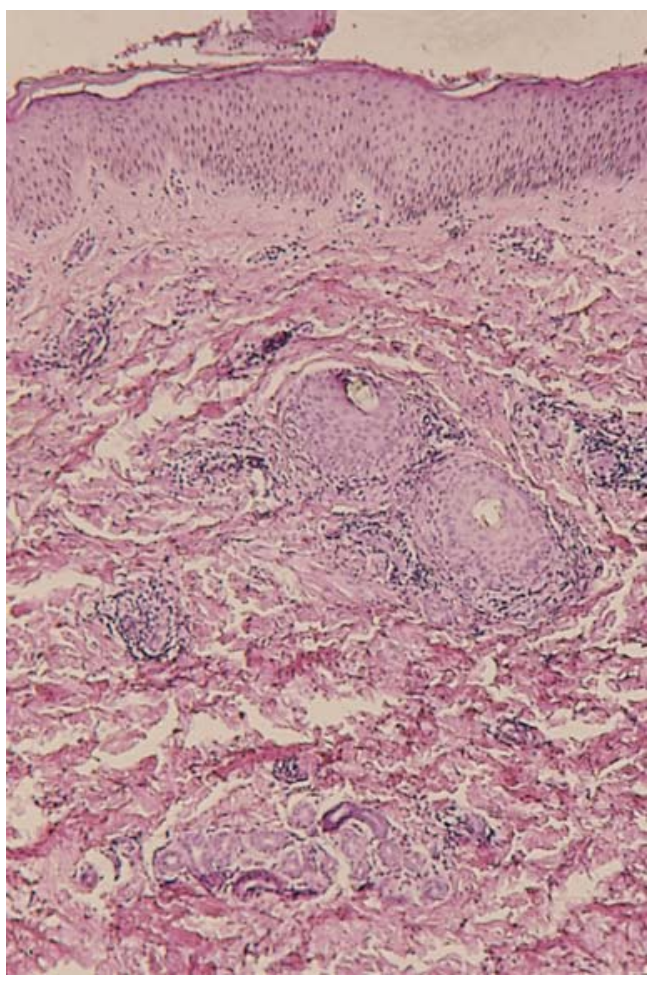

Fig. 5.89. Histological examination of the lesions shown in Fig. 5.88 yields the picture of sarcoid granuloma even though there is no clinical evidence of sarcoidosis (from [3])

patients [7]. Without this test injection or when sensitization occurs during the first treatment, long-lasting persistent granulomatous inflammatory skin reactions may develop at the injection site (Figs. 5.90, 5.91) [29].

\subsubsection{Pathophysiology}

Activation of T cells and macrophages for elimination of infectious agents plays a major role in immune defense (especially against intracellular microorganisms). When antigen cannot be eliminated totally, this can lead to continuous $\mathrm{T}$-cell activation and macrophage reactions with accumulation of epithelioid cells and formation of giant cells. Macrophages which have taken up bacterial antigens and present those may be destroyed by cytotoxic T cells, as well as by natural killer cells in an unspecific manner. Therefore, in granulomatous reactions, immu-

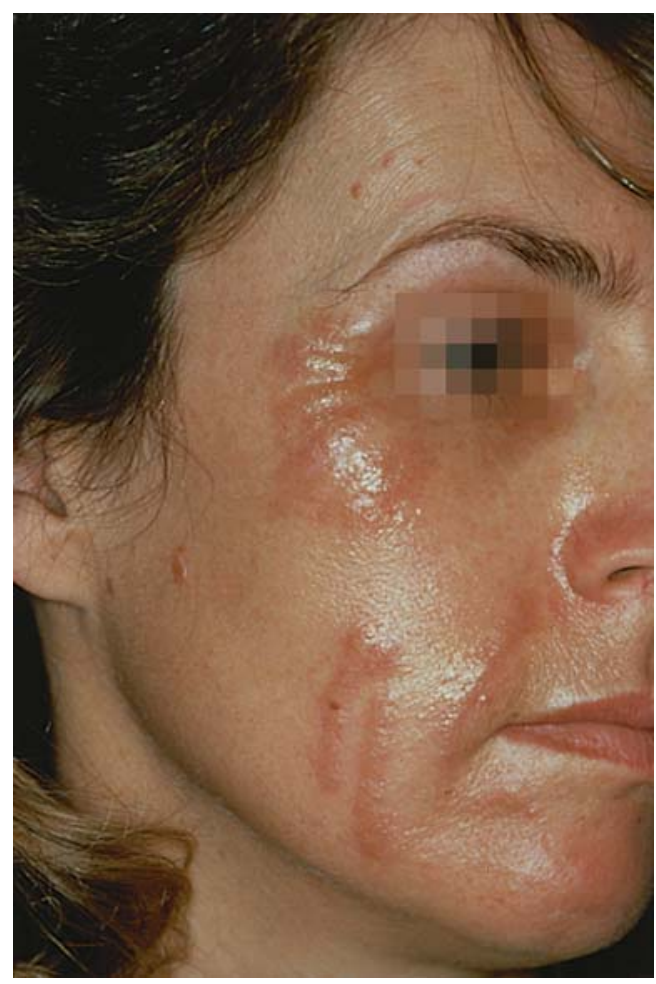

Fig. 5.90. Protruding hard inflammatory lesions following the injection of soluble bovine collagen in a patient with type V allergy (from [29])

nophenotyping often shows T cells, NK cells, and macrophages together with activated fibroblasts.

The mechanism of activation of NK cells especially the recently discovered NKT-cell subpopulation - is not well understood [22]. It seems that NKT cells appear early in the reaction while classic NK cells may stay for a longer time at the inflammatory site [23] and mediate or elicit functions of innate immunity. Among the various cytokines, especially a member of the lymphotoxin family, namely LT $\alpha 3$, plays a major role in the recruitment of lymphocytes and macrophages and, thus, the persistence of granuloma formation [24].

In the complex interaction between sensitized lymphocytes producing certain cytokines [22] and macrophages, possibly also immune complex phenomena (high antibody titers of the IgG class) may be involved. In the above-described case of bovine collagen hypersensitivi- 


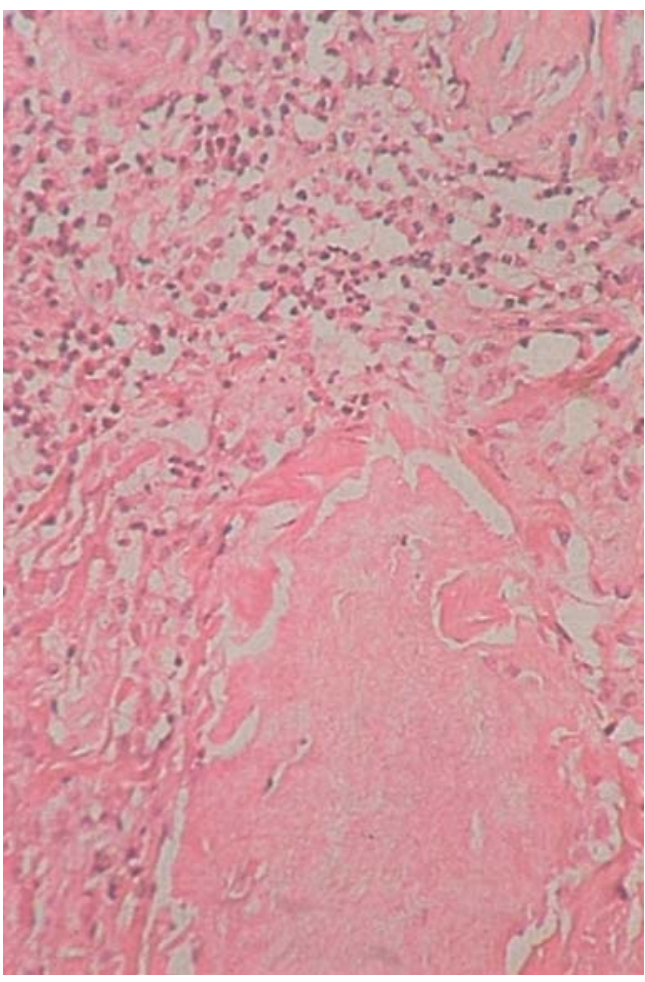

Fig. 5.91. Granulomatous infiltrate surrounding streaky eosinophilic material (injected collagen) seen in the histological preparation (from [29])

ty, a high IgG antibody antititer against bovine collagen was found [29].

A concomitant or subsequent following of immune complex reaction and granulomatous inflammation also is characteristic for the chronic stage of extrinsic allergic alveolitis (hypersensitivity pneumonitis). On the basis of these considerations, a hypothetical concept may be suggested: Persistent antigen induces after an initial type III reaction with vasculitis a strong activation of macrophages, leading finally to granulomatous inflammation. In hypersensitivity pneumonitis in the early phase changes similar to leukocytoclastic vasculitis can be seen together with high titers of precipitating antibodies, while in the chronic course the histologic pattern of granulomatous inflammation develops (see Sect. 5.4 on "Hypersensitivity Pneumonitis").

It is tempting to speculate about the pathophysiology of some other granulomatous in- flammatory skin diseases such as granuloma anulare, sarcoidosis, Melkersson-Rosenthal syndrome, M. Crohn, Wegener's granulomatosis, or Churg-Strauss granulomatosis. Some common features of these diseases might be explained by a deposit of a persisting yet unknown antigen.

In granuloma anulare in the early phase, signs of vasculitis with positive immunofluorescence $[9,14]$ can be found. It is a well-known clinical experience that granuloma anulare sometimes develops after insect stings or minimal trauma and can heal spontaneously after skin biopsy (removal of persistent antigen?). Development of granuloma anulare after injection of soluble collagen has been described [22]. We observed an exacerbation of scar sarcoidosis under immunotherapy with interferon which had been silent for decades [10].

\subsubsection{Therapy}

Treatment uses glucocorticosteroids (according to the organ manifestation). In granulomatous reactions of the skin, intralesional steroids or occlusion treatment should be tried $[3,6$, 29]; also cytostatic therapy, tuberculostatic drugs as well as UVA-1 irradiation have been used.

\section{References}

1. Apostolou I, Takahama Y, Belmant C, Kawanos T, Huerre M, Marchal G, Cui J, Taniguchi M, Nakauchi H, Fournié J-J, Kourilsky P, Gachelin G (1999) Murine natural killer cells contribute to the granulomatous reaction caused by mycobacterial cell walls. Proc Natl Acad Sci USA 96:5141-5146

2. Baumgarten C (1978) Häufigste Nebenwirkungen bei der spezifischen Hyposensibilisierung. Allergologie 1:223-228

3. Bode U, Ring J, Schmoeckel Chr (1984) Granulombildung nach intrakutaner Applikation von Procain-Polyvinylpyrrolidon (PVP). Hautarzt 35:474477

4. Bork K, Hoede N (1982) Vortäuschung maligner Tumoren durch nicht deklariertes PVP in Arzneimitteln. Hautarzt 33:373-377

5. Boros DL (1981) The role of lymphokines in granulomatous inflammations. Lymphokines 3:257281

6. Braun-Falco O, Plewig G, Wolff HH (1998) Derma- 
tologie und Venerologie, 4 th edn. Springer, Berlin Heidelberg New York

7. Castrow FF II, Krull E (1983) An injectable collagen implant - update. J Am Acad Dermatol 9: 889-893

28. Cooperman LS, Mackinnon V, Bechler G, Pharriss BB (1983) Injectable collagen: A six-year clinical investigation. Aesth Plast Surg 9:145-151

9. Dahl M, Ullmann S, Goetz RW (1977) Vasculitis in granuloma anulare. Arch Dermatol 113:463 - 467

10. Eberlein-König B, Hein R, Abeck D, Engst R, Ring J (1999) Cutaneous sarcoid foreign body granulomas developing in sites of previous skin injury after systemic interferon-alpha treatment for chronic hepatitis C. Br J Dermatol 140:370 - 372

11. Eder M, Gedigk P (1986) Lehrbuch der allgemeinen Pathologie und pathologischen Anatomie. Springer, Berlin Heidelberg New York

12. Ellingsworth LR, DeLustro F, Brennan JE, Sawamura S, McPherson J (1986) The human immune response to reconstituted bovine collagen. J Immunol 36:877-882

13. Harms M, Masouyé I, Saurat JH (1990) Silica granuloma mimicking granulomatous cheilitis. Dermatologica 181:246-247

14. Kleinhans D, Knoth W (1977) Immunhistochemischer Fibrin-Nachweis beim Granuloma anulare. Arch Dermatol Res 258:231 - 234

15. Klepzig K, Ring J, Burg G (1987) Pseudolymphom nach Hyposensibilisierung. Allergologie 10:432

16. Kligman AM, Armstrong RC (1986) Histologic response to intradermal zyderm und zyplast (glutaraldehyde crosslinked) collagen in humans. J Dermatol Surg Oncol 12:351 - 357

17. Konz B (1983) Injizierbares Kollagen. In: BraunFalco O, Burg G (eds) Fortschritte der praktischen Dermatologie und Venerologie, vol. 10, pp 193 - 198. Springer, Berlin Heidelberg New York

\subsection{Type VI Reactions (Stimulating/ Neutralizing Hypersensitivity)}

While the pathology of allergic diseases types $\mathrm{I}-\mathrm{V}$ is mainly due to activation of humoral or cellular inflammatory systems, the pathologic response of type VI reactions occurs through direct interaction of an antibody molecule with a receptor mediating a signal without inflammation (comparable to a hormone) leading to the untoward reaction.

\subsubsection{Clinical Examples of Autoimmune Diseases}

The best-known examples of type VI reactions are classical autoimmune disease $[2,6,8,9,11]$.
18. Kuhn K, Timpl R (1984) Collagens. Molecular and antigenic structure. In: Myelofibrosis and the biology of connective tissue, p. 45. Liss, New York

19. Lombardi T, Kuffer R, Dubrez B (2001) Polishingpaste-induced silica granuloma of the gingiva. Dermatology 203:177-179

20. McCoy JP, Schade WJ, Siegle RJ, Vanderveen EE, Zachary CB, Waldinger TP, Swanson NY (1987) Immune responses to bovine collagen implants. J Am Acad Dermatol 16:955 - 960

22. Rapaport M (1984) Granuloma annulare caused by injectable collagen. Arch Dermatol 120:837

23. Raupach B, Kaufman S (2001) Immune responses to intracellular bacteria. Curr Opin Immunol 13:417-428

24. Roach DR, Briscoe H, Saunders B, France MP, Riminton S, Britton WJ (2001) Secreted lymphotoxin-alpha is essential for the control of an intracellular bacterial infection. J Exp Med 193: 239-246

25. Roitt I, Delves P (2001) Essential immunology, 10th edn. Blackwell, Oxford

26. Sandritter W, Beneke G (1984) Allgemeine Pathologie. Schattauer, Stuttgart

27. Sellem PH, Caranzan FR, Bene MC, Faure GC (1987) Immunogenicity of injectable collagen implants. J Dermatol Surg Oncol 13:1199-1202

28. Shelley WB, Hurley HJ (1960) The pathogenesis of silica granulomas in man: A nonallergic colloidal phenomenon. J Invest Dermatol 34:107 - 123

29. Schurig V, Konz B, Ring J, Dorn M (1986) Granulombildung an Test- und Behandlungsstellen durch intrakutan verabreichtes, injizierbares Kollagen. Hautarzt 37:42-45

30. Shelley WB, Hurrley HJ (1958) The allergic origin of zirconium deodorant granulomas. Br J Dermatol 70:75-82

Autoimmune Thyreoiditis. The autoantibody acts like a hormone. Thyreoid-stimulating activity (long-acting thyroid-stimulating factor, LATS) was found decades ago in patients with Hashimoto's thyreoiditis. These autoantibodies stimulate specifically the TSH receptor and may elicit a thyreotoxic crisis. As IgG antibodies they pass through the placenta and may induce reversible thyreotoxicosis in neonates.

Myasthenia Gravis. Autoantibodies in myasthenia gravis do not stimulate but have a blocking effect, directed against the acetylcholine receptor on the motoric endplate of the muscle $[1,9,14]$. 
Table 5.111. Direct pathogenic effects of autoantibodies

\begin{tabular}{|c|c|c|}
\hline Disease & Specificity & Clinical symptoms \\
\hline Thyreotoxicosis & TSH receptor & Stimulation, hormone formation \\
\hline Myasthenia gravis & Acetylcholine receptor & Blockade, muscle weakness \\
\hline Antiphospholipid syndrome & Cardiolipin $/ \beta_{2}$-glycoprotein & Thromboembolic complications \\
\hline Pernicious anemia ${ }^{\mathrm{a}}$ & ATPase, gastrin receptor & $\begin{array}{l}\text { Decreased acid production, } \\
\text { decreased } \mathrm{B}_{12} \text { resorption }\end{array}$ \\
\hline Male infertility & Spermatozoa & $\begin{array}{l}\text { Agglutination and immobilization } \\
\text { of spermatozoa }\end{array}$ \\
\hline Wegener's granulomatosis & $\begin{array}{l}\text { Proteinase III (neutrophil granu- } \\
\text { locytes) }\end{array}$ & Endothelial damage \\
\hline Acanthosis nigricans (type B) & Insulin receptor & Receptor blockade, proliferation \\
\hline Pemphigus vulgaris & Desmoglein 3 & Bulla formation (acantholysis) \\
\hline
\end{tabular}

${ }^{a}$ Hematological cytopenias (anemia, thrombocytopenia); see Sect. 5.2

Other Autoimmune Diseases. Similar mechanisms can be found in a variety of other autoimmune diseases although the actual pathogenic role of autoantibodies has not been proven for each disease entity (Table 5.111) $[4,6,7,8,15]$.

\subsubsection{Stimulating Hypersensitivity in Bacterial Infection}

Some authors regard the severe acute disease of "multiorgan failure" occurring in certain bacterial infections as hypersensitivity of components of innate immunity, e.g., as overstimulation of macrophages and endothelial cells by endotoxin (lipopolysaccharide S = LPS) or unspecific T-cell activation by superantigens of Gram-positive organisms.

\subsubsection{Stimulating/Neutralizing Reactions in Classic Allergic Diseases}

In a variety of classic allergic diseases with wellknown antibody formation against exogenous allergens, recently autoantibodies of different classes against cells or surface receptors autologous with possible pathogenic importance have been found (Table 5.112). These include:

Table 5.112. IgE and autoimmune reactions

\begin{tabular}{lll}
$\begin{array}{l}\text { Autoan- } \\
\text { tibody }\end{array}$ & Specificity & Disease \\
\hline IgG & IgE & Immunotherapy \\
IgG & FceRI & Chronic urticaria \\
IgE & Hom s 1-5 (epi- & Severe atopic eczema \\
& dermal proteins) & \\
\hline
\end{tabular}

- IgG antibodies against platelet factor 4 in heparin-associated thrombocytopenia (see Sect. 5.2)

- Anti-IgE antibodies in patients with high total serum IgE or in the course of allergen-specific immunotherapy [10]

- Antibodies against the high-affinity $\operatorname{IgE}$ receptor (FceR I) in some patients with chronic urticaria and positive skin reaction to autologous serum [5]

- IgE autoantibodies against epidermal proteins (Hom s 1-5) in patients with very severe atopic eczema and high serum IgE levels [12]

- In severe asthma, antibodies against the $\beta$-adrenergic receptor have been described [13]

In clinical experimental models, it has been known for a long time that IgG antibodies against IgE or IgE receptors may elicit in vitro and in vivo similar reactions as allergen (e.g., in vitro histamine release from peripheral basophil leukocytes with anti-IgE as positive control).

The positive wheal and flare reaction after injection of anti-IgE in the passive cutaneous anaphylaxis (PCA) has been known as "reverse anaphylaxis" for a long time [7].

The better we understand the molecular mechanisms of these reactions, the more it is to be expected that overlaps between type VI and other allergic reaction types (e.g., type II) will be detected. 


\subsubsection{Therapy}

The existence of a stimulating/neutralizing hypersensitivity is not an esoterical-philosophical idea but has important practical and therapeutic implications: In patients with autoantibodies against the IgE receptor, chronic urticaria does not respond to antihistamines and should be treated with cortisone or immunosuppressives.

The skin lesions of patients with atopic eczema and high IgE autoantibodies against epidermal proteins will not improve by allergen avoidance. Active anti-inflammatory or immunosuppressive treatment is indicated.

In certain antibody-mediated autoimmune diseases, the intravenous administration of immunoglobulin $\mathrm{G}$ in high doses has proven beneficial $[4,7,8]$ (see Sect. 5.2).

\section{References}

1. Almon RR, Andrew CG, Appel SH (1974) Serum globulin in myasthenia gravis: inhibition of alphabungarotoxin binding to acetylcholine receptors. Science 186:55-57

2. Atkinson MA, Maclaren NK (1994) The pathogenesis of insulin-dependent diabetes mellitus. N Engl J Med 331:1428-1436

3. Beck K, Hertel J, Rasmussen NG, et al. (1991) Effect of maternal thyroid antibodies and postpartum thyroiditis on the fetus and neonate. Acta Endocrinol 125:146:149

4. Chapel H, Haeney M (1993) Essentials of clinical immunology, 3rd edn. Blackwell, Oxford

\subsection{0 "Eco-syndrome" ("Multiple Chemical Sensitivity," MCS)}

\subsubsection{Classification}

An increasing number of patients visit the doctor because of supposed incompatibility reactions against environmental pollutants with quite variable complaints, often involving several organ symptoms which are difficult to reproduce objectively. The patients have often undergone an odyssey of visits to various specialists, so-called special clinics, or "gurus" without having found help. The problem is well
5. Hide M, Francis DM, Grattan CE, Hakimi J, Kochan JP, Greaves MW (1993) Autoantibodies against high-affinity IgE receptor as a cause of histamine release in chronic urticaria. N Engl J Med 328:1599-1604

6. King C, Sarvetnick N (1997) Organ-specific autoimmunity. Curr Opin Immunol 9:863-871

7. Peter HH, Pichler WJ (1996) Klinische Immunologie, 2nd edn. Urban \& Schwarzenberg, Munich

8. Roitt IM (1996) Essential immunology, 8th edn. Blackwell, Oxford

9. Shoenfeld Y, Isenberg D (eds) (1993) Natural autoantibodies. CRC Press, Boca Raton, Florida

10. Stadler BM, Miescher S, Horn M, et al. (2001) Allergic manifestations as the results of a conditional autoimmune response. Int Arch Allergy Immunol 124:411-413

11. Tan EM (1982) Autoantibodies to nuclear antigens (ANA): their immunobiology and medicine. Adv Immunol 33:167-240

12. Valenta R, Seiberler S, Natter S, et al. (2000) Autoallergy: a pathogenetic factor in atopic dermatitis? J Allergy Clin Immunol 105:432 - 437

13. Venter JC, Fraser CM (1981) The development of monoclonal antibodies to beta-adrenergic receptors and their use in receptor purification and characterization. In: Eisenbarth G, Fellows R (eds) Monoclonal antibodies in endocrine research. Raven Press, New York, pp 119-134

14. Vincent A, Mewsom-Davis J (1982) Acetylcholine receptor antibody characteristics in myasthenia gravis. I. Patients with generalized myasthenia or disease restricted to ocular muscles. Clin Exp Immunol 49:257 - 265

15. Wegmann DR (1996) The immune response to islets in experimental diabetes and insulin-dependent diabetes mellitus. Curr Opin Immunol $8: 860-864$

Table 5.113. "Eco-syndrome": identical or related syndromes
"Multiple chemical sensitivity" (MCS)
"Multiorgan dysesthesia"
"Idiopathic environmental intolerance"
"Environmental illness"
"Allergy to the 20th century"
"Total allergy syndrome"
"Chronic fatigue syndrome"
- "Candidiasis hypersensitivity syndrome" ("yeast connection")
- "Wood furnishing syndrome"
- "Living room poison"
- "Toxicopia" 
Table 5.114. Eco-syndrome: common complaints (selection)

\begin{tabular}{lll} 
Neurologic symptoms & Skin and mucous membranes & General complaints \\
$\begin{array}{l}\text { Fatigue, malaise, headache, verti- } \\
\text { go, concentration disturbance, } \\
\text { sleep disturbance, psychologic } \\
\text { symptoms (confusion, anxiety, }\end{array}$ & $\begin{array}{l}\text { Itch, burning of the skin, eye irri- } \\
\text { tation, dry larynx and nose, rhi- } \\
\text { memory loss, irritability, depres- }\end{array}$ & $\begin{array}{l}\text { Gastrointestinal: nausea, diarrhea, } \\
\text { obstipation, flatulence, gastric pain }\end{array}$ \\
sion) & $\begin{array}{l}\text { Cardiovascular: cardiac pain, anxi- } \\
\text { ety, tachycardia }\end{array}$ \\
& $\begin{array}{l}\text { Flu-like symptoms: mild fever, } \\
\text { arthralgia }\end{array}$ \\
\hline
\end{tabular}

covered in the media and has received attention under different names (Table 5.113).

The mostly subjective complaints may be classified roughly into skin and mucous membrane symptoms, neurologic and general symptoms (Table 5.114) $[2,8,13,15,24,31,34]$. Many patients have fear of the "environment" and apply excessive avoidance behavior with chemicals, foods, drugs, fragrances, etc. The most common name for this condition today is "multiple chemical sensitivity" (MCS); it has to be remarked that in most of these patients, this sensitivity is not objectively measurable. The term "supposed multiple chemical sensitivity" would be better, but it seems to contradict the opinions of the patients, who are convinced of their hypersensitivity. On the other hand, there are patients who objectively suffer from multiple hypersensitivity against various chemicals, namely patients with multiple drug allergies. This, however, is a totally different group with objective signs and symptoms.

When in the early 1980s we saw the first patients with these conditions we suggested the term "eco-syndrome" as a working diagnosis for "patients suffering from mostly subjective symptoms affecting different organ systems who are convinced that the disease is due to environmental noxes."

The definition of MCS (according to Cullen) [8] is:

- Elicitation of symptoms by a variety of factors in low dose exposure

- Various symptoms manifesting in more than one organ system and improving after avoidance of exposure

- The complaints cannot be explained by classical examination

- There is a tendency to chronification
- There is immense suffering

- Exclusion of other well-defined diseases

From this list it is clear that the diagnosis "MCS" can never be made in a clear-cut fashion since certain criteria are not defined exactly (what are "classical examinations" or "other well-defined diseases"?).

Since the factors suspected are not only chemicals, but also physical factors (e.g., electromagnetic radiation, radioactive radiation), an expert committee of the WHO has proposed the term "idiopathic environmental intolerances" (IEI) [16].

\subsubsection{Differential Diagnoses}

The "eco-syndrome" partly has similarities with some differently defined but also environment-associated conditions:

- Chronic fatigue syndrome (virus infections like EBV, HHV 6, etc., are discussed) [1].

- Fibromyalgia syndrome with muscle pain in the center and disturbed pain regulation with possible disturbance in serotonin metabolism.

- Candida syndrome with mainly irritable bowel symptoms and candida phobia and immune weakness.

Complaints related to indoor exposure comprise the sick building syndrome (SBS) and building-related illnesses (BRI) (Table 5.115) $[18,19,33]$.

BRI are well-known and objective diseases, and include infectious diseases and allergies.

SBS is due to a complex interaction between physical, chemical, and biological exposure as well as psychological factors with occurrence of subjective complaints in a large number of people employed in one building. 
Table 5.115. Differential diagnosis between building-related illness (BRI), sick building syndrome (SBS), and eco-syndrome

\begin{tabular}{|c|c|c|c|}
\hline & Building-related illness & Sick building syndrome & Eco-syndrome (MCS) \\
\hline Occurrence & $\begin{array}{l}\text { Clearly building-associ- } \\
\text { ated, individual or sever- } \\
\text { al persons }\end{array}$ & $\begin{array}{l}\text { At least } 10-20 \% \text { of persons } \\
\text { employed in a building are } \\
\text { affected }\end{array}$ & Individual complaints \\
\hline Symptoms & $\begin{array}{l}\text { Objective (e.g., infection, } \\
\text { allergy) }\end{array}$ & $\begin{array}{l}\text { Mucous membrane and skin } \\
\text { irritations, neurologic com- } \\
\text { plaints }\end{array}$ & $\begin{array}{l}\text { Many organ systems in- } \\
\text { volved, diffuse psychologic } \\
\text { and physical complaints }\end{array}$ \\
\hline Pathophysiology & $\begin{array}{l}\text { Monocausal: } \\
\text { - Infectious } \\
\text { - Irritative-toxic } \\
\text { - Allergic }\end{array}$ & $\begin{array}{l}\text { Multifactorial (physical, } \\
\text { chemical, psychological) }\end{array}$ & Unknown (only hypotheses) \\
\hline Risk factors & $\begin{array}{l}\text { Atopy, higher age, immu- } \\
\text { nosuppression }\end{array}$ & $\begin{array}{l}\text { Atopy, air conditioning, } \\
\text { occupation in low social } \\
\text { grade }\end{array}$ & Atopy \\
\hline Female: male & $1: 1$ & Predominantly female & Predominantly female \\
\hline Psyche & Not prominent & $\begin{array}{l}\text { Psychosomatic-psychiatric } \\
\text { factors, not causal }\end{array}$ & $\begin{array}{l}\text { Strong psychosomatic } \\
\text { involvement }\end{array}$ \\
\hline
\end{tabular}

\subsubsection{Pathophysiological Concepts}

Toxicological Concept. Intoxication by environmental noxious agents is regarded as causal especially by followers of the so-called "clinical ecology" in the United States. Large toxicologic measurements including biomonitoring of affected individuals, however, have not yet given evidence for intoxications by environmental noxes [34]. Enzyme defects have been discussed $[12,14]$.

Immunological Concept. Another theory describes damage of the immune system by chemicals leading to disturbance of cellular and humoral immunity. However, no deviations of immune response were measurable in objective trials [30].

Allergological Concept. Many patients believe strongly that they are allergic against minute amounts of environmental poisons. In our own intensive investigations in approximately 100 patients, we found objective hypersensitivity phenomena (both allergic and pseudo-allergic in nature) in approximately one-third of our patients; this could explain some of the complaints; however, rarely were they directed against the originally suspected environmental noxes [13, $23,24,25]$. The majority of patients have an atopic diathesis and are familiar with the experi- ence of becoming sick from the environment. So it is tempting to look at the environment for elicitors of unexplained disturbances.

Neurological Concept. Many environmental noxes have an impact on the nervous system leading to psychiatric phenomena, concentration disturbance, or fatigue. The low reproducibility and subjectivity of the complaints may be the reason that this theory has not yet been proven $[1,2,3,7,28,31]$.

Olfactoric Concept. Many patients suffer from increased olfactory sensitivity and believe they can detect (smell) very low concentrations of environmental chemicals as unpleasant odors (kakosmia). According to this hypothesis, an olfactoric-hypothalamic-limbic stimulus transfer may induce symptoms in the sense of conditioned learning and amplification to olfactory stimulation $[4,22]$. In clinical practice using olfactometry, this hypothesis has not been proven.

Psychiatric Concept. Many physicians believe that patients with "eco-syndrome" suffer from psychiatric disease. Indeed, some cases of true endogenous psychoses (schizophrenia, manicdepressive reactions, etc.) were present among our patients. One of my first patients, a 35-yearold female, believed herself to be allergic against 
"Radio Free Europe"; this highly intelligent woman had previously been totally psychologically normal and healthy and only then was diagnosed as having schizophrenia. In intensive investigations comprising allergy and consultations together with exposure challenges, it was not possible to elicit the observed symptoms by the respective electromagnetic waves. In the course of our diagnostic activities, finally the diagnosis of schizophrenia was ascertained. The majority of patients, however, do not suffer from psychiatric disease $[10,13,16,26,27,31,32]$.

Psychosomatic Concept. The symptoms of eco-syndrome are very similar to a condition very common in the 19th century and called "neurasthenia" [1]. Anxiety reactions, disproportional conflict coping, as well as "somatization disturbance" in hidden depression are factors $[5,6,15,17,21,25,27,31,36]$. It is important for the patient to gain a socially acceptable diagnosis such as "nerval disturbance" in the 19 th century and "allergy" today, which are easier to bear than psychiatrization.

Similar to neurasthenia, "eco-syndrome" affects mainly females (2.5:1 female-male ratio). Some of our patients reported after careful ex- ploration a history of sexual abuse in early childhood [23, 29].

In interdisciplinary expert committees, mostly no one feels responsible: the toxicologist sees psychological phenomena, the psychiatrist thinks of allergies, and the allergist discusses toxicological effects.

Although the definition and etiopathophysiology of "eco-syndrome" are controversial and ill understood, something needs to be done for the affected patients, who suffer considerably.

It cannot be excluded that environmental noxes in low concentrations have true effects which are not yet measurable at this time or are not yet understood. Exposure of patients with atopic eczema in stable remission to low concentrations of formaldehyde in indoor air led to objectively measurable changes of transepidermal water loss, e.g., a disturbance of barrier function of the skin without subjective complaints of the patients [10].

\subsubsection{Management of Patients with "Eco-syndrome"}

Therapy of the condition follows the results of the investigations, which should be performed

Table 5.116. Recommendations for the management of patients with "eco-syndrome"

- Since many patients suffer from being neglected or primarily regarded as "psychologic," a physician-patient relationship based on mutual confidence is most important. This needs time, patience, and talking.

- The problem has to be taken seriously; at the same time, irrational expectations have to be calmed down.

- The examination requires a general understanding of the whole human being and includes the psychosocial aspects as well as possible environmental influences.

- Through cooperation with other disciplines, diseases sometimes disguised under the term "eco-syndrome" have to be excluded, such as:

- Infectious diseases (sinusitis, mononucleosis, respiratory infection)

- Allergies (rhinoconjunctivitis, atopic eczema, allergic contact eczema, urticaria)

- Metabolic toxic diseases (diabetes mellitus, drug abuse, hypo- or hyperthyreoidism)

- Malignant neoplasias

- Psychiatric disease

- Polypragmatic diagnostics and therapy have to be avoided:

- Only recommend measurements when results can be interpreted!

- Only recommend acceptable procedures (avoid prophylactic measures in houses and apartments connected with high financial and personal input).

- Do not treat laboratory results but individual disease conditions.

- Avoid "depoisoning" techniques which may be risky.

- Avoid social and human isolation.

- The evaluation of environmental parameters should be done on a strictly scientific basis, e.g.

- Objective environmental toxicological dose-response relationships and epidemiological evidence

- Allergologic-immunological examinations for detection of allergy or pseudo-allergy

- Besides rational recommendations for therapy based on diagnosis of eliciting causes, a supportive attitude is crucial including if needed psychologic-psychiatric consultations and therapies. 
with interdisciplinary cooperation. The avoidance of relevant elicitor factors is crucial, be it in the treatment of underlying diseases (e.g., chronic cholecystitis, ostemyelitis), the avoidance of allergens, the administration of specific diets (e.g., pseudo-allergic reactions to food additives), change of living conditions or psychosomatic or psychiatric counseling ( $\mathrm{Ta}-$ ble 5.116). There is considerable need for research. The major advice I give my co-workers in dealing with these patients is: "Take the patient seriously!"

There is no need for pessimism: In a longterm follow-up over 2-5 years we found that two-thirds of our patients had remarkably improved or were almost symptom free.

\section{References}

1. Abbey SE, Garfinkel PE (1991) Neurasthenia and chronic fatigue syndrome: The role of culture in making of a diagnosis. Am J Psychiatry 148: $1638-11646$

2. Altenkirch H (1995) Multiple chemical sensitivity (MCS)-Syndrom. Gesundheitswesen 57:661 - 666

3. Bartenstein PF, Grundwald F, Herholz K, Kuwert T, Tatsch K, Sabri O, Weiller C (1999) Rolle der Positronen-Emissions-Tomographie (PET) und Single-Photon-Emissions-Tomographie (SPECT) bei der sogenannten "Multiple Chemical Sensitivity" (MCS). Nuklearmedizin 38:297-301

4. Bell IR, Miller CS, Schwarz GE, et al. (1996) Neuropsychiatric and somatic characteristics of young adults with and without self-reported chemical odor intolerance and chemical sensitivity. Arch Environ Health 51:9-21

5. Binkley K, King N, Poonai N, Seeman P, Ulpian C, Kennedy J (2001) Idiopathic environmental intolerance: Increased prevalence of panic disorderassociated cholecystokinin B receptor allele 7. J Allergy Clin Immunol 107:887 - 890

6. Bornschein S, Hausteiner C, Zilker Th, Bickel H, Förstl H (2000) Psychiatrische und somatische Morbidität bei Patienten mit vermuteter Multiple Chemical Sensitivity (MCS). Nervenarzt 71: 737-744

7. Bullinger M (1989) Psychological effects of air pollution on healthy residents - a time-series approach. J Environ Psychol 9:103-118

8. Cullen MR (1987) The worker with multiple chemical sensitivities: An overview. State Art Rev Occup Med 2:655-661

9. Derbolowsky J (1999) Die Glaubwürdigkeit wieder herstellen. Zeitschr Umweltmed 7:2-4

10. Eberlein-König B, Przybilla B, Kühnl P, Pechak J,
Gebefügi I, Kleinschmidt J, Ring J (1998) Influence of airborne nitrogen dioxide or formaldehyde on parameters of skin function and cellular activation in patients with atopic eczema and control subjects. J Allergy Clin Immunol 101: $141-143$

11. Eikmann T, Herr C (2001) Ein Paradigmenwechsel in der Umweltmedizin? Umwelt Forschung Prax 6:179-180

12. Fabig K-R (1999) Glutathion-S-Transferase $T_{1}$ und Multiple Chemikaliensensitivität (MCS). Umwelt Medizin Gesellschaft 12:226-232

13. Gieler U, et al. (1998) Therapeutische Aspekte des MCS-Syndroms. Umweltmed Forschung Praxis $3: 3-10$

14. Grimm V, Ruhdorfer S, Eberlein-König B, Scherer G, Engst R, Ring J (1999) Defizit der Glutathiontransferase bei Patienten mit Öko-Syndrom? Allergo J 8 [Suppl 1]:32

15. Hüppe M, Bullinger M (1997) Verfahren zur MCS-Diagnostik. Zusammenfassung und Bewertung einer Umfrage. Umweltmed Forschung Prax 2:291-294

16. IPCS (International Programme on Chemical Safety) (1996) Report of Multiple Chemical Sensitivities (MCS) Workshop. Berlin, Inst Arch Occup Environ Health 69:224-226

17. Kofler W (1993) Umweltängste, Toxikopie-Mechanismus, komplexes evolutionäres CopingModell und die Notwendigkeit neuartiger Auflagen für genehmigungspflichtige Anlagen. In: Aurand $\mathrm{K}$, Hazard BP, Tretter F (eds) Umweltbelastungen und Ängste. Westdeutscher Verlag, Wiesbaden, pp 225-226

18. Kröling P (1989) Zur Problematik des "Sick building"-Syndroms. Allergologie 3:118-129

19. Molina C, Caillaud D, Molina N (1993) Sick building syndrome and atopy. Indoor Air 1:369-373

20. Neuhann HF, Wiesmüller GA (1994) Diagnostische Strategien bei gebäudebezogenen Gesundheitsstörungen. In: Luftverunreinigung in Innenräumen. VDI Berichte 1122

21. Nixon PGF (1982) "Total allergy syndrome" or fluctuating hypercarbia? Lancet I:516

22. Österberg OP, Akesson B, Bergendorf U, Karlson B, Seger L (1998) Suprathreshold intensity and annoyance reactions in experimental challenge to toluene and n-butyl acetate among subjects with long-term solvent exposure. Scand J Work Environ Health 24:432-438

23. Ring J, Gabriel G, Vieluf D, Przybilla B (1991) "Das klinische Ökologie-Syndrom" (“Öko-Syndrom”): Polysomatische Beschwerden bei vermuteter Allergie gegen Umweltschadstoffe. Münch Med Wochenschr 133:50-55

24. Ring J, Eberlein-König B, Behrendt H (1999) "Eco-Syndrome" ("multiple chemical sensitivity" - MCS). Zbl Hyg Umweltmed 202:207-218

25. Ring J, Triendl C, Behrendt H, Borelli S (2000) Das Öko-Syndrom (multiple chemical sensitivi- 
ty) und verwandte Syndrome. In: Przybilla B, Bergmann KCh, Ring J (eds) Praktische allergologische Diagnostik. Steinkopff, Darmstadt, pp $351-371$

26. Röttgers HR (2000) Psychisch Kranke in der Umweltmedizin. Deutsches Ärzteblatt 97:A835-A840

27. Selner JC, Staudemayer H (1992) Neuropsychophysiologic observation in patients presenting with environmental illness. Toxicol Indust Health 8:145- 155

28. Staudenmayer H, Selner J, Buhr M (1993) Doubleblind provocation chamber challenges in 20 patients presenting with "multiple chemical sensitivity". Regul Toxicol Pharmacol 18:44-53

29. Staudenmayer H, Selner M, Selner J (1993) Adult sequelae of childhood abuse presenting as environmental illness. Ann Allergy 71:538-546

30. Terr A (1993) Immunological issues in "multiple chemical sensitivities". Regul Toxicol Pharmacol 18:54-60

31. Tretter F (1996) Umweltbezogene funktionelle Syndrome. Int Praxis 37:669-686

32. Triendl C, Borelli S, Rakoski J, Herschbach P, Behrendt H, Ring J (1999) Das “Öko-Syndrom” (mul- tiple chemical sensitivity"): Allergologisch-umweltmedizinisches Management. Allergologie 22: $744-760$

33. Voack C, Borelli S, Ring J (1997) Der umweltmedizinische 4-Stufenplan. Münch Med Wochenschr 139:69-72

34. Wiesmüller GA, Hornberg D (2001) Multiple Chemikalienüberempfindlichkeiten (MCS). Eine Herausforderung moderner Diagnostik und Therapie. Allergologie 24:507-514

35. Zilker M (1991) Pathophysiological mechanisms of fibromyalgia. Clin J Pain 7 [Suppl 1]:8-15

36. Wüthrich B (2001) Allergien: Umweltkrankheiten Nummer 1. Der Allergie-Patient im Spannungsfeld zwischen Schul- und Alternativmedizin. Dermatol Beruf Umwelt/Occup Environ Dermatol 49:136 141

37. Walkowiak J, Wiener J-A, Fastabend A, Heinzow B, Krämer U, Schmidt E, Steingrüber H-J, Wundram S, Winneke G (2001) Environmental exposure to polychlorinated biphenyls and quality of the home environment: effect on psychodevelopment in early childhood. Lancet 358:1602-1607 